DOC.20050829.0004

QA: QA

TDR-WIS-MD-000003 REV 02

August 2005

\title{
The Development of the Total System Performance Assessment-License Application Features, Events, and Processes
}

Prepared for:

U.S. Department of Energy

Office of Civilian Radioactive Waste Management

Office of Repository Development

1551 Hillshire Drive

Las Vegas, Nevada 89134-6321

Prepared by:

Bechtel SAIC Company, LLC

1180 Town Center Drive

Las Vegas, Nevada 89144

Under Contract Number

DE-AC28-01RW12101 


\section{DISCLAIMER}

This report was prepared as an account of work sponsored by an agency of the United States Government. Neither the United States Government nor any agency thereof, nor any of their employees, nor any of their contractors, subcontractors or their employees, makes any warranty, express or implied, or assumes any legal liability or responsibility for the accuracy, completeness, or any third party's use or the results of such use of any information, apparatus, product, or process disclosed, or represents that its use would not infringe privately owned rights. Reference herein to any specific commercial product, process, or service by trade name, trademark, manufacturer, or otherwise, does not necessarily constitute or imply its endorsement, recommendation, or favoring by the United States Government or any agency thereof or its contractors or subcontractors. The views and opinions of authors expressed herein do not necessarily state or reflect those of the United States Government or any agency thereof. 
TDR-WIS-MD-000003 REV 02

Development of the Total System Performance Assessment-

License Application Features, Events, and Processes

Originator:
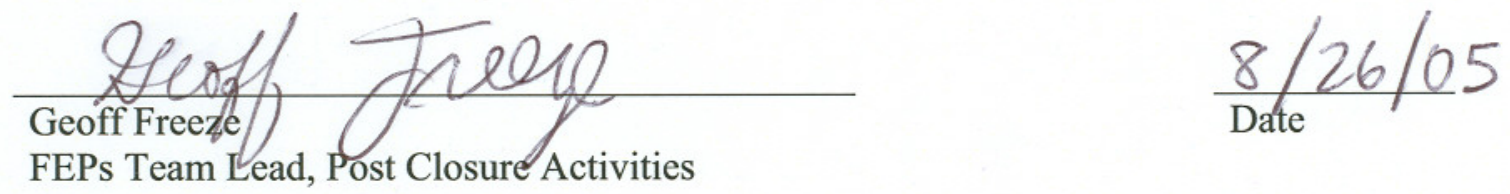

Checker:

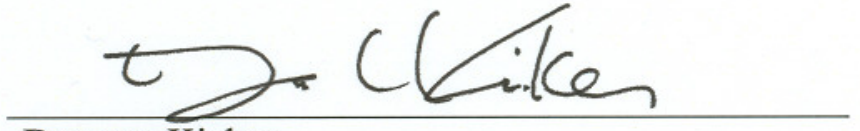

Dwayne Kicker

FEPs Team, Post Closure Activities

$\frac{8 / 26 / 05}{\text { Date }}$

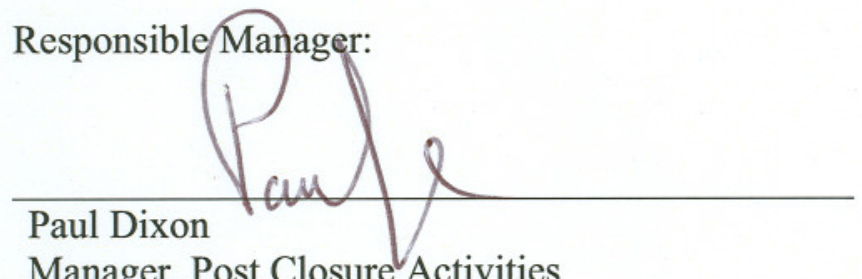

\section{$8-26-05$ \\ Date}




\section{CHANGE HISTORY}

Revision Interim
Number
0
0 $\quad \begin{aligned} & \text { Description of Change } \\ & \text { Initial issue. } \\ & \text { The U.S. Department of Energy issued a Technical Direction letter } \\ & \text { (Horton 2000 [DIRS 153941]) stating that the FEPs database } \\ & \text { REV 00 ICN 00 was "accepted with conditions". REV 00 ICN 01 } \\ & \text { was developed to address those conditions. Specific conditions } \\ & \text { were addressed through: qualification of the database routines } \\ & \text { (but not the data) in accordance with AP-SI.1Q, Software } \\ & \text { Management; incorporation of changes and revisions to the FEP } \\ & \text { AMRs to consider the "no-backfill" design; incorporation of } \\ & \text { changes and revisions to the FEP AMRs to include criticality and } \\ & \text { other identified missing FEPs; and incorporation of changes and } \\ & \text { revisions to the FEP AMRs to address regulatory and legal } \\ & \text { comments made on Rev. 00 of the FEP AMRs. } \\ & \text { Addresses updates to the development and content of FEPs for } \\ & \text { TSPA-LA. Revision incorporates process changes based on the } \\ & \text { Enhanced FEPs Plan for Features, Events, and Processes (FEPs) at } \\ & \text { Yucca Mountain (BSC 2002 [DIRS 158966])) and on KTI Letter } \\ & \text { Report Response to Additional Information Needs on TSPAI 2.05 } \\ & \text { and 2.06 (Freeze 2003 [DIRS 165394]). Revision also } \\ & \text { incorporates updates to technical information, supporting } \\ & \text { documents, and changes to the TSPA Model conducted as part of } \\ & \text { the License Application process. The revision of this document is } \\ & \text { extensive, so no margin change bars are used, and the document is } \\ & \text { being reissued in its entirety. } \\ & \text { The previous revision documented FEP development up to and } \\ & \text { including the Regulatory Integration Team process, ending in } \\ & \text { January 2005. This revision adds documentation of updates to the } \\ & \text { FEP list, FEP screening, and FEP database that were performed } \\ & \text { between January 2005 and August 2005. This revision also } \\ & \text { contains an abbreviated Appendix B. In the previous version, } \\ & \text { Appendix B documented a detailed systematic analysis identifying } \\ & \text { an alternative FEP list. In this version, Appendix B contains only } \\ & \text { a short summary of the alternative FEP list, with a historical } \\ & \text { reference to the full detailed analysis in the previous version. }\end{aligned}$




\section{INTENTIONALLY LEFT BLANK}




\section{CONTENTS}

Page

ACRONYMS xiii

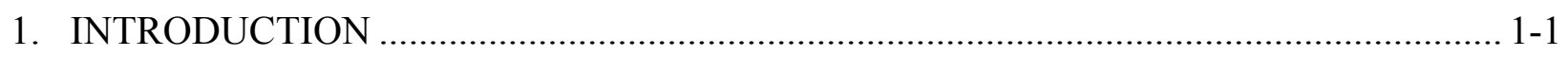

2. APPROACHES TO FEP ANALYSIS AND SCENARIO DEVELOPMENT ......................2-1

2.1 OVERVIEW OF FEP ANALYSIS METHODS ............................................... 2-4

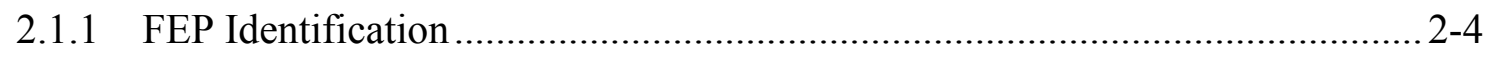

2.1.2 FEP Classification .................................................................................

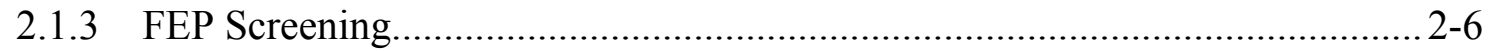

2.2 OVERVIEW OF SCENARIO DEVELOPMENT METHODS ................................. 2-6

2.2.1 Judgmental Methods …................................................................................... 2-6

2.2.2 Event Tree/Logic Diagram Approach...........................................................2- 2-7

2.2.3 Systematic Bottom-Up..........................................................................2-

2.2.4 Systematic Top-Down …………………..........................................2-8

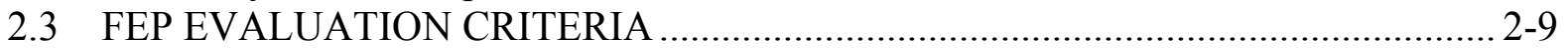

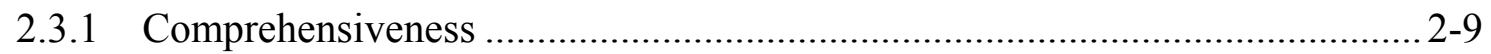

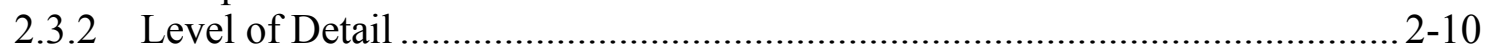

2.4 OVERVIEW OF YUCCA MOUNTAIN PROJECT FEP ANALYSIS AND

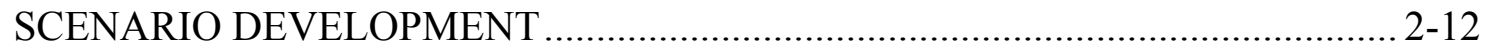

2.4.1 Yucca Mountain Project FEP Analysis ...................................................... 2-12

2.4.2 Yucca Mountain Project Scenario Development............................................... 2-16

2.4.3 Interface Team For Yucca Mountain Project FEP Analysis............................ 2-16

3. YUCCA MOUNTAIN PROJECT FEP ANALYSIS - IDENTIFICATION AND

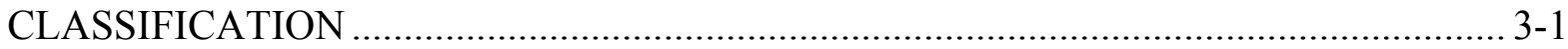

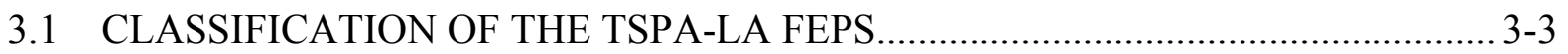

3.1.1 Hierarchical Classification Levels ......................................................... 3-4

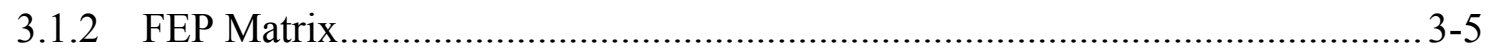

3.2 IDENTIFICATION OF THE TSPA-LA FEPS ………...................................... 3-8

3.2.1 Level of Detail for TSPA-LA FEPs......................................................... 3-8

3.2.2 Reclassification and Refinement of the TSPA-SR FEPs for TSPA-LA..........3-12

3.2.3 Identification of New FEPs for TSPA-LA ………...................................... 3-13

3.2.4 Configuration Management for Potential New FEPs ...................................... 3-17

4. YUCCA MOUNTAIN PROJECT FEP ANALYSIS - SCREENING ................................ 4-1

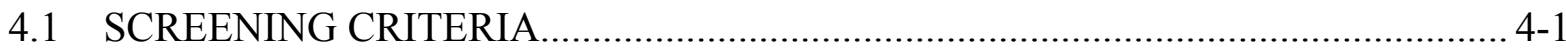

4.1.1 Low-Probability Criterion.......................................................................... 4-1

4.1.2 Low-Consequence Criteria ........................................................................ 4-2

4.1.3 By-Regulation Criteria............................................................................ 4-4

4.1.3.1 Reference Biosphere................................................................... 4-4

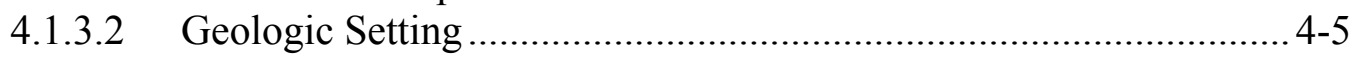

4.1.3.3 Reasonably Maximally Exposed Individual...................................... 4-5

4.1.3.4 Human Intrusion........................................................................... 4-7 


\section{CONTENTS (CONTINUED)}

Page

4.2 SCREENING PROCESS............................................................................. 4-9

4.2.1 Documentation of FEP Screening.................................................... 4-12

4.2.2 Guidelines for FEP Screening....................................................... 4-14

5. YUCCA MOUNTAIN PROJECT SCENARIO DEVELOPMENT .................................. 5-1

6. YUCCA MOUNTAIN PROJECT FEP DATABASE ..................................................... 6-1

6.1 DEVELOPMENT HISTORY OF THE ELECTRONIC FEP DATABASE............... 6-1

6.1.1 Total System Performance Assessment for Site Recommendation.................. 6-1

6.1.2 Total System Performance Assessment-License Application ........................ 6-2

6.1.2.1 TSPA-LA FEP Software ............................................................ 6-3

6.1.2.1.1 FEPs Database Software Program Version 1.0........... 6-3

6.1.2.1.2 FEPs Database Software Program Version 1.1........... 6-4

6.1.2.1.3 FEPs Database Software Program Version 1.2........... 6-5

6.1.2.2 TSPA-LA FEP Data ..................................................................... 6-5

6.2 STRUCTURE OF THE TSPA-LA FEP DATABASE ............................................ 6-6

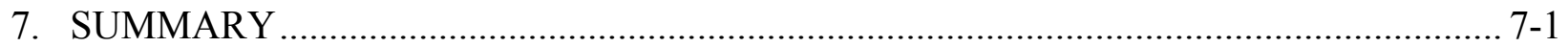

7.1 RESOLUTION OF KEY TECHNICAL ISSUE AGREEMENT TSPAI 2.07 ........... 7-3

7.2 RELEVANT YUCCA MOUNTAIN REVIEW PLAN ACCEPTANCE CRITERIA ........................................................................................... 7-3

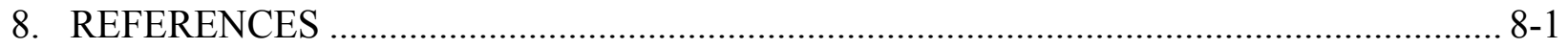

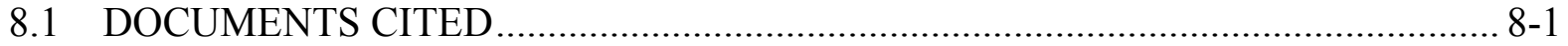

8.2 CODES, STANDARDS, REGULATIONS, AND PROCEDURES ......................... 8-8

8.3 SOURCE DATA, LISTED BY DATA TRACKING NUMBER ............................ 8-8

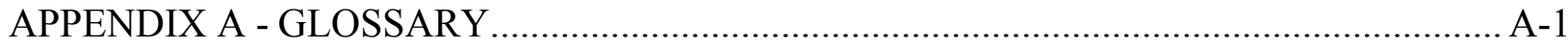

APPENDIX B - SUMMARY OF AN ALTERNATIVE SYSTEMATIC ANALYSIS IDENTIFYING A COMPLETE LIST OF FEATURES, EVENTS, AND PROCESSES THAT MIGHT AFFECT THE YUCCA MOUNTAIN REPOSITORY....

APPENDIX C - SUMMARY OF FEATURES, EVENTS, AND PROCESS

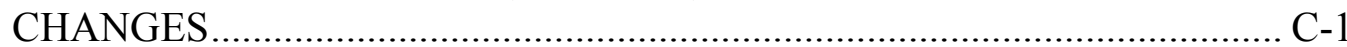

APPENDIX D - FEP CONFIGURATION MANAGEMENT-POTENTIAL FEP LOG .......... D-1

APPENDIX E - TSPA-LA FEP LIST …...........................................................................

APPENDIX F - FEPS MAPPED BY SCENARIO CLASS ….........................................

APPENDIX G - TSPA-LA DATABASE TABLES AND FIELDS ..................................... G-1 


\section{FIGURES}

Page

2-1. Schematic of the Iterative FEP Analysis Process ................................................... 2-12

3-1. FEP Matrix Showing Physical System and Process System Hierarchies......................... 3-7

4-1. Schematic Illustration of the FEP Screening Process.................................................. 4-9 


\section{INTENTIONALLY LEFT BLANK}




\section{TABLES}

Page

2-1. New FEP List Development Prior to 1989 ………...................................................... 2-1

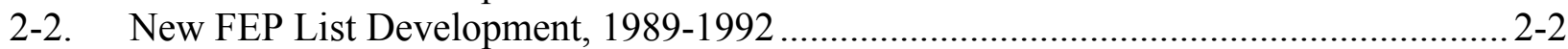

2-3. Continuing FEP List Development, 1993-1994_.......................................................2-2

2-4. Continuing FEP List Development, 1994-1996........................................................... 2-3

2-5. Systematic Bottom-Up Scenario Development Approaches ……………………............. 2-7

2-6. Systematic Top-Down Scenario Development Approaches ............................................ 2-8

2-7. FEP Analysis Reports Supporting TSPA-LA ……................................................. 2-15

3-1. Summary of KTI Agreements Related to FEP Analysis ............................................... 3-2

3-2. TSPA-LA Hierarchical Classification Levels for FEP Database Physical System .......... 3-5

3-3. TSPA-LA Hierarchical Classification Levels for FEP Database Process System ............ 3-5

3-4. TSPA LA Hierarchical Classification Levels for Q-List-Based Physical System ........... 3-6

6-1. Development History of YMP FEP Database for TSPA-SR ......................................... 6-1

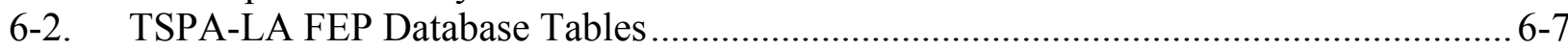

B-1. Potential FEPs That Might Enhance the Completeness of the FEP List ....................... B-2

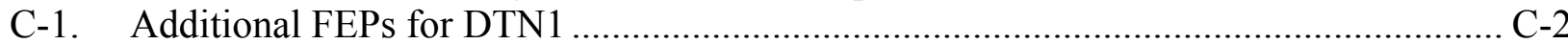

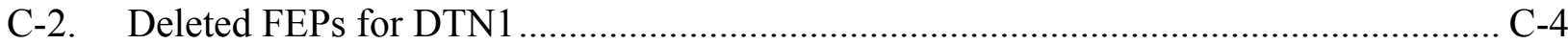

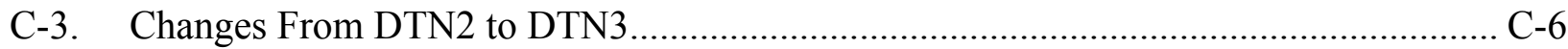

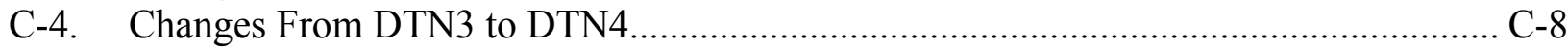

C-5. Changes From DTN5 to DTN6 ......................................................................... C-10

C-6. Changes From DTNLA0 to DTNLA1 ………………………………………..... C-15

D-1. FEP Configuration Management-Potential FEP Log …………………………........ D-1

E-1. TSPA-LA FEP List ..............................................................................................

F-1. Scenario Classes for Included FEPs .......................................................................

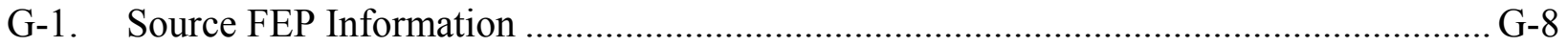




\section{INTENTIONALLY LEFT BLANK}




\section{ACRONYMS}

$\begin{array}{ll}\text { AECL } & \text { Atomic Energy of Canada, Ltd. } \\ \text { AMR } & \text { Analysis and Model Report } \\ \text { AP } & \text { Administrative Procedure } \\ \text { BIO } & \text { biosphere } \\ \text { CFR } & \text { Code of Federal Regulations } \\ \text { CRWMS } & \begin{array}{l}\text { Civilian Radioactive Waste Management System } \\ \text { commercial spent nuclear fuel }\end{array} \\ \text { CSNF } & \text { disruptive events } \\ \text { DE } & \text { Document Input Reference System } \\ \text { DIRS } & \text { U.S. Department of Energy } \\ \text { DOE } & \text { Department of Energy spent nuclear fuel } \\ \text { DSNF } & \text { Data Tracking Number } \\ \text { DTN } & \text { engineered barrier system } \\ \text { EBS } & \text { excavation-disturbed zone } \\ \text { EDZ } & \text { external feature, event, and process } \\ \text { EFEP } & \text { event and process } \\ \text { EP } & \text { feature, event, and process } \\ \text { FEP } & \text { Federal Register } \\ \text { FR } & \text { high-level waste } \\ \text { HLW } & \text { Her Majesty's Inspectorate of Pollution } \\ \text { HMIP } & \text { International Atomic Energy Agency } \\ \text { IAEA } & \text { Interim Change Number } \\ \text { ICN } & \text { in-drift geochemical environment } \\ \text { IDGE } & \text { Issue Resolution Status Report } \\ \text { IRSR } & \text { key technical issue } \\ \text { KTI } & \text { license application } \\ \text { LA } & \text { line procedure } \\ \text { LP } & \text { Management and Operating Contractor } \\ \text { M\&O } & \text { Master Directed Diagram } \\ \text { MDD } & \text { Nationale Genossenschaft Fur die Lagerung Radioaktiver Abfalle (National } \\ \text { NAGRA } & \text { Cooperative for the Disposal of Radioactive Waste) (Switzerland) } \\ \text { NEA } & \text { near-field environment } \\ \text { NFE } & \text { NRC }\end{array}$




\section{ACRONYMS (Continued)}

OECD Organisation for Economic Cooperation and Development

PA

PAAG

PID

QA

REV

RES

RMEI

SAM

SKB

SEP

SKI

SME

SR

SYS

SZ

TH

THC

THM

TMRB

TSPA

TSPAI

TSPA-LA

TSPA-SR

UK

USA

UZ

WF

WIPP

WP

YMP

YMRP

YSCP performance assessment

Performance Assessment Advisory Group

Process Influence Diagram

quality assurance

revision

Rock Engineering System

reasonably maximally exposed individual

Safety Assessment Management, Ltd.

Svensk Karnbranslehantering AB (Swedish Nuclear Fuel and Waste Management Co.)

Site and Engineering Properties

Statens Karnkraftinspektion (Swedish Nuclear Power Inspectorate)

subject matter expert

Site Recommendation

system-level

saturated zone

thermal-hydrology

thermal-hydro-chemical

thermal-hydro-mechanical

Technical Management Review Board

Total System Performance Assessment

Total System Performance Assessment and Integration

Total System Performance Assessment-License Application

Total System Performance Assessment for Site Recommendation

United Kingdom

United States of America

unsaturated zone

waste form

Waste Isolation Pilot Plant

waste package

Yucca Mountain Project

Yucca Mountain Review Plan

YMP Site Characterization Plan 


\section{INTRODUCTION}

A performance assessment is required to demonstrate compliance with the postclosure performance objectives for the U.S. Department of Energy (DOE) Yucca Mountain Project (YMP), as stated in 10 CFR 63.113 [DIRS 173273]. A performance assessment is defined in 10 CFR 63.2 [DIRS 173273] as an analysis that:" (1) Identifies the features, events, processes (except human intrusion), and sequences of events and processes (except human intrusion) that might affect the Yucca Mountain disposal system and their probabilities of occurring during 10,000 years after disposal; (2) Examines the effects of those features, events, and processes, and sequences of events and processes upon the performance of the Yucca Mountain disposal system; and (3) Estimates the dose incurred by the reasonably maximally exposed individual, including the associated uncertainties, as a result of releases caused by all significant features, events, processes, and sequences of events and processes, weighted by their probability of occurrence." The performance assessment is required to "provide the technical basis for either inclusion or exclusion of specific features, events, and processes in the performance assessment" as stated in 10 CFR 63.114 [DIRS 173273]. This report describes the feature, event, and process (FEP) analysis and scenario development approach for Total System Performance Assessment-License Application (TSPA-LA), consistent with these regulatory-specified requirements and definitions.

The purpose of this report is to document (a) the origin and development of a comprehensive list of FEPs that might affect the postclosure performance of the Yucca Mountain disposal system, (b) the methodology and guidance used to screen the FEPs for inclusion in or exclusion from the TSPA-LA analysis, and (c) the development, structure, and use of an electronic database for storing and retrieving information about the inclusion and/or exclusion of TSPA-LA FEPs. This report and the associated database also support resolution of U.S. Nuclear Regulatory Commission (NRC) Key Technical Issue (KTI) Agreement Total System Performance Assessment and Integration (TSPAI) 2.07.

The scope of the work documented in this report is outlined in Technical Work Plan for the Post Closure Activities FEPs Team (BSC 2005 [DIRS 174883], Sections 1 and 2.1). This report is a revision to The Development of the Total System Performance Assessment-License Application Features, Events, and Processes (BSC 2005 [DIRS 168706]), which described FEP analysis and scenario development for TSPA-LA through January 2005. That report was, in turn, a revision to The Development of Information Catalogued in REV 00 of the YMP FEP Database (Freeze et al. 2001 [DIRS 154365]), which described FEP analysis for Total System Performance Assessment for Site Recommendation (TSPA-SR). FEP analysis and scenario development for TSPA-LA builds upon the FEP analysis activities for TSPA-SR.

For TSPA-LA, FEP analysis and scenario development followed a five-step process that corresponds directly with the scenario analysis areas of review in Yucca Mountain Review Plan, Final Report (NRC 2003 [DIRS 163274], Section 2.2.1.2.1.1). The five steps are outlined | below:

1. Identify and classify FEPs potentially relevant to the long-term performance of the disposal system. 
2. Screen the FEPs using specified criteria (low probability, low consequence, and by regulation) to identify those FEPs that should be included in the TSPA-LA analysis and those that can be excluded from the analysis.

3. Form scenario classes from the retained (included) FEPs, as appropriate.

4. Screen the scenario classes using the same criteria applied to the FEPs to identify any scenario classes that can be excluded from the TSPA, as appropriate.

5. Specify the implementation of the scenario classes in the computational modeling for the TSPA, and document the treatment of included FEPs.

The TSPA-LA FEP analysis and scenario development approach was designed to produce a limited set of scenario classes that were considered representative of the range of possible future states of the repository system. A scenario class is a set of related scenarios sharing sufficient similarities that they can usefully be aggregated for the purposes of screening or analysis; a scenario is a well-defined, connected sequence of FEPs that is an outline of a possible future condition of the repository system, and which may be either undisturbed (nominal behavior) or disturbed (altered by disruptive events) (NRC 2003 [DIRS 163274], Section 3). FEPs are defined as follows (NRC 2003 [DIRS 163274], Section 3):

- A feature is an object, structure, or condition that has a potential to affect disposal system performance.

- An event is a natural or human-caused phenomenon that has a potential to affect disposal system performance and that occurs during an interval that is short compared to the period of performance.

- A process is a natural or human-caused phenomenon that has a potential to affect disposal system performance and that operates during all or a significant part of the period of performance.

The FEP analysis and scenario development approach for YMP is based on the methodology developed by the NRC (Cranwell et al. 1990 [DIRS 101234], Section 2). This approach is fundamentally the same as that used in many performance assessments. A summary of general approaches to FEP analysis and scenario development is presented in Section 2.

FEP analysis includes Step 1 (FEP identification and classification) and Step 2 (FEP screening) above. These steps address Scenario Analysis Acceptance Criteria 1 and 2, respectively, as outlined in Yucca Mountain Review Plan, Final Report (NRC 2003 [DIRS 163274], Section 2.2.1.2.1.3). FEP identification and classification for TSPA-LA is described in Section 3. FEP screening for TSPA-LA is described in Section 4.

Scenario development includes Step 3 (scenario class formation) and Step 4 (scenario class screening) above. These steps address Scenario Analysis Acceptance Criteria 3 and 4, respectively, as outlined in Yucca Mountain Review Plan, Final Report (NRC 2003 [DIRS 163274], Section 2.2.1.2.1.3). Scenario class formation and screening for TSPA-LA are described briefly in Section 5. However, the details of the TSPA-LA scenario classes, as well as 
the implementation of the scenario classes in TSPA-LA models (Step 5 above), are beyond the scope of this report. They are described in more detail in Total System Performance Assessment Model/Analysis for the License Application (BSC 2005 [DIRS 174227]).

The development of an electronic YMP FEP database to catalog the TSPA-LA FEP identification and screening information is described in Section 6. The electronic database is comprised of two parts: the FEP data, a data set that contains the identification information (i.e., list of TSPA-LA FEPs) and the screening information (screening decisions and associated bases); and the FEP software, Microsoft Access-based code that provides a platform for browsing the FEP data.

A summary of the identification and screening of the TSPA-LA FEPs is provided in Section 7. The summary section also provides a discussion of how the TSPA-LA FEP analysis, scenario development, and FEP database are consistent with the regulations in 10 CFR Part 63 [DIRS 173273] and address the relevant NRC Scenario Analysis Acceptance Criteria in Yucca Mountain Review Plan, Final Report (NRC 2003 [DIRS 163274], Section 2.2.1.2.1.3). Appendix A is a glossary of terms as they are used in this report. Appendices B through G provide additional details supporting TSPA-LA FEP analysis and scenario development.

The intended use of this report is to:

- Promote transparency and traceability of the FEP analysis and scenario development process for TSPA-LA,

- Provide a reference for information contained in the electronic FEP database,

- Support, in full or in part, the demonstration of compliance with Scenario Analysis Acceptance Criteria 1 through 4, outlined in Yucca Mountain Review Plan, Final Report (NRC 2003 [DIRS 163274], Section 2.2.1.2.1.3)

- Support resolution of KTI TSPAI 2.07, and,

- Serve as a communication tool to assist reviewers during the License Application (LA) process.

Limitations on the use of this report are as follows:

- The identification and screening of a comprehensive list of FEPs potentially relevant to the postclosure performance of the Yucca Mountain repository is based on site-specific information, design, and regulations. Therefore, the FEP identification and screening described in this report are specific to the regulations, repository design, and processes for the YMP available at the time of the TSPA-LA and are defensible for up to 10,000 years after disposal.

- This report cites supporting technical Analysis and Model Reports (AMRs) and other controlled documents as direct input. Therefore, the limitations of this report inherently include the limitations and constraints described in the other cited documents. 
- This report describes the development of an electronic database for storing and retrieving information about the inclusion and/or exclusion of TSPA-LA FEPs. However, this report and the associated database are not intended to be used as the source documentation for those FEP screening decisions. The source documentation is provided in the supporting technical AMRs.

The development of this report and the associated electronic database have been determined to be subject to the YMP quality assurance (QA) program, as indicated in the technical work plan (TWP) (BSC 2005 [DIRS 174883], Section 8). The TWP also identifies applicable controls for the electronic management of data (BSC 2005 [DIRS 174883], Section 8.4) during the database development activities.

The FEP analyses described herein involve investigations of items or barriers in Q-List (BSC 2005 [DIRS 171190]) and have the potential to affect the calculation of the performance of the natural barriers and various engineered barrier system (EBS) components included on the Q-List. However, the FEPs themselves do not qualify as "Q-List" items. The evaluations and conclusions do not directly impact engineered features important to safety, as defined in AP-2.22Q, Classification Analyses and Maintenance of the Q-List. 


\section{APPROACHES TO FEP ANALYSIS AND SCENARIO DEVELOPMENT}

The final report of the Nuclear Energy Agency (NEA) Performance Assessment Advisory Group (PAAG) (NEA 1992 [DIRS 100479]) provides a summary of scenario methods and their application up to about 1990. The report of the NEA Working Group on the development of an International FEP Database (NEA 1999 [DIRS 152309) provides a follow-up summary of work up to about 1997. These methods provide details about the different approaches to FEP analysis and scenario development. They are summarized in this Section.

For underground disposal of radioactive waste, postclosure performance assessment is an iterative process that includes scenario development, model development, and consequence analysis. It is generally accepted (NEA 1992 [DIRS 100479], pp. 11 through 14, and 22; NEA 1999 [DIRS 152309], p. 11; NEA 1999 [DIRS 169902], p. 8) that FEP analysis-the process of identifying, classifying, and screening potentially relevant FEPs-is a key activity supporting scenario development.

The early history of FEP analysis is summarized in NEA (1999 [DIRS 152309], pp. 16 to 17). Early generic lists of disruptive FEPs were documented in IAEA (1983 [DIRS 168519]), Merrett and Gillespie (1983 [DIRS 168544]), NAGRA (1985 [DIRS 168537], Section 4), and Cranwell et al. (1990 [DIRS 101234]). All of these lists, summarized in Table 2-1, introduced categories for natural, human-induced, and waste and repository induced FEPs.

Table 2-1. New FEP List Development Prior to 1989

\begin{tabular}{|c|c|c|c|c|c|}
\hline ID* & $\begin{array}{c}\text { Countryl } \\
\text { Organization }\end{array}$ & $\begin{array}{l}\text { Classification } \\
\text { Structure }\end{array}$ & Comments & Source* & Reference \\
\hline 0.1 & $\begin{array}{l}\text { International } \\
\text { IAEA }\end{array}$ & $\begin{array}{l}57 \text { FEPs } \\
\text { (Natural processes } \\
\text { and events, Human } \\
\text { activities, Waste and } \\
\text { repository effects) }\end{array}$ & $\begin{array}{l}\text { Suggested checklist of } \\
\text { phenomena similar to } \\
\text { Burkholder (1980 } \\
\text { [DIRS 168483]) and Koplik et al. } \\
\text { (1982 [DIRS 168541]) }\end{array}$ & New & $\begin{array}{l}\text { IAEA } 1983 \\
\text { [DIRS 168519] }\end{array}$ \\
\hline 0.2 & $\begin{array}{l}\text { USA } \\
\text { NRC }\end{array}$ & $\begin{array}{l}27 \text { FEPs } \\
\text { (Natural, } \\
\text { Human-induced, } \\
\text { Waste- and } \\
\text { repository-induced) }\end{array}$ & $\begin{array}{l}\text { Potentially disruptive events and } \\
\text { processes }\end{array}$ & New & $\begin{array}{l}\text { Cranwell et al. } 1990 \\
\text { [DIRS 101234] } \\
\text { Note that this } \\
\text { information was } \\
\text { initially distributed in } \\
1982\end{array}$ \\
\hline 0.3 & $\begin{array}{l}\text { Canada } \\
\text { AECL }\end{array}$ & $\begin{array}{l}\text { General FEPs } \\
\text { (disruptive actions of } \\
\text { man, vault-related, } \\
\text { natural phenomena) }\end{array}$ & $\begin{array}{l}\text { Initial FEPs for Canadian } \\
\text { Nuclear Fuel Waste } \\
\text { Management Program }\end{array}$ & New & $\begin{array}{l}\text { Merrett and Gillespie } \\
1983 \\
\text { [DIRS 168544] }\end{array}$ \\
\hline 0.4 & $\begin{array}{l}\text { Switzerland } \\
\text { NAGRA }\end{array}$ & $\begin{array}{l}44 \text { FEPs } \\
\text { (natural, human } \\
\text { induced, waste and } \\
\text { repository-induced) }\end{array}$ & $\begin{array}{l}\text { Relevant processes and events } \\
\text { for Project Gewahr }\end{array}$ & New & $\begin{array}{l}\text { NAGRA 1985, Table } \\
4-1 \\
\text { [DIRS 168537] }\end{array}$ \\
\hline
\end{tabular}

* ID numbers are assigned to each FEP list in Tables 2-1 through 2-4. The ID numbers are used in the Source column to identify predecessor studies for derivative lists. Original studies are designated with "New" in the Source column.

In the late 1980s and early 1990s, new FEP development continued with project specific (rather than generic) lists developed in several different countries (see Table 2-2). Continuing FEP analysis in the mid-1990s focused on the completeness of the FEP lists. Many of these efforts (see Tables 2-3 and 2-4) derived from the original studies listed in Tables 2-1 and 2-2 and are part of chronological "development chains" as indicated in the Source column of the Tables. 
Table 2-2. New FEP List Development, 1989-1992

\begin{tabular}{|c|c|c|c|c|c|}
\hline ID* & $\begin{array}{c}\text { Countryl } \\
\text { Organization }\end{array}$ & $\begin{array}{c}\text { Classification } \\
\text { Structure }\end{array}$ & Comments & Source* & Reference \\
\hline 1.1 & $\begin{array}{l}\text { Sweden } \\
\text { SKI/SKB }\end{array}$ & $\begin{array}{l}157 \text { FEPs } \\
\text { (waste, canister, } \\
\text { buffer/backfill, EDZ/ } \\
\text { near-field, disruptive } \\
\text { events-repository and } \\
\text { far-field, far-field, } \\
\text { surface) }\end{array}$ & $\begin{array}{l}\text { Categorized as either Process } \\
\text { System FEPs or External "Kept" } \\
\text { FEPs }\end{array}$ & New & $\begin{array}{l}\text { Andersson et al. } 1989 \\
\text { [DIRS 100956] }\end{array}$ \\
\hline 1.2 & $\begin{array}{l}\text { International } \\
\text { NEA }\end{array}$ & $\begin{array}{l}149 \text { FEPs } \\
\text { (Natural, Human, } \\
\text { Waste and } \\
\text { Repository) }\end{array}$ & $\begin{array}{l}\text { Derives from Hodgkinson and } \\
\text { Sumerling (1989) [DIRS 168518] }\end{array}$ & New & $\begin{array}{l}\text { NEA } 1992 \\
\text { [DIRS 100479] }\end{array}$ \\
\hline 1.3 & $\begin{array}{l}\text { UK } \\
\text { HMIP }\end{array}$ & $\begin{array}{l}305 \text { FEPs } \\
\text { (Near-Field, Far-Field, } \\
\text { Biosphere, } \\
\text { Short-Circuit } \\
\text { Pathways Related to } \\
\text { Human Activities) }\end{array}$ & $\begin{array}{l}\text { FEPs for Dry Run } 3 \text { hypothetical } \\
\text { low- and intermediate-level } \\
\text { waste repository at Harwell site }\end{array}$ & New & $\begin{array}{l}\text { Thorne } 1992 \\
\text { [DIRS 168548] }\end{array}$ \\
\hline
\end{tabular}

* ID numbers are assigned to each FEP list in Tables 2-1 through 2-4. The ID numbers are used in the Source column to identify predecessor studies for derivative lists. Original studies are designated with "New" in the Source column.

Table 2-3. Continuing FEP List Development, 1993-1994

\begin{tabular}{|c|c|c|c|c|c|}
\hline ID* & $\begin{array}{c}\text { Countryl } \\
\text { Organization }\end{array}$ & $\begin{array}{c}\text { Classification } \\
\text { Structure }\end{array}$ & Comments & Source* & Reference \\
\hline 2.1 & $\begin{array}{l}\text { Sweden } \\
\text { SKI }\end{array}$ & $\begin{array}{l}1200 \text { FEPs (approx.) } \\
\text { (Waste, Canister, } \\
\text { Buffer/Backfill, } \\
\text { Repository/ Near-Field, } \\
\text { Far-Field, Biosphere, } \\
\text { Geology/ Climate, } \\
\text { Human Influences) }\end{array}$ & $\begin{array}{l}\text { Initial FEP list combined early } \\
\text { lists from Tables } 2-1 \text { and } 2-2 \text {. } \\
\text { Initial list categorized and then } \\
\text { irrelevant, vague or } \\
\text { incomprehensible FEPs } \\
\text { removed. Complete } \\
\text { consolidated list includes } \\
\text { groupings of Process System } \\
\text { FEPs, EFEPs, and Screened } \\
\text { Out FEPs. }\end{array}$ & $\begin{array}{l}0.1,0.2 \\
0.3,0.4 \\
1.1,1.2 \\
1.3\end{array}$ & $\begin{array}{l}\text { Stenhouse et al. } 1993 \\
\text { [DIRS 168532] }\end{array}$ \\
\hline 2.2 & $\begin{array}{l}\text { Canada } \\
\text { AECL }\end{array}$ & $\begin{array}{l}281 \text { FEPs } \\
\text { (vault, geosphere, } \\
\text { biosphere) }\end{array}$ & $\begin{array}{l}\text { FEPs added to some of the } \\
\text { initial lists. Categorized under } \\
\text { Central scenarios or Alternative } \\
\text { scenarios (open borehole, } \\
\text { human intrusion) }\end{array}$ & $\begin{array}{l}\text { New } \\
0.1,0.3 \\
0.4,1.1 \\
1.2\end{array}$ & $\begin{array}{l}\text { Goodwin et al. } 1994 \\
\text { [DIRS 100983] }\end{array}$ \\
\hline 2.3 & $\begin{array}{l}\text { UK } \\
\text { HMIP }\end{array}$ & $\begin{array}{l}79 \text { FEPs } \\
\text { (Near-Field, Far-Field, } \\
\text { Climatology, Biosphere, } \\
\text { Short-Circuit Pathways) }\end{array}$ & $\begin{array}{l}\text { FEPs from Dry Run } 3 \text { analysis, } \\
\text { restructured and consolidated } \\
\text { (especially biosphere) for } \\
\text { relevance to Sellafield site }\end{array}$ & 1.3 & $\begin{array}{l}\text { Miller and Chapman } \\
1993 \text { [DIRS 100996] }\end{array}$ \\
\hline
\end{tabular}

* ID numbers are assigned to each FEP list in Tables 2-1 through 2-4. The ID numbers are used in the Source column to identify predecessor studies for derivative lists. Original studies are designated with "New" in the Source column. 
Table 2-4. Continuing FEP List Development, 1994-1996

\begin{tabular}{|c|c|c|c|c|c|}
\hline ID* & $\begin{array}{c}\text { Countryl } \\
\text { Organization }\end{array}$ & $\begin{array}{c}\text { Classification } \\
\text { Structure }\end{array}$ & Comments & Source* & Reference \\
\hline 3.1 & $\begin{array}{l}\text { Sweden } \\
\text { SKI }\end{array}$ & $\begin{array}{l}164 \text { FEPs } \\
\text { (no categories listed) }\end{array}$ & $\begin{array}{l}\text { SKI/SKB list audited against } \\
\text { Stenhouse et al. (1993 } \\
\text { [DIRS 168532]) list. FEPs } \\
\text { lumped into } 10 \text { categories as } \\
\text { a part of either Process } \\
\text { System (reference case, } \\
\text { central scenarios) or } \\
\text { Supplementary Scenarios }\end{array}$ & $1.1,2.1$ & $\begin{array}{l}\text { Chapman et al. } 1995 \\
\text { [DIRS 100970] }\end{array}$ \\
\hline 3.2 & $\begin{array}{l}\text { Switzerland } \\
\text { NAGRA }\end{array}$ & $\begin{array}{l}243 \text { FEPs } \\
\text { (radionuclides, waste, } \\
\text { canister, buffer/ } \\
\text { backfill, repository and } \\
\text { EDZ, rock-low } \\
\text { permeability, } \\
\text { rock-faults, rock-high } \\
\text { permeability, bio- } \\
\text { sphere, geologic EPs, } \\
\text { climatic EPs, human } \\
\text { activities) }\end{array}$ & $\begin{array}{l}\text { New FEPs identified then } \\
\text { audited against earlier lists. } \\
\text { Categorized under Reference } \\
\text { Scenario and Alternative } \\
\text { Scenarios (for disruptive } \\
\text { events). }\end{array}$ & $\begin{array}{l}\text { New } \\
0.2,1.1 \\
1.2,1.3 \\
2.2\end{array}$ & $\begin{array}{l}\text { NAGRA } 1994 \\
\text { [DIRS 124260] }\end{array}$ \\
\hline 3.3 & $\begin{array}{l}\text { USA } \\
\text { DOE }\end{array}$ & $\begin{array}{l}237 \text { FEPs } \\
\text { (Natural, Waste and } \\
\text { Repository, Human) }\end{array}$ & $\begin{array}{l}\text { WIPP specific FEPs } \\
\text { (e.g., seals) added to } \\
\text { Stenhouse et al. (1993 } \\
\text { [DIRS 168532]) final list. } \\
\text { FEPs then consolidated and } \\
\text { reorganized under either } \\
\text { Undisturbed performance or } \\
\text { Disturbed performance } \\
\text { (i.e., human intrusion) }\end{array}$ & $\begin{array}{l}\mathrm{New} \\
2.1\end{array}$ & $\begin{array}{l}\text { DOE } 1996, \\
\text { Sections } 6.2 \text { and } 6.3 \\
\text { [DIRS 100975] }\end{array}$ \\
\hline
\end{tabular}

* ID numbers are assigned to each FEP list in Tables 2-1 through 2-4. The ID numbers are used in the Source column to identify predecessor studies for derivative lists. Original studies are designated with "New" in the Source column.

The chronological development chains produced the following "end of chain" lists:

2.2-Canada (Goodwin et al. 1994 [DIRS 100983], Appendix B)

2.3-U.K. (Miller and Chapman 1993 [DIRS 100996], Tables 2 and 3)

3.1-Sweden (Chapman et al. 1995 [DIRS 100970], Appendix 1)

3.2-Switzerland (NAGRA 1994 [DIRS 124260], Table 4.2.2)

3.3-U.S. (DOE 1996 [DIRS 100975], Appendix SCR).

Version 1.0 of the NEA International FEP Database (Safety Assessment Management (SAM) 1997 [DIRS 139333]) documented in NEA (1999 [DIRS 152309]) contains a FEP list derived from these 5 "end of chain" lists as well as from two predecessor lists: 1.1-Sweden (Andersson et al. 1989 [DIRS 100956], Appendix B.1) and 1.2-NEA (NEA 1992 [DIRS 100479], pp. 24 to 25). This International FEP list formed an initial basis for the YMP FEP list (see Section 3).

In general, the FEP analyses described above included (a) FEP identification, (b) FEP classification, and (c) FEP screening. This corresponds to Step 1 (FEP identification and classification) and Step 2 (FEP screening) of the YMP TSPA-LA FEP analysis and scenario development approach outlined in Section 1. Issues associated with these steps, based on lessons learned from some of the FEP analysis efforts described above, are discussed in Section 2.1. For scenario development, several approaches have been explored. Scenario development 
corresponds to Step 3 (scenario class formation) and Step 4 (scenario class screening), respectively, of the YMP TSPA-LA approach (see Section 1). Methods and lessons learned associated with scenario development are described in Section 2.2. Alternate FEP analysis approaches that are part of specific scenario development methods are also discussed in Section 2.2. General observations from other programs regarding comprehensiveness and level of detail are summarized in Section 2.3. Finally, an overview of the FEP analysis and scenario development approach for TSPA-LA is presented in Section 2.4. Specific details of the TSPA-LA approach are described in Sections 3 and 4.

\subsection{OVERVIEW OF FEP ANALYSIS METHODS}

FEP analysis includes FEP identification, FEP classification, and FEP screening. Lessons learned from other FEP analysis efforts (see Tables 2-1 through 2-4) are summarized in the following subsections. The application of these lessons learned to FEP analysis for TSPA-LA is summarized in Section 2.4.1 and described in more detail in Sections 3 and 4.

\subsubsection{FEP Identification}

A general observation, based on the cumulative results from several other FEP development efforts, is:

To generate a sufficiently extensive list, this process must be free of limitations and draw on the...experience of a wide range of people. At the same time the list must be comprehensive, traceable, and well documented; this requires the process to have a basic structure (NEA 1992 [DIRS 100479], p. 22).

Input is needed from each part of the safety assessment process and from all relevant disciplines. A variety of methods should be used to formulate an initial list (NEA 1992 [DIRS 100479], p. 23). Some common FEP identification methods include (NEA 1999 [DIRS 152309], pp. 26 to 27):

- Development from existing detailed lists of FEPs

- Brainstorming (i.e., freely-structured identification by groups of relevant experts)

- Top-level-down elicitation, starting from comprehensive classification schemes

- Hybrid procedures (combinations of the other three methods) - reclassify an existing list; refine/extend the classification scheme and refine FEP names; audit against other lists to identify omissions. 


\subsubsection{FEP Classification}

The primary objectives of classification are to (a) uncover missing FEPs and interactions, and (b) provide a framework for organizing scenario development and assessment. Some general observations from other FEP classification efforts include the following:

By classifying features, events, and processes under different schemes, information on additional phenomena and interaction can be gained. ...Classification schemes that examine the system from different viewpoints should be used (NEA 1992 [DIRS 100479], p. 26).

...it is helpful to have a structure or categories so that the completeness (of categories and within categories) can be assessed, and equivalent levels of detail guided, e.g., similar numbers of FEPs might be found in each category (NEA 1999 [DIRS 152309], p. 27).

FEP lists are usually classified either on cause, field of effect, or a combination of the two (NEA 1999 [DIRS 152309], p. 28). Example classification schemes include (NEA 1992 [DIRS 100479], pp. 26 to 28):

Cause-Natural (celestial, surface, subsurface); Human-Induced (intrusion, hydrological stress); Repository and Waste Induced

Physical Field of Effect and Causative Factors-Waste; Canister; Backfill; Repository/Near-Field; Far-Field (multiple pathways); Biosphere; Geologic Processes and Events; Climatic Processes and Events; Near Surface and Human Activities (NEA 1999 [DIRS 152309], p. 28)

Location-Near-Field; Far-Field; Biosphere (also consider interfaces)

Scientific Discipline-(e.g., biology, chemistry, physics, geology)

Radionuclide Transfer Agent-Groundwater (soluble, colloidal); Gas (radioactive, aerosol); Natural (erosion, tectonics, diapirism, environmental change); Living Organism (people, animals, plants)

Radionuclide Mobilization-Release; Transport (migration pathways); Exposure (transfer from biosphere receptors to people, i.e., inhalation)

Layered-Interactions between FEPs tend to occur within each layer and in the inward direction, but not in the outward direction. Layers (from outside in) are: assessment basis, external factors (geologic, climatic, human, other-issues, processes and events originating outside the disposal system but acting upon it), system environment factors (engineered system, geosphere, biosphere-surface/human behavior), radionuclide factors (characteristics, release/migration, exposure) (NEA 1999 [DIRS 152309], pp. 28 to 30)

Time Scales-(e.g., 0 to $100 \mathrm{yrs}, 100$ to $10,000 \mathrm{yrs}, 10,000$ to $10^{6} \mathrm{yrs},>10^{6} \mathrm{yrs}$ ). 


\subsubsection{FEP Screening}

The screening process is site-, system-, and regulation-specific. FEPs are considered one by one and are checked for interactions. FEPs can be screened by regulation, probability, bounding consequence, or physical reasonableness (e.g., "phenomena which are clearly not applicable to the specific repository or site can be eliminated from consideration") (NEA 1992 [DIRS 100479], p. 29).

\subsection{OVERVIEW OF SCENARIO DEVELOPMENT METHODS}

Scenario development is typically performed after FEP analysis. FEPs retained (included) from FEP screening provide the basis for scenario formation and scenario screening. The following is a review of alternate scenario development methods that also provides some insight into alternate FEP analysis approaches and the associated lessons learned from other programs. Note that, for YMP, "scenario class" and "scenario" are defined as two distinct but related terms (see Section 1). In most other radioactive waste disposal programs the term "scenario" is used exclusively, although its use may sometimes represent either or both of the YMP terms.

Some general observations from other scenario development efforts include:

- A scenario is a "broad brush description of the characteristics and sequencing" of "one possible set of events and processes" (NEA 1992 [DIRS 100479], p. 11).

- Scenario development is "the identification, broad description, and selection of alternative futures relevant to a reliable assessment of the radioactive waste repository safety" (NEA 1992 [DIRS 100479], p. 11).

- Scenario formation forms a link between the list of FEPs and the modeling and consequence calculations. Therefore, scenario formation is influenced by the types of models and calculation tools available (NEA 1992 [DIRS 100479], p. 52).

- "Most studies indicate clearly the usefulness of defining a central or base-case scenario" (NEA 1992 [DIRS 100479], p. 52).

Specific methods are presented in NEA (1992 [DIRS 100479] Sections 5 and 6) and are summarized in the following subsections. Note that for all scenario development approaches only the screened-in (i.e., included) FEPs are considered. The application of these lessons learned to scenario development for TSPA-LA is summarized in Sections 2.4.2 and 5.

\subsubsection{Judgmental Methods}

Judgmental methods are essentially brainstorming sessions involving technical experts. They are less than systematic approaches with minimal documentation of screening rationales. They are useful for studies with limited resources that do not require full comprehensiveness or traceability (NEA 1992 [DIRS 100479], p. 35). They can be useful for formulating broad scenarios and initial FEP lists, which can then be checked against more systematic methods, but they do not provide the level of comprehensiveness required for YMP. 


\subsubsection{Event Tree/Logic Diagram Approach}

Event trees (also referred to as fault trees or logic diagrams) are used to illustrate the set of combinations of basic events (FEPs) that can cause system failure. They can be useful when combined with systematic methods, but by themselves they tend to produce an unmanageable number of event combinations (NEA 1992 [DIRS 100479], pp. 34, 35, and 38). They are primarily used as a means to organize scenario development and to complement judgmental methods. They can also be useful for examining certain subsets of the system such as was done for the TSPA-SR EBS FEPs (CRWMS M\&O 2000 [DIRS 150825]). However, they are not as useful for system components where failure modes are typically long-term and continuous rather than abrupt (i.e., in the geosphere).

\subsubsection{Systematic Bottom-Up}

Systematic bottom-up approaches are processes to combine large numbers of screened-in FEPs together to form a limited number of scenarios. Systematic bottom-up approaches are good for comprehensiveness. Specific examples are summarized in Table 2-5.

Table 2-5. Systematic Bottom-Up Scenario Development Approaches

\begin{tabular}{|c|c|c|c|}
\hline $\begin{array}{c}\text { Countryl } \\
\text { Organization }\end{array}$ & Basic Steps & $\begin{array}{l}\text { Relevant } \\
\text { FEP List ID } \\
\quad \text { from } \\
\text { Tables 2-1 } \\
\text { through 2-4 }\end{array}$ & References \\
\hline $\begin{array}{l}\text { USA } \\
\text { Sandia } \\
\text { National } \\
\text { Laboratories }\end{array}$ & $\begin{array}{l}\text { 1. Construct a base case (radionuclide release and } \\
\text { transport with no disruptive phenomena). } \\
\text { 2. Combine retained disruptive FEPs in an event tree } \\
\text { (many scenarios). } \\
\text { 3. Screen scenarios to a manageable number. }\end{array}$ & 0.2 & $\begin{array}{l}\text { Cranwell et al. } 1990 \\
\text { [DIRS 101234] } \\
\text { NEA 1992, pp. } 39 \text { to } \\
41 \\
\text { [DIRS 100479] }\end{array}$ \\
\hline $\begin{array}{l}\text { Sweden } \\
\text { SKI/SKB }\end{array}$ & $\begin{array}{l}\text { 1. Construct a Process System (the organized assembly of } \\
\text { all FEPs required to describe barrier performance and } \\
\text { radionuclide-behavior that can be predicted with at least } \\
\text { some degree of determinism). } \\
\text { 2. Combine remaining FEPs (referred to as: primary } \\
\text { cause, major external events, scenario-generating) into } \\
\text { scenarios. } \\
\text { 3. Apply a top-down approach to reduce the number of } \\
\text { scenarios and couplings. The Process System was } \\
\text { simplified to } 3 \text { barriers (canister, near-field, far-field) each } \\
\text { having } 3 \text { states (ordinary, less efficient, short circuit) for } \\
27 \text { combinations. } \\
\text { 4. Apply scenario-generating FEPs to the } 27 \text { combinations, } \\
\text { where appropriate. }\end{array}$ & 1.1 & $\begin{array}{l}\text { Andersson et al. } 1989 \\
\text { [DIRS 100956] } \\
\text { NEA 1992, pp. } 42 \text { to } \\
44,48 \\
\text { [DIRS 100479] }\end{array}$ \\
\hline $\begin{array}{l}\text { Canada } \\
\text { AECL }\end{array}$ & $\begin{array}{l}\text { 1. Construct a central scenario (FEPs that are expected to } \\
\text { be always important, or to occur frequently or to be } \\
\text { capable of proceeding to a significant degree over the } \\
\text { time scale of the assessment). } \\
\text { 2. Group residual FEPs in all possible combinations to form } \\
\text { alternative scenarios, which act in combination with the } \\
\text { central scenario. } \\
\text { 3. Reduce the number of residual FEPs and alternative } \\
\text { scenarios through additional screening and grouping. }\end{array}$ & 2.2 & $\begin{array}{l}\text { Goodwin et al. } 1994 \\
\text { [DIRS 100983] } \\
\text { NEA 1992, pp. } 44 \text { to } \\
45 \\
\text { [DIRS 100479] }\end{array}$ \\
\hline
\end{tabular}


All of the systematic bottom-up approaches described in Table 2-5 are similar. Nominal FEPs are combined into a base-case (reference/central) scenario and remaining FEPs are grouped and screened to form a manageable number of disruptive scenarios that act upon the base-case scenario.

\subsubsection{Systematic Top-Down}

In systematic top-down approaches, end point consequences or states are postulated and then the mechanisms by which these states may be reached are considered. They adopt certain characteristics of event tree analysis, but systematically limit the number of FEP combinations.

Top-down approaches do not always ensure comprehensiveness unless they are truly systematic. Table 2-6 summarizes specific examples.

Table 2-6. Systematic Top-Down Scenario Development Approaches

\begin{tabular}{|c|c|c|c|}
\hline $\begin{array}{c}\text { Countryl } \\
\text { Organization }\end{array}$ & Basic Steps & $\begin{array}{l}\text { Relevant } \\
\text { FEP List ID } \\
\text { from } \\
\text { Tables 2-1 } \\
\text { through 2-4 }\end{array}$ & References \\
\hline $\begin{array}{l}\text { UK } \\
\text { Department of } \\
\text { the } \\
\text { Environment }\end{array}$ & $\begin{array}{l}\text { 1. Identify target event (risk) and main factors (release from } \\
\text { vault, transmission through geosphere, uptake in } \\
\text { biosphere) considered to affect the outcome of the target } \\
\text { event. } \\
\text { 2. Define alternative states (3) of each barrier (main factor) } \\
\text { and their probabilities. } \\
\text { 3. Evaluate probabilistic consequence based on each of the } \\
27 \text { combinations. }\end{array}$ & None & $\begin{array}{l}\text { Dalrymple et al. } 1986, \\
\text { Sections } 6.1 .3 .2 \\
\text { and } 6.2 \\
\text { [DIRS } 170075 \text { ] } \\
\text { NEA 1992, pp. } 47 \text { to } \\
48 \\
\text { [DIRS 100479] }\end{array}$ \\
\hline $\begin{array}{l}\text { UK } \\
\text { Nirex }\end{array}$ & $\begin{array}{l}\text { 1. Define scenario elements (groups of FEPs based on } \\
\text { cause or field of effect) and develop an influence diagram } \\
\text { to show dependencies. } \\
\text { 2. Define a comprehensive set of states for each scenario } \\
\text { element. } \\
\text { 3. Perform influence screening to eliminate or "fix" those that } \\
\text { do not affect the state of another downstream element. } \\
\text { 4. Select scenarios from the remaining multi-state elements. }\end{array}$ & None & $\begin{array}{l}\text { Billington et al. } 1989 \\
\text { [DIRS 169925] } \\
\text { NEA 1992, pp. } 48 \text { to } \\
51 \\
\text { [DIRS 100479] }\end{array}$ \\
\hline $\begin{array}{l}\text { Sweden } \\
\text { SKI }\end{array}$ & $\begin{array}{l}\text { 1. Construct a Process Influence Diagram (PID) to represent } \\
\text { the Process System. PID is built top-down. } \\
\text { 2. Map nominal FEPs to the PID to create the Reference } \\
\text { Case and Central Scenarios. } \\
\text { 3. Create and screen Supplementary Scenarios by lumping } \\
\text { remaining FEPs (EFEPs). }\end{array}$ & 3.1 & $\begin{array}{l}\text { Chapman et al. } 1995 \text {, } \\
\text { pp. } 39 \text { to } 61 \\
\text { [DIRS 100970] }\end{array}$ \\
\hline $\begin{array}{l}\text { Sweden } \\
\text { SKB }\end{array}$ & $\begin{array}{l}\text { 1. A structured Rock Engineering System (RES) matrix is } \\
\text { used to assist is identifying and checking } \\
\text { comprehensiveness of FEPs. } \\
\text { 2. The RES matrix starts small with broad terms and is then } \\
\text { expanded. The RES matrix helps to identify scenarios. }\end{array}$ & None & $\begin{array}{l}\text { Hudson } 1992 \\
\text { [DIRS 169926] } \\
\text { Eng et al. 1994 } \\
\text { [DIRS 169927] }\end{array}$ \\
\hline
\end{tabular}


Table 2-6. Systematic Top-Down Scenario Development Approaches (Continued)

\begin{tabular}{|c|c|c|c|}
\hline $\begin{array}{c}\text { Countryl } \\
\text { Organization }\end{array}$ & Basic Steps & $\begin{array}{l}\text { Relevant } \\
\text { FEP List ID } \\
\text { from } \\
\text { Tables 2-1 } \\
\text { through 2-4 }\end{array}$ & References \\
\hline $\begin{array}{l}\text { UK } \\
\text { Nirex }\end{array}$ & $\begin{array}{l}\text { 1. Develop a structured Master Directed Diagram (MDD) to } \\
\text { organize FEPs starting at PA "endpoints" (i.e., risk) and } \\
\text { moving into more detail where necessary. } \\
\text { 2. Define FEPs in the MDD as scenario defining FEPs or } \\
\text { scenario FEPs. } \\
\text { 3. Build a base scenario from some of the scenario defining } \\
\text { FEPs. } \\
\text { 4. Group the remaining scenario defining FEPs into variant } \\
\text { scenarios. } \\
\text { 5. Use weight-risk diagrams and subsume lesser risk } \\
\text { scenarios to retain a few important scenarios. } \\
\text { 6. Put FEPs in any one scenario into an Influence Matrix } \\
\text { diagram to show interactions. }\end{array}$ & None & $\begin{array}{l}\text { Kelly and Billington } \\
1998 \\
\text { [DIRS 169928] } \\
\text { NEA 1999, pp. } 21 \text { to } \\
24 \\
\text { [DIRS 169902] }\end{array}$ \\
\hline
\end{tabular}

The last two approaches in Table 2-6, the SKB Rock Engineering System (RES) method and the UK Nirex Master Directed Diagram (MDD) method, both contain steps where FEPs are put into a matrix to help identify interactions and check comprehensiveness.

\subsection{FEP EVALUATION CRITERIA}

This section includes lessons learned from other programs regarding comprehensiveness and level of detail. The application of these lessons learned to FEP analysis for TSPA-LA is summarized in Section 7.

\subsubsection{Comprehensiveness}

Some general observations about comprehensiveness from other FEP analysis efforts include:

Comprehensiveness can never be accomplished in one step, and will have to be judged against a record of continuous and open reviews, the most recent of these reviews having given evidence of no major findings. ...Comprehensiveness can only be sought and achieved in relation to a specific site, a specific type of waste, and a specific regulatory context. (NEA 1999 [DIRS 169902], p. 15)

Review by external experts is important for arguing comprehensiveness... (NEA 1999 [DIRS 169902], p. 16).

It is impossible to demonstrate comprehensiveness or completeness, in the sense that it is impossible to exhaustively identify all possible FEPs and interactions within a complex and evolving system. It is possible, however, to list a range of broadly-defined FEPs that might be relevant to consider in safety assessments. This is the aim of the International FEP List: to be comprehensive in a broad sense rather than in a detailed sense. (NEA 1999 [DIRS 152309], pp. 24 to 25) 
The [International FEP Database] classification scheme captures a range of radioactive waste disposal assessment projects within its scope. ...this will be an aid to achieving comprehensiveness of assessments... (NEA 1999 [DIRS 152309], p. 43).

A formal audit process can give confidence in the comprehensiveness of considerations. The [FEP list] was audited against a combined list of over 1000 FEPs identified in other assessment and scenario development studies...no critical omissions were identified. (NAGRA 1994 [DIRS 124260], pp. 112 to 113 )

Confidence in the comprehensiveness of the list of factors is developed by organizing and ordering the information in many different ways. (Goodwin et al. 1994 [DIRS 100983], p. 7)

For the Waste Isolation Pilot Plant (WIPP) project, confidence in the comprehensiveness and appropriateness of the FEP list was supported by (DOE 1996 [DIRS 100975], Appendix SCR, Attachment 1, p. 13):

- Nine lists from different countries used as a starting point

- List extended through review of WIPP project literature

- Formal presentations and reviews with stakeholders and regulator

- Formal documented reviews within the project

- Reduction of the list in documented manner

- Participation in the International FEP Database.

In summary, comprehensiveness of a FEP list cannot be proven with absolute certainty. However, confidence can be gained through a combination of formal and systematic reviews (both top-down and bottom-up), audits, and comparisons with other FEP lists and through the application of more than one classification scheme.

\subsubsection{Level of Detail}

Some general observations regarding the level of detail for FEPs, taken from other FEP analysis efforts include:

"A list that is too general will not be useful. On the other hand, a list that [is too detailed] will tend to become incomplete as it becomes more difficult to be comprehensive at more detailed levels." (NEA 1999 [DIRS 152309], p. 25)

"The Working Group thought that, as a guide, the International List should contain a total of about 100 FEPs, and not more than about 200 FEPs. The larger the list, the finer the classification of FEPs that can be achieved, but the list becomes harder to use. The list is designed to be short enough that a user can become generally familiar with it and will not inadvertently overlook a FEP on the list." (NEA 1999 [DIRS 152309], p. 25) 
"Consideration within a variant scenario does not necessarily imply explicit representation of a specific FEP, many FEPs have a similar impact on system performance. It may be possible to represent a number of FEPs by a single representative scenario-defining FEP.” (Bailey et al. 1998 [DIRS 169945], pp. 4.1 to 4.2$)$

"The aim of the MDD is to provide a comprehensive set of FEPs. For each FEP on the MDD, the following question may be asked: 'Is it helpful for modeling purposes to include additional FEPs at the next level down, in order to represent this FEP?' If the answer is 'no', then the MDD can be considered comprehensive at that level. ...As the MDD is developed downwards, the FEPs become more specific. Eventually, there comes a point at which the level of detail of the FEPs is equivalent to that which has to be considered in a numerical model of the FEP. Development of these FEPs then ceases, as no additional benefit will be gained by decomposing to greater levels of detail. ...Therefore, the lowest level FEPs on the MDD should reflect an appropriate level of detail to enable model development to proceed. ...It should be noted that at the lowest levels, the MDD does not necessarily represent all FEP interactions as this would introduce unnecessary complexity. Instead, interactions between key FEPs were considered using a matrix diagram in the conceptual model development stage. ...It is sometimes found that certain high-level FEPs do not require decomposition, even though their level of detail is insufficient for mathematical model development. This might arise when...further decomposition would only lead to FEPs that do not need to be considered (such as ...human intrusion...excluded on... Regulatory Guidance)." (Bailey et al. 1998 [DIRS 169945], pp. 3.3 to 3.4)

"The objective of lumping is to reduce the number of FEPs that are to be combined into scenarios by grouping 'similar' FEPs together and only work with the groups...in practice, it is necessary to resort to lumping in order to reduce the number of FEPs such that the final number of formed scenarios is manageable." (Andersson et al. 1989 [DIRS 100956], pp. 17 to 18)

"... it may not only be necessary to check that all FEPs have been processed in a logical and consistent way, but to also split up some of the FEPs into smaller ones before repeating the screening/lumping process..." (Andersson et al. 1989 [DIRS 100956], p. 23).

“...the initial list will be a mixture of loosely defined factors at different levels of detail. Therefore, it is necessary to define the FEPs in more detail, to sort out inconsistencies and eliminate overlap....and to structure or categorise them in a way that facilitates systematic consideration..." (NEA 1992 [DIRS 100479], p. 30).

In summary, the level of detail of a FEP list should be guided by grouping/lumping such that the final list contains on the order of a few hundred FEPs. The level of detail should also be guided by the complexity required for modeling or screening. 


\subsection{OVERVIEW OF YUCCA MOUNTAIN PROJECT FEP ANALYSIS AND SCENARIO DEVELOPMENT}

\subsubsection{Yucca Mountain Project FEP Analysis}

The identification and screening of a comprehensive list of FEPs potentially relevant to the postclosure performance of the Yucca Mountain repository was an iterative process based on site-specific information, design, and regulations. The iterative process was initiated to support TSPA-SR and continued through TSPA-LA FEP analysis. A general schematic of the iterative process is shown in Figure 2-1. The process is iterative in the sense that there are multiple evaluation and feedback steps (e.g., the separate preliminary, interim, and final analyses shown in Figure 2-1). The process is also iterative in the sense that the entire set (preliminary, interim, final) of analyses occurs more than once (e.g., once for TSPA-SR, once post TSPA-SR, once for TSPA-LA).

\begin{tabular}{|c|c|}
\hline \multicolumn{2}{|r|}{ Preliminary FEP Identification } \\
\hline Input & - Source FEPs \\
\hline Actions & $\begin{array}{l}\text { - Consolidate source FEPs into a systematic, structured, and comprehensive list of FEPs potentially relevant } \\
\text { to postclosure performance of the Yucca Mountain disposal system (FEP Team) } \\
\text { - Identify the technical subject area(s) (i.e., FEP AMR) where each FEP will be addressed (FEP Team) }\end{array}$ \\
\hline Output & $\begin{array}{l}\text { - Preliminary FEP List (Name, Number, Description) } \\
\text { - Preliminary FEP Assignment (FEP AMR) }\end{array}$ \\
\hline Documentation & - Preliminary FEPs Data File (DTN) \\
\hline \multicolumn{2}{|r|}{ Preliminary FEP Screening } \\
\hline Input & - Preliminary FEP List \\
\hline Actions & $\begin{array}{l}\text { - Evaluate the preliminary FEP list and, where appropriate, suggest new FEPs or revisions to existing FEPs } \\
\text { to enhance comprehensiveness (FEP AMR Leads, SMEs) } \\
\text { - Identify preliminary screening decisions (included or excluded) for each FEP (SMEs) } \\
\text { - For excluded FEPs, identify the technical basis for exclusion. Where the technical basis for exclusion is } \\
\text { insufficient, identify additional information needs or change screening decision to include. (FEP AMR } \\
\text { Leads, SMEs) } \\
\text { - For included FEPs, identify supporting technical AMRs where the method of implementation in TSPA will } \\
\text { be partially or completely addressed (FEP AMR Leads) } \\
\text { - Coordinate FEP revisions and preliminary screening decisions to ensure consistency (FEP Team) }\end{array}$ \\
\hline Output & $\begin{array}{l}\text { - Revised Preliminary FEP List (Name, Number, Description-all revised where appropriate) } \\
\text { - Preliminary FEP Assignment (FEP AMR - revised where appropriate, Supporting Technical AMRs) } \\
\text { - Preliminary Screening Decision }\end{array}$ \\
\hline Documentation & - Revised Preliminary FEPs Data File (DTN) \\
\hline
\end{tabular}

Figure 2-1. Schematic of the Iterative FEP Analysis Process 


\begin{tabular}{|c|c|}
\hline \multicolumn{2}{|r|}{ Interim FEP Analysis and Documentation } \\
\hline Input & - Revised Preliminary FEP List \\
\hline Actions & $\begin{array}{l}\text { - Evaluate the revised preliminary FEP list and, where appropriate, suggest new FEPs or revisions to } \\
\text { existing FEPs to enhance comprehensiveness (FEP AMR Leads, SMEs) } \\
\text { - For excluded FEPs, review the technical basis for exclusion. Where the technical basis for exclusion is not } \\
\text { defensible, identify additional information needs or change screening decision to include. (FEP AMR } \\
\text { Leads, SMEs) } \\
\text { - For included FEPs, document the method of implementation in TSPA in the appropriate interim supporting } \\
\text { technical AMRs (SMEs) } \\
\text { - Coordinate FEP revisions and interim screening decisions to ensure consistency (FEP Team) } \\
\text { - Review documentation of included FEPs in interim supporting technical AMRs for adequacy and } \\
\text { consistency (FEP Team) } \\
\text { - Coordinate changes from the Potential FEP Log (FEP Team) } \\
\text { - Document the interim screening decisions, technical bases for exclusion (for excluded FEPs), and } \\
\text { methods of implementation in TSPA (for included FEPs) in the appropriate interim FEP AMRs (FEP AMR } \\
\text { Leads, SMEs) } \\
\text { - Review documentation of included and excluded FEPs in the interim FEP AMRs for adequacy and } \\
\text { consistency (FEP Team) }\end{array}$ \\
\hline Output & $\begin{array}{l}\text { - Interim FEP List (Name, Number, Description) } \\
\text { - Interim FEP Assignment (FEP AMR, Supporting Technical AMRs) } \\
\text { - Interim Screening Decision } \\
\text { - Interim TSPA Disposition (Included FEPs only - how implemented in TSPA) } \\
\text { - Interim Screening Argument (Excluded FEPs only-technical basis for exclusion) }\end{array}$ \\
\hline Documentation & $\begin{array}{l}\text { - Interim Supporting Technical AMRs } \\
\text { - Interim FEP AMRs } \\
\text { - Interim FEPs Data File (DTN) }\end{array}$ \\
\hline \multicolumn{2}{|r|}{ Final FEP Analysis and Documentation } \\
\hline Input & $\begin{array}{l}\text { - Interim FEP List } \\
\text { - Interim Documentation of Screening }\end{array}$ \\
\hline Actions & $\begin{array}{l}\text { - Review the interim FEP list and, where appropriate, suggest new FEPs or revisions to existing FEPs to } \\
\text { enhance comprehensiveness (FEP AMR Leads, SMEs) } \\
\text { - Coordinate changes from the Potential FEP Log (FEP Team) } \\
\text { - Review the interim screening decisions, technical bases for exclusion (for excluded FEPs), and methods of } \\
\text { implementation in TSPA (for included FEPs) for consistency with available information (FEP AMR Leads, } \\
\text { SMEs) } \\
\text { - For excluded FEPs, document the technical basis for exclusion in the appropriate FEP AMRs (FEP AMR } \\
\text { Leads, SMEs) } \\
\text { - For included FEPs, document the method of implementation in TSPA in the appropriate supporting } \\
\text { technical AMRs and appropriate FEP AMRs. The documentation in the FEP AMRs consolidates } \\
\text { information from the relevant supporting technical AMRs (FEP AMR Leads, SMEs) } \\
\text { - Coordinate FEP revisions and final screening decisions to ensure consistency (FEP Team) } \\
\text { - Review final documentation of included and excluded FEPs in supporting technical AMRs and FEP AMRs } \\
\text { for adequacy and consistency (FEP Team) }\end{array}$ \\
\hline Output & $\begin{array}{l}\text { - Final FEP List (Name, Number, Description) } \\
\text { - Final FEP Assignment (FEP AMR, Supporting Technical AMRs) } \\
\text { - Final Screening Decision } \\
\text { - Final TSPA Disposition (Included FEPs only-how implemented in TSPA) } \\
\text { - Final Screening Argument (Excluded FEPs only-technical basis for exclusion) }\end{array}$ \\
\hline Documentation & $\begin{array}{l}\text { - Final Supporting Technical AMRs } \\
\text { - Final FEP AMRs } \\
\text { - Final FEPs Data File (DTN) }\end{array}$ \\
\hline
\end{tabular}

Figure 2-1. Schematic of the Iterative FEP Analysis Process (Continued) 
As noted in Section 2.1.1, there are four common FEP identification methods: (1) development from an existing list; (2) brainstorming by groups of relevant experts; (3) top-down elicitation from a classification scheme; and (4) hybrid procedures. These methods were applied both for the initial FEP identification activities supporting TSPA-SR and for the continuing FEP identification activities for TSPA-LA.

For TSPA-SR, FEP identification fully or partially applied all four of the methods, as summarized below:

- Existing list-Used Version 1.0 of the NEA International FEP Database (Safety Assessment Management (SAM) 1997 [DIRS 139333]) as a basis for the initial FEP list, augmented by site-specific information (Freeze et al. 2001 [DIRS 154365], Section 2.1).

- Brainstorming-Used to develop some of the initial YMP-specific FEPs in project documents (Freeze et al. 2001 [DIRS 154365], Section 2.2) and to identify FEPs by subject matter experts (SMEs) during technical workshops and reviews (Freeze et al. 2001 [DIRS 154365], Section 2.3).

- Top-down elicitation-Used to develop general event tree logic diagrams for nominal flow (Barr et al. 1995 [DIRS 100592]), tectonic processes (Barr et al. 1996 [DIRS 100310]), igneous activity (Barr et al. 1993 [DIRS 100311]), and EBS degradation modes (CRWMS M\&O 2000 [DIRS 150825]). These documents provided the basis for identification of some of the YMP-specific FEPs (Freeze et al. 2001 [DIRS 154365], Sections 2.2 and 2.3).

- Hybrid procedures-Used in the refinement and reclassification of the NEA FEPs to make them relevant to YMP (Freeze et al. 2001 [DIRS 154365], Section 3).

For TSPA-LA, the FEP identification methods were further applied. FEP identification (see Section 3.2) started with the TSPA-SR FEP list (method 1). The list was revised for TSPA-LA in part with an application of a hybrid procedure that included reclassification, refinement, and audits against other recently published international lists (method 4). A top-down interaction diagram analysis, summarized in Appendix B and described in detail in The Development of the Total System Performance Assessment-License Application Features, Events, and Processes (BSC 2005 [DIRS 168706], Appendix B), was employed to evaluate the completeness of and identify omissions from the TSPA-LA FEP list (method 3). Additional refinements resulted from continuous iterative reviews and associated brainstorming (method 2) of the FEP list by SMEs (see Section 3.2.3). The combined use of all four FEP identification methods from TSPA-SR through TSPA-LA supports the demonstration of comprehensiveness. Further details of YMP FEP identification are presented in Section 3.2.

For TSPA-SR, FEP classification (Freeze et al. 2001 [DIRS 154365], Section 3) derived from an NEA classification scheme (NEA 1999 [DIRS 152309], pp. 28 to 34) that was based on a combination of the classification schemes listed in Section 2.1.2. The TSPA-SR classification was a layered scheme, with different layers categorized by cause, field of effects and causative factors, location, scientific discipline, radionuclide transfer agent, and/or radionuclide mobilization. As a check on comprehensiveness, TSPA-SR FEPs were also classified according 
to technical subject areas (i.e., a combination of location and physical field of effect). The alternate classification did not result in the identification of any additional FEPs. For TSPA-LA, yet another classification scheme was applied (Section 3.1), based on a mapping between YMP-specific features (i.e., locations and fields of effect) and processes (i.e., radionuclide mobilization and causative factors). This revised approach improved traceability by relating FEPs directly to YMP-specific "technical subject areas" rather than to generic international groupings. The use of multiple classification schemes from TSPA-SR through TSPA-LA supports the demonstration of comprehensive. Further details of YMP FEP classification are presented in Section 3.1.

The TSPA-SR FEP screening process (Freeze et al. 2001, [DIRS 154365] Section 4) evaluated FEPs relative to screening criteria outlined in draft regulations. For TSPA-LA, FEP screening was performed in accordance with final regulations in 10 CFR Part 63 [DIRS 173273], as identified in Section 4.1. FEP screening was documented (see Section 4.2.1) in accordance with general guidelines regarding content (see Section 4.2.2) to ensure that the technical basis for inclusion or exclusion was consistent with the regulations and technically defensible. The final results of the FEP screening analyses were documented in a set of ten FEP Analysis Reports (referred to as FEP AMRs), prepared in accordance with LP-SIII.9Q-BSC, Scientific Analyses or its predecessor, AP-SIII.9Q, Scientific Analyses. These are listed in Table 2-7. Further details of YMP FEP screening are presented in Section 4.

Table 2-7. FEP Analysis Reports Supporting TSPA-LA

\begin{tabular}{|l|l|l|}
\hline \multicolumn{1}{|c|}{ Technical Subject Area } & \multicolumn{1}{|c|}{ FEP AMR DI } & \multicolumn{1}{c|}{ Reference } \\
\hline Unsaturated Zone Flow and Transport (UZ) & ANL-NBS-MD-000001 REV 04 & $\begin{array}{l}\text { BSC 2005 } \\
\text { [DIRS 174191] }\end{array}$ \\
\hline Saturated Zone Flow and Transport (SZ) & ANL-NBS-MD-000002 REV 04 & $\begin{array}{l}\text { BSC 2005 } \\
\text { [DIRS 174190] }\end{array}$ \\
\hline Biosphere (BIO) & ANL-MGR-MD-000011 REV 05 & $\begin{array}{l}\text { BSC 2005 } \\
\text { [DIRS 174107] }\end{array}$ \\
\hline Disruptive Events (DE) & ANL-WIS-MD-000005 REV 03 & $\begin{array}{l}\text { BSC 2005 } \\
\text { [DIRS 173981] }\end{array}$ \\
\hline $\begin{array}{l}\text { Waste Package and Drip Shield } \\
\text { Degradation (WP) }\end{array}$ & ANL-EBS-PA-000002 REV 05 & $\begin{array}{l}\text { BSC 2005 } \\
\text { [DIRS 174995] }\end{array}$ \\
\hline Waste Form Degradation (WF) & ANL-WIS-MD-000009 REV 02 & $\begin{array}{l}\text { BSC 2004 } \\
\text { [DIRS 170020] }\end{array}$ \\
\hline Clad Degradation (CLAD) & ANL-WIS-MD-000008 REV 02 & $\begin{array}{l}\text { BSC 2004 } \\
\text { [DIRS 170019] }\end{array}$ \\
\hline Engineered Barrier System (EBS) & ANL-WIS-PA-000002 REV 05 & $\begin{array}{l}\text { BSC 2005 } \\
\text { [DIRS 175014] }\end{array}$ \\
\hline System Level (SYS) & ANL-WIS-MD-000019 REV 02 & $\begin{array}{l}\text { BSC 2004 } \\
\text { [DIRS 170021] }\end{array}$ \\
\hline Criticality (CRIT) & ANL-EBS-NU-000008 REV 01 & $\begin{array}{l}\text { BSC 2004 } \\
\text { [DIRS 168556] }\end{array}$ \\
\hline
\end{tabular}




\subsubsection{Yucca Mountain Project Scenario Development}

For TSPA-LA, FEP analysis and scenario development was basically a systematic bottom-up approach (see Section 2.2.3) with some systematic top-down (see Section 2.2.4) checks and balances to further demonstrate comprehensiveness. The last two top-down approaches listed in Table 2-6, the SKB RES method and the UK Nirex MDD method, both contain steps where FEPs are put into a matrix to help identify interactions and check comprehensiveness. This matrix approach has been adopted for the TSPA-LA FEP classification (see Section 3.1). In addition, as noted in Section 2.4.1, a top-down FEP analysis (see Appendix B) and audits against other recently published international lists were also employed to produce checklists to identify omissions from the TSPA-LA FEP list. This analysis also supports the comprehensiveness of the TSPA-LA scenario classes. Further details of YMP scenario class formation are presented in Section 5.

\subsubsection{Interface Team For Yucca Mountain Project FEP Analysis}

Total System Performance Assessment-License Application Methods and Approach (BSC 2003 [DIRS 166296], Section 3.2.1) describes the use of a team approach for FEP analysis for TSPA-LA. The team approach was used to provide consistency in the identification and screening of FEPs.

The FEP Team included a FEP Team Lead (FTL) and FEP Experts. The FTL was responsible for managing the FEP analysis process described in this report, with support from the FEP Experts. The FEP Team was responsible for maintaining the TSPA-LA FEP list, ensuring consistent treatment and documentation of the FEPs in TSPA-LA documentation (i.e., in the supporting technical AMRs and in the FEP AMRs, as described in Section 4.2.1), and developing the FEP database.

The FEP Team was supported by a FEP AMR Lead and one or more SMEs supporting each of the FEP AMR technical subject areas. The FEP AMR Leads were responsible for ensuring that relevant FEPs were treated appropriately within their FEP AMRs. SMEs were most technically knowledgeable about individual FEPs and were responsible for developing the explicit screening decisions, technical bases, and documentation (collectively referred to as screening discussions) in the FEP AMRs. Guidelines for FEP screening content (within the FEP AMRs) are provided in Section 4.2.2. The FEP Team worked closely with the FEP AMR Leads and SMEs and served as reviewers for the supporting technical AMRs and FEP AMRs in accordance with LP-2.14QBSC, Document Review. 


\section{YUCCA MOUNTAIN PROJECT FEP ANALYSIS - IDENTIFICATION AND CLASSIFICATION}

The iterative process for FEP analysis (see Figure 2-1) was initiated to support TSPA-SR and continued through the TSPA-LA. For TSPA-SR, an initial list of FEPs relevant to Yucca Mountain was developed from a comprehensive list of FEPs from radioactive waste disposal programs in other countries (Freeze et al. 2001 [DIRS 154365], Section 2.1) and was supplemented with additional YMP-specific FEPs from project literature, technical workshops, and reviews (Freeze et al. 2001 [DIRS 154365], Sections 2.2 through 2.4).

The all-inclusive TSPA-SR FEP identification approach produced 1,656 specific FEPs and 152 associated classifications (derived from Version 1.0 of the NEA International FEP Database (Safety Assessment Management (SAM) 1997 [DIRS 139333]) and from YMP-specific information), and resulted in considerable redundancy in the FEPs list, because the same FEPs were frequently identified by multiple sources. To eliminate the redundancy and to create a more efficient aggregation of FEPs to carry forward into the TSPA-SR screening process, each of the $1808 \mathrm{FEP}$ entries was subjected to a classification process (Freeze et al. 2001 [DIRS 154365], Section 3.2). The TSPA-SR classification process was designed to produce a subset (referred to as primary FEPs) of the 1,808 initially identified FEP entries that captured all of the issues relevant to the postclosure performance of the proposed repository. For TSPA-SR, the classification process resulted in an interim list of 323 primary FEPs (Freeze et al. 2001 [DIRS 154365], Section 5.4) in June 2000 and a final updated list of 328 primary FEPs (Freeze et al. 2001 [DIRS 154365], Section 5.5) in February 2001. Each of the TSPA-SR primary FEPs encompassed a single process or event, or a few closely related or coupled processes or events that could be addressed by a specific screening discussion. The 323 interim TSPA-SR FEPs are contained in a database (CRWMS M\&O 2000 [DIRS 150806], Appendix B) and are listed in CRWMS M\&O (2000 [DIRS 153246], Appendix B). The 328 final TSPA-SR FEPs are contained in a database (FEPs Database Software Program, Version 0.2 (BSC 2002 [DIRS 159684])). This final TSPA-SR list of 328 FEPs was the starting point for TSPA-LA FEP analysis.

Subsequent to TSPA-SR, comments from a series of internal and external reviews of the TSPA-SR FEP identification, screening, and database became available. These reviews and the resulting comments are listed in The Enhanced Plan for Features, Events, and Processes (FEPS) at Yucca Mountain (BSC 2002 [DIRS 158966], Section 3.1) (referred to hereafter as the enhanced FEP plan). During one of these reviews, the NRC/DOE TSPAI Technical Exchange in August 2001, seven KTI Agreements (identified as TSPAI 2.01 through 2.07) related to FEP

analysis were identified. These KTI Agreements, listed in Table 3-1, capture the essence of all of the internal and external review comments. 
Table 3-1. Summary of KTI Agreements Related to FEP Analysis

\begin{tabular}{|c|c|}
\hline ID & Agreement \\
\hline TSPAI 2.01 & $\begin{array}{l}\text { Provide clarification of the screening arguments, as summarized in Attachment } 2 \text {. See Comment \# 5, 7, 8, 9, } 10 \text {, } \\
13,18,19 \text { (Part 5), } 21,32,41,47,50,53,58,67, \mathrm{~J}-5, \mathrm{~J}-16 \text {, and J-18. DOE will clarify the screening arguments, } \\
\text { as summarized in Attachment 2, for the highlighted FEPs. The clarifications will be provided in the referenced } \\
\text { FEPs AMR and will be provided to the NRC in FY } 2003 \text {. }\end{array}$ \\
\hline TSPAI 2.02 & $\begin{array}{l}\text { Provide the technical basis for the screening argument, as summarized in Attachment } 2 \text {. See Comment \# 3, 4, } \\
11,12,19 \text { (Parts 1, 2, and 6), 25, 26, 29, 34, 35, 36, 37, 38, 39, 42, 43, 44, 48, 49,51,54,55, 56, 57, 59, 60, 61, } \\
62,63,64,65,66,68,69,70,78,79, \mathrm{~J}-1, \mathrm{~J}-2, \mathrm{~J}-3, \mathrm{~J}-4, \mathrm{~J}-7, \mathrm{~J}-8, \mathrm{~J}-9, \mathrm{~J}-10, \mathrm{~J}-11, \mathrm{~J}-12, \mathrm{~J}-13, \mathrm{~J}-14, \mathrm{~J}-15, \mathrm{~J}-17, \mathrm{~J}-20 \text {, } \\
\mathrm{J}-21, \mathrm{~J}-22, \mathrm{~J}-23, \mathrm{~J}-24, \mathrm{~J}-25, \mathrm{~J}-26 \text {, and J-27. DOE will provide the technical basis for the screening argument, as } \\
\text { summarized in Attachment 2, for the highlighted FEPs. The technical basis will be provided in the referenced } \\
\text { FEPs AMR and will be provided to the NRC in FY 2003. }\end{array}$ \\
\hline TSPAI 2.03 & $\begin{array}{l}\text { Add the FEPs highlighted in Attachment } 2 \text { to the appropriate FEPs AMRs. See Comment } 19 \text { (Part } 7 \text { and } 8 \text { ), 20, } \\
\text { and J-6. DOE will add the FEPs highlighted in Attachment } 2 \text { to the appropriate FEPs AMRs. The FEPs will be } \\
\text { added to the appropriate FEPs AMRs, and the AMRs will be provided to the NRC in FY } 2003 \text {. }\end{array}$ \\
\hline TSPAI 2.04 & $\begin{array}{l}\text { Provide a clarification of the description of the primary FEP. See Comments } 24,31 \text {, and } 33 \text {. DOE will clarify the } \\
\text { description of the primary FEPs, as summarized in Attachment 2, for the highlighted FEPs. The clarifications will } \\
\text { be provided in the referenced FEPs AMR and will be provided to the NRC in FY } 2003 \text {. }\end{array}$ \\
\hline TSPAI 2.05 & $\begin{array}{l}\text { It is not clear to the NRC that the current list of FEPs (i.e., the list of FEPs documented in TDR-WIS-MD-000003, } \\
00 / 01 \text { ) is sufficiently comprehensive or exhibits the necessary attribute of being auditable (e.g., transparent and } \\
\text { traceable). As discussed in the two TSPAI technical exchanges, there are unclear aspects of the approach that } \\
\text { DOE plans to use to develop the necessary documentation of those features, events, and processes that they } \\
\text { have considered. Accordingly, to provide additional confidence that the DOE will provide NRC with: (1) auditable } \\
\text { documentation of what has been considered by the DOE, (2) the technical basis for excluding FEPs, and (3) an } \\
\text { indication of the way in which included FEPs have been incorporated in the performance assessment; DOE will } \\
\text { provide NRC with a detailed plan (the Enhanced FEP Plan) for comment. In the Enhanced FEP Plan, DOE will } \\
\text { address the following items (listed separately as } 2.05-1 \text { through 2.05-13). DOE will provide the Enhanced Plan to } \\
\text { NRC by March } 2002 \text {. }\end{array}$ \\
\hline $2.05-1$ & $\begin{array}{l}\text { The approach used to develop a pre-screening set of FEPs (i.e., the documentation of those things that DOE } \\
\text { considered and which the DOE would use to provide support for a potential license application). }\end{array}$ \\
\hline $2.05-2$ & The guidance on the level-of-detail that DOE will use for redefining FEPs during the enhanced FEP process. \\
\hline $2.05-3$ & The form that the pre-screening list of FEPs will take (e.g., list, database, other descriptions). \\
\hline $2.05-4$ & The approach DOE would use for the ongoing evaluation of FEPs (e.g., how to address potentially new FEPs). \\
\hline $2.05-5$ & The approach that DOE would use to evaluate and update the existing scope and description of FEPs \\
\hline $2.05-6$ & The approach that DOE would use to improve the consistency in the level of detail among FEPs \\
\hline $2.05-7$ & How the DOE would evaluate the results of its efforts to update the existing scope and definition of FEPs \\
\hline $2.05-8$ & $\begin{array}{l}\text { How the Enhanced FEP process would support assertions that the resulting set of FEPs will be sufficiently } \\
\text { comprehensive (e.g., represents a wide range of both beneficial and potential adverse effects on performance) to } \\
\text { reflect clearly what DOE has considered. }\end{array}$ \\
\hline $2.05-9$ & How DOE would indicate their disposition of included FEPs in the performance assessment. \\
\hline $2.05-10$ & $\begin{array}{l}\text { The role and definition of the different hierarchical levels used to document the information (e.g., "components of } \\
\text { FEPs" and "modeling issues"). }\end{array}$ \\
\hline $2.05-11$ & $\begin{array}{l}\text { How the hierarchical levels used to document the information would be used within DOE's enhanced FEP } \\
\text { process. }\end{array}$ \\
\hline $2.05-12$ & $\begin{array}{l}\text { How the Enhanced FEP Plan would result in documentation that facilitates auditing (i.e., lead to a process that is } \\
\text { transparent and traceable). }\end{array}$ \\
\hline $2.05-13$ & $\begin{array}{l}\text { DOE's plans for using configuration management controls to identify FEP dependencies on ongoing work and } \\
\text { design changes. }\end{array}$ \\
\hline TSPAI 2.06 & $\begin{array}{l}\text { Provide justification for the approach to: (1) the level of detail used to define FEPs; (2) the degree of consistency } \\
\text { among FEPs; and (3) comprehensiveness of the set of FEPs initially considered (i.e., before screening). } \\
\text { DOE proposes to meet with NRC periodically to provide assessments of the DOE's progress, once it has initiated } \\
\text { the Enhanced FEP process, and on changes to the approach documented in the Enhanced FEP Plan. During } \\
\text { these progress meetings DOE agrees to provide a justification for their approach to: (1) the level of detail used to } \\
\text { define FEPs; (2) the degree of consistency among FEPs; and (3) comprehensiveness of the pre-screening set of } \\
\text { FEPs. }\end{array}$ \\
\hline TSPAI 2.07 & $\begin{array}{l}\text { Provide results of the implementation of the Enhanced FEP Plan (e.g., the revised FEP descriptions, screening } \\
\text { arguments, the mapping of FEPs to TSPA keywords, and a searchable index of FEP components), in updates to } \\
\text { the FEP AMR documents and the FEP Database. DOE agrees to provide the results of their implementation of } \\
\text { the Enhanced FEP Plan (e.g., the revised FEP descriptions, screening arguments, improved database navigation } \\
\text { through, for example, the mapping of FEPs to TSPA keywords, a searchable index of FEP components, etc.), } \\
\text { information requested in updates to the FEP documents and the FEP Database (or other suitable documents) in } \\
\text { FY } 2003 \text {. }\end{array}$ \\
\hline
\end{tabular}

NOTE: Wording is verbatim from KTI Agreements. For additional details see Reamer 2001 [DIRS 158380]. 
KTI Agreements 2.01 through 2.04 required enhancements to specific FEP screening discussions and were addressed through revisions to the FEP AMRs (see Table 2-7), as described in Key Technical Issue Letter Report (Response to TSPAI 2.01, 2.02, 2.03, 2.04, and 2.07) (BSC 2004 [DIRS 172439]). KTI Agreements 2.05 and 2.06 required documentation of planning for TSPA-LA FEP analysis activities and were addressed by the enhanced FEP plan (BSC 2002 [DIRS 158966], Section 3.2) and KTI Letter Report, Response to Additional Information Needs on TSPAI 2.05 and TSPAI 2.06 (Freeze 2003 [DIRS 165394]). KTI Agreement TSPAI 2.07 required documentation of the implementation of these activities and is addressed by this report. FEP classification is described in Section 3.1, FEP identification in Section 3.2, and FEP screening in Section 4. A summary of these activities with respect to the KTI Agreements is provided in Section 7.

\subsection{CLASSIFICATION OF THE TSPA-LA FEPS}

The process for classifying TSPA-SR FEPs is described in Freeze et al. (2001 [DIRS 154365], Section 3). The classification process was based on a layered hierarchical database-compatible structure (4 Layers, subdivided into 13 Categories, further subdivided into 135 Headings) developed by a multi-national NEA FEPs working group, as described in Freeze et al. (2001 [DIRS 154365], Section 3.1). The subdivision of each hierarchical level (Layers, Categories, and Headings) was based on multiple classification schemes (see Section 2.4.1). Most relevant to the YMP FEP process was the Heading level, at which the postclosure performance of the repository was categorized into 135 roughly equivalent topics. These Headings were selected by the multi-national FEPs experts to provide comprehensive coverage of potential FEPs for any high-level waste (HLW) repository system (NEA 1999 [DIRS 152309], pp. 28 to 34). Where possible, the Headings were selected to be mutually exclusive and have roughly equivalent levels of importance. However, because HLW repository systems are influenced by many coupled processes, and because certain technical considerations carry higher levels of importance depending on design, not all Headings were mutually exclusive or had an equivalent level of importance. This additional classification step, which was based on technical subject areas (similar to those listed in Table 2-7), did not result in the identification of any additional FEPs.

The hierarchical classification process for TSPA-SR FEPs also included the identification of two tiers of FEPs: primary and secondary. The entire set of TSPA-SR FEPs included complete sets of FEPs from several other radioactive waste disposal programs as noted in Section 2. A set of primary FEPs (a subset of the complete list of FEPs) was selected such that they encompassed all technical considerations relevant to the postclosure performance of the potential repository. The remaining FEPs, called secondary FEPs, were considered redundant or duplicative of the primary FEPs and were retained only for traceability of FEP origins to support the demonstration of comprehensiveness. The final TSPA-SR list of 328 primary FEPs (BSC 2002 [DIRS 159684]) provides the starting point for TSPA-LA FEP classification and identification. As described in Sections 3.2.1 and 3.2.2, the issues associated with TSPA-SR secondary FEPs were captured in the TSPA-LA FEPs, but the secondary FEP themselves were not retained.

For the TSPA-LA FEPs, a new hierarchical classification structure was developed. The new FEP classification structure approximates the structure used to describe the TSPA-LA model and considers the structures, systems, and components identified in Q-List (BSC 2005 [DIRS 171190], Appendix A), while still retaining some traceability to the NEA hierarchy. This 
provides more consistency with YMP project literature and promotes more intuitive navigation | within the database for reviewers, which improves transparency and traceability.

\subsubsection{Hierarchical Classification Levels}

The enhanced FEP plan (BSC 2002 [DIRS 158966], Section 3.2.1) and KTI Letter Report, Response to Additional Information Needs on TSPAI 2.05 and TSPAI 2.06 (Freeze 2003 [DIRS 165394], Section 2) identified the development of a FEP matrix, constructed from multiple hierarchical levels, to classify the TSPA-LA FEPs. The hierarchical classification levels define an organizational structure into which individual FEPs are mapped (identification and mapping of the individual FEPs are discussed in Section 3.2).

In general, a FEP consists of a process or event acting upon a feature. Therefore, the bases for the TSPA-LA hierarchical classification are two separate systems - one corresponding to the system of features and physical elements (the physical system), the other corresponding to the system of processes and events (the process system). Each system is divided into three hierarchical classification levels. Hierarchical Level 1 simply represents the separate physical and process systems. Hierarchical Level 2 represents a coarse division of each system. Hierarchical Level 3 represents a finer division of each system.

Table 3-2 shows the physical system hierarchy that is utilized by the TSPA-LA FEP Database Software (Section 6.1.2.1). The physical system is subdivided at Level 2 into three broad spatial regions: Engineered System, Natural System, and Biosphere. The physical system also contains one overarching Level 2 region, Repository System that captures issues common to multiple spatial regions or to the system in general. At Level 3, specific features and physical elements are identified. They are generally mutually exclusive because they are separate physical components, but one element, Emplacement Drift, is used, where necessary, to represent the broader "drift as a whole" and may, in some FEPs, interface with or subsume other Level 3 Engineered System features. Special considerations for these multiple component FEPs are discussed in Sections 3.2.1 (FEP level of detail) and 4.2.2 (FEP screening guidelines). Finally, one Level 3 element, Backfill, contains two components: backfill at the ends of emplacement drifts, that is associated with the magma bulkheads (filled keyways); and backfill throughout the length of the emplacement drifts, that is no longer part of the baseline design.

Table 3-3 shows the process system hierarchy that is utilized by the TSPA-LA FEP Database Software (Section 6.1.2.1). The process system is subdivided at Level 2 into Nominal and Disruptive, corresponding to TSPA-LA scenario classes (see Section 5). The process system also contains one additional Level 2 classification, Assessment and Design Basis that captures process and event issues that are related to the assessment strategy or design in general rather than to a specific nominal and/or disruptive process/event. At Level 3, specific types of processes and events are identified. They are not always mutually exclusive, particularly for coupled processes, where thermal, hydrologic (e.g., flow), chemical, and mechanical processes may act jointly on one or more features or physical elements. 
Table 3-2. TSPA-LA Hierarchical Classification Levels for FEP Database Physical System

\begin{tabular}{|c|c|c|}
\hline Level 1 & Level 2 & Level 3 \\
\hline \multirow{15}{*}{$\begin{array}{l}\text { Subsystem Physical } \\
\text { Elements and Features }\end{array}$} & \multirow[t]{10}{*}{ Engineered System } & Emplacement Drift \\
\hline & & Ground Support \\
\hline & & Backfill \\
\hline & & Drip Shield \\
\hline & & Waste Package \\
\hline & & Cladding \\
\hline & & Waste Form \\
\hline & & Emplacement Pallet \\
\hline & & Invert \\
\hline & & Seals \\
\hline & \multirow[t]{3}{*}{ Natural System } & Excavation Disturbed Zone \\
\hline & & Unsaturated Zone \\
\hline & & Saturated Zone \\
\hline & Biosphere & Biosphere \\
\hline & Repository System & System \\
\hline
\end{tabular}

Table 3-3. TSPA-LA Hierarchical Classification Levels for FEP Database Process System

\begin{tabular}{|c|c|c|}
\hline Level 1 & Level 2 & Level 3 \\
\hline \multirow[t]{13}{*}{ Processes and Events } & \multirow[t]{8}{*}{ Nominal } & Flow \\
\hline & & Transport \\
\hline & & Characteristics \\
\hline & & Chemical \\
\hline & & Mechanical \\
\hline & & Thermal \\
\hline & & Microbiological \\
\hline & & Radiological \\
\hline & \multirow[t]{4}{*}{ Disruptive } & Igneous \\
\hline & & Seismic \\
\hline & & Criticality \\
\hline & & Human Intrusion \\
\hline & Assessment and Design Basis & Basis \\
\hline
\end{tabular}

The physical and process system hierarchies shown in Tables 3-2 and 3-3 provide a convenient classification structure for representing the TSPA-LA FEPs in an electronic database. However, for representing TSPA-LA FEPs in licensing documentation (rather than in an electronic database) it is desirable to develop a physical hierarchy that more closely represents the subsystems and components of the Q-List (BSC 2005 [DIRS 171190], Appendix A) that are important to waste isolation. An appropriate Q-List-based physical system hierarchy is shown in Table 3-4. Differences between the database-based physical system (Table 3-2) and the Q-Listbased physical system (Table 3-4) are as follows. In the Engineered System, Ground Support, Backfill, and Seals do not exist as independent Level 3 elements in the Q-List-based physical hierarchy. Ground Support is subsumed within Emplacement Drift, while Backfill (specifically, magma bulkhead associated backfill) and Seals are combined into a single Q-List component, 
Closure. The in-drift backfill that is no longer part of the baseline design is not on the Q-List; therefore, it is not part of the Q-List-based physical system. In the Natural System, Unsaturated Zone and Excavation Disturbed Zone do not exist as independent Level 3 elements in the Q-Listbased physical hierarchy. Unsaturated Zone is divided into three subsystems: Topography and Surficial Soils, Unsaturated Zone to the Repository Horizon, Unsaturated Zone Below the Repository Horizon. Excavation Disturbed Zone, while not explicitly identified in the Q-List, is implicitly part of Unsaturated Zone to the Repository Horizon and Unsaturated Zone Below the Repository Horizon.

Table 3-4. TSPA LA Hierarchical Classification Levels for Q-List-Based Physical System

\begin{tabular}{|c|c|c|}
\hline Level 1 & Level 2 & Level 3 \\
\hline \multirow{14}{*}{$\begin{array}{l}\text { Subsystem Physical } \\
\text { Elements and Features }\end{array}$} & \multirow[t]{8}{*}{ Engineered System } & Emplacement Drift \\
\hline & & Closure (backfill and seals) \\
\hline & & Drip Shield \\
\hline & & Waste Package \\
\hline & & Cladding \\
\hline & & Waste Form \\
\hline & & Emplacement Pallet \\
\hline & & Invert \\
\hline & \multirow[t]{4}{*}{ Natural System } & Topography and Surficial Soils \\
\hline & & Unsaturated Zone to the Repository Horizon \\
\hline & & Unsaturated Zone Below the Repository Horizon \\
\hline & & Saturated Zone \\
\hline & Biosphere & Biosphere \\
\hline & Repository System & System \\
\hline
\end{tabular}

\subsubsection{FEP Matrix}

It is at Level 3 that individual FEPs, a process or event acting upon a feature, are defined. This is shown graphically in a FEP matrix (Figure 3-1). The FEP matrix has two axes, corresponding to the physical and process systems. The matrix intersections represent "boxes" for which potential FEPs may exist. For each of the Level 3 matrix boxes that are a credible combination of the physical and process systems, there are associated FEPs. All FEPs are mapped to at least one matrix box; broad or overarching FEPs are mapped to multiple boxes. The mapping of FEPs to the matrix boxes is described in Section 3.2. Utilization of the TSPA-LA FEP Database Software (see Section 6.1.2.1) populates the matrix boxes, shown "empty" in Figure 3-1, with their associated FEPs, based on the mapping described in Section 3.2.

The FEP matrix provides a top-down review of the comprehensiveness of the TSPA-LA FEP analysis. It complements the bottom-up approach to FEP identification employed for TSPA-SR. The consistency of this hierarchical classification structure with other project literature also enhances the transparency and traceability of the underlying FEPs and aids in navigation within the database. 


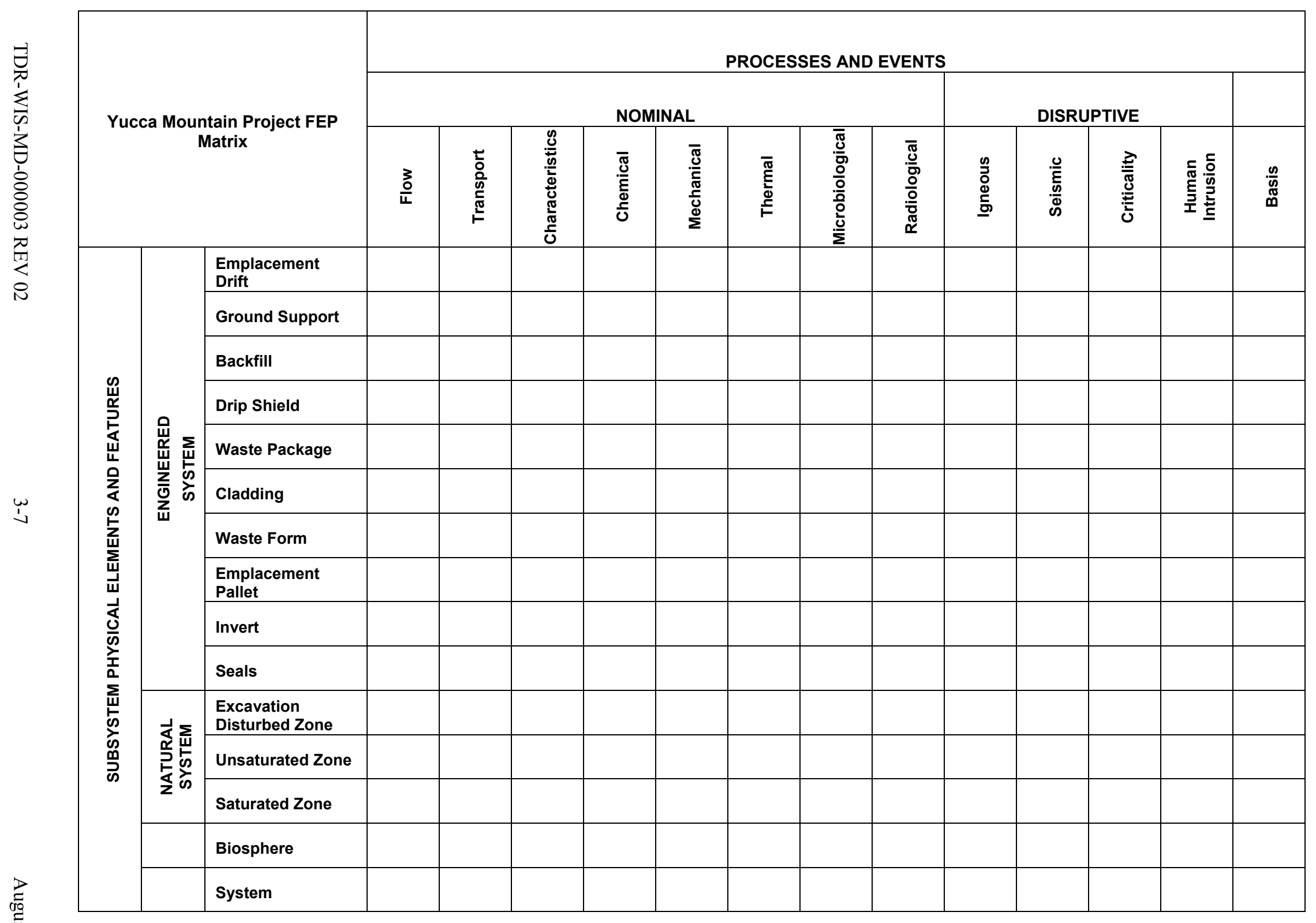

Figure 3-1. FEP Matrix Showing Physical System and Process System Hierarchies 


\subsection{IDENTIFICATION OF THE TSPA-LA FEPS}

The final TSPA-SR list of 328 FEPs (BSC 2002 [DIRS 159684]) provided the starting point for TSPA-LA FEP identification. The TSPA-SR FEPs were developed using the following approach (Freeze et al. 2001 [DIRS 154365], Section 2):

- Develop an initial list of general FEPs from other radioactive waste disposal programs.

- Supplement the general list with FEPs from project-specific literature.

- Augment the list through iterative discussion and review with subject matter experts (e.g., at technical workshops and in technical reports)

- Augment the list with feedback from external sources (e.g., NRC/DOE Technical Exchange and Appendix 7 Meetings, NRC IRSRs).

FEP identification for TSPA-LA, which built upon the TSPA-SR basis, was performed in two phases:

- Refinement of the TSPA-SR FEP list for consistency with the new classification scheme (as described in Section 3.1) and for a more consistent level of detail between FEPs (as described in Section 3.2.1). Implementation of this phase did not change the technical content of the overall FEP list, but did result in a minor change in the number of FEPs due to a re-organization and shifting of the scope of certain FEPs. Details of the implementation of this phase of FEP identification are provided in Section 3.2.2.

- Identification of potential new FEPs and changes to existing FEPs based on updated or new technical information and audits against other recently published international lists. Implementation of this phase resulted in further changes to the overall FEP list, including technical content. Details of the implementation of this phase of FEP identification are provided in Section 3.2.3. Potential FEP changes were evaluated and tracked using a formal FEP configuration management system (Section 3.2.4).

This approach augments the bottom-up (i.e., non-systematic, all-inclusive) TSPA-SR FEP identification and top-down (i.e., systematic) series of TSPA-SR reviews, with a hybrid procedure-reclassification, refinement, additional iterative reviews of the prior list, and audits against other lists published subsequent to the TSPA-SR.

\subsubsection{Level of Detail for TSPA-LA FEPs}

There is no uniquely correct level of detail at which to define and/or aggregate FEPs. However, bounding cases for level of detail can be defined. In the "too specific" case, FEPs are narrowly defined, such that there are many independent FEPs, and it is impractical to develop specific screening decisions for each FEP. In the "too broad" case, FEPs are coarsely defined and it is difficult to isolate important issues for each FEP. Consequently, some important issues may get excluded. 
For TSPA-SR, FEPs were aggregated at the coarsest level at which technically sound screening decisions could be made, while still maintaining an adequate level of detail for the purposes of the analysis. The definition of adequate is not precise, but clearly falls between the bounding "too specific" and "too broad" cases. This aggregation process produced a greater number of TSPA-SR FEPs in the areas where more complex processes predominate. As noted in Section 3, this process, when combined with the TSPA-SR classification process, also resulted in two tiers of TSPA-SR FEPs: primary and secondary. The primary FEPs were selected such that they encompassed all technical considerations relevant to the postclosure performance of the potential repository. The secondary FEPs were considered redundant or duplicative of the primary FEPs. However, the KTI Agreements related to FEPs (Table 3-1) and the underlying reviews of the TSPA-SR FEPs (BSC 2002 [DIRS 158966], Section 3.1) identified the need for enhancements with regard to (a) the level of detail and consistency among FEPs, (b) FEPs that are partially included and partially excluded, and (c) the use of secondary FEPs.

To address these concerns, the following level-of-detail criteria were established for TSPA-LA FEPs:

- Each FEP is aggregated to the coarsest level at which a technically sound screening decision can be made.

- A FEP may encompass a single feature, process or event, or a few closely related or coupled processes provided that the entire FEP can be addressed by a single specific screening discussion or model.

- A FEP has a level of detail consistent with the detail required for analysis. There is no value in subdividing a FEP into multiple FEPs for screening, and then re-combining them into a coarser representation for modeling.

- A FEP has a level of detail no coarser than Hierarchical Level 3 (Tables 3-2 and 3-3).

- A FEP is aggregated, based on the four preceding bullets, to a level that produces a reasonable number of FEPs to describe the system. If FEPs are too narrowly defined, the number of interrelated FEPs will increase, making it difficult for the database user to isolate discussions pertaining to a single issue. However, there is no a priori limit on the number of FEPs.

- A FEP encompasses all appropriate aspects of an issue such that screening based on low probability or low consequence is reasonable. However, FEPs are not too narrowly defined, which might cause them to be inappropriately excluded.

- A FEP has a level of detail such that the entire FEP can be either included or excluded (i.e., no FEPs can be partially included and partially excluded). The application of this criterion should be based on physical, spatial, or temporal considerations rather than on an arbitrary splitting of issues.

The above level-of-detail criteria defined bounds for level-of-detail for TSPA-LA FEPs-they can be no coarser than Hierarchical Level 3 and no finer than the level of detail required for analysis. 
While these bounds resulted in a certain amount of consistency in the level of detail among FEPs, there were still variations within those bounds. In particular, more detailed FEPs were required in areas where more complex processes, and hence more detailed analyses, predominated (e.g., important subsystems or subsystem features that are controlled by complex processes). In the engineered system, complex processes were typically addressed with a separate FEP for each EBS component (e.g., process affects waste package, process affects drip shield, etc.), whereas more general processes were addressed with a single FEP (e.g., process affects EBS components). Similarly, in the natural system, complex processes were typically addressed with a separate FEP for each component (e.g., process affects UZ, process affects SZ), whereas more general processes were addressed with a single FEP (e.g., process affects geosphere). However, because it is consistent with risk-informed model considerations which focus the performance assessment on FEPs "that most affect compliance with the overall performance objective" (NRC 2003 [DIRS 163274], Sections 2.2.1 and 2.2.1.2.1.1), this varying level of detail among FEPs, within the preestablished bounds, is considered appropriate.

Regardless of the level of detail explicitly captured in a FEP, it is common that a FEP subsumes, either explicitly or implicitly, several very specific issues and/or finer details, all of which are addressed by the same "technically sound screening decision". The application of the above level-of-detail criteria provides guidelines for a minimum, necessary, and sufficient level-of-detail, without which the TSPA-LA FEP list could be subdivided ad infinitum. However, no matter what level of detail is provided in a FEP list, the "next finest" level of detail is always desirable to better support a demonstration of completeness. In TSPA-SR and other prior FEP documentation, these "next finest" details were variously referred to and/or incorporated as part of "secondary FEPs", "FEP components", or "modeling issues". For TSPA-LA, none of these terms are used. Instead, to capture the finer conceptual details of TSPA-LA FEPs (i.e., details that are implicitly addressed by the existing technically sound screening but whose explicit identification might benefit the demonstration of completeness) without creating an unmanageably large FEP list, the FEP Team performed the following tasks:

- Revised TSPA-LA FEP descriptions, where necessary, to explicitly identify important finer details (see Section 3.2.2). One minor objective of the TSPA-LA FEP identification was to try to minimize, where possible, substantive changes in names and descriptions from the TSPA-SR FEP list. Therefore, in some cases where a FEP was augmented from TSPA-SR, the FEP description was not altered. Instead the change was captured by the addition of a keyword, mapping to relevant source FEPs, and/or explicit mention in the FEP screening discussion (screening argument or TSPA disposition), as described in the next three bullets. As a result, each TSPA-LA FEP is completely described by the combination of FEP name, description, keywords, and relevant source FEPs.

- Created a set of keywords that (a) provide a consistent set of phrases/terms across the entire FEP list, (b) augment, where necessary, the existing FEP descriptions, and (c) explicitly identify important finer details. Keywords are primarily used in electronic database searches to find general details of interest across the entire FEP list. However, they also aid in the search for important finer details. Keywords were derived from a set of descriptor phrases, as described in the "Keyword History" of the "FEP History File" 
Table in Appendix G. Keywords are also described further in Appendix G as part of the "KeywordsSource" Table.

- Provided links and traceability to finer details by explicitly mapping each source FEP (e.g., general FEPs identified in Version 1.0 of the NEA International FEP Database and YMP-specific FEPs identified from project literature) to one or more TSPA-LA FEPs. These historical source FEPs number in the thousands and provided the basis for the TSPA-SR FEPs (both primary and secondary FEPs) and consequently for the TSPA-LA FEPs. The large number of source FEPs suggests that, in some cases, they address finer details (e.g., at a level finer than is required for TSPA-LA analysis) of issues more broadly captured in the TSPA-LA FEPs. Therefore, this mapping of the source FEPs to the corresponding TSPA-LA FEPs provides an additional indication of finer details that are implicitly captured by TSPA-LA FEPs. Source FEPs are described further in Appendix G as part of the "SourceFEPs" Table.

- Performed formal reviews of the FEP AMRs (see Section 4.2) to determine whether the FEP screening guidelines outlined in Section 4.2.2 had been followed. In a few cases, important finer details were addressed in a screening discussion (screening argument for excluded FEPs, TSPA disposition for included FEPs) even though they were not explicitly mentioned in the FEP name, description, keywords, or relevant source FEPs. In these cases, the finer details can be found using the text search option of the database software (see Section 6.1.2.1)

In summary, there are conflicting goals in defining an appropriate level of detail for FEPs. On the one hand, there is motivation to define FEPs coarsely, so as to minimize redundant screening arguments and produce a reasonable number of FEPs. On the other hand, there is motivation to define FEPs specifically so that important issues are explicitly screened. The implementation of level-of-detail criteria, and the use of keywords and mapping to source FEPs to capture finer details, provides a balance between these conflicting goals. However, the priorities for TSPA-LA FEP identification were as follows:

1. Coarseness-The over-riding definition of a FEP is that it is aggregated to the coarsest level at which a technically sound screening decision can be made. Therefore, FEPs that met this definition were not subdivided further. The addition of keywords and the mapping to source FEPs helped to identify relevant finer details, even for coarsely aggregated FEPs. This priority resulted in fewer, broad FEPs.

2. Specificity-FEPs need to be defined specifically enough to ensure that important issues are explicitly treated as FEPs. This priority resulted in more, finer FEPs in areas where more complex processes predominated. 


\subsubsection{Reclassification and Refinement of the TSPA-SR FEPs for TSPA-LA}

The final TSPA-SR list of 328 FEPs (BSC 2002 [DIRS 159684]) was reclassified in accordance with the new hierarchical classification structure (Section 3.1.1) and revised in accordance with the level-of-detail criteria (Section 3.2.1). The reclassification and revisions were accomplished through the following tasks. The tasks are inter-related and were performed concurrently.

- Each of the 328 TSPA-SR FEPs was mapped to the TSPA-LA hierarchical classification structure by assigning it to one or more boxes in the FEP matrix (Figure 3-1).

- Each of the TSPA-SR FEP names and descriptions was re-evaluated. Changes, where necessary, were based on the following criteria:

- Produce a set of FEPs that is consistent with the new classification structure. FEPs should exist for all credible FEP matrix boxes and, where possible, there should be parallelism within rows and columns. In some cases this resulted in a shifting of scope from one FEP to another.

- Ensure that the FEPs conform to the level-of-detail criteria and priorities outlined in Section 3.2.1.

- Capture (explicitly) important finer details of FEPs in FEP descriptions and/or keywords.

- Capture (implicitly) other finer details of FEPs through mapping to source FEPs.

- Eliminate secondary FEPs by ensuring that associated issues are captured, either implicitly or explicitly, in the finer details. Note the mapping of source FEPs to TSPA-LA FEPs implicitly captures the TSPA-SR secondary FEPs, since the secondary FEPs also derived from the source FEPs. Nonetheless, for traceability a separate mapping of TSPA-SR FEPs (both primary and secondary) to TSPA-LA FEPs also exists (see Table 6-2)

- TSPA-SR FEPs that were partially included and partially excluded were re-evaluated, and where appropriate, were subdivided. For TSPA-LA, all FEPs have a single screening decision, either included or excluded. No FEPs are partially included and partially excluded.

- TSPA-SR FEPs that were shared between multiple technical subject areas, and therefore were addressed either in whole or in part in multiple FEP AMRs, were re-evaluated, and where appropriate, were subdivided. For TSPA-SR, shared FEPs sometimes contained duplicative screening information, which was not always integrated. For TSPA-LA, an attempt was made to minimize the number of shared FEPs while still honoring the level-of-detail criteria. However, there still remained a limited number of shared FEPs for TSPA-LA. In these cases, the FEPs were assigned to more than one FEP AMR and their screening was addressed collectively by all of the sharing FEP AMRs. 
- A preliminary review of the FEPs was performed to examine the treatment of coupled processes and coupling between FEPs. This preliminary review was based on the assignment of FEPs to the FEP matrix and the resulting coverage of FEPs across the matrix. Examination of FEP coverage across a row (a physical element or feature) or down a column (a process or event) provided a preliminary indication of treatment, or lack thereof, of coupling between FEPs. Where necessary, FEPs were re-organized or subdivided.

During the implementation of the above tasks, informal input and feedback on proposed changes was received from the FEP AMR Leads and the SMEs. Completion of these tasks resulted in a preliminary list of 359 TSPA-LA FEPs (DTN: MO0301SEPFEPS1.000 [DIRS 161496]), each assigned, for screening, to a technical subject area and FEP AMR. In some cases, broadly defined FEPs (e.g., a process or event acting upon multiple features) were shared by multiple technical subject areas and FEP AMRs. In these cases, a single screening decision was reached, but, between all of the sharing AMRs, each of the multiple features comprising the FEP was explicitly addressed within the screening discussions.

An obvious change from TSPA-SR to TSPA-LA was a change in the FEP numbering scheme. TSPA-LA FEP numbers all end in a letter (e.g., .0A, .0B, etc.) whereas TSPA-SR FEP numbers ended in a number (e.g., .00 for primary FEPs, .01, .02, etc. for secondary FEPs). In general, TSPA-SR primary FEPs, with numbers ending in .00, were converted to TSPA-LA FEPs, with numbers ending in .0A. Where existing TSPA-SR FEPs were split (e.g., to eliminate the occurrence of a FEP that was partially included and partially excluded), the additional TSPA-LA FEPs were assigned numbers ending in $.0 \mathrm{~B}, .0 \mathrm{C}$, etc., to ensure traceability to their origin in TSPA-SR. Additional details about TSPA-LA FEP numbers are described in Section 4.2.2. The technical content of the preliminary TSPA-LA FEP list was not different from the TSPA-SR list (i.e., there was no new scope), however, the number of FEPs changed due to the reclassification and revisions (i.e., there was a shifting and/or splitting of scope).

A summary of the changes from the TSPA-SR FEP list to the preliminary TSPA-LA FEP list (DTN: MO0301SEPFEPS1.000 [DIRS 161496]) is provided in Appendix C. As described in Table 6-2 and in Appendix C, full documentation of the scope shifts and splits from TSPA-SR to TSPA-LA and a mapping of TSPA-SR FEPs to TSPA-LA FEPs are contained within the data set itself.

Enhancements to the FEP list resulting in new scope are discussed in Section 3.2.3.

\subsubsection{Identification of New FEPs for TSPA-LA}

The preliminary list of 359 TSPA-LA FEPs (DTN: MO0301SEPFEPS1.000 [DIRS 161496]) was distributed to FEP AMR Leads and SMEs in January 2003. The TSPA-LA FEP list then evolved through a series of iterative (for technical defensibility) and collaborative (for consistency) evaluations by FEP AMR Leads, SMEs, and the FEP Team. The FEP list evolved in parallel with the implementation of the screening process (see Section 4.2). Three iterative cycles can be identified. The first cycle, from January 2003 to July 2003, corresponds to preliminary FEP identification and screening (see Figure 2-1). It is coincident with the planning and preparation of the supporting technical AMRs. The second cycle, from August 2003 to 
May 2004, corresponds to interim FEP analysis documentation (see Figure 2-1). It is coincident with the completion of interim versions of the supporting technical AMRs and FEP AMRs. The third cycle, from June 2004 to August 2005, corresponds to final FEP analysis and documentation (see Figure 2-1). It is coincident with the completion of the final supporting technical AMRs and FEP AMRs that support LA.

During the first iterative cycle (January 2003 to July 2003), FEPs from the preliminary FEP list (DTN: MO0301SEPFEPS1.000 [DIRS 161496]) relevant to each technical subject area were reviewed and discussed by the appropriate SMEs. These reviews and discussions, performed concurrently with preliminary screening analyses (see Section 4.2), resulted in some minor changes to the FEP list. In addition, where necessary, new or missing FEPs, or "potential FEPs" (see Section 3.2.4) were identified. Also during this period, the FEP Team responded to informal comments regarding the comprehensiveness and completeness of the FEP list. Specific FEP identification actions that were performed during this preliminary analysis period are as follows:

- FEP AMR Leads and SMEs evaluated the preliminary FEP list and, where appropriate, suggested new FEPs or revisions to existing FEPs to enhance comprehensiveness. This included enhancements associated with KTI Agreements TSPAI 2.01 through 2.04 (see Table 3-1).

- FEP AMR Leads and SMEs made preliminary screening decisions (included or excluded) for each FEP (see Section 4.2).

- The FEP Team coordinated FEP revisions and preliminary screening decisions to ensure consistency.

These actions during the first iterative cycle produced a succession of FEP lists (DTN: MO0303SEPFEPS2.000 [DIRS 162452] in March 2003 and DTN: MO0306SEPFEPS3.000 [DIRS 163746] in June 2003), culminating in a revised preliminary TSPA-LA FEP list containing 367 FEPs in July 2003 (DTN: MO0307SEPFEPS4.000 [DIRS 164527]). These FEP list DTNs were produced to trace the development of the TSPA-LA FEP list, but did not supersede each other and were unqualified. A summary of the changes made in the succession of FEP lists from DTN: MO0301SEPFEPS 1.000 [DIRS 161496] to DTN: MO0307SEPFEPS4.000 [DIRS 164527] is provided in Appendix C. Full documentation of the changes is contained within the data sets themselves.

During the second iterative cycle (August 2003 to May 2004), FEPs from the revised preliminary FEP list (DTN: MO0307SEPFEPS4.000 [DIRS 164527]) and the associated preliminary screening decisions were again reviewed and discussed by the appropriate SMEs, concurrent with interim screening analyses (see Section 4.2). In addition, during this period, the FEP Team continued to respond to informal comments regarding the comprehensiveness and completeness of the TSPA-LA FEP list and, where necessary, "potential FEPs" (see Section 3.2.4) continued to be identified. Specific FEP identification actions that were performed during this interim analysis period are as follows: 
- FEP AMR Leads and SMEs evaluated the revised preliminary FEP list and, where appropriate, suggested new FEPs or revisions to existing FEPs to enhance comprehensiveness.

- The FEP Team coordinated FEP revisions and interim screening decisions to ensure consistency.

- The FEP Team performed an audit against recently published listings of radioactive waste disposal FEPs associated with fractured rock in Japan (JNC 1999 [DIRS 171894], Table 3.1-1) and with clay sites in various countries (Mazurek et al. 2003 [DIRS 171895], Table 2). Subjective comparisons by the FEP Team concluded that all of these recently published FEPs were adequately captured by the TSPA-LA FEPs and no new FEPs were identified.

- The FEP Team performed an audit against new information in Version 1.1 of the NEA International FEP Database (OECD 2000 [DIRS 152952], Appendix D). Version 1.1 augmented Version 1.0 by adding 144 FEPs from a Canadian study (OECD 2000 [DIRS 152952], Appendix D) and 13 FEPs from a re-evaluation of a Swiss study (NAGRA 1994 [DIRS 124260]). No new FEPs were identified, but these additional source FEPs were added to the source FEP list (see Table G-1) and were mapped to TSPA-LA FEPs consistent with other source FEPs.

- A top-down interaction diagram analysis was performed to identify an alternate, independent set of YMP FEPs (see Appendix B). A comparison between the revised preliminary version of the TSPA-LA FEP list (DTN: MO0307SEPFEPS4.000 [DIRS 164527]) and the alternate FEP list from Appendix B identified 9 issues that might be potential FEPs (Appendix B, Table B-1) because they were not explicitly addressed by the TSPA-LA FEP list. These issues were entered into the Potential FEP Log for evaluation (see Section 3.2.4). The potential FEP evaluation determined that all 9 issues were adequately captured by the TSPA-LA FEPs, thereby supporting the completeness of the TSPA-LA FEP list.

- FEP AMR Leads and SMEs evaluated potential changes from the Potential FEP Log (see Section 3.2.4).

These actions during the second iterative cycle produced a further succession of FEP lists (DTN: MO0312SEPFEPS5.000 [DIRS 167431] in December 2003), culminating in an interim TSPA-LA FEP list containing 371 FEPs in May 2004 (DTN: MO0405SEPFEPS6.000 [DIRS 169612]). In addition to containing the further revisions to the FEP list, DTN: MO0405SEPFEPS6.000 [DIRS 169612]) also contained interim FEP screening results (see Section 4.2), specifically screening decisions, screening arguments (for excluded FEPs) and TSPA dispositions (for included FEPs). DTN: MO0405SEPFEPS6.000 [DIRS 169612] superseded all previous FEP list DTNs. As described in Appendix C, a qualified version (DTN: MO0407SEPFEPLA.000 [DIRS 170760]) of the interim TSPA-LA FEP list was subsequently produced. DTN: MO0407SEPFEPLA.000 [DIRS 170760] contained the same interim FEP list and screening results as, and superseded, DTN: MO0405SEPFEPS6.000 [DIRS 169612]. A summary of the changes made in the succession of FEP lists from 
DTN: MO0307SEPFEPS4.000 [DIRS 164527] to DTN: MO0407SEPFEPLA.000 [DIRS 170760] is provided in Appendix C. Full documentation of the changes is contained within the data sets themselves.

During the third iterative cycle (June 2004 to August 2005), a final review of the qualified interim FEP list (DTN: MO0407SEPFEPLA.000 [DIRS 170760]) and the associated interim screening results was performed by the appropriate FEP AMR Leads and SMEs, concurrent with the final screening analyses (see Section 4.2). Where necessary, new or missing FEPs, or "potential FEPs" (see Section 3.2.4) continued to be identified and the FEP Team continued to respond to informal comments regarding the comprehensiveness and completeness of the TSPA-LA FEP list. In addition, during this period, a systematic editorial review of FEP descriptions was performed to improve consistency in nomenclature and thereby enhance text search capabilities available in the database software (see Section 6.1.2.1). Specific FEP identification actions that were performed during this final analysis period are as follows:

- FEP AMR Leads and SMEs reviewed the qualified interim FEP list and, where appropriate, suggested new FEPs or revisions to existing FEPs to enhance comprehensiveness.

- FEP AMR Leads and SMEs evaluated potential changes from the Potential FEP Log (see Section 3.2.4).

- The FEP Team coordinated final FEP revisions and screening decisions to ensure consistency.

These actions during the third and final iterative cycle produced three successive FEP lists. The first list was a controlled FEP list, without screening results, produced in August 2004 (BSC 2004 [DIRS 171888], Attachment 1). The controlled FEP list incorporated changes from the interim FEP list (DTN: MO0407SEPFEPLA.000 [DIRS 170760]) resulting from (a) the final FEP AMR Lead and SME reviews, (b) "potential FEPs", and (c) the systematic editorial improvements. As described in Section 3.2.4, the controlled FEP list was controlled via the Technical Management Review Board (TMRB). The controlled list provided the TSPA-LA FEP list for final screening. The second list was a qualified FEP list, with screening results, produced in January 2005 (DTN: MO0501SEPFEPLA.001 [DIRS 172601]). The third list was the final qualified TSPA-LA FEP list, with final screening results, produced in August 2005 (DTN: MO0508SEPFEPLA.002 [DIRS 175064]).

The final TSPA-LA FEP list (DTN: MO0508SEPFEPLA.002 [DIRS 175064]) contained 375 FEPs and contained final qualified FEP screening results (see Section 4.2), specifically screening decisions, screening arguments (for excluded FEPs) and TSPA dispositions (for included FEPs) from the FEP AMRs listed in Table 2-7. A summary of the changes made in the FEP list from DTN: MO0407SEPFEPLA.000 [DIRS 170760] to DTN: MO0508SEPFEPLA.002 [DIRS 175064] is provided in Appendix C. Full documentation | of the changes is contained within the data sets themselves. 


\subsubsection{Configuration Management for Potential New FEPs}

One condition of FEP analysis is that a FEP list must always be open to new FEPs. For TSPA-LA FEP analysis, the identification of design changes and/or new information that could result in new FEPs or changes to existing FEPs and the documentation of the evaluations of the resulting potential FEPs were tracked using configuration management controls. A preliminary outline for FEP configuration management was described in the enhanced FEP plan (BSC 2002 [DIRS 158966], Section 3.2.2.1). This section describes the final implementation for TSPA-LA.

As described in Section 3.2.2, the preliminary TSPA-LA FEP list (DTN: MO0301SEPFEPS1.000 [DIRS 161496]) derived from the final TSPA-SR FEP list (BSC 2002 [DIRS 159684]). Changes between the final TSPA-SR FEP list and the preliminary TSPA-LA FEP list were limited to reclassification of existing scope. Although some new FEPs resulted from splitting and re-organizing scope, no new scope was added. Potential changes to the overall scope of the FEP list due to design changes and/or new technical information were not considered, and therefore, FEP configuration management was not required during the development of the preliminary TSPA-LA FEP list. Instead, the changes were documented, FEP-by-FEP, directly in the FEP data set (DTN: MO0301SEPFEPS1.000 [DIRS 161496]) as described in Appendix C.

The TSPA-LA FEP list then evolved through a series of iterative FEP identification cycles (see Section 3.2.3), performed concurrently with the FEP screening (see Section 4.2). During these FEP identification and screening cycles (January 2003 through August 2005), which were coincident with the planning and preparation of the supporting technical AMRs and FEP AMRs, a formal FEP configuration management process was implemented to evaluate and track potential new FEPs and changes to existing FEPs. The configuration management process consisted of the following steps:

1. Identification of Potential FEPs-The term "potential FEP" is used to refer collectively to potential new FEPs and potential changes to existing FEPs. Potential FEPs represent possible changes to the overall scope of the FEP list. Potential FEPs can come from sources such as introduction of alternative conceptual models, design changes, and new technical information from internal project documents or from external documents. Potential FEPs must be formally evaluated (see Step 2) to determine whether a change to the FEP list is necessary. Several complementary tasks were performed to enable the FEP Team to capture project-wide input regarding potential FEPs. These tasks included:

- Informal communications with SMEs and FEP AMR Leads during the iterative FEP identification and screening cycles.

- Informal communications with TSPA modelers during TSPA model development.

- Formal notification of Information Exchange Diagram (IED) updates. Updates to the IEDs communicated design changes to the FEP Team that might lead to potential FEPs. 
- Formal reviews, in accordance with LP-2.14Q-BSC, Document Review (or its predecessor AP-2.14Q, Document Review), of all supporting technical AMRs and FEP AMRs. During this process, the FEP Team became aware of new information and analyses that might lead to potential FEPs.

- Systematic identification of TSPA-LA FEP completeness "gaps". The following completeness checks were performed by the FEP Team:

- Mapping to the TSPA-LA FEPs from the source FEPs (see Section 3.2.1) and from the TSPA-SR FEP list (see Section 3.2.2) to ensure that no FEPs or finer details were omitted.

- An audit against new information in Version 1.1 of the NEA International FEP Database (OECD 2000 [DIRS 152952], Appendix D), specifically 144 new FEPs from a Canadian study (OECD 2000 [DIRS 152952], Appendix D]) and 13 new FEPs from a re-evaluation of a Swiss study (NAGRA 1994 [DIRS 124260]). No new FEPs were identified (see Section 3.2.3).

- An audit against recently published listings of radioactive waste disposal FEPs associated with fractured rock in Japan (JNC 1999 [DIRS 171894], Table 3.1-1) and with clay sites in various countries (Mazurek et al. 2003 [DIRS 171895], Table 2). No new FEPs were identified (see Section 3.2.3).

- A comparison with a YMP FEP list developed from the independent top-down interaction diagram analysis summarized in Appendix B (see Section 3.2.3). No new FEPs were added.

- An evaluation of the mapping of FEPs to the FEP matrix boxes. "Empty" boxes in the FEP matrix were re-evaluated to confirm that there were no credible FEPs associated with them. "Populated" boxes of the FEP matrix were examined to determine if additional detail (e.g., new FEPs or changes to FEPs) was warranted in accordance with the level-of-detail criteria.

2. Evaluation and Resolution of Potential FEPs-The potential FEPs identified in Step 1 represent possible changes to the FEP list. The FEP Team performed an evaluation of each potential FEP in collaboration with the affected FEP AMR Lead(s) and SMEs. Based on this collaboration, the FEP Team determined whether a change to the FEP list was necessary and documented a final resolution. A potential FEP can have one of three possible resolutions:

- It results in a new FEP. In this case, the new FEP was added to the FEP list and its screening was documented in the appropriate FEP AMR(s).

- It results in a scope change to one or more existing FEPs. In this case, the change(s) were incorporated in the FEP list, and the modifications to screening were documented in the appropriate FEP AMR(s). 
- It does not result in a change to the FEP list. In this case, the justification that the potential FEP is completely addressed by an existing FEP or FEPs was documented in the Potential FEP Log (see Step 3).

3. Tracking and Documentation of Potential FEPs-All potential FEPs (identified in Step 1) were entered into a Potential FEP Log. The FEP Team maintained the Potential FEP Log to track the status of each potential FEP through to the documentation of its final resolution (as described in Step 2). For each potential FEP, the following information was recorded: Log Number, Date Submitted, Submitted By, Issue Title, Source, Discussion of Issue, Resolution, and Date of Resolution.

The Potential FEP Log was maintained by the FEP Team as an electronic data table. The final $\log$ is stored directly in data set DTN: MO0508SEPFEPLA.002 [DIRS 175064] as Table "Potential FEP Log" (see Table 6-2 and Appendix G) and is listed in Appendix D of this report. The Potential FEP Log contains information documenting all resulting changes to the FEP list and justifying all cases where changes were not made. Changes to the FEP list, in addition to being documented in the Potential FEP Log are also identified in the data set (DTN: MO0508SEPFEPLA.002 [DIRS 175064]) in the "Historical_Notes" field in Table | "FEPs" and in Table "FEP History File" (see Table 6-2 and Appendix G).

The formal FEP configuration management process described in Steps 1 through 3 above, while described sequentially, is an ongoing and iterative process. It addresses all potential FEPs that could be identified and documented to support License Application. During the final iterative FEP identification cycle (June 2004 through August 2005), a controlled FEP list (BSC 2004 [DIRS 171888], Attachment 1) was produced prior to final screening. The controlled FEP list was controlled via the Technical Management Review Board (TMRB) and contained all changes to FEP names and descriptions resulting from the Potential FEP Log. The issuance of the controlled FEP list represented an increase in the level of configuration control. Any subsequent changes to the controlled FEP list (i.e., new potential FEP issues) required a TMRB Decision Proposal and were subject to TMRB approval (BSC 2005 [DIRS 174991], (BSC 2005 [DIRS 174965], (BSC 2005 [DIRS 174989], and (BSC 2005 [DIRS 174990]). Finally, because potential FEPs can be identified at any time, any potential FEPs that are identified after this report is approved are planned to be tracked, evaluated, and documented in a Post-LA Potential FEP Log using a three-step process similar to that described above. 
INTENTIONALLY LEFT BLANK 


\section{YUCCA MOUNTAIN PROJECT FEP ANALYSIS - SCREENING}

As noted in Section 3.2.3, FEP screening was performed in parallel with FEP identification. Preliminary screening, coincident with the planning and preparation of the supporting technical AMRs, was performed from January 2003 to July 2003. Interim screening, coincident with the development of the interim supporting technical AMRs and FEP AMRs, was performed from August 2003 to May 2004. Final screening, coincident with the completion of the final supporting technical AMRs and FEP AMRs, was performed from June 2004 to August 2005.

This section describes the FEP screening criteria (Section 4.1) and screening process (Section 4.2). While the FEP identification and classification (see Section 3) for TSPA-LA built upon FEP identification that supported TSPA-SR, the screening of FEPs for TSPA-LA has no historical links to TSPA-SR.

\subsection{SCREENING CRITERIA}

The criteria that can be used to exclude a FEP from TSPA-LA are given in the following subsections.

\subsubsection{Low-Probability Criterion}

The low-probability criterion is explicitly stated in 10 CFR 63.114(d) [DIRS 173273]:

"Consider only events that have at least one chance in 10,000 of occurring over 10,000 years."

This is supported by 10 CFR 63.342 [DIRS 173273]:

"DOE's performance assessments shall not include consideration of very unlikely features, events, or processes, i.e., those that are estimated to have less than one chance in 10,000 of occurring within 10,000 years of disposal."

This low-probability criterion for very unlikely FEPs is assumed to correspond to an annual-exceedance probability of $10^{-8}$, where the annual-exceedance probability is defined as the probability that a specified value will be exceeded during one year (BSC 2004 [DIRS 168030], Glossary). The assumption of equivalence to the annual-exceedance probability is appropriate if the possibility of an event is equal for any given year.

Furthermore, it is stated in 10 CFR 63.342 [DIRS 173273] that:

"DOE's assessments for the human intrusion and ground-water protection standards shall not include consideration of unlikely features, events, and processes, or sequences of events and processes, i.e., those that are estimated to have less than one chance in 10 and at least one chance in 10,000 of occurring within 10,000 years of disposal." 
This low-probability criterion for unlikely FEPs is assumed to correspond to an annual-exceedance probability of greater than or equal to $10^{-8}$, which is the lower boundary for very unlikely FEPs, but less than $10^{-5}$.

Based on the above criterion, a low-probability screening argument can be made through a comparison (usually quantitative) of the probability of occurrence of a specific FEP, independent of its effect on the repository, with the regulatory low-probability criterion of "one chance in 10,000 of occurring over 10,000 years". Probability screening is particularly germane to processes where the phenomena are well defined, such as naturally-occurring events. Typically, the mean probability of an event (which reflects the range in the underlying uncertainty in supporting information) is used to represent the probability of occurrence for the purposes of comparison with the regulatory standard. A probability less than the mean probability was never considered for screening purposes.

\subsubsection{Low-Consequence Criteria}

The low-consequence screening criteria are explicitly stated in 10 CFR 63.114(e) and (f) [DIRS 173273]:

(e) Provide the technical basis for either inclusion or exclusion of specific features, events, and processes in the performance assessment. Specific features, events, and processes must be evaluated in detail if the magnitude and time of the resulting radiological exposures to the reasonably maximally exposed individual, or radionuclide releases to the accessible environment, would be significantly changed by their omission.

(f) Provide the technical basis for either inclusion or exclusion of degradation, deterioration, or alteration processes of engineered barriers in the performance assessment, including those processes that would adversely affect the performance of natural barriers. Degradation, deterioration, or alteration processes of engineered barriers must be evaluated in detail if the magnitude and time of the resulting radiological exposures to the reasonably maximally exposed individual, or radionuclide releases to the accessible environment, would be significantly changed by their omission.

The term "significantly changed" is undefined in the regulations. The absence of significant change was inferred for FEPs screening purposes to be equivalent to having negligible or no effect.

Based on these criteria, a low-consequence screening argument can be made through an evaluation of either the direct or indirect effects of a specific FEP on radiological exposures to the RMEI or radionuclide releases to the accessible environment. In some cases, the direct effects of a FEP on radiological exposures or radionuclide releases can easily be identified. In other cases, only the effects of a FEP on an intermediate performance measure that can be identified. In these cases, the intermediate performance measure is then linked to radiological exposures or radionuclide releases. Typically, if a FEP can be shown to have no significant effect on unsaturated zone or saturated zone flow and transport, waste-package integrity, and/or 
other components of the EBS or natural system, then the FEP does not provide a mechanism that results in a significant effect on the radiological exposures to the RMEI or radionuclide releases to the accessible environment.

Low-consequence screening arguments can also be postulated using "worst-case" values for the sequence of processes and events and/or the associated intermediate performance measures. Often, it can be demonstrated that even with worst-case values, the FEP still has no significant effect on repository performance. Various means to demonstrate no significant effect include site-specific data, sensitivity analyses, expertise of SMEs (including, in some cases, the expert elicitation process), natural analogues, modeling studies outside of the TSPA, and reasoned arguments based on literature research or corroborative data.

Some FEPs have a beneficial effect on the TSPA, as opposed to an adverse effect. As identified in 10 CFR 63.102(j) [DIRS 173273], the concept of a performance assessment includes:

The features, events, and processes considered in the performance assessment should represent a wide range of both beneficial and potentially adverse effects on performance (e.g., beneficial effects of radionuclide sorption; potentially adverse effects of fracture flow or a criticality event). Those features, events, and processes expected to materially affect compliance with [10 CFR] 63.113(b) or be potentially adverse to performance are included, while events (event classes or scenario classes) that are very unlikely (less than one chance in 10,000 over 10,000 years) can be excluded from the analysis.

Yucca Mountain Review Plan, Final Report (NRC 2003 [DIRS 163274], Section 2.2.1) states:

In many regulatory applications, a conservative approach can be used to decrease the need to collect additional information or to justify a simplified modeling approach. Conservative estimates for the dose to the reasonably maximally exposed individual may be used to demonstrate that the proposed repository meets U.S. Nuclear Regulatory Commission regulations and provides adequate protection of public health and safety. ...The total system performance assessment is a complex analysis with many parameters, and the U.S. Department of Energy may use conservative assumptions to simplify its approaches and data collection needs. However, a technical basis ... must be provided.

In some cases a beneficial FEP may not be implemented in TSPA-LA (e.g., where there is an insufficient technical basis for inclusion). In these cases, it is acceptable, on the basis of the above statements, to demonstrate that a beneficial FEP can only improve the performance (of an otherwise compliant system) and therefore that its omission cannot "materially affect compliance". In these cases, FEPs that are demonstrated to have only beneficial effects on the radiological exposures to the reasonably maximally exposed individual, or radionuclide releases to the accessible environment, can be excluded on the basis of low consequence because they have no adverse effects on performance. 
Finally, 10 CFR 63.342 [DIRS 173273] states:

DOE's performance assessments need not evaluate the impacts resulting from any features, events, and processes or sequences of events and processes with a higher chance of occurrence if the results of the performance assessments would not be changed significantly.

This "low-impact" criterion is a variation of a low-consequence screening argument. For some of the FEPs it was determined that the probability of the condition, event or process occurring during the regulatory period of 10,000 years was extremely low. However, it was difficult to provide a detailed quantification of the exact probability, given the current state of knowledge of data and models and the uncertainty associated with a 10,000 time period, that was sufficient to exclude the FEP based solely on low probability criterion. In these cases, a qualitative evaluation of the consequence, considering the low probability of the FEP (or the antecedent conditions associated with the FEP), was made. These evaluations represent a "risk-informed" approach that examines the joint outcome of the probability and the consequence of such FEPs. If these "risk-informed" evaluations indicated insignificant impact on the results of performance assessment (or on an intermediate performance measure), then the FEP was excluded based on low consequence. This is consistent with the definition of performance assessment in 10 CFR 63.2 [DIRS 173273] that requires that the consequences of all significant FEPs (i.e., "the dose incurred by the RMEI") be "weighted by their probability of occurrence".

\subsubsection{By-Regulation Criteria}

Yucca Mountain Review Plan, Final Report (NRC 2003 [DIRS 163274], Section 2.2.1.2.1.3, Acceptance Criterion 2) states that, "An acceptable justification for excluding features, events, and processes is that ... the feature, event, or process is specifically excluded by regulation ..."

Regulations that specify characteristics, concepts, and definitions may serve as the basis for exclusion of FEPs by regulation. The most commonly used for screening TSPA-LA FEPs include the characteristics, concepts and definitions pertaining to the reference biosphere (see Section 4.1.3.1), geologic setting (see Section 4.1.3.2), the RMEI (see Section 4.1.3.3), and human intrusion (see Section 4.1.3.4).

\subsubsection{Reference Biosphere}

Per 10 CFR 63.2 [DIRS 173273], the reference biosphere is defined as:

"The description of the environment inhabited by the reasonably maximally exposed individual. The reference biosphere comprises the set of specific biotic and abiotic characteristics of the environment, including, but not necessarily limited to, climate, topography, soils, flora, fauna, and human activities."

The characteristics pertaining to the reference biosphere are presented at 10 CFR 63.305(a), (b), and (d) [DIRS 173273]: 
(a) Features, events, and processes that describe the reference biosphere must be consistent with present knowledge of the conditions in the region surrounding the Yucca Mountain site.

(b) DOE should not project changes in society, the biosphere (other than climate), human biology, and increase or decreases of human knowledge or technology. In all analyses done to demonstrate compliance with this part, DOE must assume that all those factors remain constant as they are at the time of license application.

(d) Biosphere pathways must be consistent with arid or semi-arid conditions.

This is further supported by 10 CFR 63.102(i) [DIRS 173273] that states, “...The environment inhabited by the reasonably maximally exposed individual, along with the associated human exposure pathways, make up the reference biosphere, as described in 10 CFR 63.305." and "... Characteristics of the reference biosphere ... are to be based on current human behavior and biospheric conditions in the region, as described in 10 CFR 63.305 and 10 CFR 63.312."

\subsubsection{Geologic Setting}

Per 10 CFR 63.2 [DIRS 173273], the geologic setting is defined as:

The geologic, hydrologic, and geochemical systems of the region in which the geologic repository is or may be located.

The evolution of the geologic setting is described in 10 CFR 63.305(c) [DIRS 173273]:

(c) DOE must vary factors relating to the geology, hydrology, and climate, based upon cautious, but reasonable assumptions, consistent with present knowledge of factors that could affect the Yucca Mountain disposal system in the next 10,000 years.

\subsubsection{Reasonably Maximally Exposed Individual}

At 10 CFR 63.102(i) [DIRS 173273] it states,

...The reasonably maximally exposed individual, as a hypothetical person living in a community with the characteristics of the Town of Amargosa Valley, is representative of a person using water with average concentrations of radionuclides as described at 10 CFR 63.312. The reasonably maximally exposed individual is selected to represent those persons in the vicinity of Yucca Mountain who are reasonably expected to receive the greatest exposure to radioactive material released from a geologic repository at Yucca Mountain. Characteristics of the ... the reasonably maximally exposed individual are to be based on current human behavior and biospheric conditions in the region, as described in 10 CFR 63.305 and 10 CFR 63.312. 
The characteristics of the RMEI are given at 10 CFR Section 63.312 [DIRS 173273]:

The RMEI is a hypothetical person who meets the following criteria:

(a) Lives in the accessible environment above the highest concentration of radionuclides in the plume of contamination

(b) Has a diet and living style representative of the people who now reside in the Town of Amargosa Valley, Nevada ...

(c) Uses well water with average concentrations based on an annual water demand of 3000 acre-feet

(d) Drinks 2 liters of water per day from wells drilled into the ground water at the location specified in paragraph (a) ...

(e) Is an adult with metabolic and physiological considerations consistent with present knowledge of adults.

Pertinent to the definition of the RMEI is the spatial relationship between the repository and the RMEI, which must consider the areal extent of the accessible environment and of the controlled area. From 10 CFR 63.302 [DIRS 173273], the accessible environment is defined as "Any point outside of the controlled area ...". Also at 10 CFR 63.302 [DIRS 173273], the controlled area is defined as:

(1) The surface area, identified by passive institutional controls, that encompasses no more than 300 square kilometers. It must not extend farther:

(i) South than $36^{\circ} 40^{\prime} 13.6661$ " North latitude, in the predominant direction of ground water flow; and

(ii) Than five kilometers from the repository footprint in any other direction; and

(2) The subsurface underlying the surface area.

The preamble to 10 CFR Part 63 (66 FR 55732 [DIRS 156671], p. 55753) states:

At distances less than $18 \mathrm{~km}$ to the Yucca Mountain site, there is evidence of intermittent or temporary occupation in modern (historic) times in and around the site-for prospecting or ranching. There also are a number of Native American archeological sites reported throughout Nevada Test Site (NTS) closer to the site than the Lathrop Wells location. However, the literature indicates that these were never permanently occupied, and most were abandoned by the end of the 1800's. Overall, the literature suggests many reasons for the absence of permanent inhabitation at distances much closer than $18 \mathrm{~km}$ to the site-unfavorable agricultural conditions, inhospitable terrain, the scarcity of mineral resources, and limitations on water availability. 
These definitions and concepts indicate that the RMEI is located no closer than $18 \mathrm{~km}$ to the south in the direction of groundwater flow and over a contaminated groundwater plume (in accordance with 10 CFR 63.312(a) [DIRS 173273]) and that the limit of the controlled area is no greater than $5 \mathrm{~km}$ from the repository in any other direction (as specified at 10 CFR 63.302 [DIRS 173273]).

\subsubsection{Human Intrusion}

Human intrusion is defined at 10 CFR 63.302 [DIRS 173273] as:

... breaching any portion of the Yucca Mountain disposal system, within the repository footprint, by any human activity.

There are also specific regulatory provisions regarding consideration of human intrusion. At 10 CFR 63.322 ([DIRS 173273]), it states that:

For the purposes of the analysis of human intrusion, DOE must make the following assumptions:

(a) There is a single human intrusion as a result of exploratory drilling for ground water;

(b) The intruders drill a borehole directly through a degraded waste package into the uppermost aquifer underlying the Yucca Mountain repository;

(c) The drillers use the common techniques and practices that are currently employed in exploratory drilling for ground water in the region surrounding Yucca Mountain;

(d) Careful sealing of the borehole does not occur, instead natural degradation processes gradually modify the borehole;

(e) No particulate waste material falls into the borehole;

(f) The exposure scenario includes only those radionuclides transported to the saturated zone by water (e.g., water enters the waste package, releases radionuclides, and transports radionuclides by way of the borehole to the saturated zone; and

(g) No releases are included which are caused by unlikely natural processes and events.

At 10 CFR 63.321 [DIRS 173273], the criteria under which human intrusion must be evaluated are specified:

DOE must determine the earliest time after disposal that the waste package would degrade sufficiently that a human intrusion could occur without recognition by the drillers. 
And, per 10 CFR 63.321(a) [DIRS 173273], DOE must:

Provide the analyses and its technical bases used to determine the time of occurrence of human intrusion (see 10 CFR 63.322) without recognition by the drillers.

If the waste package penetration is projected to occur before or at the 10,000-year performance period, then the DOE is to provide a demonstration per 10 CFR 63.321(b)(1) [DIRS 173273] | that:

...there is a reasonable expectation that the reasonably maximally exposed individual receives no more than an annual dose of 0.15 milliSieverts $(\mathrm{mSv})$ $(15 \mathrm{mrem})$ as a result of a human intrusion, at or before 10,000 years after disposal.

And, per 10 CFR 63.321(b)(2) [DIRS 173273]:

If the exposure of the RMEI occurs after 10,000 years, or if the intrusion is projected to occur after 10,000 years, the results of the analysis and the bases of the analysis are to be provided in the environmental impact statement for Yucca Mountain.

With regard to the motivation of a human intrusion being intentional/deliberate or inadvertent/accidental, the regulations at 10 CFR Part 63 ([DIRS 173273], All Sections) are I silent.

However, in the preamble to 40 CFR Part 197 (66 FR 32074 [DIRS 155216], p. 32105, Item 3 "What is the Standard for Human Intrusion?"), it states:

Comments we received proposing alternative drilling frequencies and intentions, such as deliberately drilling into the repository, did not provide a sufficient rationale to abandon the NAS recommendations and we therefore retained our original framing for the scenario.

And in the preamble to 40 CFR Part 197 (FR 32074 [DIRS 155216], p. 32127, Item 10, "Is the Single-Borehole Scenario a Reasonable Approach to Judge the Resilience of the Yucca Mountain Disposal System Following Human Intrusion?"), it states that:

Some comments suggested that there is a strong possibility for deliberate intrusion into the repository to access its content as possible resources. We believe that there is no useful purpose to assessing the consequences of deliberate intrusions because in that case the intruders would be aware of the risks and consequences and would have decided to assume the risks.

Consequently, all deliberate human intrusion FEPs can be excluded based on the regulatory intent, and all inadvertent intrusions are considered within the context of the regulatory requirements (e.g., assume the stylized human intrusion as per 10 CFR 63.322 [DIRS 173273]). 


\subsection{SCREENING PROCESS}

As described in Section 4.1, FEPs can be excluded from TSPA by low probability, low consequence, or by regulation. The specified exclusion criteria can be summarized in the form of the three following FEP screening statements.

1. FEPs having less than one chance in 10,000 of occurring over 10,000 years may be excluded (screened out) from the TSPA on the basis of low probability (see Section 4.1.1).

2. FEPs whose omission would not significantly change the magnitude and time of the radiological exposures to the RMEI, or radionuclide releases to the accessible environment, may be excluded (screened out) from the TSPA on the basis of low consequence (see Section 4.1.2).

3. FEPs that are inconsistent with the characteristics, concepts, and definitions specified in 10 CFR Part 63 [DIRS 173273] may be excluded (screened out) from the TSPA by regulation (see Section 4.1.3).

The FEP screening process for TSPA-LA, based on these three criteria, is illustrated in Figure 4-1. A FEP need only satisfy one of the exclusion screening criteria to be excluded from TSPA. A FEP that does not satisfy any of the exclusion screening criteria must be included (screened in) in the TSPA-LA model.

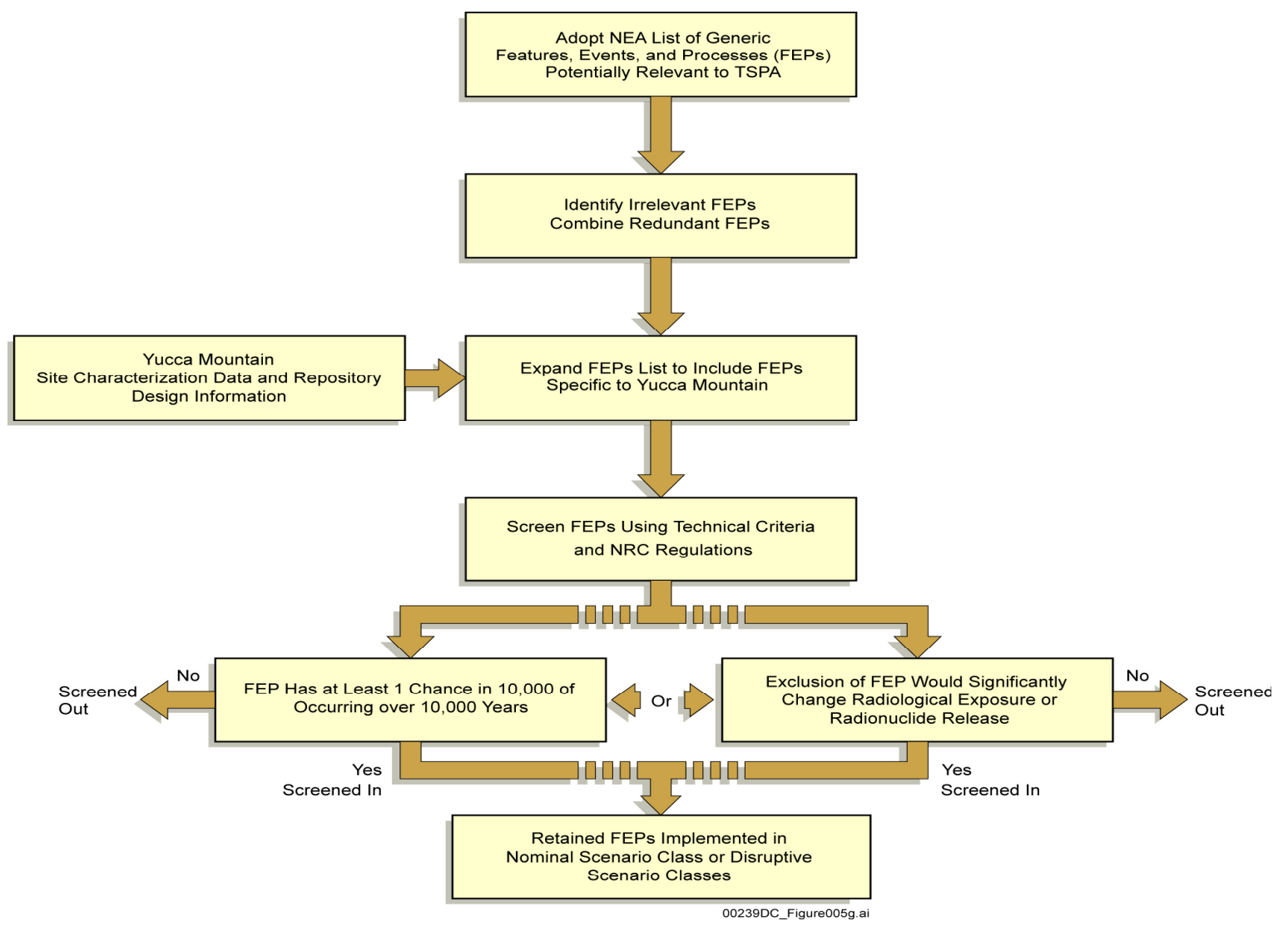

Figure 4-1. Schematic Illustration of the FEP Screening Process 
Evaluation of the FEPs against these screening statements may be done in any order. In practice, by-regulation criteria were examined first, and then either low probability or low consequence criteria were examined. FEPs that could not be excluded based on one criterion (e.g., regulatory guidance) were also considered against the other criteria (probability and consequence). Consequently, the application of the analyst's judgment regarding the order in which to apply the criteria did not affect the final decision. Allowing the analyst to choose the most appropriate order to apply the criteria prevented needless work, such as developing quantitative probability arguments for low-consequence events or complex consequence models for low-probability events.

As noted in Section 3.2.3, the TSPA-LA FEP list evolved through a series of iterative and collaborative evaluations by FEP AMR Leads, SMEs, and the FEP Team. The various stages of screening (preliminary, interim, and final, as identified in Figure 2-1) were performed concurrently with the FEP list evolution. Preliminary screening was performed during the planning and preparation of the supporting technical AMRs, coincident with the first FEP identification cycle, from January 2003 to July 2003. Interim screening was performed during the development of the interim supporting technical AMRs and FEP AMRs, coincident with the second FEP identification cycle, from August 2003 to May 2004. Final screening was performed during the completion of the final supporting technical AMRs and FEP AMRs, coincident with the third FEP identification cycle, from June 2004 to August 2005. FEP screening was performed by SMEs and FEP AMR Leads and was reviewed for adequacy and consistency by the FEP Team. Screening decisions were based on screening criteria identified in Section 4.1. Screening arguments (for excluded FEPs) and TSPA dispositions (for included FEPs) were documented as described in Section 4.2.1 and were formulated in accordance with the guidelines outlined in Section 4.2.2.

During preliminary screening (January 2003 to July 2003), FEPs from the preliminary FEP list (DTN: MO0301SEPFEPS1.000 [DIRS 161496]) relevant to each technical subject area were reviewed, discussed, and assigned preliminary screening decisions by the appropriate SMEs. Specific FEP screening actions that were performed during this period are as follows:

- FEP AMR Leads and SMEs made preliminary screening decisions (included or excluded) for each FEP

- For excluded FEPs, they identified a preliminary defensible technical basis for exclusion. Where the technical basis for exclusion seemed insufficient, they identified additional information needs or changed the screening decision to include.

- For included FEPs, they identified one or more supporting technical AMRs where the method of implementation (in a process model and subsequently in TSPA) would be partially or completely addressed. These AMRs were then listed in the appropriate TWPs. 
During interim screening (August 2003 to May 2004), FEPs from the revised preliminary FEP list (DTN: MO0307SEPFEPS4.000 [DIRS 164527]) and the associated preliminary screening decisions were again reviewed, discussed, and documented by the appropriate SMEs. Specific FEP screening actions that were performed during this period are as follows:

- FEP AMR Leads and SMEs reviewed screening decisions (included or excluded) for each FEP

- SMEs documented the included FEPs (e.g., the method of implementation in a process model and subsequently in TSPA-LA) in the appropriate interim supporting technical AMRs, in accordance with the TWPs. In some cases, additional evaluation and/or changes in AMR scope resulted in deviations from the TWP "mapping".

- The FEP Team reviewed (as per AP-2.14Q, Document Review) the documentation and traceability of the included FEPs in the interim supporting technical AMRs for technical adequacy and coordinated preliminary screening decisions to ensure consistency.

- FEP AMR Leads and SMEs documented the interim FEP screening decisions

- For excluded FEPs, they documented the technical basis for exclusion in the appropriate interim FEP AMRs.

- For included FEPs, they consolidated the documentation of the method of implementation in TSPA from one or more supporting technical AMRs into the appropriate interim FEP AMRs.

- The FEP Team and SMEs reviewed (as per AP-2.14Q, Document Review) the documentation and traceability of the included and excluded FEPs in the interim FEP AMRs for technical adequacy and coordinated screening decisions to ensure consistency.

During final screening (June 2004 to August 2005), FEPs from the qualified interim FEP list (DTN: MO0407SEPFEPLA.000 [DIRS 170760]) and the associated interim screening results were again reviewed, discussed, and documented by the appropriate SMEs. Specific FEP screening actions that were performed during this period are as follows:

- FEP AMR Leads and SMEs confirmed final screening decisions (included or excluded) for each FEP

- FEP AMR Leads and SMEs documented the final FEP screening decisions

- For excluded FEPs, they documented the technical basis for exclusion in the appropriate FEP AMRs.

- For included FEPs, they documented the method of implementation (in a process model and subsequently in TSPA) in one or more supporting technical AMRs. They then consolidated the information into the appropriate FEP AMRs. Note that seven 
of the included system level FEPs, identified in Table F-1, were inherently included directly in TSPA, and are not documented in any supporting technical AMR.

- The FEP Team and SMEs reviewed (as per LP-2.14Q-BSC, Document Review or its predecessor, AP-2.14Q, Document Review) the documentation and traceability of the included and excluded FEPs in the FEP AMRs for technical adequacy and coordinated screening decisions to ensure consistency.

As noted in Section 3.2.3, the culmination of the third and final identification and screening cycle produced a final qualified TSPA-LA FEP list of 375 FEPs in August 2005 (DTN: MO0508SEPFEPLA.002 [DIRS 175064]) that contained both FEP identification information (e.g., FEP names, numbers, and descriptions) and FEP screening information (screening decisions and screening arguments and/or TSPA dispositions). A summary of this information is provided in Appendix E. Of the 375 total FEPs, 149 were included in TSPA-LA and 226 were excluded from TSPA-LA.

\subsubsection{Documentation of FEP Screening}

As described in Section 4.2, FEP screening was performed by the SMEs and the FEP AMR Leads. The screening analyses were documented in a hierarchical fashion. First, the technical details supporting screening were identified by the SMEs in a set of approximately 100 supporting technical AMRs. Then, the technical bases for screening were consolidated by the FEP AMR Leads into a set of 10 FEP AMRs. Finally, the screening information was incorporated into an electronic database by the FEP Team.

Documentation in the supporting technical AMRs was limited to included FEPs (e.g., FEPs that are included in TSPA-LA). Preliminary screening (see Section 4.2) resulted in preliminary screening decisions for each FEP. For each included FEP, one or more supporting technical AMRs was identified to provide a discussion of the implementation of the FEP (in a process model and subsequently in TSPA). This mapping of included FEPs to supporting technical AMRs was then combined with a document hierarchy that identified (a) interactions among the supporting technical AMRs, and (b) which supporting technical AMRs provided direct feeds to TSPA-LA. The result was the identification of the "flow" of included FEPs through the set of supporting technical documents. Documentation of AMR and FEP relationships identified in this process is described in Section 4.2.2. To help ensure complete, consistent, and traceable coverage of each included FEP, the FEP information flow was used to corroborate and/or identify minor changes to the mapping of included FEPs to supporting technical AMRs based on the following considerations:

- All included FEPs must be addressed in at least one of the direct feed AMRs. This is consistent with all included FEPs being implemented in TSPA-LA.

- Any included FEP that is addressed in a supporting technical AMR that is on the "lower end" of a path in the document hierarchy should also be addressed in all other supporting technical AMRs "upward" on the same path up to and including the direct feed AMR. As an example, an included FEP in a process model is also an included FEP (although 
perhaps implicitly) in all subsequent AMRs up to and including the abstraction model AMR that feeds TSPA-LA.

During interim and final screening (see Section 4.2), the preliminary screening decisions and FEP information flow were refined and confirmed. Each included FEP was documented in the appropriate supporting technical AMRs. The documentation in each supporting technical AMR consisted of a "Table of Included FEPs Addressed in This Report". The Table contained three columns: FEP Number, FEP Name, and Section(s) in This Report Where the FEP is Addressed. In some cases where a FEP was implicitly included in an AMR on the upper end of document path, the "Section(s) in This Report Where the FEP is Addressed" might make reference to a "lower" AMR in the path where the FEP was explicitly addressed. The FEP Team reviewed (as per LP-2.14Q-BSC, Document Review or its predecessor, AP-2.14Q, Document Review) the documentation and traceability of the included FEPs in the supporting technical AMRs for technical adequacy and coordinated the screening decisions to ensure consistency. This documentation and review cycle was repeated twice, once for interim screening and once for final screening. The interim screening cycle resulted in a set of interim supporting technical AMRs and FEP AMRs, which were subsequently updated and revised during the final screening cycle.

The final set of 10 FEP AMRs, listed in Table 2-7, was prepared in accordance with LP-SIII.9QBSC, Scientific Analyses or its predecessor, AP-SIII.9Q, Scientific Analyses. Documentation in the final FEP AMRs addressed both included and excluded FEPs. For included FEPs, a TSPA disposition was presented that consolidated the included FEP information from the final supporting technical AMRs into a single discussion that described the implementation of the FEP in TSPA-LA (i.e., how the FEP was included). For excluded FEPs, a screening argument was presented that provided a defensible technical basis for exclusion of the FEP in accordance with the screening criteria listed in Section 4.1 (i.e., why the FEP was excluded). While the excluded FEPs were not explicitly documented (i.e., there was no listing of FEP names and numbers for excluded FEPs) in the supporting technical AMRs, in some cases, all or part of the technical basis for exclusion was described therein in general terms. In these cases, the screening argument referenced the supporting technical AMR. In other cases, the screening argument referenced other documents. Guidelines for the FEP screening and the content of the TSPA dispositions and screening arguments are presented in Section 4.2.2. The FEP Team reviewed (as per LP-2.14Q-BSC, Document Review or its predecessor, AP-2.14Q, Document Review) the documentation and traceability of the included and excluded FEPs in the FEP AMRs for technical adequacy and coordinated the screening decisions to ensure consistency.

An electronic database was created to provide a navigational tool for searching and reviewing the FEP identification information (e.g., FEP names, numbers, and descriptions) and FEP screening information (screening decisions, screening arguments, and TSPA dispositions). The database was created by importing the information (i.e., text) directly from the final set of 10 FEP AMRs into a data file (DTN: MO0508SEPFEPLA.002 [DIRS 175064]) in accordance with the procedures outlined in the TWP (BSC 2005 [DIRS 174883], Section 8.4). Additional details about the electronic database are presented in Section 6.

The database provides a platform to view the FEP identification and screening information (i.e., data set DTN: MO0508SEPFEPLA.002 [DIRS 175064]), however, all of the information 
was developed external to the database. In particular, the technical defensibility of the screening information is provided by the final FEP AMRs, not by the database. Hyperlinks from the database to the FEP AMRs are provided for each FEP.

\subsubsection{Guidelines for FEP Screening}

To satisfy the FEP exclusion screening criteria (low probability, low consequence, or by-regulation) identified in Section 4.1, and to satisfy Scenario Analysis Acceptance Criteria 1 and 2 outlined in Yucca Mountain Review Plan, Final Report (NRC 2003 [DIRS 163274], Section 2.2.1.2.1.3), guidelines were established to ensure that the scope, defensibility, and traceability of the technical bases for screening were consistent and complete. These guidelines apply to the documentation of the FEP screening, specifically the supporting technical AMRs, and the FEP AMRs (see Section 4.2.1).

The scope of each FEP is assigned through the FEP identification process and is defined collectively by the FEP name, FEP description, keywords, and relevant source FEPs (see Section 3.2.1). The screening of each FEP must fully address all of the scope represented by the FEP name and FEP description. In addition, the screening for each FEP must address any scope explicitly identified in the keywords and the relevant source FEPs that is not captured in the FEP name or FEP description. This is especially important for broadly-scoped FEPs. In the engineered system these broadly-scoped FEPs are typically defined as "process affects EBS components". Unless the FEP name or description explicitly limits the affected EBS components, the screening for this type of EBS FEPs explicitly addresses all of the relevant EBS components (i.e., all of the Level 3 Engineered System elements in Table 3-2). Similarly, in the natural system, the screening explicitly addresses all of the relevant Level 3 Natural System elements in Table 3-2 unless the FEP name or description explicitly limits the scope.

The defensibility of the FEPs is produced through the FEP screening process (see Sections 4.2 and 4.2.1) and is provided in the screening decision, screening argument (for excluded FEPs), and TSPA disposition (for included FEPs) as documented in the FEP AMRs.

The information flow of the included FEPs through the set of supporting technical AMRs (see Section 4.2.1) is documented in each FEP AMR under a "field" called "Supporting Reports". For each included FEP, all of the supporting technical AMRs that list the FEP in the "Table of Included FEPs Addressed in This Report" are listed as "Supporting Reports".

Specific guidelines for each of these "fields" are outlined below. All of these guidelines were considered in the preparation of the FEP AMRs, whereas only FEP number and FEP name were applicable to the supporting technical AMRs.

FEP Number-Must have the form \#.\#.\#\#.\#\#.0x. The first three groups (\#.\#.\#\#) are numeric and are based on the hierarchical classification levels in the NEA International FEP Database (see Section 3.1) and correspond to NEA Layer, Category, and Heading (Freeze et al. 2001 [DIRS 154365], Section 3.1). The fourth group is also numeric and is simply a sequential indicator. The final group is alphanumeric with the form $.0 \mathrm{~A}, .0 \mathrm{~B}, .0 \mathrm{C}$, etc. The last group of the TSPA-LA FEP number provides some traceability back to the TSPA-SR FEP numbers. For example, TSPA-LA FEPs \#.\#.\#\#.\#\#.0A and \#.\#.\#\#.\#\#.0B both derive from TSPA-SR FEP 
\#.\#.\#\#.\#\#.00. Mapping of TSPA-SR FEP numbers to TSPA-LA FEP numbers is provided in Table "FEPMappingSRtoLA" (see Table 6-2 and Appendix G).

FEP Name-Must be a short identification of the FEP and be relevant to YMP.

FEP Description-Must be relevant to YMP and must encompass a single feature, event or process or a few closely related or coupled processes. Where possible, the description should explicitly capture certain "next finest" related details (see Section 3.2.1) that have been identified in relevant source FEPs. However, as noted in Section 3.2.1, in some cases, the "next finest" details may only be captured through the mapping to relevant source FEPs or by keywords.

Screening Decision-Must state whether the FEP is included or excluded from the TSPA. For excluded FEPs, the exclusion criteria (low probability, low consequence, or by-regulation) must be explicitly identified. For some broadly defined FEPs, the screening decision alone may represent an overly general interpretation of what is included or excluded. In these cases, the screening argument (for excluded FEPs) or TSPA disposition (for included FEPs) provides more specific details of inclusion or exclusion.

Screening Argument (Excluded FEPs Only)-A summary of the technical basis for exclusion must be presented (i.e., why is the FEP excluded from TSPA-LA). The summary should address all aspects of the FEP name, FEP description, keywords, and relevant source FEPs.

Low probability exclusions should include an explicit comparison of the probability of occurrence to the regulatory criteria (see Section 4.1.1). The probability should be quantified where possible, although non-quantitative low-probability arguments are acceptable.

Low consequence exclusions should include an explicit statement, consistent with the regulatory criteria (see Section 4.1.2), that "the magnitude and time of the resulting radiological exposures to the reasonably maximally exposed individual, or radionuclide releases to the accessible environment" would not be "significantly changed" by the omission of the FEP. The basis for this statement should be explained. The change in radiological exposure or radionuclide release should be quantified where possible, and the interpretation of "significant change" should be described (it may be different for each FEP). It is acceptable to quantify the change in an intermediate performance measure (e.g., radionuclide mass release to the saturated zone). However, in that case, the qualitative link to change in exposure or release should be explicitly stated.

By-regulation exclusions should identify a specific regulation and clearly state the rationale for the exclusion. Regulatory exclusions should generally be limited to FEPs associated with the reference biosphere, geologic setting, the characteristics of the reasonably maximally exposed individual (RMEI), or human intrusion, as outlined in Section 4.1.3.

Screening arguments should meet the NRC expectations in Yucca Mountain Review Plan, Final Report (NRC 2003 [DIRS 163274], Section 2.2.1.2.1.3). Note that in the case of shared FEPs, the screening argument in a single FEP AMR may only address part of the FEP. In these cases, the FEP Team reviews ensured that the entire scope of the FEP was addressed collectively by all of the sharing FEP AMRs, and that the sharing FEP AMRs did not contain contradictory screening information. 
TSPA Disposition (Included FEPs Only)-A summary discussion of the treatment of the FEP in the TSPA must be presented (i.e., how is the FEP included in TSPA-LA). The summary should address the implementation of all aspects of the FEP name, FEP description, keywords, and relevant source FEPs. An indication of the implementing model component and/or model abstraction and/or parameter(s) is desirable.

The TSPA disposition in the FEP AMR should be a consolidated summary of, and be consistent with, the relevant information from the "Section(s) in This Report Where FEP is Addressed" from all supporting technical AMRs where the FEP is listed in the "Table of Included FEPs Addressed in This Report". The TSPA disposition should be primarily based on the relevant information from the direct feed AMR, since it is most likely to best describe how the FEP is implemented in TSPA-LA, and be augmented by information from the other supporting technical reports.

Note that in the case of shared FEPs, the TSPA disposition in a single FEP AMR may only address part of the FEP. In these cases, the FEP Team reviews ensured that the entire scope of the FEP was addressed collectively by all of the sharing FEP AMRs, and that the sharing FEP AMRs did not contain contradictory screening information.

Supporting Reports (Included FEPs Only)-Must list all supporting technical AMRs where the FEP was listed in the "Table of Included FEPs Addressed in This Report". This provides the information flow of the Included FEP through the set of supporting technical AMRs (see Section 4.2.1). 


\section{YUCCA MOUNTAIN PROJECT SCENARIO DEVELOPMENT}

The objective of scenario development for TSPA-LA was to define a limited set of scenario classes that could reasonably be analyzed quantitatively while still maintaining comprehensive coverage of the range of possible future states of the repository system. There are an essentially infinite number of possible future states, and for scenario development to be useful, it must generate scenario classes that are representative of the range of futures that are potentially relevant to the licensing of the facility. The term "event class" is defined in 10 CFR 63.102(j) [DIRS 173273] as consisting of "all possible specific initiating events that are caused by a common natural process (e.g., the event class for seismicity includes the range of credible earthquakes for the Yucca Mountain site)". For the purposes of this report, event classes are assumed to be synonymous with scenario classes and the term "event class" is not used.

As described in Section 1, FEP analysis and scenario development for TSPA-LA followed a five-step process. Scenario development comprises Step 3 (scenario class formation) and Step 4 (scenario class screening) of that process. A summary of scenario class formation for TSPA-LA is presented in this section. Specific details about the TSPA-LA scenario classes and about scenario class screening are described in Total System Performance Assessment Model/Analysis for the License Application (BSC 2005 [DIRS 174227], Sections 6, 6.1.1, and 6.1.3).

Scenario classes were formed from the included TSPA-LA FEPs (i.e., those FEPs that were not excluded based on the screening criteria process described in Section 4.2). The scenario classes for TSPA-LA derived from the scenario classes for TSPA-SR, with adjustments made to account for updates in FEP screening decisions. For TSPA-SR there was a nominal scenario class, a disruptive event scenario class, and a human intrusion scenario class (CRWMS M\&O 2000 [DIRS 153246], Section 2.1.2). The TSPA-SR disruptive event scenario class consisted of two igneous modeling cases: igneous intrusion and volcanic eruption. Because only igneous modeling cases were included, it was also referred to as the igneous scenario class.

For TSPA-LA, the scenario classes were updated based on an evaluation of the included TSPA-LA FEPs. All included FEPs were captured in at least one scenario class. The re-evaluation resulted in a nominal scenario class, and two disruptive event scenario classes: igneous and seismic.

The TSPA-LA nominal scenario class contains all included FEPs that are likely to occur after closure (i.e., FEPs that have a probability of occurrence of at least one chance in 10 within 10,000 years of disposal, but that may have uncertain consequences). The nominal scenario class represents the most plausible evolution of the repository system and includes both favorable future conditions and potentially adverse future conditions. The nominal scenario class is addressed by two modeling cases: nominal corrosion failure and nominal early failure.

The disruptive event scenario classes contain combinations of included FEPs that have a low probability of occurrence (but greater than the screening probability criteria of one chance in 10,000 of occurring over 10,000 years) but might produce potentially adverse future conditions (i.e., radiological exposures or radionuclide releases would be significantly changed by their omission). Disruptive event FEPs are typically, but not necessarily, unlikely FEPs (i.e., FEPs that have "less than one chance in 10 and at least one chance in 10,000 of occurring within 
10,000 years of disposal"). The disruptive event scenario classes also contain many of the nominal FEPs and represent low-probability perturbations to the expected evolution of the repository system. As in TSPA-SR, the TSPA-LA igneous scenario class is addressed by two modeling cases: igneous intrusion and volcanic eruption. The TSPA-LA seismic scenario class contains several seismic FEPs that had been excluded from TSPA-SR but were re-evaluated and included for TSPA-LA. It is also addressed by two modeling cases: seismic ground motion and seismic fault displacement.

Throughout the FEP analysis and scenario development process, the potential for a combination (i.e., sequence) of low consequence FEPs to result in a combined significant consequence was considered. A systematic combination of all FEPs excluded by low consequence was not feasible because the number of permutations was simply too high to do it without exercising judgment about the viability of specific combinations. However, the most logical and relevant combinations were formally considered on a case-by-case basis by SMEs and FEP AMR Leads as they reviewed their FEPs and produced their FEP AMRs (see Sections 3.2.3 and 4.2).

The human intrusion scenario class was not evaluated in TSPA-LA because all of the human intrusion FEPs were excluded. Inadvertent human intrusion is not projected to occur before 10,000 years after disposal. This projection is based on a consideration of land-surface drilling using common techniques and practices that are currently employed in exploratory drilling for groundwater in the region around Yucca Mountain. The compressive strength and ductility of the metals from which the drip shields and waste packages are fabricated differ significantly from the rock that would surround them (BSC 2004 [DIRS 170021], Section 6.2.3.2 and Appendix C) and drillers would notice these differences based on changes in the rate of penetration. For example, drill bits that are designed for rock do not easily penetrate titanium and the drilling assembly is expected to meet much greater resistance when the bit attempts to penetrate the titanium drip shield. Analyses predict that the first failures of the drip shield due to general corrosion occur after approximately 35,000 years (BSC 2004 [DIRS 169845], Section 6.10). Therefore, the earliest time a human intrusion would occur without recognition is on the order of 35,000 years.

Furthermore, in accordance with 10 CFR 63.322(g) [DIRS 173273], human intrusion did not consider the effects of unlikely events (i.e., events with an annual-exceedance probability less than $10^{-5}$ ). The mean annual probability of an igneous event intersecting the repository is $1.7 \times 10^{-8}$ (BSC 2004 [DIRS 169989], Table 7-1), which makes it an unlikely event that does not need to be considered in conjunction with human intrusion (BSC 2004 [DIRS 170021], Section 6.2.3.3]. Similarly, seismic events with annual exceedance probabilities of less than $10^{-5}$ are unlikely events and do not need to be considered in conjunction with human intrusion. Drip shield and waste package damage from seismic events with annual exceedance probabilities of $10^{-5}$ or greater (corresponding to peak ground velocities of approximately $1 \mathrm{~m} / \mathrm{s}$ or less (BSC 2005 [DIRS 173247], Figure 6.4-2)) is not significant enough to alter any material properties with respect to the potential for recognition by a driller (BSC 2004 [DIRS 170021], Section 6.2.3.4; BSC 2005 [173247], Sections 6.5, 6.6, and 6.7). Therefore, there is no additional effect with respect to human intrusion screening.

Appendix F lists the included FEPs and identifies the scenario class that contains each included FEP. Further details about the TSPA-LA scenario classes and about scenario class screening are 
described in Total System Performance Assessment Model/Analysis for the License Application (BSC 2005 [DIRS 174227], Sections 6, 6.1.1, and 6.1.3). 


\section{INTENTIONALLY LEFT BLANK}




\section{YUCCA MOUNTAIN PROJECT FEP DATABASE}

The electronic FEP database provides a practical platform for examining the FEP identification and screening information described in Sections 3 and 4. For TSPA-LA, the electronic FEP database consists of two parts:

- Software-Managed in accordance with LP-SI.11Q-BSC, Software Management and qualified in accordance with LP-SI.12Q-BSC, Qualification of Software.

- Data-Developed from the FEP identification and screening process, documented in the FEP AMRs, and tracked using a DTN.

The form of the electronic FEP database has evolved over time, as described in Section 6.1. Specific details of the TSPA-LA FEP database are described in Section 6.2.

\subsection{DEVELOPMENT HISTORY OF THE ELECTRONIC FEP DATABASE}

\subsubsection{Total System Performance Assessment for Site Recommendation}

For TSPA-SR the software (i.e., commercial off-the-shelf Microsoft Access and some limited Visual Basic for Applications code within the Microsoft Access environment that control how the data is organized and presented) and the data (i.e., the various iterations of the FEP list and the associated screening decisions and technical bases) that comprise the electronic database were combined into a single product. Therefore, whenever either the data or the software changed, a new "revision" of the database was produced and documented. The development of the electronic FEP database for TSPA-SR is described in Freeze et al. (2001 [DIRS 154365], Section 5) and is summarized in Table 6-1.

Table 6-1. Development History of YMP FEP Database for TSPA-SR

\begin{tabular}{|c|c|c|c|}
\hline Database Revision & $\begin{array}{l}\text { Number } \\
\text { of FEPs }\end{array}$ & Comments & Reference \\
\hline REV 00C & 310 & $\begin{array}{l}\text { Preliminary TSPA-SR } \\
\text { FEP list developed from } \\
\text { NEA International FEP } \\
\text { Database (SAM } 1997 \\
\text { [DIRS 139333]) and } \\
\text { augmented with } \\
\text { YMP-specific FEPs from } \\
\text { project literature. } \\
\text { Includes feedback from } \\
\text { workshops with SMEs. } \\
\text { Contains FEP list but no } \\
\text { screening. } \\
\text { [FileMaker Pro 4.1] } \\
\text { [MS Access 97] }\end{array}$ & $\begin{array}{l}\text { Freeze et al. } 2001 \\
\text { [DIRS 154365], } \\
\text { Section 5.3 } \\
\text { CRWMS M\&O } 1999 \\
\text { [DIRS 142970] }\end{array}$ \\
\hline
\end{tabular}


Table 6-1. Development History of YMP FEP Database for TSPA-SR (Continued)

\begin{tabular}{|c|c|c|c|}
\hline Database Revision & $\begin{array}{l}\text { Number } \\
\text { of FEPs }\end{array}$ & Comments & Reference \\
\hline REV 00 ICN 00 & 323 & $\begin{array}{l}\text { Interim TSPA-SR FEP } \\
\text { list, updated to consider } \\
\text { preliminary SME and } \\
\text { NRC reviews. Contains } \\
\text { FEP list and screening } \\
\text { based on first iteration } \\
\text { of TSPA-SR FEP AMRs } \\
\text { and TSPA-SR model. } \\
\text { [FileMaker Pro 4.1] } \\
\text { [MS Access 97] }\end{array}$ & $\begin{array}{l}\text { Freeze et al. } 2001 \\
\text { [DIRS 154365], } \\
\text { Section 5.4 } \\
\text { CRWMS M\&O } 2000 \\
\text { [DIRS 150806], } \\
\text { Appendix B } \\
\text { CRWMS M\&O } 2000 \\
\text { [DIRS 153246], } \\
\text { Appendix B }\end{array}$ \\
\hline $\begin{array}{l}\text { REV } 00 \text { ICN } 01 \\
\text { FEPs Database Version } 00 \\
\text { [STN: } 10418-00-00 \text { ] }\end{array}$ & 328 & $\begin{array}{l}\text { Revised interim } \\
\text { TSPA-SR FEP list, } \\
\text { updated to consider } \\
\text { additional SME and } \\
\text { NRC reviews. Also } \\
\text { addresses conditions } \\
\text { identified by DOE } \\
\text { (Horton } 2000 \\
\text { [DIRS 153941]). } \\
\text { Contains FEP list and } \\
\text { screening based on final } \\
\text { iteration of TSPA-SR } \\
\text { FEP AMRs (one in draft } \\
\text { form) and TSPA-SR } \\
\text { model. } \\
\text { [MS Access 97] }\end{array}$ & $\begin{array}{l}\text { Freeze et al. } 2001 \\
\text { [DIRS 154365], } \\
\text { Section 5.5 } \\
\text { Freeze et al. 2001 } \\
\text { [DIRS 154365], } \\
\text { Appendix B } \\
\text { CRWMS M\&O } 2001 \\
\text { [DIRS 153943] }\end{array}$ \\
\hline $\begin{array}{l}\text { REV } 00 \text { ICN } 02 \\
\text { FEPs Database Software Program } \\
\text { Version } 0.2 \\
\text { [STN: } 10418-.2-00]\end{array}$ & 328 & $\begin{array}{l}\text { Final TSPA-SR FEP list, } \\
\text { updated to contain final } \\
\text { (non draft) versions of } \\
\text { all FEP AMRs. } \\
\text { [MS Access 97] } \\
\text { [MS Access 2000] }\end{array}$ & $\begin{array}{l}\text { BSC 2002* } \\
\text { [DIRS 159684] }\end{array}$ \\
\hline
\end{tabular}

* FEPs Database Software Program Version 0.2 [STN: 10418-.2-00] contains the qualified data used as initial input for TSPA-LA FEP analysis (see Section 3). This software and the associated data were qualified at the time they were used.

\subsubsection{Total System Performance Assessment-License Application}

For TSPA-LA, the software (Microsoft Access and the associated Visual Basic for Applications code) was separated from the data. While Microsoft Access typically provides code and data in the same database file, this arrangement did not lend itself to the needs of the FEPs task. Two specific drivers for the separation were:

1. There are different quality assurance/configuration control systems in the Yucca Mountain Project for software and data. The process to qualify software does not address the accuracy of the data and the process to qualify data does not test the operational capabilities of the software. Different procedures apply to each. Neither system, by itself, could procedurally label both the software and data as qualified.

2. The software and the data undergo revisions at different rates. During the entire TSPA-LA FEP analysis process (January 2003 to August 2005), there were only three versions of the software produced (see Section 6.1.2.1). However, in response to new 
analyses, iterative reviews, and other information, the data was updated numerous times (see Section 3.2.3 and Appendix C).

The development of the software and the data for TSPA-LA FEPs are described separately in the following subsections.

\subsubsection{TSPA-LA FEP Software}

The final TSPA-SR FEP database (FEPS Database Software Program, Version 0.2 (BSC 2002 [DIRS 159684]) consisted of two parallel database files (software and data combined): one for installation on workstations running Microsoft Access 97 and one for installation on workstations running Microsoft Access 2000. This was required because, with the migration to Access 2000, Microsoft chose the ActiveX Data Object (ADO) model as the default data object model. So, it was necessary, in the Access 2000 versions, to force the system to create data objects using the Data Access Object (DAO) model. The TSPA-LA FEP database software built upon the software portion of FEPS Database Software Program, Version 0.2 (BSC 2002 [DIRS 159684]), with significant changes and enhancements, and was fully migrated to Access 2000 (with no backward compatibility to operate under Access 97). Three versions of the FEPs database software program were produced for TSPA-LA, Version 1.0 (initial), Version 1.1 (interim), and Version 1.2 (final).

\subsection{FEPs Database Software Program Version 1.0}

FEPS Database Software Program, Version 1.0 (STN: 10418-1.0-00 [DIRS 165502]) was a | significant departure from Version 0.2 (BSC 2002 [DIRS 159684]). Revisions included:

- The data structure was normalized to provide more efficient database operation.

- The graphical user interface was completely redesigned to give users a more intuitive approach to navigating the data as well as providing numerous options for navigation.

- Archaic operations left over from previous versions were updated.

- The entire database was converted to Microsoft Access 2000.

The Version 1.0 program initiates, as it did in Version 0.2 , with a splash screen. Due to the separation of the data from the software, the Version 1.0 splash screen displays the identifying information (e.g., the DTN) about the data. This feature gives the user a way of determining whether or not the data is current with that stored in the TDMS. However, after dismissing the splash screen, the interface is completely different from Version 0.2.

The primary navigation tool is the FEP matrix (see Section 3.1.2), a two-dimensional grid showing the physical system (elements and features) on one axis and the process system (processes and events) on the other axis. TSPA-LA FEPs exist at each matrix intersection (or box) and the default user screen displays the matrix and an overall count of the total numbers of included and excluded FEPs in the data set. The default user screen also shows the number of included and excluded FEPs that are "associated" with each matrix box. For traceability, some FEPs are mapped to more than one matrix box (see Section 3.1.2). Therefore, the total numbers 
of FEPs summed across all of individual matrix boxes exceeds the overall count. Clicking on a specific matrix box displays a list of those TSPA-LA FEPs associated with that matrix box. Using menu bar commands or a shortcut menu, the user can then display identification and screening information about a selected FEP; the supporting technical AMR(s) and FEP AMR(s) where the FEP was documented; keywords associated with the FEP; and the source FEPs that are addressed by the TSPA-LA FEP. The user can also access hyperlinks to the FEP AMR text itself.

Other views allow the user to display a list of TSPA-LA FEPs ordered by FEP number, to display mappings of TSPA-LA FEPs to historical TSPA-SR FEPs, and to view historical TSPA-SR FEPs in a hierarchical directory tree that can be expanded or contracted with a mouse click.

Tools are provided for the user to search for groups of TSPA-LA FEPs associated with specified keywords, selected from a pull-down menu, and to search for specified words or phrases throughout the TSPA-LA FEPs, source FEPs, and historical TSPA-SR FEPs. These searching capabilities assist the user in finding specific FEPs or groups of related FEPs, and in finding specific finer details of FEPs (see Section 3.2.1). Other searching features available in Version 0.2 (e.g., filtering, sorting, and hyperlinks to FEP AMR text) have been preserved in Version 1.0. Version 1.0 also contains embedded help files to display user guidance, information about the database, and regulatory and other documents useful to a user of the database. The help files were created with the Microsoft Help Workshop and the Microsoft HTML Help Workshop.

This version of the database was fully qualified as Level B software in accordance with AP-SI.1Q, Software Management.

\subsection{FePs Database Software Program Version 1.1}

FEPs Database Software Program, Version 1.1 (STN: 10418-1.1-00 [DIRS 172366]) was | developed to add some additional software enhancements and to address comments from beta users of Version 1.0.

Version 1.1 includes a general rearrangement of the menu bars and shortcut menus. It also incorporates provisions to allow FEPs to reside in multiple matrix boxes and a menu command to display all of the boxes in which a FEP resides. This version also provides a capability to generate printed reports in Microsoft Word.

This version of the FEPs database was a formal deliverable to DOE (PAD201) and helped to satisfy KTI Agreement TSPAI 2.07. An interim version of the database was demonstrated and provided to a DOE technical staff member on May 19, 2004 in partial fulfillment of PAD201. Minor enhancements mentioned during that demonstration and subsequent DOE evaluations were also incorporated in Version 1.1.

This version of the database software program was managed in accordance with LP-SI.11Q-BSC, Software Management, and qualified in accordance with LP-SI.12Q-BSC, Qualification of Software. 


\subsection{FEPs Database Software Program Version 1.2}

FEPs Database Software Program, Version 1.2 (STN: 10418-1.2-00 [DIRS 175078]) was developed to add further enhancements to the database software from Version 1.1. Specific enhancements included (a) adding a hyperlink to a version of this report, (b) updating the help files, and (c) improving the useability and navigation in response to user comments associated with Version 1.1.

This version of the FEPs database further helps to satisfy KTI Agreement TSPAI 2.07. This version of the database software program is managed in accordance with LP-SI.11Q-BSC, Software Management, and qualified in accordance with LP-SI.12Q-BSC, Qualification of Software.

\subsubsection{TSPA-LA FEP Data}

This section deals specifically with the technical details regarding the development of the FEP data. The content and source of the data (i.e., the FEP identification and screening information) is discussed in Sections 3.2.3 and 4.2.2.

As noted in Section 6.1.2, the FEP software and the FEP data were separated for TSPA-LA. The software, governed by LP-SI.11Q-BSC, Software Management and LP-SI.12Q-BSC, Qualification of Software (which are successors to AP-SI.1Q, Software Management), was managed through software configuration management, as described in Section 6.1.2.1.

The FEP data, however, required a different configuration management system whereby software users could (a) obtain a controlled copy of the data, and (b) determine whether they were using the most current version of the data. These objectives were accomplished by submitting the FEP data to the TDMS where it was entered into the Site and Engineering Properties (SEP) database.

Submittal of data to the SEP database required the completion of a Technical Data Information Form (TDIF), which generated a Data Tracking Number (DTN). Separate DTNs were used to specifically and uniquely identify each iterative revision of the FEP data. The DTNs represent compressed (WinZip) files containing multiple Tables (primarily Microsoft Access) that are available by downloading from the SEP database. Specific contents of the Tables are described in Table 6-2 and Appendix G.

As described in Section 3.2.3, there were nine FEP data sets submitted to the SEP database:

- DTN: MO0301SEPFEPS1.000 [DIRS 161496]

- DTN: MO0303SEPFEPS2.000 [DIRS 162452]

- DTN: MO0306SEPFEPS3.000 [DIRS 163746]

- DTN: MO0307SEPFEPS4.000 [DIRS 164527]

- DTN: MO0312SEPFEPS5.000 [DIRS 167431]

- DTN: MO0405SEPFEPS6.000 [DIRS 169612]

- DTN: MO0407SEPFEPLA.000 [DIRS 170760]

- DTN: MO0501SEPFEPLA.001 [DIRS 172601] 
- DTN: MO0508SEPFEPLA.002 [DIRS 175064].

Data sets DTN: MO0301SEPFEPS1.000 [DIRS 161496] through DTN: MO0312SEPFEPS5.000 [DIRS 167431], though sequential, were maintained concurrently in the SEP. These 5 data sets tracked the preliminary development of the FEP list (see Section 3.2.3) but did not contain any screening information. For DTN: MO0405SEPFEPS6.000 [DIRS 169612], the FEP list was updated and interim screening information (screening decisions, screening arguments, TSPA dispositions) was added from interim versions of the 10 FEP AMRs (see Section 4.2.1). The creation of DTN: MO0405SEPFEPS6.000 [DIRS 169612] superseded all of the earlier data sets.

DTN: MO0407SEPFEPLA.000 [DIRS 170760] was a qualified version of the interim TSPA-LA FEP list. It contained the same interim FEP list and screening results as, and superseded, DTN: MO0405SEPFEPS6.000 [DIRS 169612]. DTN: MO0407SEPFEPLA.000 [DIRS 170760] was created under a qualified TWP (BSC 2004 [DIRS 168024]) and was subject to the requirements of AP-SV.1Q, Control of the Electronic Management of Information (as outlined in Section 8.4 of the TWP). Further, it was reviewed and qualified in accordance with AP-SIII.3Q, Submittal and Incorporation of Data to the Technical Data Management System.

DTN: MO0501SEPFEPLA.001 [DIRS 172601] contained revised screening information (decisions, screening arguments, TSPA dispositions) from revised versions of the 10 FEP AMRs (see BSC 2005 [DIRS 168706], Table 2-7). DTN: MO0501SEPFEPLA.001 [DIRS 172601] was also created under a qualified TWP (BSC 2004 [DIRS 168024]), was also subject to the requirements in AP-SV.1Q, Control of the Electronic Management of Information (as outlined in Section 8.4 of the TWP), and was also reviewed and qualified in accordance with AP-SIII.3Q, Submittal and Incorporation of Data to the Technical Data Management System.

The final TSPA-LA FEP list (DTN: MO0508SEPFEPLA.002 [DIRS 175064]) contained final screening information (decisions, screening arguments, TSPA dispositions) from final versions of the 10 FEP AMRs (see Table 2-7 and Section 4.2.1). DTN: MO0508SEPFEPLA.002 [DIRS 175064] was created under a qualified TWP (BSC 2005 [DIRS 174883]), was subject to the requirements in LP-SV.1Q-BSC, Control of the Electronic Management of Information (the successor to AP-SV.1Q, Control of the Electronic Management of Information outlined in Section 8.4 of the TWP), and was reviewed and qualified in accordance with AP-SIII.3Q, Submittal and Incorporation of Data to the Technical Data Management System.

\subsection{STRUCTURE OF THE TSPA-LA FEP DATABASE}

The TSPA-LA FEP database consists of two files: a software file (FEPs.mde) and a data file (FEPs_be.mdb). The compiled software file contains Microsoft Access and the associated Visual Basic for Applications code used to control the database capabilities. The data file consists of 21 separate tables, which collectively comprise DTN: MO0508SEPFEPLA.002 [DIRS 175064]. The 21 database tables are summarized in Table 6-2. Details of the content of the database tables are presented in Appendix G.

The table "FEPS" contains the majority of the data relating to the 375 TSPA-LA FEPs (e.g., the FEP identification and screening documented in the 10 final FEP AMRs and tracked by DTN: MO0508SEPFEPLA.002 [DIRS 175064]. The other 20 tables contain information to 
more fully describe the TSPA-LA FEPs, to provide supporting and traceability information about the TSPA-LA FEPs, and to provide information about keywords, source FEPs and TSPA-SR FEPs. The division of information into separate tables results in faster searches and sorts.

Table 6-2. TSPA-LA FEP Database Tables

\begin{tabular}{|c|c|}
\hline Database Table Name & Content \\
\hline AMRtoAMRTitle & $\begin{array}{l}\text { Information about supporting technical AMRs and FEP } \\
\text { AMRs }\end{array}$ \\
\hline Buttons & $\begin{array}{l}\text { FEP AMR buttons on the FEP detail form. Used for } \\
\text { enabling and disabling the hyperlink buttons on the FEP } \\
\text { detail form. }\end{array}$ \\
\hline Columns & Column numbers and names for the FEPs matrix form \\
\hline Deleted FEP Info & $\begin{array}{l}\text { TSPA-SR FEPs that were deleted for TSPA-LA. Note that } \\
\text { no scope was eliminated; however, reclassification of FEPs } \\
\text { caused some FEPs to be "deleted" (see Section 3.2). }\end{array}$ \\
\hline FEP History File & $\begin{array}{l}\text { Changes made to the FEP data since the preliminary } \\
\text { TSPA-LA FEP list }\end{array}$ \\
\hline FEPMappingNEAtoLA & $\begin{array}{l}\text { Mapping between source FEP numbers (NEA and } \\
\text { YMP-specific source identifiers are listed in Table G-1) and } \\
\text { TSPA-LA FEP numbers }\end{array}$ \\
\hline FEPMappingSRtoLA & $\begin{array}{l}\text { Mapping between TSPA-SR FEP numbers and TSPA-LA } \\
\text { FEP numbers }\end{array}$ \\
\hline FEPS & $\begin{array}{l}\text { Final TSPA-LA FEP identification and screening information. } \\
\text { Also identifies home FEP matrix rows and columns. }\end{array}$ \\
\hline FEPS_REV00_ICN02 & $\begin{array}{l}\text { TSPA-SR FEP identification and screening information from } \\
\text { Version } 0.2 \text { (BSC } 2002 \text { [DIRS 159684]) }\end{array}$ \\
\hline FEPtoAMR & $\begin{array}{l}\text { Mapping of TSPA-LA FEPs to supporting technical AMRs. } \\
\text { For included FEPs only. For excluded FEPs, it is "N/A" }\end{array}$ \\
\hline Hlinks & $\begin{array}{l}\text { Hyperlinks from TSPA-LA FEP numbers into the FEP AMRs. } \\
\text { The link is the FEP number (with no periods) preceded by a } \\
\text { "b" }\end{array}$ \\
\hline KeywordsSource & Mapping of keywords to TSPA-LA FEPs \\
\hline MatrixSecondaries & $\begin{array}{l}\text { Mapping of TSPA-LA FEPs to additional matrix rows and } \\
\text { columns. It is appended to the "FEPS" table to build the } \\
\text { FEP matrix. Note that the home matrix rows and columns } \\
\text { are identified within the "FEPs" table. }\end{array}$ \\
\hline Potential FEP Log & $\begin{array}{l}\text { Tracking information and documentation of resolution of } \\
\text { potential FEPs (see Section 3.2.4). }\end{array}$ \\
\hline ReportTable & $\begin{array}{l}\text { Temporary table used to store the FEPs selected for a detail } \\
\text { report. }\end{array}$ \\
\hline Rev Data & Revision identifier (e.g., DTN) of the data file \\
\hline Rows & Row numbers and names for the FEPs matrix form \\
\hline Source FEP Categories & $\begin{array}{l}\text { Identifiers for specific categories of source (NEA and } \\
\text { YMP-specific) FEPs. See Table G-1. }\end{array}$ \\
\hline SourceFEPs & $\begin{array}{l}\text { Source (NEA and other) FEP identification information, in } \\
\text { part from OECD ( } 2000 \text { [DIRS 152952], Appendix D) and in } \\
\text { part from YMP-specific literature, reviews, and analyses. }\end{array}$ \\
\hline SRFEPTree & $\begin{array}{l}\text { Hierarchical relationships between TSPA-SR FEPs. Used to } \\
\text { build the SR FEPs Tree }\end{array}$ \\
\hline SUBColumns & Sub-column numbers and names for the FEP matrix form \\
\hline
\end{tabular}




\section{INTENTIONALLY LEFT BLANK}




\section{SUMMARY}

This report documents the following:

- A general overview of approaches and considerations to FEP analysis and scenario development (Section 2)

- The origin and development of a comprehensive list of FEPs to support TSPA-LA (Section 3)

- The methodology and guidance applied to screen the FEPs for inclusion in or exclusion from the TSPA-LA analysis (Section 4)

- Considerations in the development of scenario classes from included FEPs for TSPA-LA analysis (Section 5), and

- The development, structure, and use of an electronic database for storing and retrieving information about the inclusion and/or exclusion of TSPA-LA FEPs (Section 6).

The identification and screening of a comprehensive list of FEPs potentially relevant to the postclosure performance of the Yucca Mountain repository was an iterative process based on site-specific information, design, and regulations. The iterative process was initiated to support TSPA-SR and continued through TSPA-LA FEP analysis.

As described in Section 2.4.1, FEP identification made use of all four of the most commonly applied methods. FEP identification also made use of continuous iterative reviews of the FEP list by subject matter experts (see Section 3.2.3) and formal configuration management of potential new FEPs (see Section 3.2.4). FEP classification made use of multiple classification schemes (see Section 2.4.1) within the NEA bottom-up and FEP matrix top-down approaches (see Section 3.1). The FEP matrix classification scheme employed for TSPA-LA provides a top-down review of the comprehensiveness of the TSPA-LA FEP list. The consistency of this hierarchical classification scheme with other project literature also enhances the transparency and traceability of the underlying FEPs and aids in navigation within the database.

Level-of-detail criteria, identified in Section 3.2.1, defined bounds for the level-of-detail for TSPA-LA FEPs. More detailed FEPs were required in areas where more complex processes, and hence more detailed analyses, predominated (e.g., important subsystems or subsystem features that are controlled by complex processes). However, because it is consistent with risk-informed model considerations which focus the performance assessment on FEPs "that most affect compliance with the overall performance objective" (NRC 2003 [DIRS 163274], Sections 2.2.1 and 2.2.1.2.1.1), this varying level of detail among FEPs, within the preestablished bounds, is considered appropriate.

As noted in Section 2.3.2, "the level of detail of a FEP list should be guided by grouping/lumping such that the final list contains on the order of a few hundred FEPs. The level of detail should also be guided by the complexity required for modeling or screening." The implementation of the level-of-detail criteria, augmented by the use of keywords and mapping to 
source FEPs to capture explicit finer details (see Section 3.2.1) resulted in a reasonable number of FEPs that explicitly identified important issues yet minimized redundant screening arguments.

FEP screening was performed in accordance with final regulations in 10 CFR Part 63 [DIRS 173273], as identified in Section 4.1. FEP screening was documented (see Section 4.2.1) in accordance with general guidelines regarding content (see Section 4.2.2) to ensure that the technical basis for inclusion or exclusion was consistent with the regulations and technically defensible. The technical bases for screening were strengthened by multiple reviews and consistency checks (see Section 4.2).

The final results of FEP identification and screening were documented in a set of ten FEP AMRs, listed in Table 2-7. These final results were used to populate the final TSPA-LA FEP list (DTN: MO0508SEPFEPLA.002 [DIRS 175064]) and electronic database, containing 375 FEPs with screening decisions (included or excluded), screening arguments (for excluded FEPs) and TSPA dispositions (for included FEPs). Of the 375 total FEPs, 149 were included in TSPA-LA and 226 were excluded from TSPA-LA.

The TSPA-LA FEP documents and the FEPs database aid in transparency and traceability of the FEPs by providing:

- Documentation of FEP origins, classification, and screening methodology

- A data set that contains FEP identification, screening, and tracking (i.e., FEP AMRs and supporting technical AMRs) information

- A FEP matrix hierarchical classification structure that is consistent with other project literature

- A database user interface, based on the FEP matrix, which provides multiple ways to find and group FEPs

- Hyperlinks from the database to FEP AMRs and to this report

This transparency and traceability should serve as a FEP communication tool to assist reviewers during the License Application (LA) process.

Section 7.1 describes how this report and the associated database support resolution of KTI Agreement TSPAI 2.07. Section 7.2 summarizes how the TSPA-LA FEP analysis and scenario development process addresses the relevant Scenario Analysis Acceptance Criteria outlined in Yucca Mountain Review Plan, Final Report (NRC 2003 [DIRS 163274], Section 2.2.1.2.1.3). 


\subsection{RESOLUTION OF KEY TECHNICAL ISSUE AGREEMENT TSPAI 2.07}

KTI Agreement TSPAI 2.07 (see Table 3-1) requested that DOE provide the results of the implementation of the enhanced FEP plan (BSC 2002 [DIRS 158966]) in updates to the FEP documents and FEP database. The FEP AMRs have been updated as listed in Table 2-7. This report documents the implementation of FEP analysis for TSPA-LA, including the development of the data and software that comprise the FEP database.

\subsection{RELEVANT YUCCA MOUNTAIN REVIEW PLAN ACCEPTANCE CRITERIA}

The relevant NRC acceptance criteria are Scenario Analysis Acceptance Criteria 1 through 3, as outlined in Yucca Mountain Review Plan, Final Report (NRC 2003 [DIRS 163274], Section 2.2.1.2.1.3). Each of these three criteria is discussed individually in the remainder of this subsection.

Scenario Analysis Acceptance Criteria 1 and 2 (NRC 2003 [DIRS 163274], Section 2.2.1.2.1.3) are fully addressed in this report. Scenario Analysis Acceptance Criteria 3 (NRC 2003 [DIRS 163274], Section 2.2.1.2.1.3) is partly addressed in this report. However, the details of the TSPA-LA scenario class formation and screening are beyond the scope of this report. They are described in more detail in Total System Performance Assessment Model/Analysis for the License Application (BSC 2005 [DIRS 174227], Sections 6, 6.1.1, and 6.1.3).

\section{Acceptance Criterion 1: The Identification of a List of Features, Events, and Processes Is Adequate}

1. The Safety Analysis Report contains a complete list of features, events, and processes, related to the geologic setting or the degradation, deterioration, or alteration of engineered barriers (including those processes that would affect the performance of natural barriers), that have the potential to influence repository performance. The list is consistent with the site characterization data. Moreover, the comprehensive features, events, and processes list includes, but is not limited to, potentially disruptive events related to igneous activity (extrusive and intrusive); seismic shaking (high-frequency-low magnitude, and rare large-magnitude events); tectonic evolution (slip on existing faults and formation of new faults); climatic change (change to pluvial conditions); and criticality.

\section{How Addressed}

The FEP list was initially developed from, and, therefore, contains, the following (Freeze et al. 2001 [DIRS 154365], Section 2):

- A comprehensive set of general issues from radioactive waste disposal programs in several other countries. As noted in Yucca Mountain Review Plan, Final Report (NRC 2003 [DIRS 163274], Section 2.2.1.2.1.2, Review Method 1), "available generic lists of features, events, and processes" may be used "as a reference to determine the completeness" of the FEP list. The TSPA-LA FEP list derives specifically from a comprehensive list of FEPs from other radioactive waste disposal programs (NEA International FEP Database, Version 1.0 (Safety Assessment Management (SAM) 1997 
[DIRS 139333]) and Version 1.1 (OECD 2000 [DIRS 152952], Appendix D)). The NEA International FEP Database represents the best available compilation of generic FEPs.

- A set of YMP-specific issues, developed from documents that identify issues unique to the YMP design and setting (unsaturated fractured tuff). These documents include project literature addressing site characterization, igneous, seismic, and tectonic activity, climate change, and criticality.

The completeness of the initial FEP list was augmented with multiple iterative FEP identification, classification, screening, and review cycles (see Section 3). As noted in Section 2.3.1, "Comprehensiveness of a FEP list cannot be proven with absolute certainty. However, confidence can be gained through a combination of formal and systematic reviews (both top-down and bottom-up), audits, and comparisons with other FEP lists and through the application of more than one classification scheme." The development of the TSPA-LA FEP list combined the use of all four of the most common FEP identification methods and multiple classification schemes to increase confidence in the comprehensiveness of the TSPA-LA FEP list. Audits against an alternate independent YMP FEP list (see Appendix B and BSC 2005 [DIRS 168706], Appendix B) and against recently published international FEP lists were also performed, and no new FEPs were identified.

Continual reviews by SMEs, FEP AMR Leads, the FEP Team, external reviewers, and others further augmented completeness. As the FEP list evolved, fewer new potential FEPs were identified during each successive review cycle (see Appendix $\mathrm{C}$ and Freeze et al. 2001 [DIRS 154365], Section 2). Over time, the nature of those potential FEPs also changed, so that they were predominantly variants or finer details of existing FEPs, rather than new unique issues.

Finally, the use of the FEP matrix classification (see Section 3.1.2) provides a graphical indication of areas for FEP coverage and the mapping of source FEPs to TSPA-LA FEPs ensures that all original NEA and YMP issues are addressed.

\section{Acceptance Criterion 2: Screening of the List of Features, Events, and Processes Is Appropriate}

1. The U.S. Department of Energy has identified all features, events, and processes related to either the geologic setting or to the degradation, deterioration, or alteration of engineered barriers (including those processes that would affect the performance of natural barriers) that have been excluded;

2. The U.S. Department of Energy has provided justification for those features, events, and processes that have been excluded. An acceptable justification for excluding features, events, and processes is that either the feature, event, and process is specifically excluded by regulation; probability of the feature, event, and process (generally an event) falls below the regulatory criterion; or omission of the feature, event, and process does not significantly change the magnitude and time of the resulting radiological exposures to the reasonably maximally exposed individual, or radionuclide releases to the accessible environment; and 
3. The U.S. Department of Energy has provided an adequate technical basis for each feature, event, and process, excluded from the performance assessment, to support the conclusion that either the feature, event, or process is specifically excluded by regulation; the probability of the feature, event, and process falls below the regulatory criterion; or omission of the feature, event, and process does not significantly change the magnitude and time of the resulting radiological exposures to the reasonably maximally exposed individual, or radionuclide releases to the accessible environment.

\section{How Addressed}

As described in Section 4, each FEP was evaluated against regulatory-based screening criteria (Section 4.1) and documented with a screening decision, screening argument (for excluded FEPs), or TSPA disposition (for included FEPs). A FEP that satisfied any one of the exclusion screening criteria (low probability, low consequence, or by regulation) was excluded from TSPA. A FEP that did not satisfy any of the exclusion screening criteria was included in the TSPA-LA model.

The documentation, in a set of FEP AMRs and subsequently in the FEP database, provides justification for the technical basis for inclusion or exclusion for each FEP. The screening decisions and technical bases consider site-specific information.

\section{Acceptance Criterion 3: Formation of Scenario Classes Using the Reduced Set of Events Is Adequate}

1. Scenario classes are mutually exclusive and complete, clearly documented, and technically acceptable.

\section{How Addressed}

For TSPA-LA there was a nominal scenario class, and two disruptive event scenario classes: igneous and seismic. These scenario classes were formed from the included TSPA-LA FEPs. All included FEPs were captured in at least one scenario class.

The nominal scenario class contains all included FEPs that are likely to occur after closure (i.e., FEPs that have a probability of occurrence near 1.0, but that may have uncertain consequences). The nominal scenario class represents the most plausible evolution of the repository system and includes both favorable future conditions and potentially adverse future conditions. The nominal scenario class is addressed by two modeling cases: nominal corrosion failure and nominal early failure.

The disruptive event scenario classes contain combinations of included FEPs that have a low probability of occurrence (but greater than the screening probability criteria of one chance in 10,000 of occurring over 10,000 years) but might produce potentially adverse future conditions (i.e., radiological exposures or radionuclide releases would be significantly changed by their omission). The disruptive event scenario classes also contain many of the nominal FEPs and represent low-probability perturbations to the expected evolution of the repository system. The igneous scenario class is addressed by two modeling cases: igneous intrusion and volcanic 
eruption. The seismic scenario class is also addressed by two modeling cases: seismic ground motion and seismic fault displacement. 


\section{REFERENCES}

\subsection{DOCUMENTS CITED}

100956 Andersson, J.; Carlsson, T.; Eng, T.; Kautsky, F.; Soderman, E.; and Wingefors, S. 1989. The Joint SKI/SKB Scenario Development Project. Andersson, J., ed. SKB TR-89-35. Stockholm, Sweden: Svensk Kärnbränsleförsörjning A.B. TIC: 208568.

169945 Bailey, L.E.F.; Billington, D.E.; Hickford, G.E.; Kelly, M.; Lever, D.A.; Locke, J.; and Thorne, M.C. 1998. Overview of the FEP Analysis Approach to Model Development. Nirex Science Report S/98/009. Harwell, Oxfordshire, England: United Kingdom Nirex Limited. TIC: 256159.

100310 Barr, G.E.; Borns, D.J.; and Fridrich, C. 1996. Scenarios Constructed for the Effects of the Tectonic Processes on the Potential Nuclear Waste Repository at Yucca Mountain. SAND96-1132. Albuquerque, New Mexico: Sandia National Laboratories. ACC: MOL.19970610.0644.

100311 Barr, G.E.; Dunn, E.; Dockery, H.; Barnard, R.; Valentine, G.; and Crowe, B. 1993. Scenarios Constructed for Basaltic Igneous Activity at Yucca Mountain and Vicinity. SAND91-1653. Albuquerque, New Mexico: Sandia National Laboratories. ACC: NNA.19930811.0013.

100592 Barr, G.E.; Hunter, R.L.; Dunn, E.; and Flint, A. 1995. Scenarios Constructed for Nominal Flow in the Presence of a Repository at Yucca Mountain and Vicinity. SAND92-2186. Albuquerque, New Mexico: Sandia National Laboratories. ACC: MOL.19950202.0001.

169925 Billington, D.E.; Lever, D.A.; and Wisbey, S.J. 1990. "Radiological Assessment of Deep Geological Disposal: Work for UK Nirex Ltd." Proceedings of the Symposium on Safety Assessment of Radioactive Waste Repositories, Paris, 9-13 Octobre 1989. Pages 271-281. Paris, France: Organisation for Economic Co-Operation and Development. TIC: 10193.

159684 BSC (Bechtel SAIC Company) 2002. Software Code: FEPS Database Software Program. V.2. PC. 10418-.2-00.

158966 BSC 2002. The Enhanced Plan for Features, Events, and Processes (FEPs) at Yucca Mountain. TDR-WIS-PA-000005 REV 00. Las Vegas, Nevada: Bechtel SAIC Company. ACC: MOL.20020417.0385.

165502 BSC 2003. Software Code: FEPS Database Software Program. V1.0. PC, Windows 2000. 10418-1.0-00.

166296 BSC 2003. Total System Performance Assessment-License Application Methods and Approach. TDR-WIS-PA-000006 REV 00 ICN 01. Las Vegas, Nevada: Bechtel SAIC Company. ACC: DOC.20031215.0001. 
169989 BSC 2004. Characterize Framework for Igneous Activity at Yucca Mountain, Nevada. ANL-MGR-GS-000001 REV 02. Las Vegas, Nevada: Bechtel SAIC Company. ACC: DOC.20041015.0002.

168030 BSC 2004. Characterize Framework for Seismicity and Structural Deformation at Yucca Mountain, Nevada. ANL-CRW-GS-000003 REV 00 [Errata 001]. Las Vegas, Nevada: Bechtel SAIC Company. ACC: MOL.20000510.0175; DOC.20040223.0007.

170019 BSC 2004. Clad Degradation-FEPs Screening Arguments. ANL-WIS-MD-000008 REV 02. Las Vegas, Nevada: Bechtel SAIC Company. ACC: DOC.20041020.0014.

170021 BSC 2004. Features, Events, and Processes: System Level. ANL-WIS-MD-000019 REV 02. Las Vegas, Nevada: Bechtel SAIC Company. ACC: DOC.20041020.0009.

169845 BSC 2004. General Corrosion and Localized Corrosion of the Drip Shield. ANL-EBS-MD-000004 REV 02. Las Vegas, Nevada: Bechtel SAIC Company. ACC: DOC.20040921.0002.

172439 BSC 2004. Key Technical Issue Letter Report (Response to TSPAI 2.01, 2.02, 2.03, 2.04, and 2.07), Revision 2. Las Vegas, Nevada: Bechtel SAIC Company. ACC: MOL.20040913.0398.

168556 BSC 2004. Screening Analysis for Criticality Features, Events, and Processes for License Application. ANL-EBS-NU-000008 REV 01. Las Vegas, Nevada: Bechtel SAIC Company. ACC: DOC.20041022.0001.

172366 BSC 2004. Software Code: FEPS Database Software Program. V1.1. PC, Windows 2000. 10418-1.1-00.

171888 BSC 2004. Technical Management Review Board (TMRB) Decision Proposal. TMRB-2004-061. [Las Vegas, Nevada: Bechtel SAIC Company].

ACC: MOL.20041022.0150.

168024 BSC 2004. Technical Work Plan for: Decision Support and Documentation Department Activities. TWP-MGR-MD-000028 REV 04. Las Vegas, Nevada: Bechtel SAIC Company. ACC: DOC.20040303.0003.

170020 BSC 2004. Waste-Form Features, Events, and Processes. ANL-WIS-MD-000009 REV 02. Las Vegas, Nevada: Bechtel SAIC Company.

ACC: DOC.20041028.0006.

175014 BSC 2005. Engineered Barrier System Features, Events, and Processes. ANL-WISPA-000002 REV 05. Las Vegas, Nevada: Bechtel SAIC Company. 
174107 BSC 2005. Evaluation of Features, Events, and Processes (FEP) for the Biosphere Model. ANL-MGR-MD-000011 REV 05. Las Vegas, Nevada: Bechtel SAIC Company. ACC: DOC.20050718.0006.

174190 BSC 2005. Features, Events, and Processes in SZ Flow and Transport. ANL-NBSMD-000002 REV 04. Las Vegas, Nevada: Bechtel SAIC Company.

ACC: DOC.20050822.0012.

174191 BSC 2005. Features, Events, and Processes in UZ Flow and Transport. ANL-NBSMD-000001 REV 04. Las Vegas, Nevada: Bechtel SAIC Company. ACC: DOC. 20050809.0002 .

173981 BSC 2005. Features, Events, and Processes: Disruptive Events. ANL-WIS-MD000005 REV 03. Las Vegas, Nevada: Bechtel SAIC Company.

171190 BSC 2005. Q-List. 000-30R-MGR0-00500-000-001. Las Vegas, Nevada: Bechtel SAIC Company. ACC: ENG.20050217.0010.

174995 BSC 2005. Screening of Features, Events, and Processes in Drip Shield and Waste Package Degradation. ANL-EBS-PA-000002 REV 05. Las Vegas, Nevada: Bechtel SAIC Company. ACC: DOC.20050817.0003.

173247 BSC 2005. Seismic Consequence Abstraction. MDL-WIS-PA-000003 REV 02. Las Vegas, Nevada: Bechtel SAIC Company.

175078 BSC 2005. Software Code: FEPS Database Software Program. V1.2. PC, Windows 2000. 10418-1.2-00.

174965 BSC 2005. Technical Management Review Board (TMRB) Decision Proposal. TMRB-2005-047. [Las Vegas, Nevada: Bechtel SAIC Company].

ACC: MOL.20050809.0101.

174989 BSC 2005. Technical Management Review Board (TMRB) Decision Proposal. TMRB-2005-048. Las Vegas, Nevada: Bechtel SAIC Company.

ACC: MOL.20050817.0252.

174990 BSC 2005. Technical Management Review Board (TMRB) Decision Proposal. TMRB-2005-050. Las Vegas, Nevada: Bechtel SAIC Company.

ACC: MOL.20050817.0253.

174991 BSC 2005. Technical Management Review Board (TMRB) Decision Proposal. TMRB-2005-051. Las Vegas, Nevada: Bechtel SAIC Company.

ACC: MOL.20050817.0254.

174883 BSC 2005. Technical Work Plan for Post Closure Activities FEPs Team.

TWP-MGR-MD-000036 REV 00. Las Vegas, Nevada: Bechtel SAIC Company. ACC: DOC.20050504.0004. 
168706 BSC 2005. The Development of the Total System Performance Assessment-License Application Features, Events, and Processes. TDR-WIS-MD-000003 REV 01. Las Vegas, Nevada: Bechtel SAIC Company. ACC: DOC.20050214.0001.

174227 BSC 2005. Total System Performance Assessment Model/Analysis for the License Application. MDL-WIS-PA-000004 REV 01. Las Vegas, Nevada: Bechtel SAIC Company.

168483 Burkholder, H.C. 1980. "Waste Isolation Performance Assessment-A Status Report." Scientific Basis for Nuclear Waste Management, Proceedings of the International Symposium, Boston, Massachusetts, November 27-30, 1979. Northrup, C.J.M., Jr., ed. 2, 689-702. New York, New York: Plenum Press. TIC: 248272.

100970 Chapman, N.A.; Andersson, J.; Robinson, P.; Skagius, K.; Wene, C-O.; Wiborgh, M.; and Wingefors, S. 1995. Systems Analysis, Scenario Construction and Consequence Analysis Definition for SITE-94. SKI Report 95:26. Stockholm, Sweden: Swedish Nuclear Power Inspectorate. TIC: 238888.

101234 Cranwell, R.M.; Guzowski, R.V.; Campbell, J.E.; and Ortiz, N.R. 1990. Risk Methodology for Geologic Disposal of Radioactive Waste, Scenario Selection Procedure. NUREG/CR-1667. Washington, D.C.: U.S. Nuclear Regulatory Commission. ACC: NNA.19900611.0073.

142970 CRWMS M\&O 1999. YMP FEP Database Rev. O0C. Las Vegas, Nevada: CRWMS M\&O. ACC: MOL.19991214.0518; MOL.19991214.0519.

150825 CRWMS M\&O 2000. Engineered Barrier System Features, Events, and Processes, and Degradation Modes Analysis. ANL-EBS-MD-000035 REV 00 ICN 01. Las Vegas, Nevada: CRWMS M\&O. ACC: MOL.20000727.0092.

150806 CRWMS M\&O 2000. The Development of Information Catalogued in REV00 of the YMP FEP Database. TDR-WIS-MD-000003 REV 00. Las Vegas, Nevada: CRWMS M\&O. ACC: MOL.20000705.0098.

153246 CRWMS M\&O 2000. Total System Performance Assessment for the Site Recommendation. TDR-WIS-PA-000001 REV 00 ICN 01. Las Vegas, Nevada: CRWMS M\&O. ACC: MOL.20001220.0045.

153943 CRWMS M\&O 2001. Software Routine: FEPs Database. V00. 10418-00-00.

170075 Dalrymple, G.J.; Johnson, K.B.; and Phillips, L.D. 1986. Final Report on the Acquisition of Data for Use in the Probabilistic Risk Assessment of Underground Disposal of Radioactive Wastes. CAP Reference: 3097/TR/19. London, England: CAP Scientific Limited. TIC: 256238. 
100975 DOE (U.S. Department of Energy) 1996. Title 40 CFR Part 191 Compliance Certification Application for the Waste Isolation Pilot Plant. DOE/CAO-1996-2184. Twenty-one volumes. Carlsbad, New Mexico: U.S. Department of Energy, Carlsbad Area Office. TIC: 240511.

169927 Eng, T.; Hudson, J.; Stephansson, O.; Skagius, K.; and Wiborgh, M. 1994. Scenario Development Methodologies. SKB TR 94-28. Stockholm, Sweden: Svensk Kärnbränsleförsörjning A.B. TIC: 215463.

165394 Freeze, G. 2003. KTI Letter Report, Response to Additional Information Needs on TSPAI 2.05 and TSPAI 2.06. REG-WIS-PA-000003 REV 00 ICN 04. Las Vegas, Nevada: Bechtel SAIC Company. ACC: DOC.20030825.0003.

154365 Freeze, G.A.; Brodsky, N.S.; and Swift, P.N. 2001. The Development of Information Catalogued in REV00 of the YMP FEP Database. TDR-WIS-MD-000003 REV 00 ICN 01. Las Vegas, Nevada: Bechtel SAIC Company. ACC: MOL.20010301.0237.

100983 Goodwin, B.W.; Stephens, M.E.; Davison, C.C.; Johnson, L.H.; and Zach, R. 1994. Scenario Analysis for the Postclosure Assessment of the Canadian Concept for Nuclear Fuel Waste Disposal. AECL-10969. Pinawa, Manitoba, Canada: AECL Research, Whiteshell Laboratories. TIC: 215123.

168518 Hodgkinson, D.P. and Sumerling, T.J. 1990. “A Review of Approaches to Scenario Analysis for Repository Safety Assessment." Proceedings of the Symposium on Safety Assessment of Radioactive Waste Repositories, Paris, 9-13 Octobre 1989. Pages 333-350. Paris, France: Organization for Economic Co-Operation and Development. TIC: 10193.

153941 Horton, D.G. 2000. "Technical Direction: Accepted with Conditions for Deliverable SL981M3, Features, Events, and Processes Database Revision 00, WBS 1.2.21.3, Work Package Identifier 33012132M2 Total System Performance Assessment Model Development, Contract \# DE-AC08-91RW00134, YDAR 25939; TDL No. 00-0015.” Letter from D.G. Horton (DOE/YMSCO) to G.E. Dials (CRWMS M\&O), September 22, 2000. ACC: MOL.20001025.0091.

169926 Hudson, J.A. 1992. Rock Engineering Systems, Theory and Practice. New York, New York: Ellis Horwood. TIC: 8875.

168519 IAEA (International Atomic Energy Agency) 1983. Concepts and Examples of Safety Analyses for Radioactive Waste Repositories in Continental Geological Formations. Safety Series No. 58. Vienna, Austria: International Atomic Energy Agency. TIC: 7450 .

171894 JNC (Japan Nuclear Cycle Development Institute) 1999. "Geological Environment in Japan." The Second Draft, H12 Project for Assessment of the Feasibility of HLW Disposal in Japan. Supporting Report 1. [Tokai], Japan: Japan Nuclear Cycle Development Institute. TIC: 244690. 
169928 Kelly, M. and Billington, D.E. 1998. "Scenario Analysis and Conceptual Model Development, Using FANFARE." Scientific Basis for Nuclear Waste Management XXI, Symposium held September 28-October 3, 1997, Davos, Switzerland. McKinley, I.G. and McCombie, C., eds. 506, 701-708. Warrendale, Pennsylvania: Materials Research Society. TIC: 240702.

168541 Koplik, C.M.; Kaplan, M.F.; and Ross, B. 1982. "The Safety of Repositories for Highly Radioactive Wastes.” Reviews of Modern Physics, 54, (1), 269-310. New York, New York: American Physical Society. TIC: 256361.

171895 Mazurek, M.; Pearson, J.F.; Volckaert, G.; and Bock, H. 2003. Features, Events and Processes Evaluation Catalogue for Argillaceous Media. Paris, France: Organisation for Economic Co-Operation and Development, Nuclear Energy Agency. TIC: 256678.

168544 Merrett, G.J. and Gillespie, P.A. 1983. Nuclear Fuel Waste Disposal: Long-Term Stability Analysis. AECL-6820. Pinawa, Manitoba, Canada: Atomic Energy of Canada Limited. TIC: 227249.

100996 Miller, W.M. and Chapman, N.A. 1993. HMIP Assessment of Nirex Proposals, Identification of Relevant Processes (System Concept Group Report). Technical Report IZ3185-TR1 (Edition 1). [London], United Kingdom: Her Majesty's Inspectorate of Pollution (HMIP), Department of the Environment. TIC: 238458.

173265 Mitchell, J.T., Jr. 2005. "Contract No. DE-AC28-01RW12101 - Response to Contracting Officer Authorization Letter No. 05-001, Improvements and Refinements in the Technical Bases that Support the Safety Analysis Report (SAR)." Letter from J. Mitchell, Jr. (BSC) to B. Hamilton-Ray (DOE/ORD), December 3, 2004, 1203044102, with enclosures. ACC: MOL.20050110.0076.

168537 NAGRA (National Cooperative for the Storage of Radioactive Waste) 1985. Nuclear Waste Management in Switzerland: Feasibility Studies and Safety Analyses. NAGRA NGB 85-09. Baden, Switzerland: National Cooperative for the Disposal of Radioactive Waste. TIC: 256263.

124260 NAGRA (Nationale Genossenschaft fur die Lagerung Radioaktiver Abfalle) 1994. Kristallin-I, Safety Assessment Report. NAGRA Technical Report 93-22. Wettingen, Switzerland: National Cooperative for the Disposal of Radioactive Waste. TIC: 235964.

152309 NEA (Nuclear Energy Agency) 1999. An International Database of Features, Events and Processes. Paris, France: Organisation for Economic Co-operation and Development. TIC: 248820. 
169902 NEA (Nuclear Energy Agency) 1999. Nirex Methodology for Scenario and Conceptual Model Development, an International Peer Review. Paris, France: Organization for Economic Co-Operation and Development, Nuclear Energy Agency. TIC: 256158.

163274 NRC (U.S. Nuclear Regulatory Commission) 2003. Yucca Mountain Review Plan, Final Report. NUREG-1804, Rev. 2. Washington, D.C.: U.S. Nuclear Regulatory Commission, Office of Nuclear Material Safety and Safeguards. TIC: 254568.

100479 Nuclear Energy Agency 1992. Systematic Approaches to Scenario Development: A Report of the NEA Working Group on Identification and Selection of Scenarios for Performance Assessment of Radioactive Waste Disposal. Paris, France: Nuclear Energy Agency, Organisation for Economic Co-operation and Development. TIC: 8083 .

152952 OECD (Organisation for Economic Co-Operation and Development) 2000. Features, Events and Processes (FEPs) for Geologic Disposal of Radioactive Waste: An International Database. Paris, France: Organisation for Economic Co-Operation and Development. TIC: 249037.

158380 Reamer, C.W. 2001. "U.S. Nuclear Regulatory Commission/U.S. Department of Energy Technical Exchange and Management Meeting on Total System Performance Assessment and Integration (August 6 through 10, 2001)." Letter from C.W. Reamer (NRC) to S. Brocoum (DOE/YMSCO), August 23, 2001, with enclosure. ACC: MOL.20011029.0281.

139333 SAM (Safety Assessment Management) [1997]. Safety Assessment of Radioactive Waste Repositories, An International Database of Features, Events and Processes. Unpublished Draft, June 24, 1997. ACC: MOL.19991214.0522.

168532 Stenhouse, M.J.; Chapman, N.A.; and Sumerling, T.J. 1993. Site 94, Scenario Development FEP Audit List Preparation: Methodology and Presentation. SKI Report No.: TR-93:27. Stockholm, Sweden: Swedish Nuclear Power Inspectorate. TIC: 212703.

168548 Thorne, M.C. 1992. Uncertainty and Bias Audit. Volume 8 of Dry Run 3-A Trial Assessment of Underground Disposal of Radioactive Wastes Based on Probabilistic Risk Analysis. DoE/HMIP/RR/92.040. London, England: United Kingdom Department of the Environment.

165505 YMP (Yucca Mountain Site Characterization Project) 2003. Disposal Criticality Analysis Methodology Topical Report. YMP/TR-004Q, Rev. 02. Las Vegas, Nevada: Yucca Mountain Site Characterization Office. ACC: DOC.20031110.0005. 


\subsection{CODES, STANDARDS, REGULATIONS, AND PROCEDURES}

17327310 CFR 63. 2005 Energy: Disposal of High-Level Radioactive Wastes in a Geologic

Repository at Yucca Mountain, Nevada. ACC: MOL.20050405.0118.

155216 66 FR 32074. 40 CFR Part 197, Public Health and Environmental Radiation Protection Standards for Yucca Mountain, NV; Final Rule. Readily available.

15667166 FR 55732. Disposal of High-Level Radioactive Wastes in a Proposed Geologic Repository at Yucca Mountain, NV, Final Rule. 10 CFR Parts 2, 19, 20, 21, 30, 40, 51, 60, 61, 63, 70, 72, 73, and 75. ACC: MOL.20050324.0102;

MOL.20050418.0124.

\subsection{SOURCE DATA, LISTED BY DATA TRACKING NUMBER}

161496 MO0301SEPFEPS1.000. LA FEP List. Submittal date: 01/21/2003.

162452 MO0303SEPFEPS2.000. LA FEP List. Submittal date: 03/26/2003.

163746 MO0306SEPFEPS3.000. LA FEP List. Submittal date: 06/03/2003.

164527 MO0307SEPFEPS4.000. LA FEP List. Submittal date: 07/31/2003.

167431 MO0312SEPFEPS5.000. LA FEP List. Submittal date: 12/01/2003.

169612 MO0405SEPFEPS6.000. LA FEP List. Submittal date: 05/14/2004.

170760 MO0407SEPFEPLA.000. LA FEP List. Submittal date: 07/20/2004.

172601 MO0501SEPFEPLA.001. LA FEP List and Screening. Submittal date: 01/17/2005.

175064 MO0508SEPFEPLA.002. LA FEP List and Screening. Submittal date: 08/22/2005. 
APPENDIX A

GLOSSARY 


\section{APPENDIX A}

\section{GLOSSARY}

Database-A collection of information in a single database file or in a set of related database files or tables.

Disruptive FEP-An included FEP that has a probability of occurrence during the period of performance less than 1.0 (but greater than the cutoff of $10^{-4} / 10^{4}$ year). Disruptive FEPs are typically unlikely FEPs.

Disruptive Event Scenario Class-A scenario class that contains low-probability perturbations to the expected evolution of the repository system. It contains one or more disruptive FEPs and typically also contains most or all of the nominal FEPs.

Event-A natural or human-caused phenomenon that has a potential to affect disposal system performance and that occurs during an interval that is short compared to the period of performance.

Event Class-All possible specific initiating events that are caused by a common natural process (e.g., the event class for seismicity includes the range of credible earthquakes for the Yucca Mountain site). Event classes are assumed to be synonymous with scenario classes.

Excluded FEP-A FEP that is identified by the FEP screening process as not requiring analysis based on specific criteria provided by the regulations.

Feature-An object, structure, or condition that has a potential to affect disposal system performance.

FEP-A feature, event, or process.

Field (Database Field)-The basic unit of data entry in a record. One of several blocks of information (data/text) contained in a record.

Included FEP-A FEP that is identified by the FEP screening process as requiring analysis in the quantitative TSPA.

Likely FEP-A FEP that has at least one chance in 10 of occurring within 10,000 years of disposal.

Nominal FEP-An included FEP that, for the purposes of the TSPA, is assumed to occur with a probability near 1.0 during the period of performance. Nominal FEPs are typically likely FEPs.

Nominal Scenario Class-The scenario class that represents the most plausible evolution of the repository system and includes both favorable future conditions and potentially adverse future conditions. It contains all nominal FEPs and no disruptive FEPs. 
Process-A natural or human-caused phenomenon that has a potential to affect disposal system performance and that operates during all or a significant part of the period of performance.

Record (Database Record)-One set of fields in a database. Each record contains data about a single FEP or other object.

Scenario-A subset of the set of all possible futures of the disposal system that contains futures resulting from a specific combination of FEPs.

Scenario Class-A set of scenarios that share sufficient similarities that they can usefully be aggregated for the purposes of a specific analysis.

Screening Argument-Applicable to excluded FEPs. A discussion of the technical basis for exclusion.

Screening Decision-A statement of whether the FEP is included in the quantitative TSPA models or excluded from the TSPA on specific criteria provided by the regulations.

TSPA Disposition-Applicable to included FEPs. A summary discussion of the implementation of the FEP in the TSPA.

Unlikely FEP-A FEP that has less than one chance in 10 and at least one chance in 10,000 of occurring within 10,000 years of disposal.

Very Unlikely FEP-A FEP that has less than one chance in 10,000 of occurring within 10,000 years of disposal. 
APPENDIX B

SUMMARY OF AN ALTERNATIVE SYSTEMATIC ANALYSIS IDENTIFYING A COMPLETE LIST OF FEATURES, EVENTS, AND PROCESSES THAT MIGHT AFFECT THE YUCCA MOUNTAIN REPOSITORY 


\section{SUMMARY OF AN ALTERNATIVE SYSTEMATIC ANALYSIS IDENTIFYING A COMPLETE LIST OF FEATURES, EVENTS, AND PROCESSES THAT MIGHT AFFECT THE YUCCA MOUNTAIN REPOSITORY}

One of the acceptance criteria (NRC 2003 [DIRS 163274], Section 2.2.1.2.1.3, Acceptance Criterion 1) for TSPA-LA FEP analysis states that the TSPA-LA list must be a comprehensive list of all FEPs that have the potential to influence repository performance. The identification and classification of the TSPA-LA FEP list is described in Section 3 of this report. As noted in Section 2.3.1 of this report, confidence in the comprehensiveness of a FEP list can be gained by comparisons with other FEP lists and through the application of more than one classification scheme.

An alternative systematic analysis identifying a complete list of alternate FEPs that might affect the Yucca Mountain repository was documented in The Development of the Total System Performance Assessment-License Application Features, Events, and Processes (BSC 2005 [DIRS 168706], Appendix B). The alternate FEPs were developed using a top-down analysis of the barrier functions of the repository (i.e., the capability to impede radionuclide release). Each function was subdivided into successively smaller, more-detailed subfunctions (referred to as functional elements) until it could be characterized at a level of detail similar to the TSPA-LA FEPs. Therefore, each low-level functional element represented an alternate FEP or a group of related FEPs.

The top-down analysis used to develop the alternate FEP list is based on a different systematic FEP identification and classification scheme than the one described in Section 3 for the TSPALA FEP list. The alternate FEPs were also developed independently from the TSPA-LA FEP list. They were developed by an individual with FEP identification experience who was not involved in the TSPA-LA FEP list identification, and screening activities described in the main body of this report, and was not a FEP Team member, FEP AMR Lead, or SME during the independent alternate FEP development process.

A comparison (i.e., audit) of the TSPA-LA FEP list (developed as described in Section 3) against the alternate FEP list (BSC 2005 [DIRS 168706], Appendix B) was made to (a) build confidence that the TSPA-LA FEP list was complete, and (b) identify any additional FEPs that might potentially enhance completeness. The audit comparison resulted in the independent identification of nine potential FEPs that might warrant consideration as additions to the TSPA-LA FEP list to enhance completeness (BSC 2005 [DIRS 168706], Table B.6-3). These nine potential FEPs are summarized in Table B-1. Each of the potential FEPs in Table B-1 was added to the Potential FEP Log (see Appendix D) for evaluation by the FEP Team. None resulted in changes or additions to the TSPA-LA FEP list. 
Table B-1. Potential FEPs That Might Enhance the Completeness of the FEP List

\begin{tabular}{|c|c|}
\hline Issue & Description \\
\hline $\begin{array}{l}\text { Availability of surface } \\
\text { water affects soil } \\
\text { structure and stability }\end{array}$ & $\begin{array}{l}\text { Hydrologic properties of soil may change as the result of disintegrating effects of water and the } \\
\text { effects of ecological changes, both macroscopic and microscopic. }\end{array}$ \\
\hline $\begin{array}{l}\text { Moisture content of } \\
\text { rock in the UZ }\end{array}$ & $\begin{array}{l}\text { The moisture content of the rock influences the hydraulic conductivity and therefore the } \\
\text { percolation rate in the UZ. Conditions at depth may be influenced by native conditions for an } \\
\text { extended period. }\end{array}$ \\
\hline $\begin{array}{l}\text { Mining and other } \\
\text { underground activities } \\
\text { beyond the controlled } \\
\text { area }\end{array}$ & $\begin{array}{l}\text { Mining and other underground human activities (e.g., tunneling, underground construction, } \\
\text { quarrying) outside of the controlled area could affect percolation into the aquifer and thereby } \\
\text { affect both the flow rate of the aquifer and the dilution of radionuclide concentrations. }\end{array}$ \\
\hline Criticality in the UZ & $\begin{array}{l}\text { Fissile material accumulates to a critical mass at a location in the unsaturated zone as a result of } \\
\text { sorption, precipitation, or deposition. }\end{array}$ \\
\hline $\begin{array}{l}\text { Groundwater takes up } \\
\text { radionuclides that were } \\
\text { entrained or dissolved } \\
\text { in basaltic intrusion }\end{array}$ & $\begin{array}{l}\text { Groundwater erodes a basaltic intrusion or otherwise extracts radionuclide species that were } \\
\text { imbedded in a magma flow that entered the EBS. }\end{array}$ \\
\hline $\begin{array}{l}\text { Thermal conduction in } \\
\text { the EBS }\end{array}$ & $\begin{array}{l}\text { Thermal conduction may contribute to heat transfer from the waste package to the drip shield, } \\
\text { lowering the temperature of the waste package outer shell and affecting waste package corrosion } \\
\text { rates. Relevant properties are the thermal conductivities of the EBS materials. }\end{array}$ \\
\hline $\begin{array}{l}\text { Radiative heat transfer } \\
\text { in the EBS }\end{array}$ & $\begin{array}{l}\text { Thermal radiation may improve the efficiency of heat transfer from the waste package to the drip } \\
\text { shield and from the drip shield to the drift wall. The improved efficiency may lower the } \\
\text { temperature of the waste package outer shell and raise the temperature at the drift wall, affecting } \\
\text { evaporation and condensation, in-drift chemistry, waste package durability, and transport of } \\
\text { radionuclides. Relevant properties are the emissivities of the surfaces, the effects of dust and/or } \\
\text { condensation on emissivity, the densities and absorption coefficients of the various gases in the } \\
\text { drift air, and absorption by particulates in the air. }\end{array}$ \\
\hline $\begin{array}{l}\text { Dripping in the EBS } \\
\text { cavity }\end{array}$ & $\begin{array}{l}\text { Some portion of the moisture that percolates to the EBS horizon will drip into the EBS cavity, } \\
\text { depending on conditions in the cavity and in the rock and on the presence of rock bolts or other } \\
\text { irregularities in the drift crown. Dripping moisture may evaporate before it reaches a surface, } \\
\text { whether the drift shield, the invert, or an exposed waste package. }\end{array}$ \\
\hline Criticality in the SZ & $\begin{array}{l}\text { Fissile material accumulates to a critical mass at a location in the saturated zone as a result of } \\
\text { precipitation. }\end{array}$ \\
\hline
\end{tabular}


APPENDIX C

SUMMARY OF FEATURES, EVENTS, AND PROCESS CHANGES 


\section{SUMMARY OF FEP CHANGES}

This Appendix provides a summary of FEP changes during the development of TSPA-LA FEP data sets. Full documentation of the complete set of changes is found within the data sets themselves, as described in the remainder of this Appendix. The following abbreviations are used in this Appendix to represent the data sets:

- DTN1 - MO0301SEPFEPS1.000 [DIRS 161496]

- DTN2 - MO0303SEPFEPS2.000 [DIRS 162452]

- DTN3 - MO0306SEPFEPS3.000 [DIRS 163746]

- DTN4 - MO0307SEPFEPS4.000 [DIRS 164527]

- DTN5 - MO0312SEPFEPS5.000 [DIRS 167431]

- DTN6 - MO0405SEPFEPS6.000 [DIRS 169612]

- DTNLA0 - MO0407SEPFEPLA.000 [DIRS 170760]

- DTNLA1 - MO0501SEPFEPLA.001 [DIRS 172601]

- DTNLA2 - MO0508SEPFEPLA.002 [DIRS 175064].

\section{Changes From TSPA-SR to DTN1}

The final TSPA-SR list (BSC 2002 [DIRS 159684]) contained 328 FEPs. The reclassification and refinement described in Section 3.2.2 resulted in a number of cases of where scope was shifted between FEPs and/or a TSPA-SR FEP was split into multiple TSPA-LA FEPs. However, no new scope was added to the FEP list. The reclassification and refinement resulted in the addition of 52 FEPs (due to shifting and/or splitting of scope) and the deletion of 21 FEPs (due to redundancy with other FEPs), producing a preliminary TSPA-LA FEP list (DTN: MO0301SEPFEPS1.000 [DIRS 161496]) containing 359 FEPs in January 2003. The reclassification also resulted in TSPA-SR FEP numbers, ending in .00, in general being converted to corresponding TSPA-LA FEP numbers, ending in .0A. Where TSPA-SR FEPs were split, the new TSPA-LA FEPs were assigned numbers ending in .0B, .0C, etc.

The 52 new FEPs are listed in Table C-1 with the justification for their addition. Forty-three of TSPA-SR FEPs were split, producing 46 additional TSPA-LA FEPs. Six more additional TSPA-LA FEPs were created through scope shifting, independent of FEP splitting. Full documentation of these changes, along with other scope shifts that did not result in the addition of new FEPs, is presented in the "Notes" field of the "FEPS" Table within DTN: MO0301SEPFEPS1.000 [DIRS 161496].

The 21 deleted FEPs are listed in Table C-2 with the justification for their deletion. These deletions are listed in the "Deleted FEP Info" table within DTN: MO0301SEPFEPS1.000 [DIRS 161496]. 
Table C-1. Additional FEPs for DTN1

\begin{tabular}{|c|c|c|}
\hline FEP Number & FEP Description & Justification \\
\hline 1.1.01.01.0B & Influx through holes drilled in drift wall or crown & $\begin{array}{l}\text { Result of 1.1.01.01.0A being split into geosphere } \\
\text { effects and EBS effects }\end{array}$ \\
\hline 1.1.02.00.0B & $\begin{array}{l}\text { Mechanical effects of excavation/construction in } \\
\text { EBS }\end{array}$ & $\begin{array}{l}\text { Result of 1.1.02.00.0A being split into chemical and } \\
\text { mechanical effects }\end{array}$ \\
\hline 1.1.03.01.0B & Error in backfill emplacement & $\begin{array}{l}\text { Result of 1.1.03.01.0A being split into waste and } \\
\text { backfill }\end{array}$ \\
\hline 1.2.03.02.0B & $\begin{array}{l}\text { Seismic induced rockfall damages EBS } \\
\text { components }\end{array}$ & $\begin{array}{l}\text { Result of 1.2.03.02.0A being split into ground motion } \\
\text { and rockfall }\end{array}$ \\
\hline 1.2.04.07.0B & Ash redistribution & $\begin{array}{l}\text { Result of 1.2.04.07.0A being split into air and water/soil } \\
\text { transport }\end{array}$ \\
\hline 2.1.01.02.0B & Interactions between co-disposed waste & $\begin{array}{l}\text { Result of 2.1.01.02.0A being split into co-location and } \\
\text { co-disposal }\end{array}$ \\
\hline 2.1.02.25.0B & Naval SNF Cladding & $\begin{array}{l}\text { Result of 2.1.02.25.0A being split into DSNF and Naval } \\
\text { SNF }\end{array}$ \\
\hline 2.1.03.01.0B & General corrosion of drip shields & Result of 2.1.03.01.0A being split into WP and DS \\
\hline 2.1.03.02.0B & Stress corrosion cracking (SCC) of drip shields & Result of 2.1.03.02.0A being split into WP and DS \\
\hline 2.1.03.03.0B & Localized corrosion of drip shields & Result of 2.1.03.03.0A being split into WP and DS \\
\hline 2.1.03.04.0B & Hydride cracking of drip shields & Result of 2.1.03.04.0A being split into WP and DS \\
\hline 2.1.03.05.0B & $\begin{array}{l}\text { Microbially influenced corrosion (MIC) of drip } \\
\text { shields }\end{array}$ & Result of 2.1.03.05.0A being split into WP and DS \\
\hline 2.1.03.07.0B & Mechanical impact on drip shield & Result of 2.1.03.07.0A being split into WP and DS \\
\hline 2.1.03.08.0B & Early failure of drip shields & Result of 2.1.03.08.0A being split into WP and DS \\
\hline 2.1.03.10.0B & Healing of drip shields & Result of 2.1.03.10.0A being split into WP and DS \\
\hline 2.1.06.05.0B & Mechanical degradation of invert & $\begin{array}{l}\text { Result of 2.1.06.05.0A being split into invert/pedestal } \\
\text { and mechanical/chemical effects }\end{array}$ \\
\hline 2.1.06.05.0C & Chemical degradation of pedestal & $\begin{array}{l}\text { Result of } 2.1 .06 .05 .0 \mathrm{~A} \text { being split into invert/pedestal } \\
\text { and mechanical/chemical effects }\end{array}$ \\
\hline 2.1.06.05.0D & Chemical degradation of invert & $\begin{array}{l}\text { Result of 2.1.06.05.0A being split into invert/pedestal } \\
\text { and mechanical/chemical effects }\end{array}$ \\
\hline 2.1.06.06.0B & Oxygen embrittlement of drip shields & $\begin{array}{l}\text { Result of 2.1.06.06.0A being split into flow and } \\
\text { chemical/mechanical effects }\end{array}$ \\
\hline 2.1.06.07.0B & Mechanical effects at EBS component interfaces & $\begin{array}{l}\text { Result of 2.1.06.07.0A being split into chemical and } \\
\text { mechanical effects }\end{array}$ \\
\hline 2.1.07.04.0B & Hydrostatic pressure on drip shield & Result of 2.1.07.04.0A being split into WP and DS \\
\hline 2.1.07.05.0B & Creep of metalic materials in the drip shield & Result of 2.1.07.05.0A being split into WP and DS \\
\hline 2.1.08.01.0B & Effects of rapid influx into the repository & $\begin{array}{l}\text { Result of 2.1.08.01.0A being split into nominal and } \\
\text { extreme effects }\end{array}$ \\
\hline 2.1.09.01.0B & Chemical characteristics of water in waste package & $\begin{array}{l}\text { Result of 2.1.09.01.0A being split into in-drift and in- } \\
\text { package }\end{array}$ \\
\hline 2.1.09.03.0B & $\begin{array}{l}\text { Volume increase of corrosion products impacts } \\
\text { waste package }\end{array}$ & Result of 2.1.09.03.0A being split into cladding and WP \\
\hline 2.1.09.08.0B & Advection of dissolved radionuclides in EBS & $\begin{array}{l}\text { Result of 2.1.09.08.0A being split into diffusion and } \\
\text { advection }\end{array}$ \\
\hline 2.1.09.19.0B & Advection of colloids in EBS & $\begin{array}{l}\text { Result of 2.1.09.19.0A being split into sorption and } \\
\text { advection }\end{array}$ \\
\hline 2.1.09.21.0B & Transport of particles larger than colloids in the SZ & Result of 2.1.09.21.0A being split into EBS, SZ, and UZ \\
\hline 2.1.09.21.0C & Transport of particles larger than colloids in the UZ & Result of 2.1.09.21.0A being split into EBS, SZ, and UZ \\
\hline
\end{tabular}


Table C-1. Additional FEPs for DTN1 (Continued)

\begin{tabular}{|c|c|c|}
\hline FEP Number & FEP Description & Justification \\
\hline 2.1.09.27.0A & Coupled effects on radionuclide transport in EBS & $\begin{array}{l}\text { For LA, this FEP consolidates several other "mixed } \\
\text { decision" EBS coupled process FEPs }\end{array}$ \\
\hline 2.1.11.06.0B & Thermal sensitization of drip shields & Result of 2.1.11.06.0A being split into WP and DS \\
\hline 2.1.11.09.0B & Thermally-driven flow (convection) in the EBS & $\begin{array}{l}\text { Result of 2.1.11.09.0A being split into thermal effects } \\
\text { on flow and thermally-driven flow }\end{array}$ \\
\hline 2.2.01.01.0B & $\begin{array}{l}\text { Chemical effects of excavation/construction in the } \\
\text { near-field }\end{array}$ & $\begin{array}{l}\text { Result of 2.2.01.01.0A being split into mechanical and } \\
\text { chemical effects }\end{array}$ \\
\hline 2.2.01.02.0B & Chemical changes in the near-field from backfill & $\begin{array}{l}\text { Result of 2.2.01.02.0A being split into mechanical and } \\
\text { chemical effects }\end{array}$ \\
\hline 2.2.06.02.0B & $\begin{array}{l}\text { Seismic activity changes porosity and permeability } \\
\text { of fractures }\end{array}$ & $\begin{array}{l}\text { For LA, this FEP addresses seismically-induced } \\
\text { changes to fractures }\end{array}$ \\
\hline 2.2.07.06.0B & $\begin{array}{l}\text { Long-term release of radionuclides from the } \\
\text { repository }\end{array}$ & $\begin{array}{l}\text { Result of 2.2.07.06.0A being split into episodic and } \\
\text { non-episodic releases }\end{array}$ \\
\hline 2.2.07.15.0B & Advection and dispersion in the UZ & Result of 2.2.07.15.0A being split into SZ and UZ \\
\hline 2.2.07.20.0A & Flow diversion around repository drifts & $\begin{array}{l}\text { For LA, this FEP addresses flow diversion around } \\
\text { repository drifts }\end{array}$ \\
\hline 2.2.07.21.0A & Drift shadow forms below repository & $\begin{array}{l}\text { For LA, this FEP addresses drift shadow formation } \\
\text { below repository }\end{array}$ \\
\hline 2.2.08.01.0B & Chemical characteristics of groundwater in the UZ & Result of 2.2.08.01.0A being split into $S Z$ and $U Z$ \\
\hline 2.2.08.03.0B & Geochemical interactions and evolution in the UZ & Result of 2.2.08.03.0A being split into SZ and UZ \\
\hline 2.2.08.06.0B & Complexation in the UZ & Result of 2.2.08.06.0A being split into $\mathrm{SZ}$ and $\mathrm{UZ}$ \\
\hline 2.2.08.07.0B & Radionuclide solubility limits in the UZ & Result of 2.2.08.07.0A being split into $S Z$ and $U Z$ \\
\hline 2.2.08.08.0B & Matrix diffusion in the UZ & Result of 2.2.08.08.0A being split into SZ and UZ \\
\hline 2.2.08.09.0B & Sorption in the UZ & Result of 2.2.08.09.0A being split into $S Z$ and $U Z$ \\
\hline 2.2.08.10.0B & Colloidal transport in the UZ & Result of 2.2.08.10.0A being split into $S Z$ and $U Z$ \\
\hline 2.2.09.01.0B & Microbial activity in the UZ & Result of 2.2.09.01.0A being split into $S Z$ and $U Z$ \\
\hline 2.2.10.03.0B & Natural geothermal effects on flow in the UZ & Result of 2.2.10.03.0A being split into SZ and UZ \\
\hline 2.2.10.04.0B & $\begin{array}{l}\text { Thermo-mechanical stresses alter characteristics of } \\
\text { faults near repository }\end{array}$ & For LA, this FEP addresses thermal effects on faults \\
\hline 2.2.12.00.0B & Undetected features in the SZ & Result of 2.2.12.00.0A being split into $\mathrm{SZ}$ and $\mathrm{UZ}$ \\
\hline 2.3.13.04.0A & $\begin{array}{l}\text { Radionuclide release to accessible environment } \\
\text { away from the receptor location }\end{array}$ & $\begin{array}{l}\text { For LA, this FEP consolidates elements from other } \\
\text { "mixed decision" FEPs that address the accessible } \\
\text { environment away from the receptor location }\end{array}$ \\
\hline 2.4.09.01.0B & Agricultural land use and irrigation & $\begin{array}{l}\text { Result of 2.4.09.01.0A being split into existing and } \\
\text { future conditions }\end{array}$ \\
\hline
\end{tabular}


Table C-2. Deleted FEPs for DTN1

\begin{tabular}{|c|c|c|}
\hline FEP Number & FEP Description & Justification \\
\hline 1.1.01.02.00 & Loss of integrity of borehole seals & This FEP is redundant to 1.1.01.01.0A. \\
\hline 1.2.03.01.00 & Seismic activity & $\begin{array}{l}\text { This FEP is redundant to other seismic FEPs- } \\
1.2 .03 .0 \times .0 A \text {. }\end{array}$ \\
\hline 1.2.04.01.00 & Igneous activity & $\begin{array}{l}\text { This FEP is redundant to other igneous FEPs- } \\
1.2 .04 .0 x .0 \mathrm{~A} \text {. }\end{array}$ \\
\hline 1.4.04.02.00 & Abandoned and undetected boreholes & This FEP is redundant to 1.1.01.01.0A. \\
\hline 2.1.03.12.00 & Container failure (long-term) & $\begin{array}{l}\text { This is a broad FEP this is addressed entirely by } \\
\text { several other individual FEPs. }\end{array}$ \\
\hline 2.1.04.06.00 & Properties of bentonite & This FEP is not credible for the current design \\
\hline 2.1.04.07.00 & Buffer characteristics & This FEP is not credible for the current design. \\
\hline 2.1.04.08.00 & Diffusion in backfill & This FEP is redundant to 2.1.04.09.0A. \\
\hline 2.1.06.03.00 & Degradation of the liner & $\begin{array}{l}\text { This FEP is redundant to other ground support FEPs- } \\
2.1 .06 .0 \times .0 \mathrm{~A}\end{array}$ \\
\hline 2.1.07.03.00 & Movement of containers & $\begin{array}{l}\text { This FEP is redundant to other FEPs. Relevant text } \\
\text { has been merged where appropriate to: } 2.1 .03 .07 .0 \mathrm{~A} \\
\text { (WP Mechanical), 2.1.03.07.0B (DS mechanical), and } \\
\text { 2.1.06.05.0A (pedestal mechanical) }\end{array}$ \\
\hline 2.1.08.08.00 & $\begin{array}{l}\text { Induced hydrological changes in the waste and } \\
\text { EBS }\end{array}$ & $\begin{array}{l}\text { This FEP is broad and is redundant to other FEPs. } \\
\text { Any non-redundant text could moved to the following } \\
\text { FEPs: } \\
\text { 1.1.02.00.0A (chemical effects of } \\
\text { excavation/construction) } \\
\text { 1.1.02.00.0B (mechanical effects of } \\
\text { excavation/construction) } \\
\text { Issues related to THC effects on flow in the invert } \\
\text { (which are Excluded), have been moved to FEP } \\
\text { 2.1.08.12.0A. }\end{array}$ \\
\hline 2.1.08.10.00 & Desaturation/dewatering of the repository & $\begin{array}{l}\text { This FEP is redundant to FEP 2.1.08.03.0A. Some of } \\
\text { the NFE text under TSPA Disposition may be usefully } \\
\text { copied to the TSPA Disposition of FEP 2.1.08.03.0A. }\end{array}$ \\
\hline 2.1.08.13.00 & Drains & $\begin{array}{l}\text { The issues about wetting and ponding have been } \\
\text { merged into } 2.1 .08 .12 .0 \mathrm{~A} \text {. The design issue about } \\
\text { drains is not credible and will be so documented. }\end{array}$ \\
\hline 2.1.09.14.00 & Colloid formation in waste and EBS & $\begin{array}{l}\text { This FEPs effects are addressed completely in other } \\
\text { colloid FEPs. }\end{array}$ \\
\hline 2.1.11.04.00 & $\begin{array}{l}\text { Temperature effects / coupled processes in waste } \\
\text { and EBS }\end{array}$ & $\begin{array}{l}\text { This FEP is broad and is redundant to other FEPs. } \\
\text { Any non-redundant text could be moved to other FEPs. }\end{array}$ \\
\hline 2.1.12.05.00 & Gas generation from concrete & $\begin{array}{l}\text { Chemical effects from radiolysis is moved to } \\
2.1 .13 .01 .0 \mathrm{~A} \text {. } \\
\text { Gas from microbial growth is moved to } 2.1 .12 .04 .0 \mathrm{~A} \text {. }\end{array}$ \\
\hline 2.1.14.01.00 & Criticality in waste and EBS & Redundant to other 2.1.14.0x.0A FEPs. \\
\hline 2.2.08.02.00 & $\begin{array}{l}\text { Radionuclide transport occurs in a carrier plume in } \\
\text { geosphere }\end{array}$ & Redundant to 2.2.08.01.0x and 2.2.08.03.0x. \\
\hline 2.2.14.01.00 & Critical assembly forms away from repository & Redundant to other 2.2.14.0x.0A FEPs. \\
\hline
\end{tabular}


Table C-2. Deleted FEPs for DTN1 (Continued)

\begin{tabular}{|l|l|l|}
\hline FEP Number & \multicolumn{1}{|c|}{ FEP Description } & \multicolumn{1}{|c|}{ Justification } \\
\hline 2.3.13.02.00 & Biosphere transport & Redundant to other biosphere transport FEPs: \\
& & $2.3 .02 .03 .0 \mathrm{~A}$ (soil) \\
& & $2.3 .04 .010 \mathrm{~A}$ (surf. water) \\
& & $2.3 .09 .01 .0 \mathrm{~A}$ (animal) \\
& $2.4 .09 .01 .0 \mathrm{~B}$ (irrigation) \\
& & .2.10.00.0A (air) \\
& Note that this FEP was restored as part of DTN4 \\
& (Table C-4). It was erroneously retained in the \\
& FEP Table of DTN2 and DTN3 although it was \\
& not counted in the total number of FEPs in those \\
& DTNs. \\
\hline 2.4.03.00.00 & Diet and fluid intake & Redundant to 3.3.01.00.0A. \\
\hline
\end{tabular}

\section{Changes From DTN1 to DTN2}

The data contained in DTN: MO0303SEPFEPS2.000 [DIRS 162452] is identical to DTN: MO0301SEPFEPS1.000 [DIRS 161496]. Both contain 359 FEPs. The changes resulting in the creation of DTN: MO0303SEPFEPS2.000 [DIRS 162452] in March 2003 were purely administrative. The data set includes a Microsoft Word file, which was not part of DTN1, that contains several of the fields from the "FEPS" table. In particular the changes from TSPA-SR to DTN1/DTN2 (the same changes documented in the "Notes" field of the "FEPS" table) are also listed in the "Changes for LA" column of the Microsoft Word file.

\section{Changes From DTN2 to DTN3}

DTN: MO0306SEPFEPS3.000 [DIRS 163746] was created in June 2003 to document preliminary changes from DTN: MO0303SEPFEPS2.000 [DIRS 162452], consisting of changes to names and/or descriptions for 71 existing FEPs, other scope shifts that did not require a name or description change, and changes to input FEP AMRs. These changes did not result in any additions or deletions to the FEP list, so the total number of FEPs remained at 359. Table C-3 lists the 71 changed FEPs and identifies the type of changes implemented. These changes, along with the other scope shifts and changes to input FEP AMRs, are fully documented in the "Notes" field of the "FEPS" Table and the "FEP History File" Table within DTN: MO0306SEPFEPS3.000 [DIRS 163746]. 
Table C-3. Changes From DTN2 to DTN3

\begin{tabular}{|c|c|c|}
\hline FEP Number & FEP Name & Changes \\
\hline 1.2.04.02.0A & Igneous activity changes rock properties & Description expanded \\
\hline 1.2.04.04.0A & Igneous intrusion interacts with EBS components & Description edited \\
\hline 1.2.04.05.0A & Magmatic or pyroclastic transport of waste & Description and name expanded \\
\hline 1.2.04.06.0A & Eruptive conduit to surface intersects repository & Description edited \\
\hline 1.2.04.07.0B & Ash redistribution & Description expanded \\
\hline 1.2.06.00.0A & Hydrothermal activity & Description edited \\
\hline 1.2.07.01.0A & Erosion/denudation & Description edited \\
\hline 1.2.07.02.0A & Deposition & Description edited \\
\hline 1.2.08.00.0A & Diagenesis & Description edited * \\
\hline 1.2.10.02.0A & Hydrologic response to igneous activity & Description edited \\
\hline 1.3.01.00.0A & Climate change & Name edited \\
\hline 1.3.07.02.0A & Water table rise affects $S Z$ & $\begin{array}{l}\text { Name and Description edited } \\
\text { To be split (as part of DTN 4) }\end{array}$ \\
\hline 1.4.01.00.0A & Human influences on climate & Description edited \\
\hline 1.4.01.01.0A & Climate modification increases recharge & Description edited \\
\hline 2.1.01.02.0A & Interactions between co-located waste & Description edited \\
\hline 2.1.02.25.0A & DSNF cladding & Description edited \\
\hline 2.1.02.25.0B & Naval SNF Cladding & Description edited \\
\hline 2.1.03.03.0A & Localized corrosion of waste packages & Description edited \\
\hline 2.1.03.03.0B & Localized corrosion of drip shields & Description edited \\
\hline 2.1.03.07.0A & Mechanical impact on waste package & Description edited \\
\hline 2.1.03.07.0B & Mechanical impact on drip shield & Description edited \\
\hline 2.1.06.05.0A & Mechanical degradation of pedestal & Description edited \\
\hline 2.1.06.05.0B & Mechanical degradation of invert & Description edited \\
\hline 2.1.06.06.0A & Effects of drip shield on flow & Description edited \\
\hline 2.1.06.07.0B & Mechanical effects at EBS component interfaces & Description edited \\
\hline 2.1.08.03.0A & Repository dry-out due to waste heat & Description clarified \\
\hline 2.1.08.04.0A & $\begin{array}{l}\text { Condensation forms on roofs of drifts (drift-scale cold } \\
\text { traps) }\end{array}$ & $\begin{array}{l}\text { Description edited } \\
\text { To be split (as part of DTN4) }\end{array}$ \\
\hline 2.1.08.11.0A & Repository resaturation due to waste cooling & Description clarified \\
\hline 2.1.08.12.0A & Induced hydrologic changes in invert & Description edited \\
\hline 2.1.09.02.0A & Chemical interaction with corrosion products & Description expanded \\
\hline 2.1.09.08.0A & Diffusion of dissolved radionuclides in EBS & Description edited \\
\hline 2.1.09.08.0B & Advection of dissolved radionuclides in EBS & Description edited \\
\hline 2.1.09.16.0A & Formation of pseudo-colloids (natural) in EBS & Description edited \\
\hline 2.1.09.17.0A & $\begin{array}{l}\text { Formation of pseudo-colloids (corrosion product) in } \\
\text { EBS }\end{array}$ & Description edited \\
\hline 2.1.09.18.0A & Formation of microbial colloids in EBS & Description edited \\
\hline
\end{tabular}


Table C-3. Changes From DTN2 to DTN3 (Continued)

\begin{tabular}{|c|c|c|}
\hline FEP Number & FEP Name & Changes \\
\hline 2.1.11.01.0A & Heat generation in EBS & Description edited \\
\hline 2.1.11.07.0A & Thermal expansion/stress of in-drift EBS components & Description edited \\
\hline 2.1.12.01.0A & Gas generation (repository pressurization) & Description edited \\
\hline 2.1.12.03.0A & Gas generation $\left(\mathrm{H}_{2}\right)$ from waste package corrosion & Description edited \\
\hline 2.2.06.02.0A & $\begin{array}{l}\text { Seismic activity changes porosity and permeability of } \\
\text { faults }\end{array}$ & Description edited \\
\hline 2.2.06.03.0A & Seismic activity alters perched water zones & Name edited \\
\hline 2.2.07.02.0A & Unsaturated groundwater flow in the geosphere & Description edited \\
\hline 2.2.07.03.0A & Capillary rise in the UZ & Description edited \\
\hline 2.2.07.05.0A & Flow in the UZ from episodic infiltration & Description edited \\
\hline 2.2.07.06.0A & Episodic / pulse release from repository & Description edited \\
\hline 2.2.07.11.0A & Resaturation of geosphere dry-out zone & Description edited \\
\hline 2.2.07.20.0A & Flow diversion around repository drifts & Description edited \\
\hline 2.2.08.03.0A & Geochemical interactions and evolution in the SZ & Description edited \\
\hline 2.2.08.03.0B & Geochemical interactions and evolution in the UZ & Description edited \\
\hline 2.2.08.04.0A & $\begin{array}{l}\text { Redissolution of precipitates directs more corrosive } \\
\text { fluids to containers }\end{array}$ & Description edited \\
\hline 2.2.08.05.0A & Diffusion in the UZ & Description edited \\
\hline 2.2.08.07.0A & Radionuclide solubility limits in the SZ & Description edited \\
\hline 2.2.08.07.0B & Radionuclide solubility limits in the UZ & Description edited \\
\hline 2.2.08.11.0A & $\begin{array}{l}\text { Groundwater discharge to surface within the reference } \\
\text { biosphere }\end{array}$ & Changes to Name and Description \\
\hline 2.2.08.12.0A & Chemistry of water flowing into the drift & $\begin{array}{l}\text { Name and Description edited } \\
\text { To be split (as part of DTN4) }\end{array}$ \\
\hline 2.2.09.01.0A & Microbial activity in the SZ & Description edited \\
\hline 2.2.09.01.0B & Microbial activity in the UZ & Description edited \\
\hline 2.2.10.01.0A & Repository-induced thermal effects on flow in the UZ & Description edited \\
\hline 2.2.10.12.0A & Geosphere dry-out due to waste heat & Description clarified \\
\hline 2.2.10.13.0A & Repository-induced thermal effects on flow in the SZ & Description edited \\
\hline 2.3.02.02.0A & Radionuclide accumulation in soils & Description edited \\
\hline 2.3.02.03.0A & Soil and sediment transport in the biosphere & Changes to Description \\
\hline 2.3.09.01.0A & Animal burrowing/intrusion & Changes to Description \\
\hline 2.3.11.01.0A & Precipitation & Description expanded \\
\hline 2.3.11.02.0A & Surface runoff and flooding & Change to Description \\
\hline 2.3.11.04.0A & $\begin{array}{l}\text { Groundwater discharge to surface outside the } \\
\text { reference biosphere }\end{array}$ & Name and Description edited \\
\hline 2.3.13.01.0A & Biosphere characteristics & Description reworded \\
\hline 2.3.13.04.0A & Radionuclide release outside the reference biosphere & Name and Description edited \\
\hline 3.3.02.01.0A & Plant uptake & Description edited \\
\hline 3.3.02.02.0A & Animal uptake & Description edited \\
\hline 3.3.02.03.0A & Fish uptake & Changes to Name and Description \\
\hline
\end{tabular}

* Change documented in "Notes" field of "FEPS" Table, but not in "FEP History File" Table. 


\section{Changes From DTN3 to DTN4}

DTN: MO0307SEPFEPS4.000 [DIRS 164527] was created in July 2003 to document additional changes to TSPA-LA FEP list. Changes from DTN: MO0306SEPFEPS3.000 [DIRS 163746] consisted of the addition of eight FEPs and changes to names and/or descriptions for 12 other existing FEPs, producing a revised TSPA-LA FEP list (DTN: MO0307SEPFEPS4.000 [DIRS 164527]) containing 367 FEPs.

The eight new FEPs resulted from (a) five FEPs were split, producing five additional FEPs, (b) one previously deleted FEP was restored, with a slight alteration in scope, and (c) two new deliquescence FEPs were identified. The new FEPs along with the 12 changed FEPs ( 4 of which changed due to splitting) are listed in Table C-4. These changes, along with one change to an input FEP AMR, are fully documented in the "Notes" field of the "FEPS" table and the "FEP History File" table within DTN: MO0307SEPFEPS4.000 [DIRS 164527].

Table C-4. Changes From DTN3 to DTN4

\begin{tabular}{|c|c|c|}
\hline FEP Number & FEP Name & Changes \\
\hline 1.1.02.02.0A & Preclosure ventilation & Description edited \\
\hline 1.2.02.03.0A & Fault displacement damages EBS components & Description edited \\
\hline 1.2.04.07.0B & Ash redistribution in groundwater & $\begin{array}{l}\text { Split. Name and Description edited to reflect } \\
\text { splitting of FEP }\end{array}$ \\
\hline 1.2.04.07.0C & $\begin{array}{l}\text { Ash redistribution via soil and sediment } \\
\text { transport }\end{array}$ & $\begin{array}{l}\text { Result of 1.2.04.07.0B being split into water and } \\
\text { soil transport* }\end{array}$ \\
\hline 1.3.07.02.0A & Water table rise affects SZ & Split (edited in DTN 3) \\
\hline 1.3.07.02.0B & Water table rise affects UZ & Result of 1.3.07.02.0A being split into $S Z$ and $U Z$ \\
\hline 1.4.07.02.0A & Wells & $\begin{array}{l}\text { Description expanded to include recycling of } \\
\text { radionuclides }\end{array}$ \\
\hline $2.1 .08 .04 .0 \mathrm{~A}$ & $\begin{array}{l}\text { Condensation forms on roofs of drifts (drift-scale } \\
\text { cold traps }\end{array}$ & Split (edited in DTN 3) \\
\hline 2.1.08.04.0B & $\begin{array}{l}\text { Condensation forms at repository edges } \\
\text { (repository-scale cold traps) }\end{array}$ & $\begin{array}{l}\text { Result of 2.1.08.04.0A being split into drift-scale } \\
\text { and repository-scale }\end{array}$ \\
\hline 2.1.08.15.0A & Consolidation of EBS components & Name edited (uncapitalized word) ** \\
\hline 2.1.09.03.0C & $\begin{array}{l}\text { Volume increase of corrosion products impacts } \\
\text { other EBS components }\end{array}$ & $\begin{array}{l}\text { Result of 2.1.09.03.0B being split into WP and } \\
\text { other EBS components }\end{array}$ \\
\hline 2.1.09.28.0A & Deliquescence on waste package outer surface & FEP added \\
\hline 2.1.09.28.0B & Deliquescence on drip shield outer surface & FEP added \\
\hline 2.1.11.10.0A & Thermal effects on transport in EBS & Description edited (comma deleted) ${ }^{* *}$ \\
\hline 2.2.08.12.0A & Chemistry of water flowing into the drift & Split (edited in DTN 3) \\
\hline 2.2.08.12.0B & $\begin{array}{l}\text { Chemistry of water flowing into the waste } \\
\text { package }\end{array}$ & $\begin{array}{l}\text { Result of 2.2.08.12.0A being split into in-drift and } \\
\text { in-package }\end{array}$ \\
\hline 2.2.12.00.0B & Undetected features in the SZ & Description edited ("than" to "that") ** \\
\hline 2.3.13.01.0A & Biosphere characteristics & Description edited (hyphens removed) ** \\
\hline
\end{tabular}


Table C-4. Changes From DTN3 to DTN4 (Continued)

\begin{tabular}{|c|c|c|}
\hline FEP Number & FEP Name & Changes \\
\hline 2.3.13.02.0A & $\begin{array}{l}\text { Radionuclide alteration during biosphere } \\
\text { transport }\end{array}$ & $\begin{array}{l}\text { FEP Restored. This FEP only addresses } \\
\text { alteration in the biosphere. Issues related to } \\
\text { transport have been moved to the following other } \\
\text { biosphere transport FEPs: } \\
2.3 .02 .03 .0 \mathrm{~A} \text { (soil) } \\
2.3 .04 .01 .0 \mathrm{~A} \text { (surf water) } \\
2.3 .09 .01 .0 \mathrm{~A} \text { (animal) } \\
2.4 .09 .01 .0 \mathrm{~B} \text { (irrigation) } \\
\text { 3.2.10.00.0A (air).] } \\
\text { Description has been edited to reflect this change }\end{array}$ \\
\hline 2.3.13.04.0A & $\begin{array}{l}\text { Radionuclide release outside the reference } \\
\text { biosphere }\end{array}$ & Description edited ("may" added) ** \\
\hline
\end{tabular}

* Change documented in "Notes" field of "FEPS" table, but not in "FEP History File" table.

** Minor correction of typographical error, not documented in "Notes" field of "FEPS" table or in "FEP History File" table.

\section{Changes From DTN4 to DTN5}

There was no change in the number of FEPs from DTN: MO0307SEPFEPS4.000 [DIRS 164527] to DTN: MO0312SEPFEPS5.000 [DIRS 167431]. The change consisted of adding preliminary screening information to the data in December 2003. This preliminary screening information was based on review copies (i.e., not final or approved) of the FEP AMRs. The reason for adding non-final information to the data set was to make the data set compatible with FEPs Database Software Program, Version 1.0 (STN: 10418-1.0-00 [DIRS 165502]).

\section{Changes From DTN5 to DTN6}

DTN: MO0405SEPFEPS6.000 [DIRS 169612] was created in May 2004 as the first complete data set with approved FEP identification and FEP screening information. The following changes were made to DTN: MO0312SEPFEPS5.000 [DIRS 167431] to produce DTN: MO0405SEPFEPS6.000 [DIRS 169612]:

- Editorial changes to 55 FEPs

- Technical changes to 24 FEPs

- Redefinition of the criticality FEPs (deleting the existing 20 and replacing them with 16 new FEPs)

- Addition of 2 new combined FEPs (related to disruptive events combined with human intrusion)

- Creation 3 new independents FEPs by shifting scope from existing FEPs (2 FEPs related to seismic induced drift collapse and 1 FEP related to recycling)

- Creation of 3 new FEPs from splitting of existing FEPs

- Replacement of preliminary screening information with screening information from the interim versions of the FEP AMRs. 
The net result of the additions and deletions was a total of 371 FEPs. Table C-5 summarizes the changes. These changes, along with the other changes to input FEP AMRs, are fully documented in the "Notes" field of the "FEPS" table, in the "FEP History File" table, and in the "Deleted FEP Info" table, all within DTN: MO0405SEPFEPS6.000 [DIRS 169612]. DTN: MO0405SEPFEPS6.000 [DIRS 169612] superseded all previous FEP list DTNs.

\section{Table C-5. Changes From DTN5 to DTN6}

\begin{tabular}{|c|c|c|}
\hline FEP Number & FEP Name & Changes * \\
\hline 1.1.05.00.0A & Records and markers for the repository & Name edited $(\mathrm{E})$ \\
\hline 1.1.08.00.0A & Inadequate quality control and deviations from design & Description edited $(\mathrm{E})$ \\
\hline 1.1.10.00.0A & Administrative control of the repository site & $\begin{array}{l}\text { Name and Description } \\
\text { edited }(T)\end{array}$ \\
\hline 1.1.11.00.0A & Monitoring of the repository & Name edited $(\mathrm{E})$ \\
\hline 1.1.12.01.0A & Accidents and unplanned events during construction and operation & Name edited $(\mathrm{E})$ \\
\hline 1.2.01.01.0A & Tectonic activity-large scale & Description edited $(\mathrm{E})$ \\
\hline 1.2.02.02.0A & Faults & Description edited $(\mathrm{E})$ \\
\hline 1.2.03.02.0A & Seismic ground motion damages EBS components & Description edited $(\mathrm{E})$ \\
\hline 1.2.03.02.0B & Seismic induced rockfall damages EBS components & $\begin{array}{l}\text { Description edited to shift } \\
\text { drift collapse to } \\
\text { 1.2.03.02.0C and } \\
\text { 1.2.03.02.0D (T) }\end{array}$ \\
\hline 1.2.03.02.0C & Seismic induced drift collapse damages EBS components & $\begin{array}{l}\text { New FEP-scope shifted } \\
\text { from 1.2.03.02.0B and } \\
2.1 .07 .02 .0 \mathrm{~A}\end{array}$ \\
\hline 1.2.03.02.0D & Seismic induced drift collapse alters in-drift thermal-hydrologic & $\begin{array}{l}\text { New FEP-scope shifted } \\
\text { from 1.2.03.02.0B and } \\
2.1 .07 .02 .0 \mathrm{~A}\end{array}$ \\
\hline 1.2.04.04.0A & Igneous intrusion interacts with EBS components & Description edited $(\mathrm{E})$ \\
\hline 1.2.04.05.0A & Magma or pyroclastic base surge transports waste & $\begin{array}{l}\text { Name and Description } \\
\text { edited }(E)\end{array}$ \\
\hline 1.2.07.02.0A & Deposition & Description edited $(E)$ \\
\hline 1.2.10.01.0A & Hydrologic response to seismic activity & Name edited $(E)$ \\
\hline 1.3.07.01.0A & Water table decline & Description edited $(\mathrm{E})$ \\
\hline 1.3.07.02.0A & Water table rise affects $S Z$ & Description edited $(\mathrm{E})$ \\
\hline 1.3.07.02.0B & Water table rise affects UZ & Description edited $(\mathrm{E})$ \\
\hline 1.4.02.03.0A & Igneous Event Precedes Human Intrusion & $\begin{array}{l}\text { New FEP-igneous event } \\
\text { combined with human } \\
\text { intrusion }\end{array}$ \\
\hline 1.4.02.04.0A & Seismic Event Precedes Human Intrusion & $\begin{array}{l}\text { New FEP-seismic event } \\
\text { combined with human } \\
\text { intrusion }\end{array}$ \\
\hline 1.4.03.00.0A & Unintrusive site investigation & Name edited $(E)$ \\
\hline
\end{tabular}


Table C-5. Changes From DTN5 to DTN6 (Continued)

\begin{tabular}{|c|c|c|}
\hline FEP Number & FEP Name & Changes * \\
\hline 1.4.04.00.0A & Drilling activities (human intrusion) & Description edited $(\mathrm{T})$ \\
\hline 1.4.07.02.0A & Wells & $\begin{array}{l}\text { Description edited to shift } \\
\text { recycling to } 1.4 .07 .03 .0 \mathrm{~A} \\
\text { (T) }\end{array}$ \\
\hline 1.4.07.03.0A & Recycling of accumulated radionuclides from soils to groundwater & $\begin{array}{l}\text { New FEP-scope shifted } \\
\text { from 1.4.07.02.0A }\end{array}$ \\
\hline 2.1.01.01.0A & Waste inventory & Description edited $(\mathrm{E})$ \\
\hline 2.1.01.03.0A & Heterogeneity of waste inventory & Description edited $(E)$ \\
\hline 2.1.01.04.0A & Repository-scale spatial heterogeneity of emplaced waste & Description edited $(\mathrm{E})$ \\
\hline 2.1.02.04.0A & Alpha recoil enhances dissolution & Description edited (E) \\
\hline 2.1.02.06.0A & HLW glass recrystallization & Description edited $(\mathrm{T})$ \\
\hline 2.1.02.07.0A & Radionuclide release from gap and grain boundaries & Description edited $(E)$ \\
\hline $2.1 .02 .11 .0 \mathrm{~A}$ & Degradation of cladding from waterlogged rods & Description edited $(T)$ \\
\hline $2.1 .02 .14 .0 \mathrm{~A}$ & Microbially influenced corrosion (MIC) of cladding & $\begin{array}{l}\text { Name and Description } \\
\text { edited (E) }\end{array}$ \\
\hline 2.1.02.15.0A & Localized (radiolysis enhanced) corrosion of cladding & Description edited $(\mathrm{T})$ \\
\hline $2.1 .02 .19 .0 \mathrm{~A}$ & Creep rupture of cladding & Description edited $(\mathrm{T})$ \\
\hline 2.1.02.24.0A & Mechanical impact on cladding & Description edited $(\mathrm{T})$ \\
\hline 2.1.02.27.0A & Localized (fluoride enhanced) corrosion of cladding & Description edited $(E)^{* *}$ \\
\hline 2.1.02.29.0A & Flammable gas generation from DSNF & Description edited $(E)$ \\
\hline 2.1.03.02.0A & Stress corrosion cracking of waste packages & $\begin{array}{l}\text { Name and Description } \\
\text { edited }(E)^{* *}\end{array}$ \\
\hline 2.1.03.02.0B & Stress corrosion cracking of drip shields & $\begin{array}{l}\text { Name and Description } \\
\text { edited }(E)^{* *}\end{array}$ \\
\hline 2.1.03.03.0A & Localized corrosion of waste packages & Description edited $(T)$ \\
\hline 2.1.03.03.0B & Localized corrosion of drip shields & Description edited $(T)$ \\
\hline 2.1.03.04.0A & Hydride cracking of waste packages & Description edited $(\mathrm{T})$ \\
\hline 2.1.03.04.0B & Hydride cracking of drip shields & Description edited $(\mathrm{T})$ \\
\hline 2.1.03.05.0A & Microbially influenced corrosion of waste packages & Name edited $(E) * *$ \\
\hline 2.1.03.05.0B & Microbially influenced corrosion of drip shields & Name edited $(E) * *$ \\
\hline 2.1.03.07.0A & Mechanical impact on waste package & Description edited $(\mathrm{T})$ \\
\hline 2.1.03.07.0B & Mechanical impact on drip shield & Description edited $(\mathrm{T})$ \\
\hline 2.1.03.09.0A & Copper corrosion in Engineered Barrier System & Name edited $(E)^{* *}$ \\
\hline 2.1.06.05.0A & Mechanical degradation of emplacement pallet & $\begin{array}{l}\text { Name and Description } \\
\text { edited }(E)\end{array}$ \\
\hline 2.1.06.05.0C & Chemical degradation of emplacement pallet & $\begin{array}{l}\text { Name and Description } \\
\text { edited (E) }\end{array}$ \\
\hline 2.1.06.07.0B & Mechanical effects at Engineered Barrier System component interfaces & Name edited $(E)^{* *}$ \\
\hline 2.1.07.01.0A & Rockfall & Description edited $(\mathrm{T})$ \\
\hline 2.1.07.02.0A & Drift collapse & $\begin{array}{l}\text { Description edited to shift } \\
\text { seismic to } 1.2 .03 .02 .0 \mathrm{C} \\
\text { and 1.2.03.02.0D (T) }\end{array}$ \\
\hline 2.1.07.06.0A & Floor buckling & Description edited (E) \\
\hline $2.1 .08 .15 .0 \mathrm{~A}$ & Consolidation of EBS components & Description edited $(\mathrm{T})$ \\
\hline 2.1.09.02.0A & Chemical interaction with corrosion products & Description edited $(E)$ \\
\hline 2.1.09.06.0A & Reduction-oxidation potential in waste package & $\begin{array}{l}\text { Split. Name and } \\
\text { Description edited to } \\
\text { reflect splitting of FEP }(T)\end{array}$ \\
\hline
\end{tabular}


Table C-5. Changes From DTN5 to DTN6 (Continued)

\begin{tabular}{|c|c|c|}
\hline FEP Number & FEP Name & Changes * \\
\hline 2.1.09.06.0B & Reduction-oxidation potential in drifts & $\begin{array}{l}\text { New FEP-result of } \\
2.1 .09 .06 .0 \mathrm{~A} \text { being split } \\
\text { into in-drift and in- } \\
\text { package }\end{array}$ \\
\hline 2.1.09.07.0A & Reaction kinetics in waste package & $\begin{array}{l}\text { Split. Name and } \\
\text { Description edited to } \\
\text { reflect splitting of FEP (T) }\end{array}$ \\
\hline 2.1.09.07.0B & Reaction kinetics in drifts & $\begin{array}{l}\text { New FEP-result of } \\
2.1 .09 .07 .0 \mathrm{~A} \text { being split } \\
\text { into in-drift and in- } \\
\text { package }\end{array}$ \\
\hline 2.1.09.11.0A & Chemical effects of waste-rock contact & Description edited $(\mathrm{T})$ \\
\hline 2.1.09.16.0A & Formation of pseudo-colloids (natural) in EBS & Description edited (E) \\
\hline 2.1.09.17.0A & Formation of pseudo-colloids (corrosion product) in EBS & Description edited $(\mathrm{E})$ \\
\hline 2.1.09.28.0A & Deliquescence on waste package outer surface & Description edited $(\mathrm{E})$ \\
\hline 2.1.09.28.0B & Deliquescence on drip shield outer surface & Description edited $(\mathrm{E})$ \\
\hline 2.1.11.06.0A & Thermal sensitization of waste packages & Description edited $(\mathrm{E})$ ** \\
\hline 2.1.11.07.0A & Thermal expansion/stress of in-drift Engineered Barrier System components & Description edited $(T)$ \\
\hline 2.1.11.09.0B & Thermally driven flow (convection) in the EBS & $\begin{array}{l}\text { Split. Name and } \\
\text { Description edited to } \\
\text { reflect splitting of FEP (as } \\
\text { part of DTNLA1) }(T)^{*}\end{array}$ \\
\hline 2.1.11.09.0C & Thermally driven flow (convection) in Drifts & $\begin{array}{l}\text { New FEP-result of } \\
2.1 .11 .09 .0 B \text { being split } \\
\text { into in-drift and in- } \\
\text { package ** }\end{array}$ \\
\hline 2.1.13.01.0A & Radiolysis & Description edited $(\mathrm{E})$ ** \\
\hline 2.1.13.02.0A & Radiation damage in Engineered Barrier System & Description edited $(\mathrm{E})$ \\
\hline 2.1.14.02.0A & Criticality in situ, nominal configuration, top breach & $\begin{array}{l}\text { Deleted-replaced by new } \\
\text { criticality FEPs }\end{array}$ \\
\hline 2.1.14.03.0A & $\begin{array}{l}\text { Criticality in situ, WP internal structures degrade faster than waste form, top } \\
\text { breach }\end{array}$ & $\begin{array}{l}\text { Deleted-replaced by new } \\
\text { criticality FEPs }\end{array}$ \\
\hline 2.1.14.04.0A & $\begin{array}{l}\text { Criticality in situ, WP internal structures degrade at same rate as waste form, } \\
\text { top breach }\end{array}$ & $\begin{array}{l}\text { Deleted-replaced by new } \\
\text { criticality FEPs }\end{array}$ \\
\hline 2.1.14.05.0A & $\begin{array}{l}\text { Criticality in situ, WP internal structures degrade slower than waste form, top } \\
\text { breach }\end{array}$ & $\begin{array}{l}\text { Deleted-replaced by new } \\
\text { criticality FEPs }\end{array}$ \\
\hline 2.1.14.06.0A & Criticality in situ, waste form degrades in place and swells, top breach & $\begin{array}{l}\text { Deleted-replaced by new } \\
\text { criticality FEPs }\end{array}$ \\
\hline 2.1.14.07.0A & $\begin{array}{l}\text { Criticality in situ, bottom breach allows flow through WP, fissile material } \\
\text { collects at bottom of WP }\end{array}$ & $\begin{array}{l}\text { Deleted-replaced by new } \\
\text { criticality FEPs }\end{array}$ \\
\hline 2.1.14.08.0A & $\begin{array}{l}\text { Criticality in situ, bottom breach allows flow through WP, waste form degrades } \\
\text { in place }\end{array}$ & $\begin{array}{l}\text { Deleted-replaced by new } \\
\text { criticality FEPs }\end{array}$ \\
\hline 2.1.14.09.0A & Near-field criticality, fissile material deposited in near-field pond & $\begin{array}{l}\text { Deleted-replaced by new } \\
\text { criticality FEPs }\end{array}$ \\
\hline 2.1.14.10.0A & Near-field criticality, fissile solution flows into drift low point & $\begin{array}{l}\text { Deleted-replaced by new } \\
\text { criticality FEPs }\end{array}$ \\
\hline 2.1.14.11.0A & Near-field criticality, fissile solution is adsorbed or reduced in invert & $\begin{array}{l}\text { Deleted-replaced by new } \\
\text { criticality FEPs }\end{array}$ \\
\hline 2.1.14.12.0A & Near-field criticality, filtered slurry or colloidal stream collects on invert surface & $\begin{array}{l}\text { Deleted-replaced by new } \\
\text { criticality FEPs }\end{array}$ \\
\hline 2.1.14.13.0A & Near-field criticality associated with colloidal deposits & $\begin{array}{l}\text { Deleted-replaced by new } \\
\text { criticality FEPs }\end{array}$ \\
\hline
\end{tabular}


Table C-5. Changes From DTN5 to DTN6 (Continued)

\begin{tabular}{|c|c|c|}
\hline FEP Number & FEP Name & Changes * \\
\hline 2.1.14.14.0A & Criticality resulting from disruptive events & $\begin{array}{l}\text { Deleted-replaced by new } \\
\text { criticality FEPs }\end{array}$ \\
\hline 2.1.14.15.0A & In-package criticality (intact configuration) & $\begin{array}{l}\text { New FEP-replaces } \\
2.1 .14 .02 .0 \mathrm{~A}\end{array}$ \\
\hline 2.1.14.16.0A & In-package criticality (degraded configuration) & $\begin{array}{l}\text { New FEP-consolidates } \\
2.1 .14 .03 .0 \mathrm{~A} \text {, } \\
2.1 .14 .04 .0 \mathrm{~A} \text {, } \\
2.1 .14 .05 .0 \mathrm{~A}, \\
2.1 .14 .06 .0 \mathrm{~A} \text {, } \\
2.1 .14 .07 .0 \mathrm{~A} \text {, and } \\
2.1 .14 .08 .0 \mathrm{~A}\end{array}$ \\
\hline 2.1.14.17.0A & Near-field criticality & $\begin{array}{l}\text { New FEP-consolidates } \\
2.1 .14 .09 .0 \mathrm{~A} \text {, } \\
2.1 .14 \cdot 10.0 \mathrm{~A} \text {, } \\
2.1 .14 \cdot 11.0 \mathrm{~A} \text {, } \\
2.1 .14 .12 .0 \mathrm{~A} \text {, and } \\
2.1 .14 \cdot 13.0 \mathrm{~A}\end{array}$ \\
\hline 2.1.14.18.0A & In-package criticality resulting from a seismic event (intact configuration) & $\begin{array}{l}\text { New FEP-partially } \\
\text { replaces 2.1.14.14.0A }\end{array}$ \\
\hline 2.1.14.19.0A & In-package criticality resulting from a seismic event (degraded configuration) & $\begin{array}{l}\text { New FEP-partially } \\
\text { replaces 2.1.14.14.0A }\end{array}$ \\
\hline 2.1.14.20.0A & Near-field criticality resulting from a seismic event & $\begin{array}{l}\text { New FEP-partially } \\
\text { replaces 2.1.14.14.0A }\end{array}$ \\
\hline 2.1.14.21.0A & In-package criticality resulting from rockfall (intact configuration) & $\begin{array}{l}\text { New FEP-partially } \\
\text { replaces 2.1.14.14.0A }\end{array}$ \\
\hline 2.1.14.22.0A & In-package criticality resulting from rockfall (degraded configuration) & $\begin{array}{l}\text { New FEP-partially } \\
\text { replaces 2.1.14.14.0A }\end{array}$ \\
\hline 2.1.14.23.0A & Near-field criticality resulting from rockfall & $\begin{array}{l}\text { New FEP-partially } \\
\text { replaces 2.1.14.14.0A }\end{array}$ \\
\hline 2.1.14.24.0A & In-package criticality resulting from an igneous event (intact configuration) & $\begin{array}{l}\text { New FEP-partially } \\
\text { replaces 2.1.14.14.0A }\end{array}$ \\
\hline 2.1.14.25.0A & In-package criticality resulting from an igneous event (degraded configurations) & $\begin{array}{l}\text { New FEP-partially } \\
\text { replaces 2.1.14.14.0A }\end{array}$ \\
\hline 2.1.14.26.0A & Near-field criticality resulting from an igneous event & $\begin{array}{l}\text { New FEP-partially } \\
\text { replaces 2.1.14.14.0A }\end{array}$ \\
\hline 2.2.06.01.0A & Seismic activity changes porosity and permeability of rock & Description edited (E) \\
\hline 2.2.07.01.0A & Locally saturated flow at bedrock/alluvium contact & Description edited $(\mathrm{E})$ \\
\hline 2.2.07.12.0A & Saturated groundwater flow in the geosphere & Description edited $(\mathrm{E})$ \\
\hline 2.2.07.15.0A & Advection and dispersion in the SZ & Description edited $(\mathrm{E}){ }^{* *}$ \\
\hline 2.2.08.04.0A & Redissolution of precipitates directs more corrosive fluids to containers & Description edited $(\mathrm{E})$ \\
\hline 2.2.08.08.0B & Matrix diffusion in the UZ & Description edited $(\mathrm{T})$ \\
\hline 2.2.10.02.0A & Thermal convection cell develops in SZ & Description edited $(\mathrm{E})$ \\
\hline 2.2.10.03.0A & Natural geothermal effects on flow in the SZ & Description edited $(\mathrm{E}){ }^{* *}$ \\
\hline 2.2.12.00.0A & Undetected features in the UZ & Description edited (E) \\
\hline 2.2.14.02.0A & Far-field criticality, precipitation in organic reducing zone in or near water table & $\begin{array}{l}\text { Deleted-replaced by new } \\
\text { criticality FEPs }\end{array}$ \\
\hline 2.2.14.03.0A & Far-field criticality, sorption on clay/zeolite in TSbv & $\begin{array}{l}\text { Deleted-replaced by new } \\
\text { criticality FEPs }\end{array}$ \\
\hline 2.2.14.04.0A & $\begin{array}{l}\text { Far-field criticality, precipitation caused by hydrothermal upwell or redox front } \\
\text { in the SZ }\end{array}$ & $\begin{array}{l}\text { Deleted-replaced by new } \\
\text { criticality FEPs }\end{array}$ \\
\hline 2.2.14.05.0A & Far-field criticality, precipitation in perched water above TSbv & $\begin{array}{l}\text { Deleted-replaced by new } \\
\text { criticality FEPs }\end{array}$ \\
\hline
\end{tabular}


Table C-5. Changes From DTN5 to DTN6 (Continued)

\begin{tabular}{|c|c|c|}
\hline FEP Number & FEP Name & Changes * \\
\hline 2.2.14.06.0A & Far-field criticality, precipitation in fractures of TSw rock & $\begin{array}{l}\text { Deleted-replaced by new } \\
\text { criticality FEPs }\end{array}$ \\
\hline 2.2.14.07.0A & Far-field criticality, dry out produces fissile salt in a perched water basin & $\begin{array}{l}\text { Deleted-replaced by new } \\
\text { criticality FEPs }\end{array}$ \\
\hline 2.2.14.08.0A & Far-field criticality associated with colloidal deposits & $\begin{array}{l}\text { Deleted-replaced by new } \\
\text { criticality FEPs }\end{array}$ \\
\hline 2.2.14.09.0A & Far-field criticality & 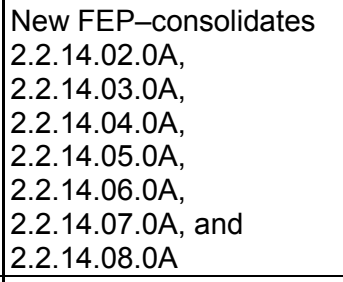 \\
\hline 2.2.14.10.0A & Far-field criticality resulting from a seismic event & $\begin{array}{l}\text { New FEP-partially } \\
\text { replaces 2.1.14.14.0A }\end{array}$ \\
\hline 2.2.14.11.0A & Far-field criticality resulting from rockfall & $\begin{array}{l}\text { New FEP-partially } \\
\text { replaces 2.1.14.14.0A }\end{array}$ \\
\hline 2.2.14.12.0A & Far-field criticality resulting from an igneous event & $\begin{array}{l}\text { New FEP-partially } \\
\text { replaces 2.1.14.14.0A }\end{array}$ \\
\hline 2.3.11.03.0A & Infiltration and recharge & Description edited $(\mathrm{E}) * *$ \\
\hline 2.3.13.01.0A & Biosphere characteristics & Description edited $(\mathrm{E})$ \\
\hline 2.3.13.03.0A & Effects of repository heat on the biosphere & $\begin{array}{l}\text { Name and Description } \\
\text { edited }(\mathrm{E})\end{array}$ \\
\hline 2.3.13.04.0A & Radionuclide release outside the reference biosphere & Description edited (E) \\
\hline 2.4.09.01.0A & Implementation of new agricultural practices or land use & Description edited $(E)$ \\
\hline 2.4.09.01.0B & Agricultural land use and irrigation & Description edited $(E)$ \\
\hline 3.3.08.00.0A & Radon and radon daughter exposure & Description edited $(E)$ \\
\hline
\end{tabular}

${ }^{*}(T)=$ technical change, $(E)=$ editorial change

** Change not documented in "Notes" field of "FEPS" table or in "FEP History File" table.

\section{Changes From DTN6 to DTNLA0}

DTN: MO0407SEPFEPLA.000 [DIRS 170760], created in July 2004, is a qualified version of, and supersedes, DTN: MO0405SEPFEPS6.000 [DIRS 169612]. Both DTNs contain the same interim list of 371 FEPs and the same screening results, from the interim versions of the FEP AMRs. DTN: MO0407SEPFEPLA.000 [DIRS 170760] was created under a qualified TWP (BSC 2004, [DIRS 168024]) and was subject to the requirements of AP-SV.1Q, Control of the Electronic Management of Information (as outlined in Section 8.4 of the TWP). Further, it was reviewed and qualified in accordance with AP-SIII.3Q, Submittal and Incorporation of Data to the Technical Data Management System.

The qualification process resulted in only a few minor editorial changes (e.g., adding missing periods and spaces) in FEP screening information for verbatim agreement between the DTN and the interim FEP AMRs. These changes were so minor that they are not formally documented within DTN: MO0407SEPFEPLA.000 [DIRS 170760]. However, full documentation of the cumulative set of all changes from DTN1 through DTNLA0 (as described in the preceding subsections of this Appendix) is contained in DTN: MO0407SEPFEPLA.000 [DIRS 170760], in the "Notes" field of the "FEPS" table and in the "FEP History File" table. In addition, changes 
from the final TSPA_SR list to DTN1 are also documented in the "Notes" field of the "FEPS" table and in the Deleted FEP Info" table.

\section{Changes From DTNLA0 to DTNLA1}

DTN: MO0501SEPFEPLA.001 [DIRS 172601], produced in January 2005, contains 374 FEPs and contains revised FEP screening results, derived from the analyses documented in The Development of the Total System Performance Assessment-License Application Features, Events, and Processes (BSC 2005 [DIRS 168706], Table 2-7, Section 3, and Section 4). The following substantive changes were made to DTN: MO0407SEPFEPLA.000 [DIRS 170760] to produce DTN: MO0501SEPFEPLA.001 [DIRS 172601]:

- Creation of 3 new independents FEPs by shifting scope from existing FEPs (1 FEP related to seismic induced drift collapse, 1 FEP related to magmatic volatiles, and 1 FEP related to solubility limits)

- Expanded scope for 2 FEPs to incorporate new issues related to advection through cracks in the waste package and drip shield

- Altered scope for 2 FEPs by shifting and/or clarifying existing scope.

- Replacement of interim screening information with revised information from the revised versions of the 10 FEP AMRs listed in The Development of the Total System Performance Assessment-License Application Features, Events, and Processes (BSC 2005 [DIRS 168706], Table 2-7).

These changes are summarized in Table C-6.

Table C-6. Changes From DTNLA0 to DTNLA1

\begin{tabular}{|l|l|l|}
\hline FEP Number & \multicolumn{1}{|c|}{ FEP Name } & \multicolumn{1}{|c|}{ Changes } \\
\hline 1.2.03.02.0D & $\begin{array}{l}\text { Seismic-induced drift collapse alters in-drift } \\
\text { thermohydrology }\end{array}$ & $\begin{array}{l}\text { Description expanded to explicitly address in-drift } \\
\text { condensation subsequent to seismic-induced drift } \\
\text { collapse }\end{array}$ \\
\hline 1.2.03.02.0E & $\begin{array}{l}\text { Seismic-induced drift collapse alters in-drift } \\
\text { chemistry }\end{array}$ & $\begin{array}{l}\text { New FEP to explicitly address the effects of } \\
\text { seismic-induced drift collapse on in-drift chemistry }\end{array}$ \\
\hline 1.2.04.04.0B & $\begin{array}{l}\text { Chemical effects of magma and magmatic } \\
\text { volatiles }\end{array}$ & $\begin{array}{l}\text { New FEP to explicitly consolidate magmatic } \\
\text { volatile issues in a single FEP. }\end{array}$ \\
\hline $2.1 .03 .10 .0 \mathrm{~A}$ & $\begin{array}{l}\text { Advection of liquids and solids through cracks in } \\
\text { the waste package }\end{array}$ & $\begin{array}{l}\text { New scope added to existing FEP on healing of } \\
\text { waste packages }\end{array}$ \\
\hline $2.1 .03 .10 .0 \mathrm{~B}$ & $\begin{array}{l}\text { Advection of liquids and solids through cracks in } \\
\text { the drip shield }\end{array}$ & $\begin{array}{l}\text { New scope added to existing FEP on healing of } \\
\text { drip shields }\end{array}$ \\
\hline $2.1 .11 .09 .0 \mathrm{~B}$ & $\begin{array}{l}\text { Thermally-driven flow (convection) in waste } \\
\text { packages }\end{array}$ & $\begin{array}{l}\text { This FEP was previously split from an EBS focus } \\
\text { into separate in-package and in-drift parts. } \\
\text { However, the FEP name, description, and FEP } \\
\text { AMRs for this, the in-package part, were } \\
\text { erroneously not revised. The proper revisions } \\
\text { were made during this update. * }\end{array}$ \\
\hline $2.2 .08 .07 .0 \mathrm{C}$ & Radionuclide solubility limits in the biosphere & $\begin{array}{l}\text { New FEP to explicitly address solubility limits in } \\
\text { the biosphere }\end{array}$ \\
\hline
\end{tabular}

* Change not documented in "Historical_Notes" field of "FEPS" table or in "FEP History File" table. 
The following additional editorial and consistency changes were also made:

- Minor editorial changes and/or typographical error corrections to FEP names

- Editorial changes to FEP descriptions resulting from FEP AMR Lead and SME reviews | and from a systematic technical edit for consistency.

- Reassignment of input FEP AMRs for a few FEPs

All of these changes for DTNLA1 are fully documented in the "FEP History File" Table within DTN: MO0501SEPFEPLA.001 [DIRS 172601]. Additionally, the "Notes" field of the "FEPS" table, which also documents these changes, along with all previous changes from TSPA-SR through DTNLA0, was copied into a new field in the "FEPS" table in DTN: MO0501SEPFEPLA.001 [DIRS 172601]. As a result, full documentation of the cumulative set of all changes from DTN1 through DTNLA0 (as described in the preceding subsections of this Appendix) is contained in DTN: MO0501SEPFEPLA.001 [DIRS 172601], in the "Historical_Notes" field of the "FEPS" table and in the "FEP History File" table. In addition, changes from the final TSPA_SR list to DTN1 are also documented in the "Historical_Notes" field of the "FEPS" table and in the Deleted FEP Info" table.

DTNLA1 was the first data set completed subsequent to the introduction of the TMRBcontrolled FEP list (BSC 2004 [DIRS 171888], Attachment 1) in August 2004. The controlled FEP list captures all FEP list changes identified in Potential FEP Log items 1 through 45 (see Appendix D), but does not contain any screening results. DTNLA1 contains the identical FEP list, but adds the minor editorial changes to the FEP list identified in Potential FEP Log items 46 and 47 (see Appendix D), and revised screening results.

DTN: MO0501SEPFEPLA.001 [DIRS 172601] was created under a qualified TWP (BSC 2004 [DIRS 168024]), was subject to the requirements in AP-SV.1Q, Control of the Electronic Management of Information (as outlined in Section 8.4 of the TWP), and was reviewed and qualified in accordance with AP-SIII.3Q, Submittal and Incorporation of Data to the Technical Data Management System.

\section{Changes From DTNLA1 to DTNLA2}

The final TSPA-LA FEP list (DTN: MO0508SEPFEPLA.002 [DIRS 175064]), produced in August 2005, contains 375 FEPs and contains final FEP screening results from the FEP AMRs listed in Table 2-7. The following substantive changes were made to the FEP list in DTN: MO0501SEPFEPLA.001 [DIRS 172601] to produce the FEP list in DTN: MO0508SEPFEPLA.002 [DIRS 175064] (References to TMRB configuration control and to the associated Potential FEP Log items (Appendix D) are indicated in parentheses, where applicable):

- Creation of new FEP 1.2.04.04.0C (Magma and gas flow through bulkheads). This new FEP consolidated issues related to the magma bulkheads in a single FEP by shifting scope from other FEPs. No new scope was created. (BSC 2005 [DIRS 174991] and Appendix D, item 50) 
- Changes to the FEP name and description of FEP 2.1.09.28.0A (Localized corrosion on waste package outer surface due to deliquescence) to focus the scope on localized corrosion from deliquescence. Other effects of deliquescence on the waste package are addressed in other FEPs. (BSC 2005 [DIRS 174965] and Appendix D, item 51)

- Changes to the FEP name and description of FEP 2.1.09.28.0B (Localized corrosion on drip shield surfaces due to deliquescence) to focus the scope on localized corrosion from deliquescence. Other effects of deliquescence on the drip shield are addressed in other drip shield FEPs. (BSC 2005 [DIRS 174990] and Appendix D, item 53)

The following additional editorial and consistency changes were also made to the FEP list:

- Minor editorial changes to FEP descriptions for FEPs 3.1.01.01.0A and 3.3.05.01.0A resulting from final FEP AMR Lead and SME reviews. (BSC 2005 [DIRS 174989] and Appendix D, item 52)

- Reassignment of input FEP AMRs for a FEPs 2.1.03.10.0A, 2.1.03.10.0B, and 2.1.09.28.0A

In addition, revisions to several of the FEP AMRs (Table 2-7) subsequent to DTN: MO0501SEPFEPLA.001 [DIRS 172601] resulted in updates to the screening decisions, screening arguments (for excluded FEPs) and TSPA dispositions (for included FEPs) for many FEPs. These revisions documented new information and/or analyses (e.g., Mitchell 2005 [DIRS 173265]) and reflected iterative reviews by DOE subject matter and licensing experts. As identified in the change histories of the FEP AMRs, the revisions focused on, but were not limited to, the following areas:

- Solubility and other geochemical processes in the natural system

- Mountain-scale modeling

- Lateral dispersion of plumes in the unsaturated zone

- Dust deliquescence on the waste package

- Creep of the drip shield

- Fluoride enhanced corrosion of the drip shield

- Magma bulkhead performance.

These revisions to the screening information are captured in the Potential FEP Log (Appendix D, items 48 and 49), but did not result in any changes to the FEP list and are, therefore, not subject to TMRB control.

All of the above changes to the FEP list and to the screening information for DTNLA2 are fully documented in the "FEP History File" table within DTN: MO0508SEPFEPLA.002 [DIRS 175064]. Additionally, the "Historical_Notes" field of the "FEPS" table documents these 
changes, along with all previous changes from TSPA-SR through DTNLA1. As a result, full documentation of the cumulative set of all changes from DTN1 through DTNLA1 (as described in the preceding subsections of this Appendix) is contained in DTN: MO0508SEPFEPLA.002 [DIRS 175064], in the "Historical_Notes" field of the "FEPS" table and in the "FEP History File" table. In addition, changes from the final TSPA_SR list to DTN1 are also documented in the "Historical_Notes" field of the "FEPS" table and in the Deleted FEP Info" table.

DTN: MO0508SEPFEPLA.002 [DIRS 175064] was created under a qualified TWP (BSC 2005, [DIRS 174883]), was subject to the requirements in LP-SV.1Q-BSC, Control of the Electronic Management of Information (as outlined in Section 8.4 of the TWP), and was reviewed and qualified in accordance with AP-SIII.3Q, Submittal and Incorporation of Data to the Technical Data Management System. 
APPENDIX D

FEP CONFIGURATION MANAGEMENT-POTENTIAL FEP LOG 


\section{FEP CONFIGURATION MANAGEMENT-POTENTIAL FEP LOG}

Table D-1. FEP Configuration Management-Potential FEP Log

\begin{tabular}{|c|c|c|c|c|c|c|c|}
\hline $\begin{array}{c}\text { Log } \\
\#\end{array}$ & $\begin{array}{c}\text { Date } \\
\text { Submitted }\end{array}$ & Submitted By & Issue Title & Source & Discussion of Issue & Resolution & $\begin{array}{c}\text { Date of } \\
\text { Resolution }\end{array}$ \\
\hline 1 & $6 / 25 / 2003$ & Geoff Freeze & $\begin{array}{l}\text { Deliquescence on } \\
\text { waste package }\end{array}$ & $\begin{array}{l}\text { Geoff Freeze, } \\
\text { Pete Mast }\end{array}$ & $\begin{array}{l}\text { Preliminary drafts of several EBS } \\
\text { department AMRs were reviewed by } \\
\text { the FEP Team for concurrence with } \\
\text { the Performance Based Incentive } \\
\text { (PBI) criteria for documentation of } \\
\text { included FEPs in supporting AMRs. } \\
\text { During these reviews, which were } \\
\text { completed on March 12, 2003, and } \\
\text { during concurrent discussions } \\
\text { between the FEP Team Lead (Geoff } \\
\text { Freeze) and the EBS FEP Lead } \\
\text { (Pete Mast) it was determined that } \\
\text { the process of deliquescence was } \\
\text { not adequately identified in any } \\
\text { existing FEPs. }\end{array}$ & $\begin{array}{l}\text { New FEP created as part of } \\
\text { DTN: MO0307SEPFEPS4.000 - } \\
\text { 2.1.09.28.0A (Deliquescence on } \\
\text { waste package outer surface) - } \\
\text { Assigned to EBS. }\end{array}$ & $6 / 25 / 2003$ \\
\hline 2 & $6 / 25 / 2003$ & Geoff Freeze & $\begin{array}{l}\text { Deliquescence on } \\
\text { drip shield }\end{array}$ & $\begin{array}{l}\text { Geoff Freeze, } \\
\text { Pete Mast }\end{array}$ & $\begin{array}{l}\text { Preliminary drafts of several EBS } \\
\text { department AMRs were reviewed by } \\
\text { the FEP Team for concurrence with } \\
\text { the Performance Based Incentive } \\
\text { (PBI) criteria for documentation of } \\
\text { included FEPs in supporting AMRs. } \\
\text { During these reviews, which were } \\
\text { completed on March 12, 2003, and } \\
\text { during concurrent discussions } \\
\text { between the FEP Team Lead (Geoff } \\
\text { Freeze) and the EBS FEP Lead } \\
\text { (Pete Mast) it was determined that } \\
\text { the process of deliquescence was } \\
\text { not adequately identified in any } \\
\text { existing FEPs. }\end{array}$ & $\begin{array}{l}\text { New FEP created as part of } \\
\text { DTN: MO0307SEPFEPS4.000 - } \\
\text { 2.1.09.28.0B (Deliquescence on } \\
\text { drip shield outer surface) - } \\
\text { Assigned to EBS. }\end{array}$ & $6 / 25 / 2003$ \\
\hline
\end{tabular}


Table D-1. FEP Configuration Management-Potential FEP Log (Continued)

\begin{tabular}{|c|c|c|c|c|c|c|c|}
\hline $\begin{array}{c}\text { Log } \\
\#\end{array}$ & $\begin{array}{c}\text { Date } \\
\text { Submitted }\end{array}$ & Submitted By & Issue Title & Source & Discussion of Issue & Resolution & $\begin{array}{c}\text { Date of } \\
\text { Resolution }\end{array}$ \\
\hline 3 & $8 / 20 / 2003$ & Geoff Freeze & $\begin{array}{l}\text { Cold traps outside } \\
\text { repository }\end{array}$ & $\begin{array}{l}\text { Ernie Hardin, } \\
\text { Ovadia Lev }\end{array}$ & $\begin{array}{l}\text { Cold traps outside repository was } \\
\text { raised as an issue during } \\
\text { preparation of TSPA-SR FEP AMRs } \\
\text { at the same time FEPs for cold } \\
\text { traps inside the repository were } \\
\text { introduced. }\end{array}$ & $\begin{array}{l}\text { Covered by existing FEP - } \\
\text { 2.2.07.10.0A (Condensation zone } \\
\text { forms around drifts). Documented } \\
\text { in UZ FEP AMR (ANL-NBS-MD- } \\
\text { 000001REV 02B). }\end{array}$ & $8 / 29 / 2003$ \\
\hline 4 & 8/20/2003 & Geoff Freeze & $\begin{array}{l}\text { Criticality following } \\
\text { waste package early } \\
\text { failure }\end{array}$ & $\begin{array}{l}\text { Dan } \\
\text { McGregor, } \\
\text { Rob Howard }\end{array}$ & $\begin{array}{l}\text { In an e-mail dated 06/13/01, Dan } \\
\text { McGregor (SYS/CRIT FEP AMR } \\
\text { Lead) drafted a paragraph that } \\
\text { discussed whether an early waste } \\
\text { package failure could lead to a } \\
\text { criticality. }\end{array}$ & $\begin{array}{l}\text { This issue is explicitly addressed in } \\
\text { FEPs documented in the CRIT FEP } \\
\text { AMR (ANL-EBS-NU-000008 REV } \\
\text { OOF3). In the CRIT FEP AMR, a } \\
\text { new set of criticality FEPs was } \\
\text { produced, superseding the set in } \\
\text { DTN: MO0307SEPFEPS4.000. } \\
\text { Criticality following waste package } \\
\text { early failure is addressed in base } \\
\text { case FEPs 2.1.14.16.0A (in-situ), } \\
\text { 2.1.14.17.0A (near-field), and } \\
\text { 2.2.14.09.0A (far-field) }\end{array}$ & $1 / 14 / 2003$ \\
\hline 5 & 8/20/2003 & Geoff Freeze & $\begin{array}{l}\text { Criticality resulting } \\
\text { from disruptive } \\
\text { events }\end{array}$ & Geoff Freeze & $\begin{array}{l}\text { In a draft of the Criticality FEP AMR, } \\
\text { the screening for FEP 2.1.14.14.0A } \\
\text { (Criticality resulting from disruptive } \\
\text { events) was broken into three } \\
\text { categories - seismic, igneous, and } \\
\text { rockfall as per the description. The } \\
\text { approach to screening is different } \\
\text { for each of these categories. Are } \\
\text { separate FEPs needed? }\end{array}$ & $\begin{array}{l}\text { In the CRIT FEP AMR (ANL-EBS- } \\
\text { NU-000008 REV 00F3), a new set } \\
\text { of criticaliti FEPs was produced, } \\
\text { superseding the set in } \\
\text { DTN: MO0307SEPFEPS4.000. } \\
\text { There are a total of } 16 \text { criticality } \\
\text { FEPs: } 4 \text { for the nominal case, } 4 \text { for } \\
\text { seismic events, } 4 \text { for igneous } \\
\text { events, and } 4 \text { for rockfall events. } \\
\text { Three new Descriptor Phrases were } \\
\text { also added: "Criticality (from a } \\
\text { seismic event)", "Criticality (from an } \\
\text { igneous event)", and "Criticality } \\
\text { (from a rockfall event)". }\end{array}$ & $1 / 14 / 2003$ \\
\hline
\end{tabular}


Table D-1. FEP Configuration Management-Potential FEP Log (Continued)

\begin{tabular}{|c|c|c|c|c|c|c|c|}
\hline $\begin{array}{c}\text { Log } \\
\#\end{array}$ & $\begin{array}{c}\text { Date } \\
\text { Submitted }\end{array}$ & Submitted By & Issue Title & Source & Discussion of Issue & Resolution & $\begin{array}{c}\text { Date of } \\
\text { Resolution }\end{array}$ \\
\hline 6 & 8/20/2003 & Geoff Freeze & $\begin{array}{l}\text { Effects of corrosive } \\
\text { gases }\end{array}$ & Bret Leslie & $\begin{array}{l}\text { In a Draft version of an NFE } \\
\text { evaluation file from Bret Leslie } \\
\text { (NRC) dated 11/29/00, it was stated } \\
\text { that TSPA-SR FEP 2.1.12.01.00 } \\
\text { had an "inadequate technical basis } \\
\text { that the presence of corrosive } \\
\text { gases would be low consequence. }\end{array}$ & $\begin{array}{l}\text { This issue is explicitly addressed in } \\
\text { FEPs } 2.1 .03 .01 .0 B \text { (General } \\
\text { corrosion of drip shields) and } \\
2.1 .03 .01 .0 A \text { (General corrosion of } \\
\text { waste packages) in the WP FEP } \\
\text { AMR (ANL-EBS-PA-000002 REV } \\
\text { O2F). Descriptor Phrases were also } \\
\text { added to each of these } \\
\text { FEPs: "Effects of corrosive gases } \\
\text { on corrosion of waste packages" } \\
\text { and "Effects of corrosive gases on } \\
\text { corrosion of drip shields" }\end{array}$ & 1/20/2004 \\
\hline 7 & $8 / 20 / 2003$ & Geoff Freeze & $\begin{array}{l}\text { Effects of temporal } \\
\text { changes in SZ } \\
\text { chemistry on } \\
\text { radionuclide } \\
\text { concentrations }\end{array}$ & Bradbury & $\begin{array}{l}\text { In an e-mail dated 4/17/03, Kathy } \\
\text { Economy (SZ FEP AMR Lead) } \\
\text { noted that KTI TSPAI } 3.31 \text { states } \\
\text { "DOE will evaluate the effects of } \\
\text { temporal changes in saturated zone } \\
\text { chemistry on radionuclide } \\
\text { concentrations". Kathy Economy } \\
\text { suggests a description as } \\
\text { follows: "Potential swings in } \\
\text { saturated zone groundwater redox } \\
\text { conditions (from reducing to } \\
\text { oxidizing waters) could cause } \\
\text { significant variation in redox } \\
\text { sensitive radionuclide } \\
\text { concentrations. The radionuclides } \\
\text { most likely to be affected are Np, } \\
\text { Pu, Tc, and U. This situation could } \\
\text { lead to a large pulse of } \\
\text { radionuclides, that were sorbed to } \\
\text { the host rock, to desorb then be } \\
\text { transported in solution to the } 18 \mathrm{~km} \\
\text { boundary." }\end{array}$ & $\begin{array}{l}\text { This issue is explicitly addressed in } \\
\text { the Supplemental Discussion of } \\
\text { FEP 2.2.08.03.0A (Geochemical } \\
\text { interactions and evolution in the SZ) } \\
\text { in the SZ FEP AMR (ANL-NBS-MD- } \\
000002 \text { REV 02F). }\end{array}$ & $12 / 4 / 2003$ \\
\hline
\end{tabular}


Table D-1. FEP Configuration Management-Potential FEP Log (Continued)

\begin{tabular}{|c|c|c|c|c|c|c|c|}
\hline $\begin{array}{c}\text { Log } \\
\#\end{array}$ & $\begin{array}{c}\text { Date } \\
\text { Submitted }\end{array}$ & Submitted By & Issue Title & Source & Discussion of Issue & Resolution & $\begin{array}{c}\text { Date of } \\
\text { Resolution }\end{array}$ \\
\hline 8 & 8/20/2003 & Geoff Freeze & $\begin{array}{l}\text { Thermal } \\
\text { consequences of } \\
\text { early drift collapse }\end{array}$ & Jim Blink & $\begin{array}{l}\text { An e-mail from Jim Blink } \\
\text { (PASS/DSDD) dated 3/13/03 asks } \\
\text { whether there is a FEP for thermal } \\
\text { consequences of relatively early } \\
\text { drift collapse. Unstated, but } \\
\text { assumed, is that the early collapse } \\
\text { results from a seismic event. }\end{array}$ & $\begin{array}{l}\text { New FEP created - 1.2.03.02.0D } \\
\text { (Seismic induced drift collapse } \\
\text { alters in-drift thermohydrology) - } \\
\text { Assigned to EBS and DE. The } \\
\text { seismic effects on drift collapse are } \\
\text { addressed in the DE FEP AMR } \\
\text { (ANL-WIS-MD-000005 REV 01). } \\
\text { The effects on thermohydrology are } \\
\text { addressed in the EBS FEP AMR } \\
\text { (ANL-WIS-PA-000002 REV 02F). }\end{array}$ & \begin{tabular}{|l}
$10 / 31 / 2003$ \\
(DE) \\
$04 / 07 / 2004$ \\
(EBS)
\end{tabular} \\
\hline 9 & 8/20/2003 & Geoff Freeze & $\begin{array}{l}\text { Flow in EBS after } \\
\text { drift collapse }\end{array}$ & Jim Blink & $\begin{array}{l}\text { An e-mail from Jim Blink } \\
\text { (PASS/DSDD) dated } 3 / 13 / 03 \text { asks } \\
\text { whether there is a FEP for how } \\
\text { water contact with the engineered } \\
\text { barriers changes after drift collapse. } \\
\text { Unstated, but assumed, is that the } \\
\text { early collapse results from a seismic } \\
\text { event. }\end{array}$ & $\begin{array}{l}\text { New FEP created }-1.2 .03 .02 .0 D \\
\text { (Seismic induced drift collapse } \\
\text { alters in-drift thermohydrology) - } \\
\text { Assigned to EBS and DE. The } \\
\text { seismic effects on drift collapse are } \\
\text { addressed in the DE FEP AMR } \\
\text { (ANL-WIS-MD-000005 REV 01). } \\
\text { The effects on thermohydrology are } \\
\text { addressed in the EBS FEP AMR } \\
\text { (ANL-WIS-PA-000002 REV 02F). }\end{array}$ & \begin{tabular}{|l}
$10 / 31 / 2003$ \\
(DE) \\
$04 / 07 / 2004$ \\
(EBS)
\end{tabular} \\
\hline
\end{tabular}


Table D-1. FEP Configuration Management-Potential FEP Log (Continued)

\begin{tabular}{|c|c|c|c|c|c|c|c|}
\hline $\begin{array}{c}\text { Log } \\
\#\end{array}$ & $\begin{array}{c}\text { Date } \\
\text { Submitted }\end{array}$ & Submitted By & Issue Title & Source & Discussion of Issue & Resolution & $\begin{array}{c}\text { Date of } \\
\text { Resolution }\end{array}$ \\
\hline 10 & $8 / 21 / 2003$ & Geoff Freeze & $\begin{array}{l}\text { Invert performance } \\
\text { after drift collapse }\end{array}$ & Jim Blink & $\begin{array}{l}\text { An e-mail from Jim Blink } \\
\text { (PASS/DSDD) dated } 3 / 13 / 03 \text { asks } \\
\text { whether there is a FEP for invert } \\
\text { performance after collapse. }\end{array}$ & $\begin{array}{l}\text { For seismic induced drift collapse, } \\
\text { this issue in now addressed as part } \\
\text { of new FEPs 1.2.03.02.0C (Seismic } \\
\text { induced drift collapse damages EBS } \\
\text { components) and 1.2.03.02.0D } \\
\text { (Seismic induced drift collapse } \\
\text { alters in-drift thermohydrology) - } \\
\text { Both are assigned to EBS and DE. } \\
\text { The seismic effects on drift collapse } \\
\text { are addressed in the DE FEP AMR } \\
\text { (ANL-WIS-MD-000005 REV 01). } \\
\text { The effects on thermohydrology are } \\
\text { addressed in the EBS FEP AMR } \\
\text { (ANL-WIS-PA-000002 REV 02F). } \\
\text { For nominal drift collapse, this issue } \\
\text { is now addressed as part of FEP } \\
\text { 2.1.07.02.0A (Drift collapse) in the } \\
\text { EBS FEP AMR (ANL-WIS-PA- } \\
000002 \text { REV 02F). A new } \\
\text { Descriptor Phrase was also } \\
\text { added: "Drift collapse (invert } \\
\text { damage)". }\end{array}$ & $\begin{array}{l}10 / 31 / 2003 \\
(\mathrm{DE}) \\
04 / 07 / 2004 \\
(\mathrm{EBS})\end{array}$ \\
\hline 11 & $8 / 21 / 2003$ & Geoff Freeze & $\begin{array}{l}\text { Contamination of WP } \\
\text { outer surface prior to } \\
\text { emplacement }\end{array}$ & $\begin{array}{l}\text { Mark Tynan, } \\
\text { Kirk Lachman }\end{array}$ & $\begin{array}{l}\text { An e-mail from Mark Tynan (DOE) } \\
\text { notes that current plans do not call } \\
\text { for decontamination of WP prior to } \\
\text { emplacement and that } \\
\text { contamination from packaging and } \\
\text { handling might impact releases. } \\
\text { Subsequent report on } \\
\text { "Recommended Surface } \\
\text { Contamination Limits for Waste } \\
\text { Packages Prior to Placement in the } \\
\text { Repository" proposes design limits. } \\
\text { Therefore, exceeding the surface } \\
\text { contamination limit can be covered } \\
\text { as a "design deviation". If limits } \\
\text { were not in place then surface } \\
\text { contamination could be also be } \\
\text { covered as an "undesirable material } \\
\text { left" }\end{array}$ & $\begin{array}{l}\text { This issue is addressed in FEP } \\
\text { 1.1.03.01.0A (Error in waste } \\
\text { emplacement) in the EBS FEP AMR } \\
\text { (ANL-WIS-PA-000002 REV 02F). }\end{array}$ & $4 / 7 / 2004$ \\
\hline
\end{tabular}


Table D-1. FEP Configuration Management-Potential FEP Log (Continued)

\begin{tabular}{|c|c|c|c|c|c|c|c|}
\hline$\stackrel{\text { Log }}{\#}$ & $\begin{array}{c}\text { Date } \\
\text { Submitted }\end{array}$ & Submitted By & Issue Title & Source & Discussion of Issue & Resolution & $\begin{array}{c}\text { Date of } \\
\text { Resolution }\end{array}$ \\
\hline 12 & $8 / 21 / 2003$ & Geoff Freeze & Burnup misload & Paige Russell & $\begin{array}{l}\text { An e-mail from Paige Russell (DOE) } \\
\text { notes that current plans do not call } \\
\text { for verification measurements of } \\
\text { fuel burnup. Therefore, "burnup } \\
\text { misload" must be evaluated. The } \\
\text { issue is that if burnup of fuel is not } \\
\text { as great as our design burnup then } \\
\text { the probability of criticality is } \\
\text { increased. }\end{array}$ & $\begin{array}{l}\text { This issue is addressed in the CRIT } \\
\text { FEP AMR (ANL-EBS-NU-00008 } \\
\text { REV 00F3). In the CRIT FEP AMR, } \\
\text { a new set of criticality FEPs was } \\
\text { produced, superseding the set in } \\
\text { DTN: MO0307SEPFEPS4.000. } \\
\text { Criticality associated with burnup } \\
\text { misload is addressed in base case } \\
\text { FEPs 2.1.14.16.0A (in-situ), } \\
\text { 2.1.14.17.0A (near-field), and } \\
\text { 2.2.14.09.0A (far-field). This issue } \\
\text { is also noted as a part of FEP } \\
1.1 .03 .01 .0 A \text { in the WP FEP AMR } \\
\text { (ANL-EBS-PA-000002 REV 02E). }\end{array}$ & $1 / 14 / 2003$ \\
\hline 13 & $8 / 21 / 2003$ & Geoff Freeze & $\begin{array}{l}\text { Crud on surface of } \\
\text { CSNF }\end{array}$ & Eric Siegmann & $\begin{array}{l}\text { An e-mail from Eric Siegmann } \\
\text { (CLAD FEP AMR Lead) notes that } \\
\text { we must (based on NRC } \\
\text { comments) address the issue of } \\
\text { "crud on CSNF surfaces". The } \\
\text { Inventory AMR (ANL-WIS-MD- } \\
\text { 000020) suggests that } \\
\text { "radionuclides from activated } \\
\text { mineral deposits (crud)" can be } \\
\text { excluded, but that Tc-99 and C-14 } \\
\text { from activation of CSNF assembly } \\
\text { hardware is included. }\end{array}$ & $\begin{array}{l}\text { This issue is addressed in FEP } \\
\text { 2.1.01.01.0A (Waste inventory) in } \\
\text { the WF FEP AMR (ANL-WIS-MD- } \\
\text { 000009 REV 01E) }\end{array}$ & 3/24/2004 \\
\hline
\end{tabular}


Table D-1. FEP Configuration Management-Potential FEP Log (Continued)

\begin{tabular}{|c|c|c|c|c|c|c|c|}
\hline$\stackrel{\text { Log }}{\#}$ & $\begin{array}{c}\text { Date } \\
\text { Submitted }\end{array}$ & Submitted By & Issue Title & Source & Discussion of Issue & Resolution & $\begin{array}{c}\text { Date of } \\
\text { Resolution }\end{array}$ \\
\hline 14 & $8 / 21 / 2003$ & Geoff Freeze & $\begin{array}{l}\text { Effects of basket } \\
\text { degradation on } \\
\text { cladding }\end{array}$ & $\begin{array}{l}\text { International } \\
\text { Peer Review } \\
\text { Panel }\end{array}$ & $\begin{array}{l}\text { As noted in Section } 7.4 \text { of the Clad } \\
\text { Degradation AMR (ANL-WIS-MD- } \\
000021 \text { ), "effects of the degradation } \\
\text { of basket components on cladding } \\
\text { integrity" need to be addressed. } \\
\text { The AMR suggests that it is } \\
\text { excluded and will be addressed in } \\
\text { 2.1.09.03.0A which is an included } \\
\text { FEP. }\end{array}$ & $\begin{array}{l}\text { This issue is addressed in two FEPs } \\
\text { in the CLAD FEP AMR (ANL-WIS- } \\
\text { MD-000008 REV 01G). In FEP } \\
\text { 2.1.02.24.0A (Mechanical impact on } \\
\text { cladding) the effects of short-term } \\
\text { (dynamic) stresses from the impact } \\
\text { of degraded basket components on } \\
\text { the outside of the cladding are } \\
\text { addressed. In FEP 2.1.09.03.0A } \\
\text { (Volume increase of corrosion } \\
\text { products impacts cladding) the } \\
\text { effects of longer-term (static) } \\
\text { stresses from basket corrosion } \\
\text { product volume increase on the } \\
\text { inside of the cladding are } \\
\text { addressed. }\end{array}$ & $1 / 27 / 2003$ \\
\hline 15 & $8 / 21 / 2003$ & Geoff Freeze & $\begin{array}{l}\text { Cladding damage } \\
\text { from drift collapse }\end{array}$ & $\begin{array}{l}\text { International } \\
\text { Peer Review } \\
\text { Panel }\end{array}$ & $\begin{array}{l}\text { As noted in Section } 7.5 \text { of the Clad } \\
\text { Degradation AMR (ANL-WIS-MD- } \\
000021 \text { ), "breakage of cladding } \\
\text { from the static loading of rock } \\
\text { overburden" needs a stronger } \\
\text { technical basis for the exclusion } \\
\text { argument. The AMR suggests that } \\
\text { it is addressed in 2.1.07.0A (typo - } \\
\text { is it 01.0A or 02.0A?). }\end{array}$ & $\begin{array}{l}\text { This issue is addressed as part of } \\
\text { FEP 2.1.07.02.0A (Drift collapse) in } \\
\text { the EBS FEP AMR (ANL-WIS-PA- } \\
000002 \text { REV 02F). A new } \\
\text { Descriptor Phrase was also } \\
\text { added: "Drift collapse (cladding } \\
\text { damage)". }\end{array}$ & $4 / 7 / 2004$ \\
\hline
\end{tabular}


Table D-1. FEP Configuration Management-Potential FEP Log (Continued)

\begin{tabular}{|c|c|c|c|c|c|c|c|}
\hline $\begin{array}{c}\log \\
\# \\
\end{array}$ & $\begin{array}{c}\text { Date } \\
\text { Submitted }\end{array}$ & Submitted By & Issue Title & Source & Discussion of Issue & Resolution & $\begin{array}{c}\text { Date of } \\
\text { Resolution }\end{array}$ \\
\hline 16 & $8 / 21 / 2003$ & Geoff Freeze & $\begin{array}{l}\text { Static loading } \\
\text { damage from drift } \\
\text { collapse }\end{array}$ & Geoff Freeze & $\begin{array}{l}\text { Damage to WP, WF, and cladding } \\
\text { from static loading of rock } \\
\text { overburden (e.g., drift collapse) is } \\
\text { not explicitly addressed in the } \\
\text { FEPs. Note that the } 3 \text { "mechanical } \\
\text { impact on..." FEPs are limited to } \\
\text { dynamic loading. General static } \\
\text { loading between components is } \\
\text { covered by 2.1.06.07.0B. }\end{array}$ & $\begin{array}{l}\text { New FEP created - } 1.2 .03 .02 .0 \mathrm{C} \\
\text { (Seismic induced drift collapse } \\
\text { damages EBS components)- } \\
\text { Assigned to EBS and DE. The } \\
\text { seismic effects on drift collapse are } \\
\text { addressed in the DE FEP AMR } \\
\text { (ANL-WIS-MD-000005 REV 01). } \\
\text { The mechanical consequences of } \\
\text { seismic drift collapse are addressed } \\
\text { in the EBS FEP AMR (ANL-WIS- } \\
\text { PA-000002 REV 02F). } \\
\\
\text { For nominal drift collapse, this issue } \\
\text { is addressed as part of FEP } \\
\text { 2.1.07.02.0A (Drift collapse) in the } \\
\text { EBS FEP AMR (ANL-WIS-PA- } \\
\text { 000002 REV 02F). The FEP } \\
\text { Description was expanded. }\end{array}$ & $\begin{array}{l}10 / 31 / 2003 \\
(\mathrm{DE}) \\
04 / 07 / 2004 \\
\text { (EBS) }\end{array}$ \\
\hline 17 & $9 / 23 / 2003$ & Geoff Freeze & $\begin{array}{l}\text { Competitive sorption } \\
\text { between corrosion } \\
\text { products (heavy } \\
\text { metals) and } \\
\text { radionuclides may } \\
\text { reduce sorption of } \\
\text { radionuclides }\end{array}$ & Abe Van Luik & $\begin{array}{l}\text { In an e-mail dated 9/22/03, Abe Van } \\
\text { Luik summarized an issue identified } \\
\text { by a member of the public at a } \\
\text { recent NWTRB meeting and } \\
\text { documented in a draft article in Risk } \\
\text { Analysis journal authored by Jacob } \\
\text { Paz, William Gulbreth, and Delbert } \\
\text { Barth. Specifically, they suggest } \\
\text { that "TSPA fails to consider the } \\
\text { competition between [corrosion } \\
\text { products (heavy metals)] and } \\
\text { radionuclides for the limited sorptive } \\
\text { capacity of the rock and sediment } \\
\text { along the transport pathways to the } \\
\text { compliance point". If the effects of } \\
\text { competitive sorption were significant } \\
\text { then the sorptive capacity for } \\
\text { radionuclides might be reduced. In } \\
\text { a further e-mail dated 9/23/03, Van } \\
\text { Luik points out that this issue was } \\
\text { addressed in SR FEP 2.1.09.02.00. }\end{array}$ & $\begin{array}{l}\text { This issue is addressed as part of } \\
\text { FEP 2.1.09.02.0A in the EBS FEP } \\
\text { AMR (ANL-WIS-PA-000002 REV } \\
\text { 03F). It is captured, broadly, in the } \\
\text { FEP Description. }\end{array}$ & $11 / 3 / 2004$ \\
\hline
\end{tabular}


Table D-1. FEP Configuration Management-Potential FEP Log (Continued)

\begin{tabular}{|c|c|c|c|c|c|c|c|}
\hline $\begin{array}{c}\text { Log } \\
\#\end{array}$ & $\begin{array}{c}\text { Date } \\
\text { Submitted }\end{array}$ & Submitted By & Issue Title & Source & Discussion of Issue & Resolution & $\begin{array}{c}\text { Date of } \\
\text { Resolution }\end{array}$ \\
\hline 18 & $10 / 17 / 2003$ & Geoff Freeze & $\begin{array}{l}\text { Atmospheric gas } \\
\text { phase transport } \\
\text { associated with an } \\
\text { igneous event }\end{array}$ & $\begin{array}{l}\text { Steve } \\
\text { Cereghino, } \\
\text { Terry Crump }\end{array}$ & $\begin{array}{l}\text { The potential for releases of } \\
\text { gaseous radionuclides produced by } \\
\text { interactions between the waste } \\
\text { forms and a basaltic dike is not } \\
\text { explicitly addressed in the FEPs. } \\
\text { Suggest adding a new FEP } \\
\text { described by, "Exposure of waste } \\
\text { forms to thermal and chemical } \\
\text { effects associated with postclosure } \\
\text { intrusion of a dike into repository } \\
\text { drifts could alter the waste forms } \\
\text { resulting in development of gaseous } \\
\text { radionuclides that could be a source } \\
\text { of dose to the RMEl during the } \\
\text { postclosure performance period." }\end{array}$ & $\begin{array}{l}\text { A discussion of the formation of } \\
\text { gaseous radionuclides associated } \\
\text { with magma contacting waste is } \\
\text { already present in FEP } \\
1.2 .04 .04 .0 A \text { (Igneous intrusion } \\
\text { interacts with EBS components) in } \\
\text { the DE FEP AMR (ANL-WIS-MD- } \\
000002 \text { REV 02F). The conclusion } \\
\text { is that volatiles do not form. An } \\
\text { additional paragraph has also been } \\
\text { added to further address the issue. } \\
\text { The paragraph concludes that } \\
\text { "melting or volatilization of spent } \\
\text { fuel does not need to be considered } \\
\text { further". } \\
\text { Further details regarding this issue } \\
\text { are documented in the Comment } \\
\text { Sheet documenting the response to } \\
\text { AP-2.14Q comment } 119 \text { from Steve } \\
\text { Cereghino (LAP) for Features, } \\
\text { Events, and Processes: Disruptive } \\
\text { Events (ANL-WIS-MD-000005 } \\
\text { REV 01D) dated 10/13/03. }\end{array}$ & $10 / 20 / 2004$ \\
\hline
\end{tabular}


Table D-1. FEP Configuration Management-Potential FEP Log (Continued)

\begin{tabular}{|c|c|c|c|c|c|c|c|}
\hline $\begin{array}{c}\text { Log } \\
\#\end{array}$ & $\begin{array}{c}\text { Date } \\
\text { Submitted }\end{array}$ & Submitted By & Issue Title & Source & Discussion of Issue & Resolution & $\begin{array}{c}\text { Date of } \\
\text { Resolution }\end{array}$ \\
\hline 19 & $10 / 28 / 2003$ & Geoff Freeze & $\begin{array}{l}\text { Combined FEPs and } \\
\text { interactions between } \\
\text { low consequence } \\
\text { FEPs }\end{array}$ & Mark Tynan & $\begin{array}{l}\text { In an e-mail from Mark Tynan dated } \\
09 / 23 / 03 \text {, it was suggested that it } \\
\text { might be necessary to examine } \\
\text { combined effects of FEPs that were } \\
\text { excluded individually by low } \\
\text { consequence to see if the screening } \\
\text { decision was still correct for the } \\
\text { combined effects. In a follow-up e- } \\
\text { mail from Tynan dated } 10 / 24 / 03 \text {, he } \\
\text { re-iterates that the project needs to } \\
\text { formally address the effects of } \\
\text { combined FEPs, either in FEP } \\
\text { analysis or in scenario screening. } \\
\text { Specific examples were pointed out } \\
\text { by Bob Fish in a } 9 / 23 / 03 \text { e-mail } \\
\text { (1. Drip shield structural failure in } \\
\text { response to rockfall following early } \\
\text { drip shield failure from SCC, and } \\
2 \text {. Early drip shield failure from } \\
\text { SCC enhanced by rockfall), Sixto } \\
\text { Almodovar in a } 9 / 15 / 03 \text { e-mail } \\
\text { (3. Seismically induced changes in } \\
\text { flow - as per FEP } 1.2 .10 .01 .0 A \text { - } \\
\text { may be of importance to criticality), } \\
\text { and Mark Tynan/Jerry King/Eric } \\
\text { Smistad in a } 10 / 23 / 03 \text { e-mail } \\
\text { (4. Igneous intrusion produces } \\
\text { temperature increases in adjacent } \\
\text { drifts that could increase the } \\
\text { susceptibility to localized corrosion). }\end{array}$ & $\begin{array}{l}\text { A systematic combination of all } \\
\text { FEPs excluded by low consequence } \\
\text { is not feasible. The number of } \\
\text { permutations are simply too high to } \\
\text { do it without exercising judgment. } \\
\text { In any case, the most logical and } \\
\text { relevant combinations have been in } \\
\text { formally considered by SMEs as } \\
\text { they reviewed their FEPs and } \\
\text { produced their FEP AMRs. Also, } \\
\text { combining FEPs that have been } \\
\text { screened out and then re-evaluating } \\
\text { them is an additional step not } \\
\text { required by the regulation or } \\
\text { expected by the YMRP. } \\
\text { However, combined low } \\
\text { consequence FEPs will be } \\
\text { evaluated on a case-by-case basis } \\
\text { as specific combinations are } \\
\text { identified by either DOE or NRC. } \\
\text { Significant combinations are likely } \\
\text { only from DE FEPs combined with } \\
\text { nominal FEPs. } \\
\text { A discussion of combined SCC and } \\
\text { rockfall (issues } 1 \text { and } 2 \text { ) is } \\
\text { presented in FEP 2.1.03.02.0B } \\
\text { (SCC of drip shields) in the WP FEP } \\
\text { AMR (ANL-EBS-PA-000002 } \\
\text { REV 03D). } \\
\text { A discussion of seismic related } \\
\text { changes in seepage (issue } 3 \text { ) is } \\
\text { presented in FEP } 2.1 .14 .19 .0 A \text { (In- } \\
\text { package crit from seismic) in the } \\
\text { CRIT FEP AMR (ANL-EBS-NU- } \\
\text { 000008 REV 01). } \\
\text { A discussion of igneous related } \\
\text { increases in temperature (issue } 4 \text { ) } \\
\text { is presented in FEP 1.2.04.04.0A } \\
\text { (Igneous intrusion interacts with } \\
\text { EBS) in the DE FEP AMR (ANL- } \\
\text { WIS-MD-000002 REV 02F). }\end{array}$ & $\begin{array}{l}09 / 16 / 2004 \\
\text { (WP) } \\
10 / 20 / 2004 \\
(\mathrm{DE}) \\
10 / 26 / 2004 \\
(\mathrm{CRIT})\end{array}$ \\
\hline
\end{tabular}


Table D-1. FEP Configuration Management-Potential FEP Log (Continued)

\begin{tabular}{|c|c|c|c|c|c|c|c|}
\hline$\stackrel{\log }{\#}$ & $\begin{array}{c}\text { Date } \\
\text { Submitted }\end{array}$ & Submitted By & Issue Title & Source & Discussion of Issue & Resolution & $\begin{array}{c}\text { Date of } \\
\text { Resolution }\end{array}$ \\
\hline 20 & $11 / 6 / 2003$ & Geoff Freeze & $\begin{array}{l}\text { Magma encounters } \\
\text { water in a drift }\end{array}$ & Eric Smistad & $\begin{array}{l}\text { In an e-mail from Eric Smistad to } \\
\text { Dan McGregor dated } 11 / 06 / 03 \text {, it } \\
\text { was asked whether "magma } \\
\text { encountering water in drift" was a } \\
\text { FEP. In a response e-mail from } \\
\text { McGregor dated } 11 / 06 / 03, \text { he } \\
\text { indicated that the broader issue of } \\
\text { "hydrovolcanic eruption" (magma } \\
\text { intrudes a shallow water table, } \\
\text { produces an eruption and resulting } \\
\text { crater) is addressed, but that the } \\
\text { specific in-drift issue was not. }\end{array}$ & $\begin{array}{l}\text { Magma (moving as effusive flow) } \\
\text { encountering water in a drift can } \\
\text { have } 2 \text { possible } \\
\text { consequences: (1) hydrovolcanic } \\
\text { eruption does not occur and } \\
\text { effusive flow is unaffected, because } \\
\text { pressurization of water is dissipated } \\
\text { through the drift openings; } \\
\text { (2) hydrovolcanic eruption occurs, } \\
\text { and effusive flow becomes a two- } \\
\text { phase flow system due to } \\
\text { pressurization of water that does } \\
\text { not dissipate. Effusive flow is } \\
\text { addressed in FEP } 1.2 .04 .03 .0 \mathrm{~A} \\
\text { (Igneous intrusion into repository). } \\
\text { Hydrovolcanic eruption is } \\
\text { addressed in FEPs } 1.2 .04 .05 .0 \mathrm{~A} \\
\text { (magma or pyroclastic base surge } \\
\text { transports waste) and 1.2.04.06.0A } \\
\text { (Eruptive conduit to surface } \\
\text { intersects repository). The } \\
\text { discussions in the DE FEP AMR } \\
\text { (ANL-WIS-MD-000002 REV 02F) } \\
\text { for these FEPs are sufficient to } \\
\text { bound the possible effects of } \\
\text { magma encountering water in a } \\
\text { drift. Therefore an explicit } \\
\text { discussion is not provided. }\end{array}$ & $10 / 20 / 2004$ \\
\hline
\end{tabular}


Table D-1. FEP Configuration Management-Potential FEP Log (Continued)

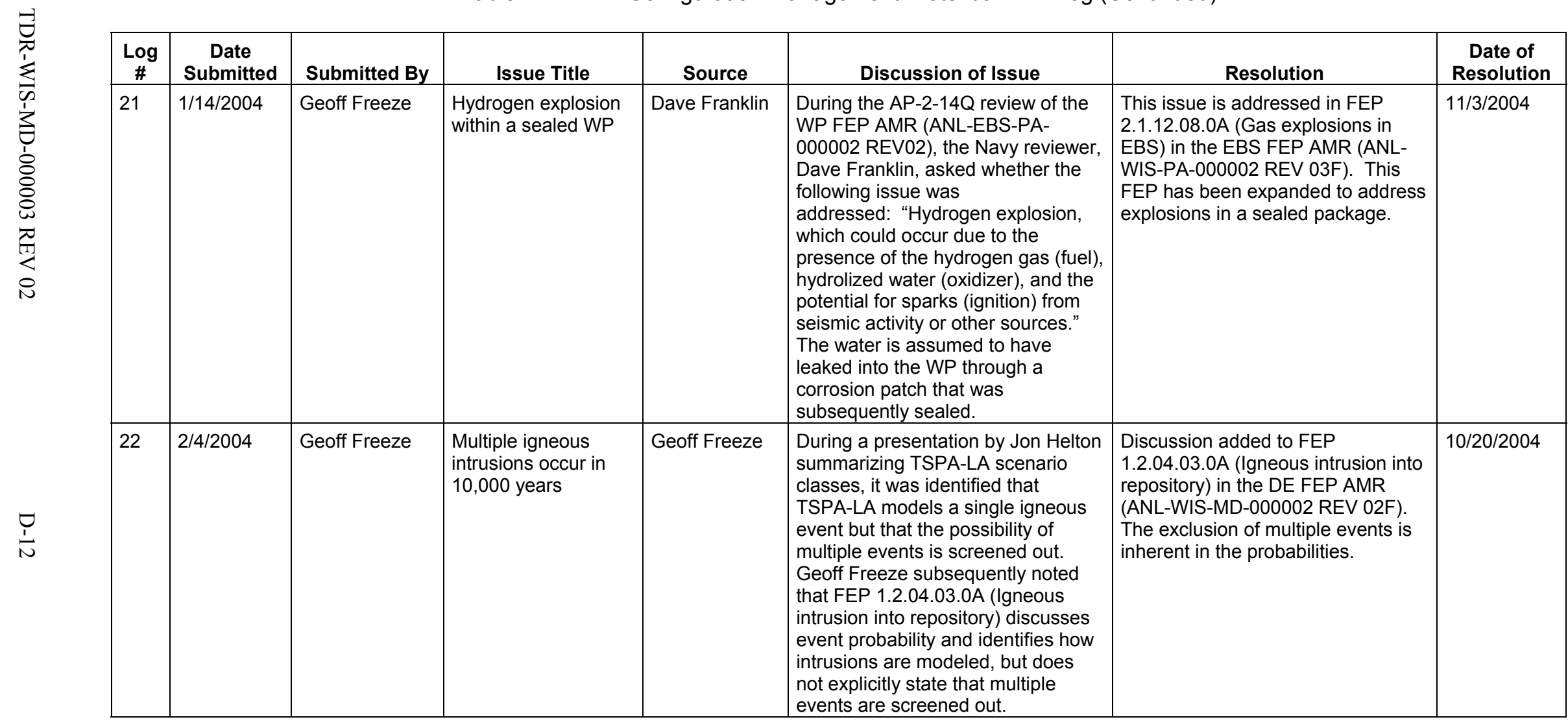


Table D-1. FEP Configuration Management-Potential FEP Log (Continued)

\begin{tabular}{|c|c|c|c|c|c|c|c|}
\hline $\begin{array}{c}\text { Log } \\
\#\end{array}$ & $\begin{array}{c}\text { Date } \\
\text { Submitted }\end{array}$ & Submitted By & Issue Title & Source & Discussion of Issue & Resolution & $\begin{array}{c}\text { Date of } \\
\text { Resolution }\end{array}$ \\
\hline 23 & $2 / 10 / 2004$ & Geoff Freeze & $\begin{array}{l}\text { Advection of solid } \\
\text { material into Navy } \\
\text { WPs }\end{array}$ & $\begin{array}{l}\text { Ernie Hardin, } \\
\text { Kathryn } \\
\text { Knowles }\end{array}$ & $\begin{array}{l}\text { In a meeting between EBS Dept } \\
\text { and Navy on Jan } 22,2004, \text { the } \\
\text { Navy identified a concern, } \\
\text { summarized in an e-mail from } \\
\text { Steven Clark on } 2 / 9 / 04 \text {, about "tuff } \\
\text { particles and other items getting into } \\
\text { the Navy WPs". This issue was } \\
\text { originally identified by NRC staff in } \\
\text { review meetings with the Navy's } \\
\text { Bechtel-Bettis group which is } \\
\text { responsible for assessing criticality } \\
\text { of Navy fuels in YMP. In an e-mail } \\
\text { dated } 2 / 12 / 04 \text {, Ernie Hardin } \\
\text { requested this issue be turned into } \\
\text { a new FEP - "Advection of solid } \\
\text { material, particularly rock, into the } \\
\text { waste package." It is stated as } \\
\text { "This FEP requires the formation of } \\
\text { one or more waste package } \\
\text { breaches of sufficient size. Once a } \\
\text { sufficient amount of solid material } \\
\text { enters the waste package, it forms a } \\
\text { neutron reflector that significantly } \\
\text { increases the k-effective for in- } \\
\text { package nuclear criticality." }\end{array}$ & $\begin{array}{l}\text { Resolved as part of FEP Log \# } 25 \\
\text { below. }\end{array}$ & $\begin{array}{l}\text { See FEP } \\
\text { Log \# } 25\end{array}$ \\
\hline 24 & $2 / 16 / 2004$ & Geoff Freeze & $\begin{array}{l}\text { Combined FEPs - } \\
\text { Human intrusion and } \\
\text { disruptive events }\end{array}$ & $\begin{array}{l}\text { Dave } \\
\text { Sevougian, } \\
\text { Peter Swift }\end{array}$ & $\begin{array}{l}\text { In e-mails dated 1/22/04 (from } \\
\text { Sevougian) and } 1 / 23 / 04 \text { (from Swift) } \\
\text { it was identified that human } \\
\text { intrusion analyses might need to } \\
\text { consider "unlikely events" in } \\
\text { determining the subsurface } \\
\text { conditions that a driller would } \\
\text { encounter. }\end{array}$ & $\begin{array}{l}\text { Two new FEPs created in the SYS } \\
\text { FEP AMR (ANL-WIS-MD } 000019 \\
\text { REV 01). The new FEPs are } \\
\text { 1.4.02.03.0A (Igneous event } \\
\text { precedes human intrusion) and } \\
\text { 1.4.02.04.0A (Seismic event } \\
\text { precedes human intrusion). }\end{array}$ & 04/20/2004 \\
\hline
\end{tabular}


Table D-1. FEP Configuration Management-Potential FEP Log (Continued)

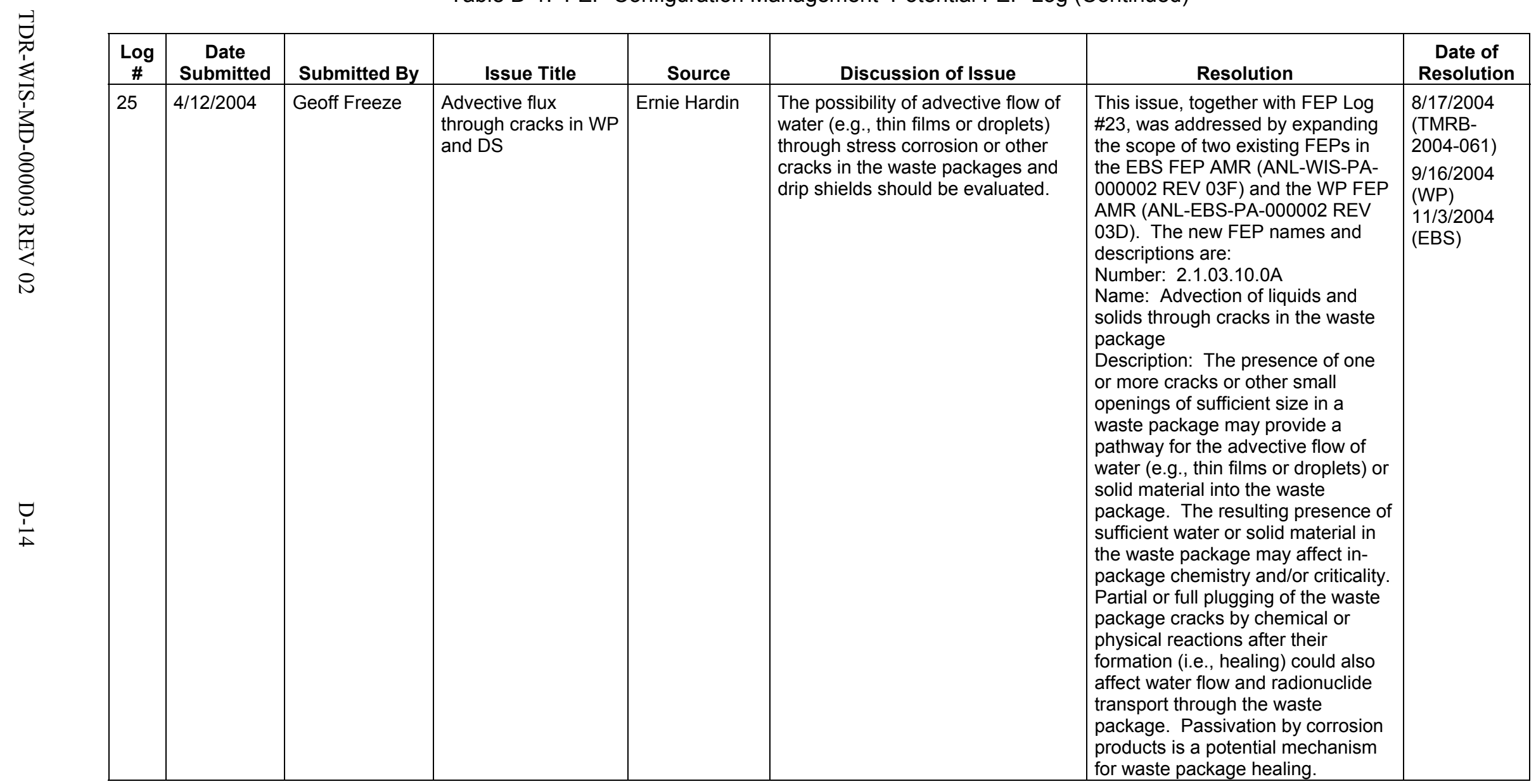


Table D-1. FEP Configuration Management-Potential FEP Log (Continued)

\begin{tabular}{|c|c|c|c|c|c|c|c|}
\hline $\begin{array}{c}\text { Log } \\
\# \\
\end{array}$ & $\begin{array}{c}\text { Date } \\
\text { Submitted }\end{array}$ & Submitted By & Issue Title & Source & Discussion of Issue & Resolution & $\begin{array}{c}\text { Date of } \\
\text { Resolution }\end{array}$ \\
\hline 25 & (Continued) & & & & & $\begin{array}{l}\text { Number : 2.1.09.29.0B } \\
\text { Name: Advection of liquids and } \\
\text { solids through cracks in the drip } \\
\text { shield } \\
\text { Description: The presence of one } \\
\text { or more cracks or other small } \\
\text { openings of sufficient size in a drip } \\
\text { shield may provide a pathway for } \\
\text { the advective flow of water } \\
\text { (e.g., thin films or droplets) or solid } \\
\text { material through the drip shield. } \\
\text { The resulting flux may affect drip } \\
\text { shield performance and/or } \\
\text { subsequent dripping onto the waste } \\
\text { packages. Partial or full plugging of } \\
\text { the drip shield cracks by chemical } \\
\text { or physical reactions after their } \\
\text { formation (i.e., healing) could also } \\
\text { affect water flow through the drip } \\
\text { shield. }\end{array}$ & \\
\hline 26 & 4/30/2004 & Geoff Freeze & $\begin{array}{l}\text { Effects on in-drift } \\
\text { chemistry from drift } \\
\text { collapse }\end{array}$ & $\begin{array}{l}\text { RIT / Geoff } \\
\text { Freeze }\end{array}$ & $\begin{array}{l}\text { During initial RIT review meetings, it } \\
\text { was asked whether the effects of } \\
\text { drift collapse on in-drift chemistry } \\
\text { have been addressed. New FEP } \\
1.2 .03 .02 .0 \mathrm{D} \text { addresses alterations } \\
\text { in in-drift thermohydrology but does } \\
\text { not capture associated alterations in } \\
\text { in-drift chemstry }\end{array}$ & $\begin{array}{l}\text { A new FEP was created in the EBS } \\
\text { FEP AMR (ANL-WIS-PA-000002 } \\
\text { REV 03F): } \\
\text { Number: } 1.2 .03 .02 .0 E \\
\text { Name: Seismic-induced drift } \\
\text { collapse alters in-drift chemistry } \\
\text { Description: Seismic activity could } \\
\text { produce jointed-rock motion and/or } \\
\text { changes in rock stress leading to } \\
\text { enhanced drift collapse and/or } \\
\text { rubble infill throughout part or all of } \\
\text { the drifts. Drift collapse, and the } \\
\text { associated changes in seepage and } \\
\text { in-drift thermohydrology could } \\
\text { impact in-drift chemistry. }\end{array}$ & $\begin{array}{l}8 / 17 / 2004 \\
\text { (TMRB- } \\
2004-061) \\
11 / 3 / 2004 \\
\text { EBS) }\end{array}$ \\
\hline 27 & $5 / 6 / 2004$ & Dan McGregor & $\begin{array}{l}\text { Effect of magmatic } \\
\text { volatiles on water } \\
\text { chemistry }\end{array}$ & $\begin{array}{l}\text { Frank Perry, } \\
\text { Jean Younker }\end{array}$ & $\begin{array}{l}\text { In an e-mail dated } 04 / 30 / 04 \text { (from } \\
\text { Younker), it was noted that the } \\
\text { potential effects of magmatic } \\
\text { volatile species on water chemistry } \\
\text { do not seem to be addressed in any } \\
\text { AMR, nor are they screened out. }\end{array}$ & $\begin{array}{l}\text { Resolved as part of FEP Log \# } 28 \\
\text { below. }\end{array}$ & 09/28/2004 \\
\hline
\end{tabular}


Table D-1. FEP Configuration Management-Potential FEP Log (Continued)

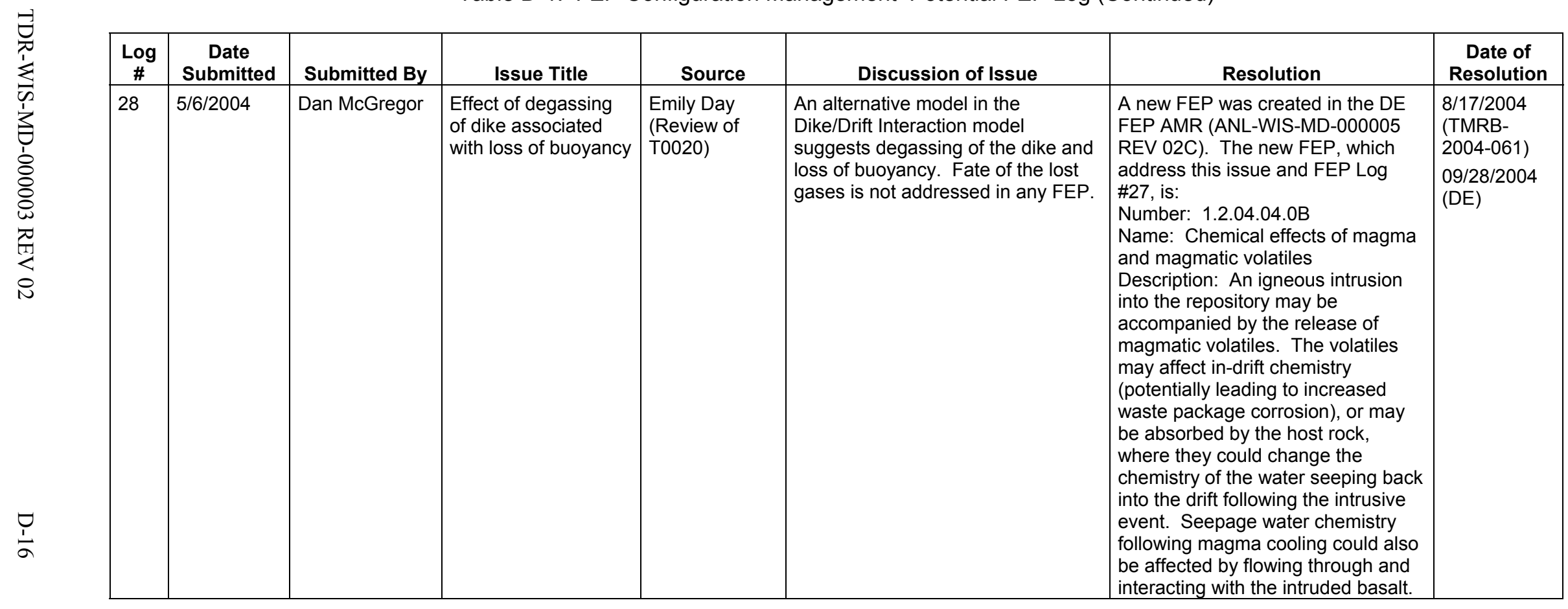


Table D-1. FEP Configuration Management-Potential FEP Log (Continued)

\begin{tabular}{|c|c|c|c|c|c|c|c|}
\hline $\begin{array}{c}\log \\
\#\end{array}$ & $\begin{array}{c}\text { Date } \\
\text { Submitted }\end{array}$ & Submitted By & Issue Title & Source & Discussion of Issue & Resolution & $\begin{array}{c}\text { Date of } \\
\text { Resolution }\end{array}$ \\
\hline 29 & $5 / 11 / 2004$ & Geoff Freeze & $\begin{array}{l}\text { Direct inhalation of } \\
\text { volcanic plume }\end{array}$ & $\begin{array}{l}\text { RIT / Jean } \\
\text { Younker }\end{array}$ & $\begin{array}{l}\text { During initial RIT review meetings, } \\
\text { one of the comments from the } \\
\text { Ashplume AMR (MDL-MGR-GS- } \\
000002 \text { REV 00) suggested that } \\
\text { "direct inhalation of the volcanic } \\
\text { plume as it passes over a populated } \\
\text { area" was not calculated by } \\
\text { ASHPLUME, nor was it addressed } \\
\text { elsewhere. It also stated that "the } \\
\text { respirable fraction of the plume } \\
\text { mass will increase downwind from } \\
\text { the volcanic cone because plume } \\
\text { depletion will preferentially remove } \\
\text { the larger particles". }\end{array}$ & $\begin{array}{l}\text { The Biosphere AMRs provide } \\
\text { information (BDCFs) that allows } \\
\text { direct inhalation of the volcanic } \\
\text { plume to be calculated. A } \\
\text { TSPA-SR sensitivity calculation } \\
\text { showed this probability-weighted } \\
\text { contribution to be below the } \\
\text { probability-weighted contribution } \\
\text { from ash on the ground (TSPA-SR } \\
\text { REV } 00 \text { ICN } 01 \text { Section 5.2.9.9). } \\
\text { The discussion of Included FEP } \\
3.3 .04 .02 .0 A \text { (Inhalation) has been } \\
\text { updated in BIO FEP AMR (ANL- } \\
\text { MGR-MD-000011 REV 04) to } \\
\text { identify that, for direct inhalation of } \\
\text { the volcanic plume, the dose factor } \\
\text { may be used in TSPA assessments } \\
\text { to evaluate whether the doses } \\
\text { received by the RMEI during } \\
\text { eruption need to be included in the } \\
\text { calculation of the expected dose. }\end{array}$ & 09/30/2004 \\
\hline 30 & $6 / 29 / 2004$ & $\begin{array}{l}\text { Dan McGregor, } \\
\text { Phil Rogers }\end{array}$ & $\begin{array}{l}\text { Radionuclide } \\
\text { solubility limits in the } \\
\text { biosphere }\end{array}$ & $\begin{array}{l}\text { KTI TSPAI } \\
2.01-2.04 \text { / } \\
\text { Bruce } \\
\text { Hastings }\end{array}$ & $\begin{array}{l}\text { The KTI Agreement called for } \\
\text { radionuclide solubility limits in the } \\
\text { biosphere to be discussed as part of } \\
\text { TSPA-SR FEP 2.2.08.07.00 } \\
\text { (Radionuclide solubility limits in } \\
\text { geosphere). For TSPA-LA this FEP } \\
\text { was split into FEP 2.2.08.07.0A } \\
\text { (Radionuclide solubility limits in SZ) } \\
\text { and FEP 2.2.08.07.0B } \\
\text { (Radionuclide solubility limits in UZ). } \\
\text { However, the effects in the } \\
\text { biosphere were not addressed in } \\
\text { either of the LA FEPs. }\end{array}$ & $\begin{array}{l}\text { A new FEP was created in the BIO } \\
\text { FEP AMR (ANL-MGR-MD-000011 } \\
\text { REV 04): } \\
\text { Number 2.2.08.07.0C } \\
\text { Name: Radionuclide solubility limits } \\
\text { in the biosphere } \\
\text { Description: Solubility limits for } \\
\text { radionuclides may be different in the } \\
\text { biosphere pathways than in the } \\
\text { water in the saturated zone. }\end{array}$ & \begin{tabular}{|l}
$8 / 17 / 2004$ \\
(TMRB- \\
$2004-061)$ \\
$9 / 30 / 2004$ \\
$(\mathrm{BIO})$
\end{tabular} \\
\hline
\end{tabular}


Table D-1. FEP Configuration Management-Potential FEP Log (Continued)

\begin{tabular}{|c|c|c|c|c|c|c|c|}
\hline $\begin{array}{c}\text { Log } \\
\#\end{array}$ & $\begin{array}{c}\text { Date } \\
\text { Submitted }\end{array}$ & Submitted By & Issue Title & Source & Discussion of Issue & Resolution & $\begin{array}{c}\text { Date of } \\
\text { Resolution }\end{array}$ \\
\hline 31 & 7/26/2004 & Dan McGregor & $\begin{array}{l}\text { Drip shield } \\
\text { separation for very } \\
\text { large ground motions }\end{array}$ & $\begin{array}{l}\text { Review } \\
\text { comments } \\
\text { from Seismic } \\
\text { Consequence } \\
\text { Abstraction } \\
\text { (MDL-WIS-PA- } \\
\text { 000003), } \\
\text { Jean Younker, } \\
\text { Mark Board }\end{array}$ & $\begin{array}{l}\text { Within the Seismic Consequence } \\
\text { Abstraction AMR it was identified } \\
\text { that very large ground motions } \\
\text { could cause drip shield separation. } \\
\text { Mark Board believes that conclusion } \\
\text { to be unrealistic and has developed } \\
\text { an alternative argument to eliminate } \\
\text { that aspect of the seismic ground } \\
\text { motion effects. }\end{array}$ & $\begin{array}{l}\text { The exclusion of drip shield } \\
\text { separation is referenced as part of } \\
\text { included FEP 1.2.03.02.0A (Seismic } \\
\text { ground motion damages EBS } \\
\text { components) and discussed as part } \\
\text { FEPs 1.2.03.02.0B (Seismic- } \\
\text { induced rockfall damages EBS } \\
\text { components) and 1.2.03.02.0C } \\
\text { (Seismic-induced drift collapse } \\
\text { damages EBS components) in the } \\
\text { DE FEP AMR (ANL-WIS-MD- } \\
000002 \text { REV 02F) and in the EBS } \\
\text { FEP AMR (ANL-WIS-PA-000002 } \\
\text { REV 03F). } \\
\text { This issue is also discussed as part } \\
\text { of TMRB-2004-062. }\end{array}$ & $\begin{array}{l}10 / 20 / 2004 \\
(\mathrm{DE}) \\
11 / 3 / 2004 \\
\text { (EBS) }\end{array}$ \\
\hline 32 & 08/04/2004 & Geoff Freeze & $\begin{array}{l}\text { Effects of crushed } \\
\text { tuff "plugs" in the } \\
\text { turnouts at the ends } \\
\text { of the drifts to } \\
\text { prevent spreading of } \\
\text { magma between } \\
\text { adjacent drifts. }\end{array}$ & \begin{tabular}{|l} 
Dan \\
McGregor, \\
Bob Andrews
\end{tabular} & $\begin{array}{l}\text { In an e-mail to Freeze, McGregor, } \\
\text { Mike Cline, Ernest Hardin, and Neil } \\
\text { Brown dated June 30, 2004, } \\
\text { Andrews identifies the need to } \\
\text { discuss the presence a "backfill" } \\
\text { "plug" within an existing FEP or as a } \\
\text { new FEP. }\end{array}$ & $\begin{array}{l}\text { These effects are adequately } \\
\text { discussed as part of FEP } \\
\text { 1.2.04.04.0A (Igneous intrusion } \\
\text { interacts with EBS components) in } \\
\text { the DE FEP AMR (ANL-WIS-MD- } \\
000002 \text { REV 02F). Note the } \\
\text { "backfill" "plug" is referred to as a } \\
\text { "filled keyway" in the DE FEP AMR. } \\
\text { This is to avoid confusion with the } \\
\text { term "backfill" that is commonly } \\
\text { used in waste disposal literature in } \\
\text { other countries to refer to the design } \\
\text { concept of material that is emplaced } \\
\text { immediately adjacent to the waste } \\
\text { package. The backfill design } \\
\text { concept is not part of the YMP } \\
\text { design, but filled keyways, } \\
\text { sometimes referred to as backfilled } \\
\text { turnouts in other YMP literature, are } \\
\text { present at YMP. }\end{array}$ & $\begin{array}{l}10 / 20 / 2004 \\
\text { (Re- } \\
\text { considered } \\
08 / 16 / 05 \text { as } \\
\text { part of FEP } \\
\text { Log \#50 } \\
\text { below) }\end{array}$ \\
\hline
\end{tabular}


Table D-1. FEP Configuration Management-Potential FEP Log (Continued)

\begin{tabular}{|c|c|c|c|c|c|c|c|}
\hline$\underset{\#}{\log }$ & $\begin{array}{c}\text { Date } \\
\text { Submitted }\end{array}$ & Submitted By & Issue Title & Source & Discussion of Issue & Resolution & $\begin{array}{c}\text { Date of } \\
\text { Resolution }\end{array}$ \\
\hline 33 & 08/04/2004 & Geoff Freeze & $\begin{array}{l}\text { Condensation on drift } \\
\text { "walls" following drift } \\
\text { collapse }\end{array}$ & $\begin{array}{l}\text { Kathryn } \\
\text { Knowles }\end{array}$ & $\begin{array}{l}\text { In an e-mail to Florie Caporuscio, } \\
\text { Steve Webb, Kathryn Knowles, and } \\
\text { Geoff Freeze dated July } 16,2004, \\
\text { Zane Walton provided a discussion } \\
\text { of condensation on drift walls } \\
\text { following seismic induced drift } \\
\text { collapse, stating that it is excluded. }\end{array}$ & $\begin{array}{l}\text { This issue is discussed as part of } \\
\text { Included FEP 1.2.03.02.0D } \\
\text { (Seismic-induced drift collapse } \\
\text { alters in-drift TH) in the EBS FEP } \\
\text { AMR (ANL-WIS-PA-000002 REV } \\
\text { 03F). Condensation is logically a } \\
\text { TH related issue. This FEP deals } \\
\text { with "alterations" from the nominal, } \\
\text { so the exclusion of condensation on } \\
\text { the drift walls, which is a change } \\
\text { from nominal FEP 2.1.08.04.0A } \\
\text { (Condensation forms on roofs of } \\
\text { drifts) is appropriate here. } \\
\text { The last sentence of the FEP } \\
\text { Description for 1.2.03.02.0D was } \\
\text { altered to, "... could impact flow } \\
\text { pathways and condensation within } \\
\text { the EBS, mechanisms ..." }\end{array}$ & \begin{tabular}{|l} 
8/17/2004 \\
(TMRB- \\
$2004-061)$ \\
$11 / 3 / 2004$ \\
(EBS)
\end{tabular} \\
\hline 34 & 08/04/2004 & Geoff Freeze & $\begin{array}{l}\text { Isotopic dilution of } \\
\text { iodine }\end{array}$ & $\begin{array}{l}\text { RIT review } \\
\text { meeting }\end{array}$ & $\begin{array}{l}\text { Isotopic dilution of iodine was } \\
\text { discussed as part of an Alternative } \\
\text { Conceptual Model (ACM) in an } \\
\text { interim version of the Biosphere } \\
\text { Model Report, but was eliminated } \\
\text { from the final version. Does it need } \\
\text { to be documented as a FEP? }\end{array}$ & $\begin{array}{l}\text { During the preparation of the final } \\
\text { version of the Biosphere Model } \\
\text { Report (MDL-MGR-MD-000001) it } \\
\text { was determined that the iodine } \\
\text { contribution to the total dose was } \\
\text { relatively insignificant and that } \\
\text { isotopic dilution would only further } \\
\text { reduce the dose from iodine. } \\
\text { Therefore there is no significant } \\
\text { consequence from this process. } \\
\text { Due to the low consequence result } \\
\text { of the scoping study, a decision was } \\
\text { made to not formally address this } \\
\text { issue as a new or revised FEP, but } \\
\text { rather to only document it in the } \\
\text { Potential FEP Log. }\end{array}$ & $8 / 20 / 2004$ \\
\hline
\end{tabular}


Table D-1. FEP Configuration Management-Potential FEP Log (Continued)

\begin{tabular}{|c|c|c|c|c|c|c|c|}
\hline$\underset{\#}{\text { Log }}$ & $\begin{array}{c}\text { Date } \\
\text { Submitted }\end{array}$ & Submitted By & Issue Title & Source & Discussion of Issue & Resolution & $\begin{array}{c}\text { Date of } \\
\text { Resolution }\end{array}$ \\
\hline 35 & 08/04/2004 & Geoff Freeze & $\begin{array}{l}\text { Gaseous release of } \\
\text { iodine during } \\
\text { irrigation }\end{array}$ & $\begin{array}{l}\text { RIT review } \\
\text { meeting }\end{array}$ & $\begin{array}{l}\text { lodine may undergo a phase } \\
\text { change (liquid to gas) during } \\
\text { irrigation. }\end{array}$ & $\begin{array}{l}\text { During preparation of the final } \\
\text { version of the Biosphere Model } \\
\text { Report (MDL-MGR-MD-000001) it } \\
\text { was determined that this process } \\
\text { would tend to dilute concentrations } \\
\text { and remove radionuclides from the } \\
\text { system without adding exposure } \\
\text { risk to the RMEI. This is due to } \\
\text { limited exposure time of only a few } \\
\text { individuals and dilution prior to } \\
\text { reaching the RMEl. Dilution would } \\
\text { reduce the dose from iodine. }\end{array}$ & 8/20/2004 \\
\hline & & & & & & $\begin{array}{l}\text { Because the iodine contribution to } \\
\text { total dose is relatively insignificant } \\
\text { and iodine phase change would } \\
\text { only further reduce the dose from } \\
\text { iodine, there is no significant } \\
\text { consequence from this process. }\end{array}$ & \\
\hline & & & & & & $\begin{array}{l}\text { Due to the low consequence result } \\
\text { of the scoping study, a decision was } \\
\text { made to not formally address this } \\
\text { issue as a new or revised FEP, but } \\
\text { rather to only document it in the } \\
\text { Potential FEP Log. }\end{array}$ & \\
\hline
\end{tabular}


Table D-1. FEP Configuration Management-Potential FEP Log (Continued)

\begin{tabular}{|c|c|c|c|c|c|c|c|}
\hline $\begin{array}{c}\text { Log } \\
\#\end{array}$ & $\begin{array}{c}\text { Date } \\
\text { Submitted }\end{array}$ & Submitted By & Issue Title & Source & Discussion of Issue & Resolution & $\begin{array}{c}\text { Date of } \\
\text { Resolution }\end{array}$ \\
\hline 36 & 08/05/2004 & Geoff Freeze & $\begin{array}{l}\text { Rock bolts might fail } \\
\text { from corrosion and } \\
\text { fall and damage the } \\
\text { drip shield }\end{array}$ & $\begin{array}{l}\text { ITRT / Mel } \\
\text { Marietta }\end{array}$ & $\begin{array}{l}\text { In a review of the TSPA-LA AMR, a } \\
\text { comment (\#47) was made that "The } \\
\text { friction-type rock bolts that are } \\
\text { planned to provide ground support } \\
\text { for the repository drifts } \\
\text { (Section } 1.1 .3 \text { ) are likely to loosen } \\
\text { and may fall out during the } \\
\text { regulatory time frame if located in } \\
\text { the drift crown. The frictional } \\
\text { resistance at the anchor is likely to } \\
\text { fail from corrosion before the bolt } \\
\text { itself is completely consumed. If the } \\
\text { bolt is relatively intact at the time } \\
\text { the anchor fails, the falling bolt } \\
\text { could damage the drip shield. This } \\
\text { potential source of damage does } \\
\text { not appear to have been accounted } \\
\text { for in TSPA-LA. Document that the } \\
\text { ground support design eliminates } \\
\text { the potential for rock bolts to } \\
\text { damage the drip shield, or } \\
\text { document that falling rock bolts } \\
\text { would not cause damage." }\end{array}$ & $\begin{array}{l}\text { Degradation of rock bolts is } \\
\text { addressed in FEPs 2.1.06.01.0A } \\
\text { (Chemical degradation of rock } \\
\text { reinforcement materials) and } \\
2.1 .06 .02 .0 \mathrm{~A} \text { (Mechanical } \\
\text { degradation of rock reinforcement } \\
\text { materials). The issue of damage to } \\
\text { the drip shield from a falling rock } \\
\text { bolt was added to FEP 2.1.06.02.0A } \\
\text { in the EBS FEP AMR (ANL-WIS- } \\
\text { PA-000002 REV 03G). }\end{array}$ & 11/18/2004 \\
\hline 37 & 08/16/2004 & Emily Day & $\begin{array}{l}\text { Availability of surface } \\
\text { water affects soil } \\
\text { structure and stability }\end{array}$ & $\begin{array}{l}\text { Bob Walsh- } \\
\text { Alternative } \\
\text { Systematic } \\
\text { Analysis } \\
\text { (Appendix B) }\end{array}$ & $\begin{array}{l}\text { Hydrologic properties of soil may } \\
\text { change as the result of } \\
\text { disintegrating effects of water and } \\
\text { the effects of ecological changes, } \\
\text { both macroscopic and microscopic. }\end{array}$ & $\begin{array}{l}\text { Effects of surface water and } \\
\text { ecological changes on the } \\
\text { hydrologic properties of soil are } \\
\text { captured implicitly in the distribution } \\
\text { of soil types and soil characteristics } \\
\text { described in FEP 2.3.02.01.0A (Soil } \\
\text { type) in the Bio FEP AMR (ANL- } \\
\text { MGR-MD-000011 REV 04F). } \\
\end{array}$ & 10/29/2004 \\
\hline 38 & 08/16/2004 & Emily Day & $\begin{array}{l}\text { Moisture content of } \\
\text { rock in the UZ }\end{array}$ & $\begin{array}{l}\text { Bob Walsh- } \\
\text { Alternative } \\
\text { Systematic } \\
\text { Analysis } \\
\text { (Appendix B) }\end{array}$ & $\begin{array}{l}\text { The moisture content of the rock } \\
\text { influences the hydraulic conductivity } \\
\text { and therefore the percolation rate in } \\
\text { the UZ. Conditions at depth may be } \\
\text { influenced by native conditions for } \\
\text { an extended period. }\end{array}$ & $\begin{array}{l}\text { The moisture content of rock in the } \\
\text { UZ is accounted for in the UZ flow } \\
\text { modeling described in FEP } \\
\text { 2.2.07.02.0A (Unsaturated } \\
\text { groundwater flow in the geosphere) } \\
\text { in the UZ FEP AMR (ANL-NBS-MD- } \\
\text { 000001 REV 03G). }\end{array}$ & $10 / 29 / 2004$ \\
\hline
\end{tabular}


Table D-1. FEP Configuration Management-Potential FEP Log (Continued)

\begin{tabular}{|c|c|c|c|c|c|c|c|}
\hline$\underset{\#}{\log }$ & $\begin{array}{c}\text { Date } \\
\text { Submitted }\end{array}$ & Submitted By & Issue Title & Source & Discussion of Issue & Resolution & $\begin{array}{c}\text { Date of } \\
\text { Resolution }\end{array}$ \\
\hline 39 & 08/16/2004 & Emily Day & $\begin{array}{l}\text { Mining and other } \\
\text { underground } \\
\text { activities beyond the } \\
\text { controlled area }\end{array}$ & $\begin{array}{l}\text { Bob Walsh- } \\
\text { Alternative } \\
\text { Systematic } \\
\text { Analysis } \\
\text { (Appendix B) }\end{array}$ & $\begin{array}{l}\text { Mining and other underground } \\
\text { human activities (e.g., tunneling, } \\
\text { underground construction, } \\
\text { quarrying) outside of the controlled } \\
\text { area could affect percolation into } \\
\text { the aquifer and thereby affect both } \\
\text { the flow rate of the aquifer and the } \\
\text { dilution of radionuclide } \\
\text { concentrations. }\end{array}$ & $\begin{array}{l}\text { This issue is addressed as part of } \\
\text { FEP 1.4.05.00.0A (Mining and other } \\
\text { underground human activities) in } \\
\text { the SYS FEP AMR (ANL-WIS-MD- } \\
\text { 000019 REV 02), which states that } \\
\text { all human intrusion activities are } \\
\text { represented by the stylized drilling } \\
\text { intrusion, and as part of FEP } \\
\text { 2.4.10.00.0A (Urban and industrial } \\
\text { land and water use) in the Bio FEP } \\
\text { AMR (ANL-MGR-MD-000011 REV } \\
\text { 04F), which states that future uses } \\
\text { of urban and industrial land and } \\
\text { water are assumed to be the same } \\
\text { as the current uses. }\end{array}$ & 10/29/2004 \\
\hline 40 & 08/16/2004 & Emily Day & Criticality in the UZ & $\begin{array}{l}\text { Bob Walsh- } \\
\text { Alternative } \\
\text { Systematic } \\
\text { Analysis } \\
\text { (Appendix B) }\end{array}$ & $\begin{array}{l}\text { Fissile material accumulates to a } \\
\text { critical mass at a location in the } \\
\text { unsaturated zone as a result of } \\
\text { sorption, precipitation, or deposition. }\end{array}$ & $\begin{array}{l}\text { Criticality in the UZ is addressed in } \\
\text { FEP 2.2.14.09.0A (Far-field } \\
\text { criticality) in the CRIT FEP AMR } \\
\text { (ANL-EBS-NU-000008 REV 01). }\end{array}$ & 10/29/2004 \\
\hline
\end{tabular}


Table D-1. FEP Configuration Management-Potential FEP Log (Continued)

\begin{tabular}{|c|c|c|c|c|c|c|c|}
\hline$\stackrel{\text { Log }}{\#}$ & $\begin{array}{c}\text { Date } \\
\text { Submitted }\end{array}$ & Submitted By & Issue Title & Source & Discussion of Issue & Resolution & $\begin{array}{c}\text { Date of } \\
\text { Resolution }\end{array}$ \\
\hline 41 & 08/16/2004 & Emily Day & $\begin{array}{l}\text { Groundwater takes } \\
\text { up radionuclides that } \\
\text { were entrained or } \\
\text { dissolved in basaltic } \\
\text { intrusion }\end{array}$ & $\begin{array}{l}\text { Bob Walsh- } \\
\text { Alternative } \\
\text { Systematic } \\
\text { Analysis } \\
\text { (Appendix B) }\end{array}$ & $\begin{array}{l}\text { Groundwater erodes a basaltic } \\
\text { intrusion or otherwise extracts } \\
\text { radionuclide species that were } \\
\text { imbedded in a magma flow that } \\
\text { entered the EBS. }\end{array}$ & $\begin{array}{l}\text { FEP 1.2.04.03.0A (Igneous } \\
\text { intrusion into repository) in the DE } \\
\text { FEP AMR (ANL-WIS-MD-000005 } \\
\text { REV 02F) addresses the case } \\
\text { where a basaltic intrusion damages } \\
\text { waste packages and permits the } \\
\text { subsequent direct transport of } \\
\text { radionuclides in groundwater. The } \\
\text { case suggested by this potential } \\
\text { FEP, in which radionuclides must } \\
\text { first be extracted from the basaltic } \\
\text { intrusion before being transported in } \\
\text { groundwater, is bounded by the } \\
\text { case addressed in FEP } \\
1.2 .04 .03 .0 A \text {. } \\
\text { Because this potential FEP is likely } \\
\text { to be insignificant relative to the } \\
\text { existing bounding FEP, a decision } \\
\text { was made to not formally address } \\
\text { this issue as a new or revised FEP, } \\
\text { but rather to only document it in the } \\
\text { Potential FEP Log. }\end{array}$ & 10/29/2004 \\
\hline 42 & 08/16/2004 & Emily Day & $\begin{array}{l}\text { Thermal conduction } \\
\text { in the EBS }\end{array}$ & $\begin{array}{l}\text { Bob Walsh- } \\
\text { Alternative } \\
\text { Systematic } \\
\text { Analysis } \\
\text { (Appendix B) }\end{array}$ & $\begin{array}{l}\text { Thermal conduction may contribute } \\
\text { to heat transfer from the waste } \\
\text { package to the drip shield, lowering } \\
\text { the temperature of the waste } \\
\text { package outer shell and affecting } \\
\text { waste package corrosion rates. } \\
\text { Relevant properties are the thermal } \\
\text { conductivities of the EBS materials. }\end{array}$ & $\begin{array}{l}\text { Thermal conduction is addressed as } \\
\text { part of FEP 2.1.11.01.0A (Heat } \\
\text { generation in the EBS) in the EBS } \\
\text { FEP AMR (ANL-WIS-PA-000002 } \\
\text { REV 03E) }\end{array}$ & 10/29/2004 \\
\hline
\end{tabular}


Table D-1. FEP Configuration Management-Potential FEP Log (Continued)

\begin{tabular}{|c|c|c|c|c|c|c|c|}
\hline $\begin{array}{c}\log \\
\# \\
\end{array}$ & $\begin{array}{c}\text { Date } \\
\text { Submitted }\end{array}$ & Submitted By & Issue Title & Source & Discussion of Issue & Resolution & $\begin{array}{c}\text { Date of } \\
\text { Resolution }\end{array}$ \\
\hline 43 & 08/16/2004 & Emily Day & $\begin{array}{l}\text { Radiative heat } \\
\text { transfer in the EBS }\end{array}$ & $\begin{array}{l}\text { Bob Walsh- } \\
\text { Alternative } \\
\text { Systematic } \\
\text { Analysis } \\
\text { (Appendix B) }\end{array}$ & $\begin{array}{l}\text { Thermal radiation may improve the } \\
\text { efficiency of heat transfer from the } \\
\text { waste package to the drip shield } \\
\text { and from the drip shield to the drift } \\
\text { wall. The improved efficiency may } \\
\text { lower the temperature of the waste } \\
\text { package outer shell and raise the } \\
\text { temperature at the drift wall, } \\
\text { affecting evaporation and } \\
\text { condensation, in-drift chemistry, } \\
\text { waste package durability, and } \\
\text { transport of radionuclides. Relevant } \\
\text { properties are the emissivities of the } \\
\text { surfaces, the effects of dust and/or } \\
\text { condensation on emissivity, the } \\
\text { densities and absorption } \\
\text { coefficients of the various gases in } \\
\text { the drift air, and absorption by } \\
\text { particulates in the air. }\end{array}$ & $\begin{array}{l}\text { Thermal radiation is addressed as } \\
\text { part of FEP 2.1.11.01.0A (Heat } \\
\text { generation in the EBS) in the EBS } \\
\text { FEP AMR (ANL-WIS-PA-000002 } \\
\text { REV 03E) }\end{array}$ & 10/29/2004 \\
\hline 44 & 08/16/2004 & Emily Day & $\begin{array}{l}\text { Dripping in the EBS } \\
\text { cavity }\end{array}$ & $\begin{array}{l}\text { Bob Walsh- } \\
\text { Alternative } \\
\text { Systematic } \\
\text { Analysis } \\
\text { (Appendix B) }\end{array}$ & $\begin{array}{l}\text { Some portion of the moisture that } \\
\text { percolates to the EBS horizon will } \\
\text { drip into the EBS cavity, depending } \\
\text { on conditions in the cavity and in } \\
\text { the rock and on the presence of } \\
\text { rock bolts or other irregularities in } \\
\text { the drift crown. Dripping moisture } \\
\text { may evaporate before it reaches a } \\
\text { surface, whether the drift shield, the } \\
\text { invert, or an exposed waste } \\
\text { package. }\end{array}$ & $\begin{array}{l}\text { The FEP 2.1.08.01.0A (water influx } \\
\text { at the repository) in the UZ FEP } \\
\text { AMR (ANL-NBS-MD-000001 REV } \\
\text { 03G) addresses all aspects of } \\
\text { seepage and dripping influx. }\end{array}$ & 10/29/2004 \\
\hline 45 & 08/16/2004 & Emily Day & Criticality in the SZ & $\begin{array}{l}\text { Bob Walsh- } \\
\text { Alternative } \\
\text { Systematic } \\
\text { Analysis } \\
\text { (Appendix B) }\end{array}$ & $\begin{array}{l}\text { Fissile material accumulates to a } \\
\text { critical mass at a location in the } \\
\text { saturated zone as a result of } \\
\text { precipitation. }\end{array}$ & $\begin{array}{l}\text { Criticality in the SZ is addressed in } \\
\text { FEP 2.2.14.09.0A (Far-field } \\
\text { criticality) in the CRIT FEP AMR } \\
\text { (ANL-EBS-NU-000008 REV 01). }\end{array}$ & $10 / 29 / 2004$ \\
\hline
\end{tabular}


Table D-1. FEP Configuration Management-Potential FEP Log (Continued)

\begin{tabular}{|c|c|c|c|c|c|c|c|}
\hline $\begin{array}{c}\text { Log } \\
\#\end{array}$ & $\begin{array}{c}\text { Date } \\
\text { Submitted }\end{array}$ & Submitted By & Issue Title & Source & Discussion of Issue & Resolution & $\begin{array}{c}\text { Date of } \\
\text { Resolution }\end{array}$ \\
\hline 46 & 08/23/2004 & Geoff Freeze & $\begin{array}{l}\text { Need to change FEP } \\
\text { Description for } \\
2.1 .12 .07 .0 \text { A from } \\
\text { TMRB-2004-061 } \\
\text { FEP list }\end{array}$ & Neil Brown & $\begin{array}{l}\text { It was identified that the FEP } \\
\text { Description for 2.1.12.07.0A, as } \\
\text { written in the TMRB-2004-061 FEP } \\
\text { list, could be misconstrued to infer } \\
\text { that } 14 \mathrm{C} \text { (rather than } 14 \mathrm{CH} 4 \text { ) was } \\
\text { produced during microbial } \\
\text { degradation. }\end{array}$ & $\begin{array}{l}\text { This was clarified by moving the } \\
\text { end parenthesis from after " } 14 \mathrm{CH} 4 \text { " } \\
\text { to after "degradation". This minor } \\
\text { editorial change did not result in an } \\
\text { update to the TMRB-2004-061 list, } \\
\text { but was reflected in the WF FEP } \\
\text { AMR (ANL-WIS-PA-000002 REV } \\
\text { 02F). }\end{array}$ & $\begin{array}{l}10 / 06 / 2004 \\
(\mathrm{WF}) \\
11 / 3 / 2004 \\
(\mathrm{EBS})\end{array}$ \\
\hline 47 & $10 / 21 / 2004$ & Geoff Freeze & $\begin{array}{l}\text { Need to change FEP } \\
\text { Description for } \\
\text { 2.1.09.19.0B from } \\
\text { TMRB-2004-061 } \\
\text { FEP list }\end{array}$ & $\begin{array}{l}\text { Bruce } \\
\text { Hastings }\end{array}$ & $\begin{array}{l}\text { In an e-mail to Geoff Freeze dated } \\
10 / 20 / 04, \text { Bruce Hastings identified } \\
\text { a typo in the FEP } \\
\text { description: "colloids and the } \\
\text { waste" should be "colloids in the } \\
\text { waste". }\end{array}$ & $\begin{array}{l}\text { This minor editorial change did not } \\
\text { result in an update to the TMRB- } \\
2004-061 \text { list, but was reflected in } \\
\text { the EBS FEP AMR (ANL-WIS-PA- } \\
000002 \text { REV 03F). }\end{array}$ & $11 / 3 / 2004$ \\
\hline 48 & 02/14/2005 & Geoff Freeze & $\begin{array}{l}\text { Improvements and } \\
\text { refinements in the } \\
\text { technical bases that } \\
\text { support the Safety } \\
\text { Analysis Report }\end{array}$ & DOE & $\begin{array}{l}\text { In DOE technical direction letter 05- } \\
001 \text {, dated } 10 / 29 / 04 \text {, DOE identified } \\
\text { several issues for evaluation that } \\
\text { might potentially affect FEP } \\
\text { screening. These issues are (a) } \\
\text { seismic induced mechanical } \\
\text { damage from package-to-package } \\
\text { interactions, (b) uncertainty in } \\
\text { dissolved Np concentrations, (c) } \\
\text { solubility limits for release of } \\
\text { radionuclides, (d) solubility limits/co- } \\
\text { precipitation as a retardation } \\
\text { mechanism, (e) alternative model } \\
\text { for dissolved Np concentrations, (f) } \\
\text { deliquescence-induced localized } \\
\text { corrosion, and (g) waste package } \\
\text { damage and waste form } \\
\text { pulverization due to igneous activity. }\end{array}$ & $\begin{array}{l}\text { Resolved as part of FEP Log \# } 49 \\
\text { below. }\end{array}$ & $\begin{array}{l}\text { See FEP } \\
\text { Log \#49 }\end{array}$ \\
\hline 49 & $04 / 20 / 2005$ & Geoff Freeze & $\begin{array}{l}\text { Improvements and } \\
\text { refinements in the } \\
\text { FEP screening in the } \\
\text { Safety Analysis } \\
\text { Report }\end{array}$ & Bob Andrews & $\begin{array}{l}\text { In an e-mail from Bob Andrews } \\
\text { dated } 4 / 20 / 05 \text {, reference was made } \\
\text { to DOE reviews of the draft Safety } \\
\text { Analysis Report, in which several } \\
\text { comments related to the } \\
\text { defensibility of the FEP screening } \\
\text { arguments were made. }\end{array}$ & $\begin{array}{l}\text { These issues, together with the } \\
\text { issues in FEP Log } \# 48 \text {, involve } \\
\text { changes to the technical bases for } \\
\text { FEP screening, but do not result in } \\
\text { any changes to the controlled FEP } \\
\text { list (i.e., FEP numbers, names, and } \\
\text { descriptions). Changes in the FEP } \\
\text { screening are captured in revisions } \\
\text { to the FEP AMRs. }\end{array}$ & 08/23/2005 \\
\hline
\end{tabular}


Table D-1. FEP Configuration Management-Potential FEP Log (Continued)

\begin{tabular}{|c|c|c|c|c|c|c|c|}
\hline $\begin{array}{c}\text { Log } \\
\#\end{array}$ & $\begin{array}{c}\text { Date } \\
\text { Submitted }\end{array}$ & Submitted By & Issue Title & Source & Discussion of Issue & Resolution & $\begin{array}{c}\text { Date of } \\
\text { Resolution }\end{array}$ \\
\hline 50 & 04/26/2005 & Geoff Freeze & $\begin{array}{l}\text { Need a separate } \\
\text { FEP for magma } \\
\text { plugs. }\end{array}$ & $\begin{array}{l}\text { Nancy } \\
\text { Williams, Bob } \\
\text { Andrews }\end{array}$ & $\begin{array}{l}\text { On } 02 / 17 / 05 \text {, a meeting was held to } \\
\text { discuss the need for a separate } \\
\text { FEP for the magma plugs at the } \\
\text { ends of the drifts designed prevent } \\
\text { spreading of magma between } \\
\text { adjacent drifts. The use of a } \\
\text { separate FEP for magma plugs is } \\
\text { more consistent with the treatment } \\
\text { of other Q-list features in the SAR. } \\
\text { This is a change from the TMRB- } \\
2004-061 \text { controlled FEP list. }\end{array}$ & $\begin{array}{l}\text { As noted in the resolution of FEP } \\
\text { Log \#32 above, the effects of the } \\
\text { magma plugs (sometimes referred } \\
\text { to as "filled keyways") were } \\
\text { previously discussed as part of FEP } \\
1.2 .04 .04 .0 A \text { (Igneous intrusion } \\
\text { interacts with EBS components) in } \\
\text { the DE FEP AMR (ANL-WIS-MD- } \\
000002 \text { REV 02). In response to } \\
\text { the re-evaluation of this issue, a } \\
\text { new DE FEP 1.2.04.04.0C (Magma } \\
\text { and gas flow through magma } \\
\text { bulkheads) was created, } \\
\text { documented, and approved in } \\
\text { TMRB-2005-051. }\end{array}$ & $\begin{array}{l}\text { 08/13/2005 } \\
\text { (TMRB- } \\
\text { 2005-051) }\end{array}$ \\
\hline 51 & 07/26/2005 & Geoff Freeze & $\begin{array}{l}\text { Need to revise the } \\
\text { FEP Name and FEP } \\
\text { Description for } \\
2.1 .09 .28 .0 A\end{array}$ & $\begin{array}{l}\text { DOE / Paige } \\
\text { Russell, Joe } \\
\text { Ziegler }\end{array}$ & $\begin{array}{l}\text { In DOE comments on the WP FEP } \\
\text { AMR (ANL-EBS-PA-00004), it was } \\
\text { suggested that the FEP Name } \\
\text { (Deliquescence on WP outer } \\
\text { surface) and FEP Description for } \\
\text { FEP 2.1.09.28.0A be changed to } \\
\text { match the AMR deliverable } \\
\text { acceptance criteria specified by } \\
\text { DOE. This is a change from the } \\
\text { TMRB-2004-061 controlled FEP list. }\end{array}$ & $\begin{array}{l}\text { FEP 2.1.09.28.0A was renamed to } \\
\text { "Localized corrosion on WP outer } \\
\text { surface due to deliquescence" and } \\
\text { the description was changed } \\
\text { accordingly, as documented and } \\
\text { approved in TMRB-2005-047. The } \\
\text { change in name and description } \\
\text { focused the scope on localized } \\
\text { corrosion from deliquescence. } \\
\text { Other potential effects of } \\
\text { deliquescence (e.g., on general } \\
\text { corrosion) are already addressed in } \\
\text { WP FEP 2.1.03.01.0A (General } \\
\text { corrosion of WPs). }\end{array}$ & $\begin{array}{l}\text { 07/29/2005 } \\
\text { (TMRB- } \\
\text { 2005-047) }\end{array}$ \\
\hline 52 & 07/27/2005 & Geoff Freeze & $\begin{array}{l}\text { Need to update the } \\
\text { FEP Descriptions for } \\
3.1 .01 .01 .0 \mathrm{~A} \text { and } \\
3.3 .05 .01 .0 \mathrm{~A}\end{array}$ & $\begin{array}{l}\text { Maryla } \\
\text { Wasiolek }\end{array}$ & $\begin{array}{l}\text { During final preparation of the BIO } \\
\text { FEP AMR (ANL-MGR-MD-00005), } \\
\text { minor editorial updates were made } \\
\text { to two FEP Descriptions for } \\
\text { consistency with current project } \\
\text { nomenclature. This is a change } \\
\text { from the TMRB-2004-061 controlled } \\
\text { FEP list. }\end{array}$ & $\begin{array}{l}\text { The controlled descriptions for } \\
\text { FEPs 3.1.01.01.0A and } \\
\text { 3.3.05.01.0A were changed, as } \\
\text { documented and approved in } \\
\text { TMRB-2005-048. The change in } \\
\text { description did not change the } \\
\text { scope of either FEP. }\end{array}$ & $\begin{array}{l}\text { 08/13/2005 } \\
\text { (TMRB- } \\
\text { 2005-048) }\end{array}$ \\
\hline
\end{tabular}


Table D-1. FEP Configuration Management-Potential FEP Log (Continued)

\begin{tabular}{|c|c|c|c|c|c|c|c|}
\hline$\stackrel{\log }{\#}$ & $\begin{array}{c}\text { Date } \\
\text { Submitted }\end{array}$ & Submitted By & Issue Title & Source & Discussion of Issue & Resolution & $\begin{array}{c}\text { Date of } \\
\text { Resolution }\end{array}$ \\
\hline 53 & 07/27/2005 & Geoff Freeze & $\begin{array}{l}\text { Need to revise the } \\
\text { FEP Name and FEP } \\
\text { Description for } \\
2.1 .09 .28 .0 B\end{array}$ & Geoff Freeze & $\begin{array}{l}\text { For consistency with the changes } \\
\text { made to FEP 2.1.09.28.0A in FEP } \\
\text { Log \#51 above, it is necessary to } \\
\text { also change the FEP Name and } \\
\text { Description for the parallel FEP } \\
\text { 2.1.09.28.0B (Deliquescence on DS } \\
\text { outer surface). This change } \\
\text { maintains consistency in the FEP } \\
\text { list, which supports completeness } \\
\text { and comprehensiveness. This is a } \\
\text { change from the TMRB-2004-061 } \\
\text { controlled FEP list. }\end{array}$ & $\begin{array}{l}\text { FEP 2.1.09.28.0B was renamed to } \\
\text { "Localized corrosion on DS surfaces } \\
\text { due to deliquescence" and the } \\
\text { description was changed } \\
\text { accordingly, as documented and } \\
\text { approved in TMRB-2005-050. The } \\
\text { change in name and description } \\
\text { focused the scope on localized } \\
\text { corrosion from deliquescence. } \\
\text { Other potential effects of } \\
\text { deliquescence (e.g., on general } \\
\text { corrosion) are already addressed in } \\
\text { WP FEP 2.1.03.01.0B (General } \\
\text { corrosion of DSs). }\end{array}$ & $\begin{array}{l}\text { 08/13/2005 } \\
\text { (TMRB- } \\
\text { 2005-050) }\end{array}$ \\
\hline
\end{tabular}




\section{INTENTIONALLY LEFT BLANK}


APPENDIX E

TSPA-LA FEP LIST 


\section{TSPA-LA FEP LIST}

This Appendix provides the TSPA-LA FEP list as documented in the "FEPS" Table of DTN: MO0508SEPFEPLA.002 [DIRS 175064]. It contains information from the FEP AMRs | listed in Table 2-7. Only FEP Number, Name, Description, Screening Decision, and FEP $\operatorname{AMR}(\mathrm{s})$ are shown for each FEP.

Table E-1. TSPA-LA FEP List

\begin{tabular}{|c|c|c|c|c|}
\hline FEP Number & FEP Name & FEP Description & Screening Decision & $\begin{array}{l}\text { FEP } \\
\text { AMR }\end{array}$ \\
\hline $0.1 .02 .00 .0 \mathrm{~A}$ & $\begin{array}{l}\text { Timescales of } \\
\text { concern }\end{array}$ & $\begin{array}{l}\text { This FEP addresses the timescales of concern over } \\
\text { which the disposal system may present a significant } \\
\text { health or environmental hazard. }\end{array}$ & Included (SYS) & SYS \\
\hline $0.1 .03 .00 .0 \mathrm{~A}$ & $\begin{array}{l}\text { Spatial domain of } \\
\text { concern }\end{array}$ & $\begin{array}{l}\text { This FEP addresses the spatial domain of concern over } \\
\text { which the disposal system may present a significant } \\
\text { health or environmental hazard. }\end{array}$ & Included (SYS) & SYS \\
\hline $0.1 .09 .00 .0 \mathrm{~A}$ & $\begin{array}{l}\text { Regulatory } \\
\text { requirements and } \\
\text { exclusions }\end{array}$ & $\begin{array}{l}\text { This FEP addresses regulatory requirements and } \\
\text { guidance specific to the Yucca Mountain repository. }\end{array}$ & Included (SYS) & SYS \\
\hline $0.1 .10 .00 .0 \mathrm{~A}$ & $\begin{array}{l}\text { Model and data } \\
\text { issues }\end{array}$ & $\begin{array}{l}\text { This FEP addresses issues related to modeling of the } \\
\text { disposal system. Model and data issues are general } \\
\text { (i.e., methodological) issues affecting the modeling } \\
\text { process and data usage. Model issues include the } \\
\text { approach and assumptions associated with the } \\
\text { selection of conceptual models, the mathematical } \\
\text { implementation of conceptual models, model geometry } \\
\text { and dimensionality, models of coupled processes, and } \\
\text { boundary and initial conditions. Data issues include the } \\
\text { derivation of data values and correlations. }\end{array}$ & Included (SYS) & SYS \\
\hline 1.1.01.01.0A & $\begin{array}{l}\text { Open site } \\
\text { investigation } \\
\text { boreholes }\end{array}$ & $\begin{array}{l}\text { Site investigation boreholes that have been left open, } \\
\text { degraded, improperly sealed, or reopened, could modify } \\
\text { flow and transport properties and produce enhanced } \\
\text { pathways between the surface and the repository. }\end{array}$ & $\begin{array}{l}\text { Excluded - low } \\
\text { consequence (UZ) }\end{array}$ & UZ \\
\hline 1.1.01.01.0B & $\begin{array}{l}\text { Influx through } \\
\text { holes drilled in } \\
\text { drift wall or crown }\end{array}$ & $\begin{array}{l}\text { Holes may be drilled through the drift walls or crown for } \\
\text { a variety of reasons including, but not limited to, rock } \\
\text { bolt and ground support, monitoring and testing, or } \\
\text { construction related activities. These openings may } \\
\text { promote flow or seepage into the drifts and onto the } \\
\text { waste packages. }\end{array}$ & $\begin{array}{l}\text { Excluded - low } \\
\text { consequence (UZ) }\end{array}$ & UZ \\
\hline 1.1.02.00.0A & $\begin{array}{l}\text { Chemical effects } \\
\text { of excavation and } \\
\text { construction in } \\
\text { EBS }\end{array}$ & $\begin{array}{l}\text { Chemical effects associated with excavation and } \\
\text { construction of the underground regions of the } \\
\text { repository may affect the long-term behavior of the } \\
\text { engineered and natural barriers. Excavation-related } \\
\text { effects include chemical changes to the rock and } \\
\text { incoming groundwater due to explosives residue. } \\
\text { Excavation and other construction activities could also } \\
\text { directly cause groundwater chemistry changes within } \\
\text { the tunnel due to contaminants such as diesel exhaust, } \\
\text { explosives residues, or other organic contaminants. } \\
\text { Finally, oxidizing water introduced into the repository } \\
\text { during excavation and construction could impact } \\
\text { repository conditions and performance. }\end{array}$ & $\begin{array}{l}\text { Excluded - low } \\
\text { consequence (EBS) }\end{array}$ & EBS \\
\hline
\end{tabular}


Table E-1. TSPA-LA FEP List (Continued)

\begin{tabular}{|c|c|c|c|c|}
\hline FEP Number & FEP Name & FEP Description & Screening Decision & $\begin{array}{l}\text { FEP } \\
\text { AMR }\end{array}$ \\
\hline 1.1.02.00.0B & $\begin{array}{l}\text { Mechanical } \\
\text { effects of } \\
\text { excavation and } \\
\text { construction in } \\
\text { EBS }\end{array}$ & $\begin{array}{l}\text { Mechanical effects associated with excavation and } \\
\text { construction of the underground regions of the } \\
\text { repository may affect the long-term behavior of the } \\
\text { engineered and natural barriers. Excavation-related } \\
\text { effects include changes to rock properties due to boring } \\
\text { and blasting. }\end{array}$ & $\begin{array}{l}\text { Excluded - low } \\
\text { consequence (EBS) }\end{array}$ & EBS \\
\hline $1.1 .02 .01 .0 \mathrm{~A}$ & $\begin{array}{l}\text { Site flooding } \\
\text { (during } \\
\text { construction and } \\
\text { operation) }\end{array}$ & $\begin{array}{l}\text { Flooding of the site during construction and operation } \\
\text { could introduce water into the underground tunnels, } \\
\text { which could affect the long-term performance of the } \\
\text { repository. }\end{array}$ & $\begin{array}{l}\text { Excluded - low } \\
\text { consequence (UZ) }\end{array}$ & UZ \\
\hline $1.1 .02 .02 .0 \mathrm{~A}$ & $\begin{array}{l}\text { Preclosure } \\
\text { ventilation }\end{array}$ & $\begin{array}{l}\text { The duration of preclosure ventilation acts together with } \\
\text { waste package spacing (as per design) to control the } \\
\text { extent of the boiling front (zone of reduced water } \\
\text { content). }\end{array}$ & $\begin{array}{l}\text { Included (EBS) } \\
\text { Included (UZ) }\end{array}$ & $\begin{array}{l}\text { EBS } \\
\text { UZ }\end{array}$ \\
\hline $1.1 .02 .03 .0 \mathrm{~A}$ & $\begin{array}{l}\text { Undesirable } \\
\text { materials left }\end{array}$ & $\begin{array}{l}\text { During construction and preclosure operation of the } \\
\text { repository, unwanted materials might be left in the } \\
\text { vicinity of the radioactive waste. These materials could, } \\
\text { to some extent, affect many long-term processes in the } \\
\text { repository from waste package corrosion to radionuclide } \\
\text { transport mechanisms. }\end{array}$ & $\begin{array}{l}\text { Excluded - low } \\
\text { consequence (EBS) }\end{array}$ & EBS \\
\hline $1.1 .03 .01 .0 \mathrm{~A}$ & $\begin{array}{l}\text { Error in waste } \\
\text { emplacement }\end{array}$ & $\begin{array}{l}\text { Deviations from the design and/or errors in waste } \\
\text { emplacement could affect long-term performance of the } \\
\text { repository. A specific example of such an error would } \\
\text { be erroneously emplacing the waste packages in a } \\
\text { saturated or wet zone of the repository. Errors of this } \\
\text { type would impact repository performance by affecting } \\
\text { waste package corrosion and radionuclide transport. }\end{array}$ & $\begin{array}{l}\text { Excluded - low } \\
\text { consequence (WP) } \\
\text { Excluded - low } \\
\text { consequence (EBS) }\end{array}$ & $\begin{array}{l}\text { EBS } \\
\text { WP }\end{array}$ \\
\hline 1.1.03.01.0B & $\begin{array}{l}\text { Error in backfill } \\
\text { emplacement }\end{array}$ & $\begin{array}{l}\text { Deviations from the design and/or errors in the backfill } \\
\text { emplacement could affect long-term performance of the } \\
\text { repository. }\end{array}$ & $\begin{array}{l}\text { Excluded - low } \\
\text { probability (EBS) }\end{array}$ & EBS \\
\hline $1.1 .04 .01 .0 \mathrm{~A}$ & $\begin{array}{l}\text { Incomplete } \\
\text { closure }\end{array}$ & $\begin{array}{l}\text { Disintegration of society could result in incomplete } \\
\text { closure, sealing, and decommissioning of the disposal } \\
\text { vault. }\end{array}$ & $\begin{array}{l}\text { Excluded - low } \\
\text { consequence (UZ) } \\
\text { Excluded - by } \\
\text { regulation (UZ) }\end{array}$ & UZ \\
\hline $1.1 .05 .00 .0 \mathrm{~A}$ & $\begin{array}{l}\text { Records and } \\
\text { markers for the } \\
\text { repository }\end{array}$ & $\begin{array}{l}\text { This FEP addresses the retention of records of the } \\
\text { contents of the repository and markers constructed to } \\
\text { inform future humans of the location and contents of the } \\
\text { repository. Performance assessments must consider } \\
\text { the potential effects of human activities that might take } \\
\text { place within the controlled area at a future time when } \\
\text { institutional controls and/or knowledge of the presence } \\
\text { of a repository cannot be assumed. }\end{array}$ & $\begin{array}{l}\text { Excluded - by } \\
\text { regulation (SYS) }\end{array}$ & SYS \\
\hline 1.1.07.00.0A & $\begin{array}{l}\text { Repository } \\
\text { design }\end{array}$ & $\begin{array}{l}\text { This FEP addresses the consideration of the design of } \\
\text { the repository and the ways in which the design } \\
\text { contributes to long-term performance. The performance } \\
\text { assessment must account for design features, material } \\
\text { characteristics, and the ways in which the design } \\
\text { influences the evolution of the in-drift environment. }\end{array}$ & Included (SYS) & SYS \\
\hline
\end{tabular}


Table E-1. TSPA-LA FEP List (Continued)

\begin{tabular}{|c|c|c|c|c|}
\hline FEP Number & FEP Name & FEP Description & Screening Decision & $\begin{array}{l}\text { FEP } \\
\text { AMR }\end{array}$ \\
\hline 1.1.08.00.0A & $\begin{array}{l}\text { Inadequate } \\
\text { quality control } \\
\text { and deviations } \\
\text { from design }\end{array}$ & $\begin{array}{l}\text { This FEP addresses issues related to inadequate quality } \\
\text { assurance and control procedures and inadequate } \\
\text { testing during the design, construction, and operation of } \\
\text { the repository. It also includes inadequacy in the } \\
\text { manufacture of the waste forms, waste packages, and } \\
\text { engineered features. Lack of quality control could result } \\
\text { in a poorly designed repository, unmodeled design } \\
\text { features, deviations from design, material defects, faulty } \\
\text { waste package fabrication, and faulty or non-design } \\
\text { standard construction. All of these may lead to } \\
\text { reduction in the effectiveness of the engineered barriers. }\end{array}$ & $\begin{array}{l}\text { Excluded - low } \\
\text { consequence (SYS) }\end{array}$ & SYS \\
\hline 1.1.09.00.0A & $\begin{array}{l}\text { Schedule and } \\
\text { planning }\end{array}$ & $\begin{array}{l}\text { This FEP addresses the sequences of events and } \\
\text { activities occurring during construction, operation, and } \\
\text { closure of the repository. Deviations from the design } \\
\text { construction or waste emplacement schedule may affect } \\
\text { the long-term performance of the disposal system. }\end{array}$ & $\begin{array}{l}\text { Excluded - by } \\
\text { regulation (SYS) }\end{array}$ & SYS \\
\hline 1.1.10.00.0A & $\begin{array}{l}\text { Administrative } \\
\text { control of the } \\
\text { repository site }\end{array}$ & $\begin{array}{l}\text { Administrative control can reduce the potential for } \\
\text { detrimental or unplanned human activity within the } \\
\text { controlled area that could inadvertently cause or } \\
\text { accelerate the release of radioactive material. }\end{array}$ & $\begin{array}{l}\text { Excluded - by } \\
\text { regulation (SYS) }\end{array}$ & SYS \\
\hline 1.1.11.00.0A & $\begin{array}{l}\text { Monitoring of the } \\
\text { repository }\end{array}$ & $\begin{array}{l}\text { Monitoring that is carried out during or after operations, } \\
\text { for either operational safety or verification of long-term } \\
\text { performance, has the potential to detrimentally affect } \\
\text { long-term performance. For example, monitoring } \\
\text { boreholes could provide enhanced pathways between } \\
\text { the surface and the repository. }\end{array}$ & $\begin{array}{l}\text { Excluded - low } \\
\text { consequence (SYS) } \\
\text { Excluded - low } \\
\text { consequence (UZ) }\end{array}$ & $\begin{array}{l}\text { UZ } \\
\text { SYS }\end{array}$ \\
\hline 1.1.12.01.0A & $\begin{array}{l}\text { Accidents and } \\
\text { unplanned events } \\
\text { during } \\
\text { construction and } \\
\text { operation }\end{array}$ & $\begin{array}{l}\text { The long-term performance of the disposal system } \\
\text { might be seriously affected by unplanned or improper } \\
\text { activities that take place during construction, operation, } \\
\text { and closure of the repository. }\end{array}$ & $\begin{array}{l}\text { Excluded - low } \\
\text { consequence (SYS) }\end{array}$ & SYS \\
\hline 1.1.13.00.0A & Retrievability & $\begin{array}{l}\text { This FEP addresses design, emplacement, operational, } \\
\text { or administrative measures that might be applied or } \\
\text { considered to enable or ease retrieval of waste. There } \\
\text { may be a requirement to retrieve all or part of the waste } \\
\text { stored in the repository, for example, to recover valuable } \\
\text { fissile materials or to replace defective waste packages. }\end{array}$ & Included (SYS) & SYS \\
\hline 1.2.01.01.0A & $\begin{array}{l}\text { Tectonic activity - } \\
\text { large scale }\end{array}$ & $\begin{array}{l}\text { Large-scale tectonic activity, such as regional uplift, } \\
\text { subsidence, folding, mountain building, or other } \\
\text { processes related to plate movements, could affect } \\
\text { repository performance by altering the physical and } \\
\text { thermohydrologic properties of the geosphere. }\end{array}$ & $\begin{array}{l}\text { Excluded - low } \\
\text { consequence (DE) }\end{array}$ & $\mathrm{DE}$ \\
\hline $1.2 .02 .01 .0 \mathrm{~A}$ & Fractures & $\begin{array}{l}\text { Groundwater flow in the Yucca Mountain region and } \\
\text { transport of any released radionuclides may take place } \\
\text { along fractures. The rate of flow and the extent of } \\
\text { transport in fractures are influenced by characteristics } \\
\text { such as orientation, aperture, asperity, fracture length, } \\
\text { connectivity, and the nature of any linings or infills. }\end{array}$ & $\begin{array}{l}\text { Included (UZ) } \\
\text { Included (SZ) }\end{array}$ & $\begin{array}{l}\text { UZ } \\
\text { SZ }\end{array}$ \\
\hline 1.2.02.02.0A & Faults & $\begin{array}{l}\text { Numerous faults of various sizes have been noted in the } \\
\text { Yucca Mountain region, and specifically in the repository } \\
\text { area. Faults may represent an alteration of the rock } \\
\text { permeability and continuity of the rock mass, an } \\
\text { alteration or short-circuiting of the flow paths and flow } \\
\text { distributions close to the repository, and/or unexpected } \\
\text { pathways through the repository. }\end{array}$ & $\begin{array}{l}\text { Included (UZ) } \\
\text { Included (SZ) }\end{array}$ & $\begin{array}{l}\text { UZ } \\
\text { SZ }\end{array}$ \\
\hline
\end{tabular}


Table E-1. TSPA-LA FEP List (Continued)

\begin{tabular}{|c|c|c|c|c|}
\hline FEP Number & FEP Name & FEP Description & Screening Decision & $\begin{array}{l}\text { FEP } \\
\text { AMR }\end{array}$ \\
\hline 1.2.02.03.0A & $\begin{array}{l}\text { Fault } \\
\text { displacement } \\
\text { damages EBS } \\
\text { components }\end{array}$ & $\begin{array}{l}\text { Movement of a fault that intersects drifts within the } \\
\text { repository may cause the EBS components to } \\
\text { experience related movement or displacement. } \\
\text { Repository performance may be degraded by such } \\
\text { occurrences as tilting of components, component-to- } \\
\text { component contact, or drip shield separation. Fault } \\
\text { displacement could cause a failure as significant as } \\
\text { shearing of drip shields and waste packages by virtue of } \\
\text { the relative offset across the fault, or as extreme as } \\
\text { exhumation of the waste to the surface. }\end{array}$ & $\begin{array}{l}\text { Included (DE) } \\
\text { Included (EBS) }\end{array}$ & $\begin{array}{l}\text { DE } \\
\text { EBS }\end{array}$ \\
\hline 1.2.03.02.0A & $\begin{array}{l}\text { Seismic ground } \\
\text { motion damages } \\
\text { EBS components }\end{array}$ & $\begin{array}{l}\text { Seismic activity that causes repeated vibration of the } \\
\text { EBS components (drip shield, waste package, pallet, } \\
\text { and invert) could result in severe disruption of the drip } \\
\text { shields and waste packages, through vibration damage } \\
\text { or through contact between EBS components. Such } \\
\text { damage mechanisms could lead to degraded } \\
\text { performance. }\end{array}$ & $\begin{array}{l}\text { Included (DE) } \\
\text { Included (EBS) }\end{array}$ & $\begin{array}{l}\text { DE * } \\
\text { EBS }\end{array}$ \\
\hline 1.2.03.02.0B & $\begin{array}{l}\text { Seismic-induced } \\
\text { rockfall damages } \\
\text { EBS components }\end{array}$ & $\begin{array}{l}\text { Seismic activity could produce jointed-rock motion } \\
\text { and/or changes in rock stress leading to enhanced } \\
\text { rockfall that could impact drip shields, waste packages, } \\
\text { or other EBS components. }\end{array}$ & $\begin{array}{l}\text { Excluded-low } \\
\text { consequence (DE) } \\
\text { Excluded-low } \\
\text { consequence (EBS) }\end{array}$ & $\begin{array}{l}\text { DE } \\
\text { EBS }\end{array}$ \\
\hline $1.2 .03 .02 .0 \mathrm{C}$ & $\begin{array}{l}\text { Seismic-induced } \\
\text { drift collapse } \\
\text { damages EBS } \\
\text { components }\end{array}$ & $\begin{array}{l}\text { Seismic activity could produce jointed-rock motion } \\
\text { and/or changes in rock stress leading to enhanced drift } \\
\text { collapse that could impact drip shields, waste packages, } \\
\text { or other EBS components. Possible effects include both } \\
\text { dynamic and static loading. }\end{array}$ & $\begin{array}{l}\text { Excluded-low } \\
\text { consequence (DE) } \\
\text { Excluded-low } \\
\text { consequence (EBS) }\end{array}$ & $\begin{array}{l}\text { DE } \\
\text { EBS }\end{array}$ \\
\hline 1.2.03.02.0D & $\begin{array}{l}\text { Seismic-induced } \\
\text { drift collapse } \\
\text { alters in-drift } \\
\text { thermohydrology }\end{array}$ & $\begin{array}{l}\text { Seismic activity could produce jointed-rock motion } \\
\text { and/or changes in rock stress leading to enhanced drift } \\
\text { collapse and/or rubble infill throughout part or all of the } \\
\text { drifts. Drift collapse could impact flow pathways and } \\
\text { condensation within the EBS, mechanisms for water } \\
\text { contact with EBS components, and thermal properties } \\
\text { within the EBS. }\end{array}$ & $\begin{array}{l}\text { Included (DE) } \\
\text { Included (EBS) }\end{array}$ & $\begin{array}{l}\text { DE } \\
\text { EBS }\end{array}$ \\
\hline 1.2.03.02.0E & $\begin{array}{l}\text { Seismic-induced } \\
\text { drift collapse } \\
\text { alters in-drift } \\
\text { chemistry }\end{array}$ & $\begin{array}{l}\text { Seismic activity could produce jointed-rock motion } \\
\text { and/or changes in rock stress leading to enhanced drift } \\
\text { collapse and/or rubble infill throughout part or all of the } \\
\text { drifts. Drift collapse, and the associated changes in } \\
\text { seepage and in-drift thermohydrology could impact in- } \\
\text { drift chemistry. }\end{array}$ & $\begin{array}{l}\text { Excluded - low } \\
\text { consequence (EBS) }\end{array}$ & EBS \\
\hline 1.2.03.03.0A & $\begin{array}{l}\text { Seismicity } \\
\text { associated with } \\
\text { igneous activity }\end{array}$ & $\begin{array}{l}\text { Seismicity associated with future igneous activity in the } \\
\text { Yucca Mountain region may affect repository } \\
\text { performance. }\end{array}$ & Included (DE) & $\mathrm{DE}$ \\
\hline 1.2.04.02.0A & $\begin{array}{l}\text { Igneous activity } \\
\text { changes rock } \\
\text { properties }\end{array}$ & $\begin{array}{l}\text { Igneous activity near the underground facility may cause } \\
\text { extreme changes in rock stress and the thermal regime, } \\
\text { and may lead to rock deformation, including activation, } \\
\text { creation, and sealing of faults and fractures. This may } \\
\text { cause changes in the rock hydrologic and mineralogic } \\
\text { properties. Permeabilities of dikes and sills and the } \\
\text { heated regions immediately around them can differ from } \\
\text { those of country rock. Mineral alterations can also } \\
\text { change the chemical response of the host rock to } \\
\text { contaminants. }\end{array}$ & $\begin{array}{l}\text { Excluded - low } \\
\text { consequence (DE) } \\
\text { Excluded - low } \\
\text { consequence (UZ) } \\
\text { Excluded - low } \\
\text { consequence (SZ) }\end{array}$ & $\begin{array}{l}\text { DE } \\
\text { UZ } \\
\text { SZ }\end{array}$ \\
\hline
\end{tabular}


Table E-1. TSPA-LA FEP List (Continued)

\begin{tabular}{|c|c|c|c|c|}
\hline FEP Number & FEP Name & FEP Description & Screening Decision & $\begin{array}{l}\text { FEP } \\
\text { AMR }\end{array}$ \\
\hline 1.2.04.03.0A & $\begin{array}{l}\text { Igneous intrusion } \\
\text { into repository }\end{array}$ & $\begin{array}{l}\text { Magma from an igneous intrusion may flow into the } \\
\text { drifts and extend over a large portion of the repository } \\
\text { site, forming a sill, dike, or dike swarm, depending on } \\
\text { the stress conditions. This intrusion could involve } \\
\text { multiple drifts. The sill could be limited to the drifts or a } \\
\text { continuous sill could form along the plane of the } \\
\text { repository, bridging between adjacent drifts. }\end{array}$ & Included (DE) & DE \\
\hline $1.2 .04 .04 .0 \mathrm{~A}$ & $\begin{array}{l}\text { Igneous intrusion } \\
\text { interacts with } \\
\text { EBS components }\end{array}$ & $\begin{array}{l}\text { An igneous intrusion in the form of a dike may occur } \\
\text { through the repository, intersecting the repository drifts, } \\
\text { resulting in magma, pyroclastics, and volcanic gases } \\
\text { entering the drift and interacting with the EBS } \\
\text { components (drip shields, waste packages, pallet, and } \\
\text { invert). This could lead to accelerated drip shield and } \\
\text { waste package failure (e.g., attack by magmatic } \\
\text { volatiles, damage by flowing or fragmented magma, } \\
\text { thermal effects) and dissolution or volatilization of } \\
\text { waste. }\end{array}$ & Included (DE) & $\mathrm{DE}$ \\
\hline 1.2.04.04.0B & $\begin{array}{l}\text { Chemical effects } \\
\text { of magma and } \\
\text { magmatic } \\
\text { volatiles }\end{array}$ & $\begin{array}{l}\text { An igneous intrusion into the repository may be } \\
\text { accompanied by the release of magmatic volatiles. The } \\
\text { volatiles may affect in-drift chemistry (potentially leading } \\
\text { to increased waste package corrosion), or may be } \\
\text { absorbed by the host rock, where they could change the } \\
\text { chemistry of the water seeping back into the drift } \\
\text { following the intrusive event. Seepage water chemistry } \\
\text { following magma cooling could also be affected by } \\
\text { flowing through and interacting with the intruded basalt. }\end{array}$ & Included (DE) & $\mathrm{DE}$ \\
\hline $1.2 .04 .04 .0 \mathrm{C}$ & $\begin{array}{l}\text { Magma and gas } \\
\text { flow through } \\
\text { magma } \\
\text { bulkheads }\end{array}$ & $\begin{array}{l}\text { The flow of magma and/or magmatic gas between drifts } \\
\text { through turnouts and access mains and associated } \\
\text { magma bulkheads might lead to enhanced degradation } \\
\text { of waste packages in drifts adjacent to an intruded drift. } \\
\text { Magma bulkheads (filled keyways) are located and } \\
\text { designed to stop the flow of magma and restrict the flow } \\
\text { of magmatic gases between drifts. }\end{array}$ & $\begin{array}{l}\text { Excluded - low } \\
\text { consequence (DE) }\end{array}$ & $\mathrm{DE}$ \\
\hline $1.2 .04 .05 .0 \mathrm{~A}$ & $\begin{array}{l}\text { Magma or } \\
\text { pyroclastic base } \\
\text { surge transports } \\
\text { waste }\end{array}$ & $\begin{array}{l}\text { As a result of an igneous intrusion, extrusive processes } \\
\text { may result in a pyroclastic density flow, base surge, dike } \\
\text { apron, effusive lava flows, and/or development of a } \\
\text { volcanic vent at land surface. Some of the waste } \\
\text { (entrained, dissolved, or volatized) could then be } \\
\text { transported away from the repository. Of most concern } \\
\text { is transport directly along the land surface to the RMEI. }\end{array}$ & $\begin{array}{l}\text { Excluded - low } \\
\text { consequence (DE) }\end{array}$ & $\mathrm{DE}$ \\
\hline 1.2.04.06.0A & $\begin{array}{l}\text { Eruptive conduit } \\
\text { to surface } \\
\text { intersects } \\
\text { repository }\end{array}$ & $\begin{array}{l}\text { As a result of an igneous intrusion, one or more volcanic } \\
\text { vents may form at land surface. The conduit(s) } \\
\text { supplying the vent(s) could pass through the repository, } \\
\text { interacting with and entraining waste. }\end{array}$ & Included (DE) & $\mathrm{DE}$ \\
\hline 1.2.04.07.0A & Ashfall & $\begin{array}{l}\text { Finely divided waste particles may be carried up a } \\
\text { volcanic vent and deposited on the land surface from an } \\
\text { ash cloud. }\end{array}$ & $\begin{array}{l}\text { Included (DE) } \\
\text { Included (Bio) }\end{array}$ & $\begin{array}{l}\text { DE } \\
\text { Bio }\end{array}$ \\
\hline 1.2.04.07.0B & $\begin{array}{l}\text { Ash redistribution } \\
\text { in groundwater }\end{array}$ & $\begin{array}{l}\text { Following deposition of contaminated ash on the } \\
\text { surface, contaminants may leach out of the ash deposit } \\
\text { and be transported through the subsurface to the } \\
\text { compliance point. }\end{array}$ & $\begin{array}{l}\text { Excluded - low } \\
\text { consequence (SZ) }\end{array}$ & $S z$ \\
\hline 1.2.04.07.0C & $\begin{array}{l}\text { Ash redistribution } \\
\text { via soil and } \\
\text { sediment } \\
\text { transport }\end{array}$ & $\begin{array}{l}\text { Following deposition of contaminated ash on the } \\
\text { surface, ash deposits may be redistributed on the } \\
\text { surface via aeolian and fluvial processes. }\end{array}$ & Included (DE) & $\mathrm{DE}$ \\
\hline
\end{tabular}


Table E-1. TSPA-LA FEP List (Continued)

\begin{tabular}{|c|c|c|c|c|}
\hline FEP Number & FEP Name & FEP Description & Screening Decision & $\begin{array}{l}\text { FEP } \\
\text { AMR }\end{array}$ \\
\hline 1.2.05.00.0A & Metamorphism & $\begin{array}{l}\text { Regional metamorphism has the potential to affect the } \\
\text { long-term performance of the repository if it occurs. } \\
\text { Metamorphic activity is defined as solid state } \\
\text { recrystallization changes to rock properties and geologic } \\
\text { structures through the effects of heat and/or pressure. }\end{array}$ & $\begin{array}{l}\text { Excluded - low } \\
\text { probability (SYS) } \\
\text { Excluded - low } \\
\text { consequence (SYS) }\end{array}$ & SYS \\
\hline 1.2.06.00.0A & $\begin{array}{l}\text { Hydrothermal } \\
\text { activity }\end{array}$ & $\begin{array}{l}\text { Naturally-occurring high-temperature groundwater may } \\
\text { induce hydrothermal alteration of minerals in the rocks } \\
\text { through which the high-temperature groundwater flows. }\end{array}$ & $\begin{array}{l}\text { Excluded - low } \\
\text { consequence (UZ) } \\
\text { Excluded - low } \\
\text { consequence (SZ) }\end{array}$ & $\begin{array}{l}\text { UZ } \\
\text { SZ }\end{array}$ \\
\hline 1.2.07.01.0A & $\begin{array}{l}\text { Erosion/denudati } \\
\text { on }\end{array}$ & $\begin{array}{l}\text { Erosion and denudation are processes which cause } \\
\text { significant changes in the present-day topography and } \\
\text { thus affect local and regional hydrology. Erosion of } \\
\text { surficial materials can occur by a variety of means, } \\
\text { including physical weathering (including glacial and } \\
\text { fluvial erosion), chemical weathering, erosion by wind } \\
\text { (aeolian erosion), and mass wasting (e.g., landslide) } \\
\text { processes. The extent of erosion depends to a large } \\
\text { extent on climate and uplift. }\end{array}$ & $\begin{array}{l}\text { Excluded - low } \\
\text { consequence (UZ) }\end{array}$ & UZ \\
\hline 1.2.07.02.0A & Deposition & $\begin{array}{l}\text { Deposition is a process that causes significant changes } \\
\text { in the present-day topography and thus affects local and } \\
\text { regional hydrology. Deposition of surficial materials can } \\
\text { occur by a variety of means, including fluvial, aeolian, } \\
\text { and lacustrine deposition and redistribution of soil } \\
\text { through weathering and mass wasting processes. }\end{array}$ & $\begin{array}{l}\text { Excluded - low } \\
\text { consequence (UZ) }\end{array}$ & UZ \\
\hline $1.2 .08 .00 .0 \mathrm{~A}$ & Diagenesis & $\begin{array}{l}\text { This FEP addresses natural processes that alter the } \\
\text { mineralogy or other properties of rocks after the rocks } \\
\text { have formed under temperature and pressure conditions } \\
\text { normal to the upper few kilometers of the earth's crust. } \\
\text { Diagenesis includes chemical, physical, and biological } \\
\text { processes that take place in rocks after formation but } \\
\text { before eventual metamorphism or weathering. This } \\
\text { FEP refers to natural diagenetic processes only. }\end{array}$ & $\begin{array}{l}\text { Excluded - low } \\
\text { consequence (SYS) }\end{array}$ & SYS \\
\hline 1.2.09.00.0A & $\begin{array}{l}\text { Salt diapirism } \\
\text { and dissolution }\end{array}$ & $\begin{array}{l}\text { This FEP addresses geologic processes relevant to } \\
\text { repositories located in salt deposits. Salt diapirism } \\
\text { refers to the tendency of salt to flow under lithostatic } \\
\text { loading when density and viscosity contrasts with } \\
\text { surrounding strata are favorable. Salt domes are the } \\
\text { best-known example of salt diapirism. Salt dissolution } \\
\text { can occur when any soluble mineral is removed by } \\
\text { flowing water. Large-scale dissolution is a potentially } \\
\text { important process in rocks that are composed } \\
\text { predominantly of water-soluble evaporite minerals, such } \\
\text { as salt. }\end{array}$ & $\begin{array}{l}\text { Excluded - by } \\
\text { regulation (SYS) }\end{array}$ & SYS \\
\hline 1.2.09.01.0A & Diapirism & $\begin{array}{l}\text { The process by which plastic, low density rocks (most } \\
\text { commonly evaporites) may flow under lithostatic loading } \\
\text { when density and viscosity contrasts with surrounding } \\
\text { strata are favorable. Such a process would modify the } \\
\text { groundwater flow regime and affect radionuclide } \\
\text { transport. }\end{array}$ & $\begin{array}{l}\text { Excluded - by } \\
\text { regulation (SYS) }\end{array}$ & SYS \\
\hline 1.2.09.02.0A & $\begin{array}{l}\text { Large-scale } \\
\text { dissolution }\end{array}$ & $\begin{array}{l}\text { Dissolution can occur when any soluble mineral is } \\
\text { removed by flowing water. Large-scale dissolution is a } \\
\text { potentially important process in rocks that are } \\
\text { composed predominantly of water-soluble evaporite } \\
\text { minerals, such as salt. }\end{array}$ & $\begin{array}{l}\text { Excluded - low } \\
\text { consequence (UZ) } \\
\text { Excluded - low } \\
\text { consequence (SZ) }\end{array}$ & $\begin{array}{l}\mathrm{UZ} \\
\mathrm{SZ}\end{array}$ \\
\hline
\end{tabular}


Table E-1. TSPA-LA FEP List (Continued)

\begin{tabular}{|c|c|c|c|c|}
\hline FEP Number & FEP Name & FEP Description & Screening Decision & $\begin{array}{l}\text { FEP } \\
\text { AMR }\end{array}$ \\
\hline $1.2 .10 .01 .0 \mathrm{~A}$ & $\begin{array}{l}\text { Hydrologic } \\
\text { response to } \\
\text { seismic activity }\end{array}$ & $\begin{array}{l}\text { Seismic activity, associated with fault movement, may } \\
\text { create new or enhanced flow pathways and/or } \\
\text { connections between stratigraphic units, or it may } \\
\text { change the stress (and therefore fluid pressure) within } \\
\text { the rock. These responses have the potential to } \\
\text { significantly change the surface and groundwater flow } \\
\text { directions, water level, water chemistry, and } \\
\text { temperature. }\end{array}$ & $\begin{array}{l}\text { Excluded - low } \\
\text { consequence (DE) } \\
\text { Excluded - low } \\
\text { consequence (UZ) } \\
\text { Excluded - low } \\
\text { probability (UZ) } \\
\text { Excluded - low } \\
\text { consequence (SZ) }\end{array}$ & $\begin{array}{l}\text { DE } \\
\text { UZ } \\
\text { SZ }\end{array}$ \\
\hline 1.2.10.02.0A & $\begin{array}{l}\text { Hydrologic } \\
\text { response to } \\
\text { igneous activity }\end{array}$ & $\begin{array}{l}\text { Igneous activity includes magmatic intrusions which } \\
\text { may alter groundwater flow pathways, and thermal } \\
\text { effects which may heat up groundwater and rock. } \\
\text { Igneous activity may change the groundwater flow } \\
\text { directions, water level, water chemistry, and } \\
\text { temperature. Eruptive and extrusive phases may } \\
\text { change the topography, surface drainage patterns, and } \\
\text { surface soil conditions. This may affect infiltration rates } \\
\text { and locations. }\end{array}$ & $\begin{array}{l}\text { Excluded - low } \\
\text { consequence (DE) } \\
\text { Excluded - low } \\
\text { consequence (UZ) } \\
\text { Excluded - low } \\
\text { consequence (SZ) }\end{array}$ & $\begin{array}{l}\text { DE } \\
\text { UZ } \\
\text { SZ }\end{array}$ \\
\hline 1.3.01.00.0A & Climate change & $\begin{array}{l}\text { Climate change may affect the long-term performance } \\
\text { of the repository. This includes the effects of long-term } \\
\text { change in global climate (e.g., glacial/interglacial cycles) } \\
\text { and shorter-term change in regional and local climate. } \\
\text { Climate is typically characterized by temporal variations } \\
\text { in precipitation and temperature. }\end{array}$ & $\begin{array}{l}\text { Included (UZ) } \\
\text { Included (Bio) }\end{array}$ & $\begin{array}{l}\text { UZ } \\
\text { Bio }\end{array}$ \\
\hline 1.3.04.00.0A & Periglacial effects & $\begin{array}{l}\text { This FEP addresses the physical processes and } \\
\text { associated landforms in cold but ice-sheet-free } \\
\text { environments. Permafrost and seasonal freeze/thaw } \\
\text { cycles are characteristic of periglacial environments. } \\
\text { These effects could include erosion and deposition. }\end{array}$ & $\begin{array}{l}\text { Excluded - low } \\
\text { consequence (UZ) } \\
\text { Excluded - low } \\
\text { probability (UZ) } \\
\text { Excluded - low } \\
\text { probability (Bio) } \\
\text { Excluded - low } \\
\text { consequence (Bio) } \\
\end{array}$ & $\begin{array}{l}\text { UZ } \\
\text { Bio }\end{array}$ \\
\hline 1.3.05.00.0A & $\begin{array}{l}\text { Glacial and ice } \\
\text { sheet effect }\end{array}$ & $\begin{array}{l}\text { This FEP addresses the effects of glaciers and ice } \\
\text { sheets occurring within the region of the repository, } \\
\text { including direct geomorphologic effects and hydrologic } \\
\text { effects. These effects include changes in topography } \\
\text { (due to glaciation and melt water), changes in flow } \\
\text { fields, and isostatic depression and rebound. These } \\
\text { effects could include erosion and deposition. }\end{array}$ & $\begin{array}{l}\text { Excluded - low } \\
\text { probability (UZ) } \\
\text { Excluded - low } \\
\text { probability (Bio) }\end{array}$ & $\begin{array}{l}\text { UZ } \\
\text { Bio }\end{array}$ \\
\hline 1.3.07.01.0A & $\begin{array}{l}\text { Water table } \\
\text { decline }\end{array}$ & $\begin{array}{l}\text { Climate change could produce decreased infiltration } \\
\text { (e.g., an extended drought), leading to a decline in the } \\
\text { water table in the saturated zone, which would affect the } \\
\text { release and exposure pathways from the repository. }\end{array}$ & $\begin{array}{l}\text { Excluded - low } \\
\text { consequence (UZ) } \\
\text { Excluded - low } \\
\text { consequence (SZ) }\end{array}$ & $\begin{array}{l}\text { UZ } \\
\text { SZ }\end{array}$ \\
\hline 1.3.07.02.0A & $\begin{array}{l}\text { Water table rise } \\
\text { affects SZ }\end{array}$ & $\begin{array}{l}\text { Climate change could produce increased infiltration, } \\
\text { leading to a rise in the regional water table, possibly } \\
\text { affecting radionuclide release from the repository by } \\
\text { altering flow and transport pathways in the SZ. A } \\
\text { regionally higher water table and change in SZ flow } \\
\text { patterns might move discharge points closer to the } \\
\text { repository. }\end{array}$ & $\begin{array}{l}\text { Included (SZ) } \\
\text { Included (Bio) }\end{array}$ & $\begin{array}{l}\text { SZ } \\
\text { Bio }\end{array}$ \\
\hline 1.3.07.02.0B & $\begin{array}{l}\text { Water table rise } \\
\text { affects UZ }\end{array}$ & $\begin{array}{l}\text { Climate change could produce increased infiltration, } \\
\text { leading to a rise in the regional water table, possibly } \\
\text { affecting radionuclide release from the repository by } \\
\text { altering flow and transport pathways in the UZ. A } \\
\text { regionally higher water table and change in UZ flow } \\
\text { patterns might flood the repository. }\end{array}$ & Included (UZ) & UZ \\
\hline
\end{tabular}


Table E-1. TSPA-LA FEP List (Continued)

\begin{tabular}{|c|c|c|c|c|}
\hline FEP Number & FEP Name & FEP Description & Screening Decision & $\begin{array}{l}\text { FEP } \\
\text { AMR }\end{array}$ \\
\hline 1.4.01.00.0A & $\begin{array}{l}\text { Human } \\
\text { influences on } \\
\text { climate }\end{array}$ & $\begin{array}{l}\text { Future human actions, either intentional or accidental, } \\
\text { could influence global, regional, or local climate. }\end{array}$ & $\begin{array}{l}\text { Excluded - by } \\
\text { regulation (UZ) } \\
\text { Excluded - by } \\
\text { regulation (Bio) }\end{array}$ & $\begin{array}{l}\text { UZ } \\
\text { Bio }\end{array}$ \\
\hline 1.4.01.01.0A & $\begin{array}{l}\text { Climate } \\
\text { modification } \\
\text { increases } \\
\text { recharge }\end{array}$ & $\begin{array}{l}\text { Climate modification causes an increase in recharge in } \\
\text { the Yucca Mountain region. Increased recharge might } \\
\text { lead to increased flux through the repository, perched } \\
\text { water, or water table rise. }\end{array}$ & Included (UZ) & UZ \\
\hline 1.4.01.02.0A & $\begin{array}{l}\text { Greenhouse gas } \\
\text { effects }\end{array}$ & $\begin{array}{l}\text { The greenhouse effect refers to the presence in the } \\
\text { atmosphere of carbon dioxide and other gases that tend } \\
\text { to allow solar radiation through to the earth's surface } \\
\text { and reflect heat back. Thus, these gases act much as } \\
\text { the glass of a greenhouse, with the earth as the } \\
\text { greenhouse. Human activities, such as burning fossil } \\
\text { fuels, clearing forests, and industrial processes, produce } \\
\text { these greenhouse gases. The greenhouse effect could } \\
\text { increase concentrations of carbon dioxide and other } \\
\text { gases in the atmosphere, and lead to changes in } \\
\text { climate such as global warming. }\end{array}$ & $\begin{array}{l}\text { Excluded - by } \\
\text { regulation (UZ) } \\
\text { Excluded - by } \\
\text { regulation (Bio) }\end{array}$ & $\begin{array}{l}\text { UZ } \\
\text { Bio }\end{array}$ \\
\hline 1.4.01.03.0A & Acid rain & $\begin{array}{l}\text { Human actions may result in acid rain on a local to } \\
\text { regional scale. Acid rain can detrimentally affect aquatic } \\
\text { and terrestrial life by interfering with the growth, } \\
\text { reproduction, and survival of organisms. It can } \\
\text { influence the behavior and transport of contaminants in } \\
\text { the biosphere, particularly by affecting surface water } \\
\text { and soil chemistry. }\end{array}$ & $\begin{array}{l}\text { Excluded - by } \\
\text { regulation (UZ) } \\
\text { Excluded - by } \\
\text { regulation (Bio) }\end{array}$ & $\begin{array}{l}\text { UZ } \\
\text { Bio }\end{array}$ \\
\hline 1.4.01.04.0A & $\begin{array}{l}\text { Ozone layer } \\
\text { failure }\end{array}$ & $\begin{array}{l}\text { Human actions (i.e., the use of certain industrial } \\
\text { chemicals) may lead to destruction or damage to the } \\
\text { earth's ozone layer. This may lead to significant } \\
\text { changes to the climate, affecting properties of the } \\
\text { geosphere such as groundwater flow patterns. }\end{array}$ & $\begin{array}{l}\text { Excluded - by } \\
\text { regulation (UZ) } \\
\text { Excluded - by } \\
\text { regulation (Bio) }\end{array}$ & $\begin{array}{l}\text { UZ } \\
\text { Bio }\end{array}$ \\
\hline $1.4 .02 .01 .0 \mathrm{~A}$ & $\begin{array}{l}\text { Deliberate human } \\
\text { intrusion }\end{array}$ & $\begin{array}{l}\text { Humans could deliberately intrude into the repository. } \\
\text { Without appropriate precautions, intruders could } \\
\text { experience high radiation exposures. Moreover, } \\
\text { containment may be left damaged, which could increase } \\
\text { radionuclide release rates to the biosphere. Motivation } \\
\text { for deliberate human intrusion includes mining, waste } \\
\text { retrieval, site remediation/improvement, archaeology, } \\
\text { sabotage, and acts of war. }\end{array}$ & $\begin{array}{l}\text { Excluded - by } \\
\text { regulation (SYS) }\end{array}$ & SYS \\
\hline 1.4.02.02.0A & $\begin{array}{l}\text { Inadvertent } \\
\text { human intrusion }\end{array}$ & $\begin{array}{l}\text { Humans could accidentally intrude into the repository. } \\
\text { Without appropriate precautions, intruders could } \\
\text { experience high radiation exposures. Moreover, } \\
\text { containment may be left damaged, which could increase } \\
\text { radionuclide release rates to the biosphere. Inadvertent } \\
\text { human intrusion might occur during scientific, mineral or } \\
\text { geothermal exploration. }\end{array}$ & $\begin{array}{l}\text { Excluded - by } \\
\text { regulation (SYS) }\end{array}$ & SYS \\
\hline $1.4 .02 .03 .0 \mathrm{~A}$ & $\begin{array}{l}\text { Igneous event } \\
\text { precedes human } \\
\text { intrusion }\end{array}$ & $\begin{array}{l}\text { An igneous event, such as a dike, could intersect the } \\
\text { repository and significantly alter the material and } \\
\text { structural properties of a drip shield and/or waste } \\
\text { package. Because of the change in properties, an } \\
\text { intruder, using groundwater exploration drilling } \\
\text { techniques, may not be able to recognize that } \\
\text { something other than naturally-occurring materials have } \\
\text { been encountered. }\end{array}$ & $\begin{array}{l}\text { Excluded - by } \\
\text { regulation (SYS) }\end{array}$ & SYS \\
\hline
\end{tabular}


Table E-1. TSPA-LA FEP List (Continued)

\begin{tabular}{|c|c|c|c|c|}
\hline FEP Number & FEP Name & FEP Description & Screening Decision & $\begin{array}{l}\text { FEP } \\
\text { AMR }\end{array}$ \\
\hline 1.4.02.04.0A & $\begin{array}{l}\text { Seismic event } \\
\text { precedes human } \\
\text { intrusion }\end{array}$ & $\begin{array}{l}\text { A seismic event could occur at the repository and } \\
\text { significantly alter the material and structural properties } \\
\text { of a drip shield and/or waste package. Because of the } \\
\text { change in properties, an intruder, using groundwater } \\
\text { exploration drilling techniques, may not be able to } \\
\text { recognize that something other than naturally-occurring } \\
\text { materials have been encountered. }\end{array}$ & $\begin{array}{l}\text { Excluded - low } \\
\text { consequence (SYS) } \\
\text { Excluded - by } \\
\text { regulation (SYS) }\end{array}$ & SYS \\
\hline 1.4.03.00.0A & $\begin{array}{l}\text { Unintrusive site } \\
\text { investigation }\end{array}$ & $\begin{array}{l}\text { This FEP addresses airborne, geophysical, or other } \\
\text { surface-based investigations of a repository site after its } \\
\text { closure. }\end{array}$ & $\begin{array}{l}\text { Excluded - by } \\
\text { regulation (SYS) } \\
\text { Excluded - low } \\
\text { consequence (SYS) }\end{array}$ & SYS \\
\hline 1.4.04.00.0A & $\begin{array}{l}\text { Drilling activities } \\
\text { (human intrusion) }\end{array}$ & $\begin{array}{l}\text { This FEP addresses any type of drilling activity in the } \\
\text { repository environment. These activities may be taken } \\
\text { with or without awareness of the presence of the } \\
\text { repository and with or without consent of the repository } \\
\text { licensee. Drilling activities may be associated with } \\
\text { natural resource exploration (water, oil and gas, } \\
\text { minerals, geothermal energy), waste disposal (liquid), } \\
\text { fluid storage (hydrocarbon, gas), or reopening existing } \\
\text { boreholes. }\end{array}$ & $\begin{array}{l}\text { Excluded - by } \\
\text { regulation (SYS) }\end{array}$ & SYS \\
\hline 1.4.04.01.0A & $\begin{array}{l}\text { Effects of drilling } \\
\text { intrusion }\end{array}$ & $\begin{array}{l}\text { Drilling activities that intrude into the repository may } \\
\text { create new release pathways to the biosphere and alter } \\
\text { existing pathways. Possible effects of a drilling intrusion } \\
\text { include interaction with waste packages, increased } \\
\text { saturation in the repository leading to enhanced } \\
\text { radionuclide transport to the SZ, changes to } \\
\text { groundwater and EBS chemistry, and waste brought to } \\
\text { the surface. }\end{array}$ & $\begin{array}{l}\text { Excluded - by } \\
\text { regulation (SYS) }\end{array}$ & SYS \\
\hline 1.4.05.00.0A & $\begin{array}{l}\text { Mining and other } \\
\text { underground } \\
\text { activities (human } \\
\text { intrusion) }\end{array}$ & $\begin{array}{l}\text { Mining and other underground human activities } \\
\text { (e.g., tunneling, underground construction, quarrying) } \\
\text { could disrupt the disposal system. }\end{array}$ & $\begin{array}{l}\text { Excluded - by } \\
\text { regulation (SYS) }\end{array}$ & SYS \\
\hline 1.4.06.01.0A & $\begin{array}{l}\text { Altered soil or } \\
\text { surface water } \\
\text { chemistry }\end{array}$ & $\begin{array}{l}\text { Human activities (e.g., industrial pollution, agricultural } \\
\text { chemicals) may produce local changes to the soil } \\
\text { chemistry or to the chemistry of water infiltrating Yucca } \\
\text { Mountain and could provide a plume of unspecified } \\
\text { nature to interact with the repository and possibly with } \\
\text { waste packages. }\end{array}$ & $\begin{array}{l}\text { Excluded - by } \\
\text { regulation (UZ) }\end{array}$ & UZ \\
\hline 1.4.07.01.0A & $\begin{array}{l}\text { Water } \\
\text { management } \\
\text { activities }\end{array}$ & $\begin{array}{l}\text { Water management is accomplished through a } \\
\text { combination of dams, reservoirs, canals, pipelines, and } \\
\text { collection and storage facilities. Water management } \\
\text { activities could have a major influence on the behavior } \\
\text { and transport of contaminants in the biosphere. }\end{array}$ & $\begin{array}{l}\text { Included (SZ) } \\
\text { Included (Bio) }\end{array}$ & $\begin{array}{l}\mathrm{SZ} \\
\mathrm{Bio}\end{array}$ \\
\hline 1.4.07.02.0A & Wells & $\begin{array}{l}\text { One or more wells drilled for human use (e.g., drinking } \\
\text { water, bathing) or agricultural use (e.g., irrigation, } \\
\text { animal watering) may intersect the contaminant plume. }\end{array}$ & $\begin{array}{l}\text { Included (SZ) } \\
\text { Included (Bio) }\end{array}$ & $\begin{array}{l}\text { SZ } \\
\text { Bio }\end{array}$ \\
\hline 1.4.07.03.0A & $\begin{array}{l}\text { Recycling of } \\
\text { accumulated } \\
\text { radionuclides } \\
\text { from soils to } \\
\text { groundwater }\end{array}$ & $\begin{array}{l}\text { Radionuclides that have accumulated in soils (e.g., from } \\
\text { deposition of contaminated irrigation water) may leach } \\
\text { out of the soil and be recycled back into the } \\
\text { groundwater as a result of recharge (either from natural } \\
\text { or agriculturally induced infiltration). The recycled } \\
\text { radionuclides may lead to enhanced radionuclide } \\
\text { exposure at the receptor. }\end{array}$ & $\begin{array}{l}\text { Excluded - By } \\
\text { regulation (SZ) }\end{array}$ & SZ \\
\hline
\end{tabular}


Table E-1. TSPA-LA FEP List (Continued)

\begin{tabular}{|c|c|c|c|c|}
\hline FEP Number & FEP Name & FEP Description & Screening Decision & $\begin{array}{l}\text { FEP } \\
\text { AMR }\end{array}$ \\
\hline 1.4.08.00.0A & $\begin{array}{l}\text { Social and } \\
\text { institutional } \\
\text { developments }\end{array}$ & $\begin{array}{l}\text { Social and institutional developments could affect the } \\
\text { long-term performance of the repository. The most } \\
\text { likely is social and institutional development resulting in } \\
\text { new activities, communities, or cities in the vicinity of } \\
\text { Yucca Mountain. }\end{array}$ & $\begin{array}{l}\text { Excluded - by } \\
\text { regulation (Bio) }\end{array}$ & Bio \\
\hline 1.4.09.00.0A & $\begin{array}{l}\text { Technological } \\
\text { developments }\end{array}$ & $\begin{array}{l}\text { Technological developments may affect the long-term } \\
\text { performance of the repository. These include changes } \\
\text { in the ability of humans to intrude the site, and changes } \\
\text { that might affect contaminant exposure and its health } \\
\text { implications. }\end{array}$ & $\begin{array}{l}\text { Excluded - by } \\
\text { regulation (Bio) }\end{array}$ & Bio \\
\hline 1.4.11.00.0A & $\begin{array}{l}\text { Explosions and } \\
\text { crashes (human } \\
\text { activities) }\end{array}$ & $\begin{array}{l}\text { Explosions or crashes resulting from future human } \\
\text { activities may affect the long-term performance of the } \\
\text { repository. Explosions may result from nuclear war, } \\
\text { underground nuclear testing, or resource exploitation. }\end{array}$ & $\begin{array}{l}\text { Excluded - by } \\
\text { regulation (SYS) } \\
\text { Excluded - low } \\
\text { consequence (SYS) }\end{array}$ & SYS \\
\hline 1.5.01.01.0A & Meteorite impact & $\begin{array}{l}\text { Meteorite impact close to the repository site might } \\
\text { disturb or remove rock so that radionuclide transport to } \\
\text { the surface is accelerated. Possible effects include } \\
\text { alteration of flow patterns (faults, fractures), changes in } \\
\text { rock stress, cratering, and exhumation of waste. }\end{array}$ & $\begin{array}{l}\text { Excluded - low } \\
\text { probability (SYS) } \\
\text { Excluded - low } \\
\text { consequence (SYS) }\end{array}$ & SYS \\
\hline 1.5.01.02.0A & $\begin{array}{l}\text { Extraterrestrial } \\
\text { events }\end{array}$ & $\begin{array}{l}\text { Extraterrestrial events (e.g., supernova, solar flare, } \\
\text { gamma-ray burster, alien life forms) may affect long- } \\
\text { term performance of the disposal system. }\end{array}$ & $\begin{array}{l}\text { Excluded - low } \\
\text { consequence (SYS) }\end{array}$ & SYS \\
\hline 1.5.02.00.0A & Species evolution & $\begin{array}{l}\text { Species living at or near the repository, including } \\
\text { humans, may evolve in the future and new behavior and } \\
\text { characteristics of living organisms may affect their } \\
\text { contaminant exposure and its health implications. }\end{array}$ & $\begin{array}{l}\text { Excluded - by } \\
\text { regulation (Bio) }\end{array}$ & Bio \\
\hline 1.5.03.01.0A & $\begin{array}{l}\text { Changes in the } \\
\text { earth's magnetic } \\
\text { field }\end{array}$ & $\begin{array}{l}\text { Changes in the earth's magnetic field could affect the } \\
\text { long-term performance of the repository. }\end{array}$ & $\begin{array}{l}\text { Excluded - low } \\
\text { consequence (SYS) }\end{array}$ & SYS \\
\hline 1.5.03.02.0A & Earth tides & $\begin{array}{l}\text { Small changes of the gravitational field due to celestial } \\
\text { movements (sun and moon) cause earth tides and may, } \\
\text { in turn, cause pressure variations in the groundwater } \\
\text { flow systems. }\end{array}$ & $\begin{array}{l}\text { Excluded - low } \\
\text { consequence (SYS) }\end{array}$ & SYS \\
\hline 2.1.01.01.0A & Waste inventory & $\begin{array}{l}\text { The waste inventory includes all potential sources of } \\
\text { radio toxicity and chemical toxicity. It consists of the } \\
\text { radionuclide inventory (typically in units of curies), by } \\
\text { specific isotope, and the non-radionuclide inventory } \\
\text { (typically in units of density or concentration), comprised } \\
\text { of physical (e.g., CSNF, DNSF, and HLW) and chemical } \\
\text { waste constituents. The radionuclide composition of the } \\
\text { waste will vary due to initial enrichment, burn-up, the } \\
\text { number of fuel assemblies per waste package, and the } \\
\text { decay time subsequent to discharge of the fuel from the } \\
\text { reactor. } \\
\text { Also consider that the fuel types, matrices, radionuclide } \\
\text { mixes, and non-radionuclide inventories in DSNF and } \\
\text { HLW may differ from CSNF. Additional waste types } \\
\text { should be considered if they are proposed for disposal } \\
\text { at Yucca Mountain. }\end{array}$ & Included (WF) & WF \\
\hline 2.1.01.02.0A & $\begin{array}{l}\text { Interactions } \\
\text { between co- } \\
\text { located waste }\end{array}$ & $\begin{array}{l}\text { Co-location refers to the disposal of CSNF, DSNF, } \\
\text { HLW, and possibly other wastes in close proximity } \\
\text { within the repository. Co-location might affect thermal } \\
\text { outputs, chemical interactions, or radionuclide } \\
\text { mobilization. }\end{array}$ & $\begin{array}{l}\text { Excluded - low } \\
\text { consequence (WF) }\end{array}$ & WF \\
\hline
\end{tabular}


Table E-1. TSPA-LA FEP List (Continued)

\begin{tabular}{|c|c|c|c|c|}
\hline FEP Number & FEP Name & FEP Description & Screening Decision & $\begin{array}{l}\text { FEP } \\
\text { AMR }\end{array}$ \\
\hline 2.1.01.02.0B & $\begin{array}{l}\text { Interactions } \\
\text { between co- } \\
\text { disposed waste }\end{array}$ & $\begin{array}{l}\text { Co-disposal refers to the disposal of different waste } \\
\text { types within the same waste package. Co-disposal } \\
\text { might affect chemical interactions or radionuclide } \\
\text { mobilization. At Yucca Mountain, the DSNF will be } \\
\text { combined with HLW canisters within a waste package. } \\
\text { This co-disposal with HLW within a waste package is } \\
\text { unique to the DSNF and does not apply to the CSNF } \\
\text { placement within waste packages. } \\
\text { The DSNF will be contained within canisters that will be } \\
\text { placed within the waste packages. The use of canisters } \\
\text { within the waste package is not typical of the CSNF } \\
\text { placement within waste packages. Also, some DSNF } \\
\text { waste packages may contain only DSNF canisters, } \\
\text { while others may contain both DSNF and HLW } \\
\text { canisters. }\end{array}$ & Included (WF) & WF \\
\hline $2.1 .01 .03 .0 \mathrm{~A}$ & $\begin{array}{l}\text { Heterogeneity of } \\
\text { waste inventory }\end{array}$ & $\begin{array}{l}\text { CSNF, DSNF, and HLW shipped to the repository may } \\
\text { contain quantities of radionuclides that vary from waste } \\
\text { package to waste package, fuel assembly to fuel } \\
\text { assembly, and canister to canister. The composition of } \\
\text { each of these waste forms may vary due to initial } \\
\text { uranium enrichment, possible plutonium enrichment, } \\
\text { and fuel burn-up, among other factors. The physical } \\
\text { state within the waste form may also vary. For example, } \\
\text { damaged fuel pellets or extremely high-burn-up fuels } \\
\text { may have greater surface area exposed to any water } \\
\text { penetrating a waste package than undamaged, low- } \\
\text { burn-up spent fuel. Given these potential differences in } \\
\text { isotopic composition and physical condition, the mass of } \\
\text { radionuclides available for transport may vary } \\
\text { significantly among waste packages. } \\
\text { The different physical (structure, geometry), chemical, } \\
\text { and radiological properties of the many forms of CSNF, } \\
\text { DSNF, and HLW could result in differences in the } \\
\text { corrosion and alteration rates based on waste-package } \\
\text { composition. This could affect repository chemistry, } \\
\text { breach times, dissolution rates, and availability of } \\
\text { radionuclides for transport. }\end{array}$ & Included (WF) & WF \\
\hline 2.1.01.04.0A & $\begin{array}{l}\text { Repository-scale } \\
\text { spatial } \\
\text { heterogeneity of } \\
\text { emplaced waste }\end{array}$ & $\begin{array}{l}\text { Waste placed in Yucca Mountain will have physical, } \\
\text { chemical, and radiological properties that will vary } \\
\text { spatially, resulting in variation in the mass of } \\
\text { radionuclides available for transport from different parts } \\
\text { of the repository. }\end{array}$ & Included (SYS) & SYS \\
\hline 2.1.02.01.0A & $\begin{array}{l}\text { DSNF } \\
\text { degradation } \\
\text { (alteration, } \\
\text { dissolution, and } \\
\text { radionuclide } \\
\text { release) }\end{array}$ & $\begin{array}{l}\text { DSNF to be disposed in Yucca Mountain contains a } \\
\text { variety of fuel types that include metallic uranium fuels; } \\
\text { oxide and MOX fuels; Three Mile Island rubble; and } \\
\text { heterogeneous fuels such as UAlx, U-ZrHx, and } \\
\text { graphite fuels. In general, the composition and structure } \\
\text { of these spent fuels are significantly different from } \\
\text { CSNF, and the degradation, alteration, and dissolution } \\
\text { may be different from the CSNF degradation. } \\
\text { Processes to be considered in this FEP include } \\
\text { alteration and dissolution of the various DSNF waste } \\
\text { forms, phase separation, oxidation of spent fuels, } \\
\text { selective leaching, and the effects of the high-integrity } \\
\text { can on DSNF degradation. }\end{array}$ & Included (WF) & WF \\
\hline
\end{tabular}


Table E-1. TSPA-LA FEP List (Continued)

\begin{tabular}{|c|c|c|c|c|}
\hline FEP Number & FEP Name & FEP Description & Screening Decision & $\begin{array}{l}\text { FEP } \\
\text { AMR }\end{array}$ \\
\hline $2.1 .02 .02 .0 \mathrm{~A}$ & $\begin{array}{l}\text { CSNF } \\
\text { degradation } \\
\text { (alteration, } \\
\text { dissolution, and } \\
\text { radionuclide } \\
\text { release) }\end{array}$ & $\begin{array}{l}\text { Alteration of the original CSNF mineralogy (under wet or } \\
\text { dry conditions) and dissolution of the uranium-oxide } \\
\text { matrix can influence the mobilization of radionuclides. } \\
\text { The degradation of } \mathrm{UO} 2 \text { could be affected by a number } \\
\text { of variables, such as surface area, burn-up, } \\
\text { temperature, overall solution electrochemical potential } \\
\text { (Eh), pH, and especially solutions containing significant } \\
\text { concentrations of calcium, sodium, carbonate, and } \\
\text { silicate ions, as well as availability of organic } \\
\text { complexing materials. In turn, these water properties } \\
\text { are affected by the alteration of the cladding and matrix. }\end{array}$ & Included (WF) & WF \\
\hline $2.1 .02 .03 .0 \mathrm{~A}$ & $\begin{array}{l}\text { HLW glass } \\
\text { degradation } \\
\text { (alteration, } \\
\text { dissolution, and } \\
\text { radionuclide } \\
\text { release) }\end{array}$ & $\begin{array}{l}\text { Glass waste forms are thermodynamically unstable over } \\
\text { long time periods, and will alter on contact with water. } \\
\text { Radionuclides can be mobilized from the glass waste by } \\
\text { a variety of processes, including degradation and } \\
\text { alteration of the glass, phase separation, congruent } \\
\text { dissolution, precipitation of silicates, co-precipitation of } \\
\text { other minerals (including iron corrosion products), and } \\
\text { selective leaching. }\end{array}$ & Included (WF) & WF \\
\hline $2.1 .02 .04 .0 \mathrm{~A}$ & $\begin{array}{l}\text { Alpha recoil } \\
\text { enhances } \\
\text { dissolution }\end{array}$ & $\begin{array}{l}\text { During decay of certain radionuclides, alpha particles } \\
\text { may be emitted with sufficiently high energies that the } \\
\text { daughter nuclide recoils appreciably to conserve system } \\
\text { momentum. A potential result of recoil is that certain } \\
\text { radionuclides, such as } 234 \cup \text {, exhibit substantially } \\
\text { greater dissolution rates (with the same solubility limits) } \\
\text { and can be transported preferentially. }\end{array}$ & $\begin{array}{l}\text { Excluded - low } \\
\text { consequence (WF) }\end{array}$ & WF \\
\hline $2.1 .02 .05 .0 \mathrm{~A}$ & $\begin{array}{l}\text { HLW glass } \\
\text { cracking }\end{array}$ & $\begin{array}{l}\text { Cracking of the HLW glass on cooling and during } \\
\text { handling means that the surface area of the glass is } \\
\text { greater than the surface area of a monolithic block. The } \\
\text { increase in the surface area could affect the rate of } \\
\text { glass alteration and radionuclide dissolution. }\end{array}$ & Included (WF) & WF \\
\hline $2.1 .02 .06 .0 \mathrm{~A}$ & $\begin{array}{l}\text { HLW glass } \\
\text { recrystallization }\end{array}$ & $\begin{array}{l}\text { HLW glass recrystallization could occur and would lead } \\
\text { to a less corrosion-resistant waste form. } \\
\text { Recrystallization is a slow process and typically occurs } \\
\text { only if a high glass temperature is maintained over a } \\
\text { prolonged period. }\end{array}$ & $\begin{array}{l}\text { Excluded - low } \\
\text { consequence (WF) }\end{array}$ & WF \\
\hline 2.1.02.07.0A & $\begin{array}{l}\text { Radionuclide } \\
\text { release from gap } \\
\text { and grain } \\
\text { boundaries }\end{array}$ & $\begin{array}{l}\text { While in the reactor at high temperatures, radionuclides } \\
\text { such as I and Cs may migrate and preferentially } \\
\text { accumulate in cracks in the fuel matrix, grain boundaries } \\
\text { of the UO2, and in the gap between the fuel and } \\
\text { cladding. After the waste package fails and the cladding } \\
\text { perforates, the release rate of this fraction of the } \\
\text { radionuclides could be rapid. In addition, reactions } \\
\text { between materials within the spent fuel assembly or } \\
\text { waste package infill such as I and Pb may affect this } \\
\text { process. }\end{array}$ & Included (WF) & WF \\
\hline $2.1 .02 .08 .0 \mathrm{~A}$ & $\begin{array}{l}\text { Pyrophoricity } \\
\text { from DSNF }\end{array}$ & $\begin{array}{l}\text { DSNF can contain pyrophoric material. Pyrophoric } \\
\text { material could ignite and produce an adverse effect on } \\
\text { repository performance. Pyrophoric events could affect } \\
\text { the thermal behavior of the system and could contribute } \\
\text { to degradation of the waste package, waste form, and } \\
\text { cladding. }\end{array}$ & $\begin{array}{l}\text { Excluded - low } \\
\text { consequence (WF) }\end{array}$ & WF \\
\hline $2.1 .02 .09 .0 \mathrm{~A}$ & $\begin{array}{l}\text { Chemical effects } \\
\text { of void space in } \\
\text { waste package }\end{array}$ & $\begin{array}{l}\text { If waste packages and/or DSNF canisters are not } \\
\text { completely filled, then the unfilled inert gas or air-filled } \\
\text { volume could influence water-chemistry calculations. }\end{array}$ & Included (WF) & WF \\
\hline $2.1 .02 .10 .0 \mathrm{~A}$ & $\begin{array}{l}\text { Organic/cellulosic } \\
\text { materials in } \\
\text { waste }\end{array}$ & $\begin{array}{l}\text { Degradation of cellulose in the waste could affect the } \\
\text { long-term performance of the disposal system. }\end{array}$ & $\begin{array}{l}\text { Excluded - low } \\
\text { consequence (WF) }\end{array}$ & WF \\
\hline
\end{tabular}


Table E-1. TSPA-LA FEP List (Continued)

\begin{tabular}{|c|c|c|c|c|}
\hline FEP Number & FEP Name & FEP Description & Screening Decision & $\begin{array}{l}\text { FEP } \\
\text { AMR }\end{array}$ \\
\hline 2.1.02.11.0A & $\begin{array}{l}\text { Degradation of } \\
\text { cladding from } \\
\text { waterlogged rods }\end{array}$ & $\begin{array}{l}\text { Failed fuel rods (attributed to breaches caused by } \\
\text { manufacturing defects and reactor operations) comprise } \\
\text { a small fraction of the fuel rods that are currently being } \\
\text { stored in commercial reactor spent fuel pools. Failed } \\
\text { fuel contains water in the fuel rod void space that may } \\
\text { promote degradation of the spent fuel cladding. Such } \\
\text { fuel is referred to as "waterlogged". The moisture } \\
\text { remaining in a "dried" fuel rod is used to determine the } \\
\text { extent of degradation of spent fuel cladding. }\end{array}$ & $\begin{array}{l}\text { Excluded - low } \\
\text { consequence (Clad) }\end{array}$ & Clad \\
\hline 2.1.02.12.0A & $\begin{array}{l}\text { Degradation of } \\
\text { cladding prior to } \\
\text { disposal }\end{array}$ & $\begin{array}{l}\text { Certain aspects of cladding degradation may occur } \\
\text { before the spent fuel arrives at Yucca Mountain. } \\
\text { Possible mechanisms include rod cladding degradation } \\
\text { during reactor operation, degradation during wet spent } \\
\text { fuel pool storage, degradation during dry storage, and } \\
\text { rod degradation during shipping (i.e., from creep and } \\
\text { from vibration and impact) and fuel handling. }\end{array}$ & Included (Clad) & Clad \\
\hline 2.1.02.13.0A & $\begin{array}{l}\text { General } \\
\text { corrosion of } \\
\text { cladding }\end{array}$ & $\begin{array}{l}\text { General corrosion of cladding could expose large areas } \\
\text { of fuel and produce hydrides. }\end{array}$ & $\begin{array}{l}\text { Excluded - low } \\
\text { consequence (Clad) }\end{array}$ & Clad \\
\hline 2.1.02.14.0A & $\begin{array}{l}\text { Microbially } \\
\text { influenced } \\
\text { corrosion (MIC) } \\
\text { of cladding }\end{array}$ & $\begin{array}{l}\text { Microbially influenced corrosion (MIC) of cladding is a } \\
\text { potential localized corrosion mechanism where } \\
\text { microbes produce a local acidic environment that could } \\
\text { produce multiple penetrations through the fuel cladding. }\end{array}$ & $\begin{array}{l}\text { Excluded - low } \\
\text { consequence (Clad) }\end{array}$ & Clad \\
\hline 2.1.02.15.0A & $\begin{array}{l}\text { Localized } \\
\text { (radiolysis } \\
\text { enhanced) } \\
\text { corrosion of } \\
\text { cladding }\end{array}$ & $\begin{array}{l}\text { Radiolysis in a nitrogen/oxygen gas mixture with the } \\
\text { presence of water film results in the formation of nitric } \\
\text { acid (HNO3). Hydrogen peroxide }(\mathrm{H} 2 \mathrm{O} 2) \text { is formed in } \\
\text { the water from radiolysis. These chemicals can } \\
\text { enhance corrosion of the fuel cladding. }\end{array}$ & $\begin{array}{l}\text { Excluded - low } \\
\text { consequence (Clad) }\end{array}$ & Clad \\
\hline 2.1.02.16.0A & $\begin{array}{l}\text { Localized (pitting) } \\
\text { corrosion of } \\
\text { cladding }\end{array}$ & $\begin{array}{l}\text { Localized corrosion in pits could produce penetrations of } \\
\text { cladding. }\end{array}$ & $\begin{array}{l}\text { Excluded - low } \\
\text { consequence (Clad) }\end{array}$ & Clad \\
\hline 2.1.02.17.0A & $\begin{array}{l}\text { Localized } \\
\text { (crevice) } \\
\text { corrosion of } \\
\text { cladding }\end{array}$ & $\begin{array}{l}\text { Localized corrosion in crevices could produce } \\
\text { penetrations of cladding. }\end{array}$ & $\begin{array}{l}\text { Excluded - low } \\
\text { consequence (Clad) }\end{array}$ & Clad \\
\hline 2.1.02.18.0A & $\begin{array}{l}\text { Enhanced } \\
\text { corrosion of } \\
\text { cladding from } \\
\text { dissolved silica }\end{array}$ & $\begin{array}{l}\text { High dissolved silica content of waters may enhance } \\
\text { corrosion of cladding. }\end{array}$ & $\begin{array}{l}\text { Excluded - low } \\
\text { consequence (Clad) }\end{array}$ & Clad \\
\hline $2.1 .02 .19 .0 \mathrm{~A}$ & $\begin{array}{l}\text { Creep rupture of } \\
\text { cladding }\end{array}$ & $\begin{array}{l}\text { At high temperatures ( }>400 \text { degrees } C \text { ) for sufficiently } \\
\text { long time intervals, creep rupture of Zircaloy cladding on } \\
\text { spent fuel can occur and produce small perforations in } \\
\text { the cladding to relieve stress. After the waste package } \\
\text { fails, the fuel can react with water and radionuclides can } \\
\text { escape over time from the fuel rod. }\end{array}$ & $\begin{array}{l}\text { Excluded - low } \\
\text { consequence (Clad) }\end{array}$ & Clad \\
\hline 2.1.02.20.0A & $\begin{array}{l}\text { Internal } \\
\text { pressurization of } \\
\text { cladding }\end{array}$ & $\begin{array}{l}\text { Increased pressure within the fuel rod due to the } \\
\text { production of helium gas could contribute to cladding } \\
\text { failure. }\end{array}$ & $\begin{array}{l}\text { Excluded - low } \\
\text { consequence (Clad) }\end{array}$ & Clad \\
\hline 2.1.02.21.0A & $\begin{array}{l}\text { Stress corrosion } \\
\text { cracking (SCC) of } \\
\text { cladding }\end{array}$ & $\begin{array}{l}\text { Stress corrosion cracking (SCC) mechanisms can } \\
\text { contribute to cladding failure. These mechanisms can } \\
\text { operate both from the inside out from the action of } \\
\text { fission products, or from the outside in from the actions } \\
\text { of salts or other chemicals within the waste package. }\end{array}$ & $\begin{array}{l}\text { Excluded - low } \\
\text { consequence (Clad) }\end{array}$ & Clad \\
\hline
\end{tabular}


Table E-1. TSPA-LA FEP List (Continued)

\begin{tabular}{|c|c|c|c|c|}
\hline FEP Number & FEP Name & FEP Description & Screening Decision & $\begin{array}{l}\text { FEP } \\
\text { AMR }\end{array}$ \\
\hline 2.1.02.22.0A & $\begin{array}{l}\text { Hydride cracking } \\
\text { of cladding }\end{array}$ & $\begin{array}{l}\text { Cladding contains hydrogen after reactor operation. } \\
\text { The cladding might pick up more hydrogen from } \\
\text { cladding general corrosion (wet oxidation) after the } \\
\text { waste package is breached. The hydrogen can exist } \\
\text { both as zirconium hydride precipitates and as hydrogen } \\
\text { in solid solution with zirconium. Hydrides might also } \\
\text { form from UO2 oxidation after waste package and } \\
\text { cladding perforation. In addition, hydrides may dissolve } \\
\text { in warmer areas of the cladding and migrate to cooler } \\
\text { areas. Hydrogen can also move from places of low } \\
\text { stress to places of high stress, causing hydride } \\
\text { reorientation or delayed hydride cracking. The buildup } \\
\text { of hydrides can cause existing cracks to propagate by } \\
\text { delayed hydride cracking or hydride embrittlement. }\end{array}$ & $\begin{array}{l}\text { Excluded - low } \\
\text { consequence (Clad) }\end{array}$ & Clad \\
\hline $2.1 .02 .23 .0 \mathrm{~A}$ & $\begin{array}{l}\text { Cladding } \\
\text { unzipping }\end{array}$ & $\begin{array}{l}\text { In either dry or wet oxidizing conditions and with } \\
\text { perforated fuel cladding, the UO2 fuel can oxidize. The } \\
\text { volume increase of the fuel as it oxidizes can create } \\
\text { stresses in the cladding that may cause gross rupture of } \\
\text { the fuel cladding (unzipping). }\end{array}$ & Included (Clad) & Clad \\
\hline 2.1.02.24.0A & $\begin{array}{l}\text { Mechanical } \\
\text { impact on } \\
\text { cladding }\end{array}$ & $\begin{array}{l}\text { Mechanical failure of cladding may result from external } \\
\text { stresses, such as rockfall or impact from waste package } \\
\text { internals. Seismic-induced impacts are addressed in a } \\
\text { separate FEP. }\end{array}$ & $\begin{array}{l}\text { Excluded - low } \\
\text { probability (Clad) }\end{array}$ & Clad \\
\hline 2.1.02.25.0A & DSNF cladding & $\begin{array}{l}\text { DSNF to be disposed in Yucca Mountain contains a } \\
\text { variety of fuel types that may not be similar to CSNF. } \\
\text { Some of the fuel types may have initial cladding- } \\
\text { degradation characteristics that are different from those } \\
\text { for CSNF. Therefore, the effectiveness of DSNF } \\
\text { cladding as a barrier to radionuclide mobilization might } \\
\text { be different from CSNF. This FEP addresses all types } \\
\text { of DSNF cladding except Naval SNF cladding. }\end{array}$ & $\begin{array}{l}\text { Excluded - low } \\
\text { consequence (WF) }\end{array}$ & WF \\
\hline 2.1.02.25.0B & $\begin{array}{l}\text { Naval SNF } \\
\text { Cladding }\end{array}$ & $\begin{array}{l}\text { DSNF to be disposed of in Yucca Mountain has a } \\
\text { variety of fuel types that may not be similar to the CSNF } \\
\text { to be disposed. Some of the fuel types may have initial } \\
\text { cladding-degradation characteristics that are different } \\
\text { from those for the CSNF. Therefore, the effectiveness } \\
\text { of DSNF cladding as a barrier to radionuclide } \\
\text { mobilization might be different from CSNF. This FEP } \\
\text { addresses Naval SNF cladding only. }\end{array}$ & Included (Clad) & Clad \\
\hline 2.1.02.26.0A & $\begin{array}{l}\text { Diffusion- } \\
\text { controlled cavity } \\
\text { growth in } \\
\text { cladding }\end{array}$ & $\begin{array}{l}\text { Diffusion-controlled cavity growth is a possible creep } \\
\text { rupture mechanism that could occur under the } \\
\text { temperature and pressure conditions that prevail during } \\
\text { dry storage of spent fuel. It might also occur during } \\
\text { disposal. }\end{array}$ & $\begin{array}{l}\text { Excluded - low } \\
\text { consequence (Clad) }\end{array}$ & Clad \\
\hline 2.1.02.27.0A & $\begin{array}{l}\text { Localized } \\
\text { (fluoride } \\
\text { enhanced) } \\
\text { corrosion of } \\
\text { cladding }\end{array}$ & $\begin{array}{l}\text { Fluoride is present in Yucca Mountain groundwater, and } \\
\text { zirconium has been observed to corrode in } \\
\text { environments containing fluoride. Therefore, fluoride } \\
\text { corrosion of cladding may occur in waste packages. }\end{array}$ & $\begin{array}{l}\text { Excluded - low } \\
\text { consequence (Clad) }\end{array}$ & Clad \\
\hline 2.1.02.28.0A & $\begin{array}{l}\text { Grouping of } \\
\text { DSNF waste } \\
\text { types into } \\
\text { categories }\end{array}$ & $\begin{array}{l}\text { Several hundred distinct types of DSNF may potentially } \\
\text { be stored in the repository. These represent many more } \\
\text { types than can viably be examined for their individual } \\
\text { effect on the repository. A limited number of } \\
\text { representative or bounding degradation models must be } \\
\text { selected and/or abstracted. }\end{array}$ & Included (WF) & WF \\
\hline
\end{tabular}


Table E-1. TSPA-LA FEP List (Continued)

\begin{tabular}{|c|c|c|c|c|}
\hline FEP Number & FEP Name & FEP Description & Screening Decision & $\begin{array}{l}\text { FEP } \\
\text { AMR }\end{array}$ \\
\hline 2.1.02.29.0A & $\begin{array}{l}\text { Flammable gas } \\
\text { generation from } \\
\text { DSNF }\end{array}$ & $\begin{array}{l}\text { DSNF to be disposed in Yucca Mountain will contain a } \\
\text { small percentage of carbide fuel. When carbide is } \\
\text { exposed to water, flammable gases such as methane } \\
\text { and its minor constituents ethane, ethylene, and } \\
\text { acetylene (referred as ethyne by the International Union } \\
\text { of Pure and Applied Chemistry) are generated. If these } \\
\text { gases ignite, localized increases in temperature can } \\
\text { occur, which might affect fuel degradation. The area } \\
\text { around the ignition point may be mechanically and/or } \\
\text { thermally perturbed, which could affect waste package } \\
\text { or host-rock properties in the adjacent area of the EBS. }\end{array}$ & $\begin{array}{l}\text { Excluded - low } \\
\text { consequence (WF) }\end{array}$ & WF \\
\hline 2.1.03.01.0A & $\begin{array}{l}\text { General } \\
\text { corrosion of } \\
\text { waste packages }\end{array}$ & $\begin{array}{l}\text { General corrosion may contribute to waste package } \\
\text { failure. }\end{array}$ & Included (WP) & WP \\
\hline 2.1.03.01.0B & $\begin{array}{l}\text { General } \\
\text { corrosion of drip } \\
\text { shields }\end{array}$ & General corrosion may contribute to drip shield failure. & Included (WP) & WP \\
\hline 2.1.03.02.0A & $\begin{array}{l}\text { Stress corrosion } \\
\text { cracking (SCC) of } \\
\text { waste packages }\end{array}$ & $\begin{array}{l}\text { Waste packages may become wet at specific locations } \\
\text { that are stressed leading to stress corrosion cracking } \\
\text { (SCC). The possibility of SCC under dry conditions or } \\
\text { due to thermal stresses are also addressed as part of } \\
\text { this FEP. }\end{array}$ & Included (WP) & WP \\
\hline 2.1.03.02.0B & $\begin{array}{l}\text { Stress corrosion } \\
\text { cracking (SCC) of } \\
\text { drip shields }\end{array}$ & $\begin{array}{l}\text { Drip shields may become wet at specific locations that } \\
\text { are stressed leading to stress corrosion cracking (SCC). } \\
\text { The possibility of SCC under dry conditions or due to } \\
\text { thermal stresses are also addressed as part of this FEP. }\end{array}$ & $\begin{array}{l}\text { Excluded - low } \\
\text { consequence (WP) }\end{array}$ & WP \\
\hline 2.1.03.03.0A & $\begin{array}{l}\text { Localized } \\
\text { corrosion of } \\
\text { waste packages }\end{array}$ & $\begin{array}{l}\text { Localized corrosion (pitting or crevice corrosion) could } \\
\text { enhance degradation of the waste packages. }\end{array}$ & Included (WP) & WP \\
\hline 2.1.03.03.0B & $\begin{array}{l}\text { Localized } \\
\text { corrosion of drip } \\
\text { shields }\end{array}$ & $\begin{array}{l}\text { Localized corrosion (pitting or crevice corrosion) could } \\
\text { enhance degradation of the drip shields. }\end{array}$ & $\begin{array}{l}\text { Excluded - low } \\
\text { probability (WP) }\end{array}$ & WP \\
\hline 2.1.03.04.0A & $\begin{array}{l}\text { Hydride cracking } \\
\text { of waste } \\
\text { packages }\end{array}$ & $\begin{array}{l}\text { The uptake of hydrogen and the formation of metal } \\
\text { hydrides may mechanically weaken the waste packages } \\
\text { and promote corrosion. }\end{array}$ & $\begin{array}{l}\text { Excluded - low } \\
\text { probability (WP) }\end{array}$ & WP \\
\hline 2.1.03.04.0B & $\begin{array}{l}\text { Hydride cracking } \\
\text { of drip shields }\end{array}$ & $\begin{array}{l}\text { The uptake of hydrogen and the formation of metal } \\
\text { hydrides may mechanically weaken the drip shields and } \\
\text { promote corrosion. }\end{array}$ & $\begin{array}{l}\text { Excluded - low } \\
\text { probability (WP) }\end{array}$ & WP \\
\hline 2.1.03.05.0A & $\begin{array}{l}\text { Microbially } \\
\text { influenced } \\
\text { corrosion (MIC) } \\
\text { of waste } \\
\text { packages }\end{array}$ & $\begin{array}{l}\text { Microbial activity may catalyze waste package corrosion } \\
\text { by otherwise kinetically hindered oxidizing agents. The } \\
\text { most likely process is microbial reduction of } \\
\text { groundwater sulfates to sulfides and reaction of iron with } \\
\text { dissolved sulfides. }\end{array}$ & Included (WP) & WP \\
\hline 2.1.03.05.0B & $\begin{array}{l}\text { Microbially } \\
\text { influenced } \\
\text { corrosion (MIC) } \\
\text { of drip shields }\end{array}$ & $\begin{array}{l}\text { Microbial activity may catalyze drip shield corrosion by } \\
\text { otherwise kinetically hindered oxidizing agents. The } \\
\text { most likely process is microbial reduction of } \\
\text { groundwater sulfates to sulfides and reaction of iron with } \\
\text { dissolved sulfides. }\end{array}$ & $\begin{array}{l}\text { Excluded - low } \\
\text { consequence (WP) }\end{array}$ & WP \\
\hline 2.1.03.06.0A & $\begin{array}{l}\text { Internal corrosion } \\
\text { of waste } \\
\text { packages prior to } \\
\text { breach }\end{array}$ & $\begin{array}{l}\text { Aggressive chemical conditions within the waste } \\
\text { package could contribute to corrosion from the inside } \\
\text { out. Effects of different waste forms, including CSNF } \\
\text { and DSNF, are considered in this FEP. }\end{array}$ & $\begin{array}{l}\text { Excluded - low } \\
\text { consequence (WF) } \\
\text { Excluded - low } \\
\text { consequence (WP) }\end{array}$ & $\begin{array}{l}\text { WF } \\
\text { WP }\end{array}$ \\
\hline
\end{tabular}


Table E-1. TSPA-LA FEP List (Continued)

\begin{tabular}{|c|c|c|c|c|}
\hline FEP Number & FEP Name & FEP Description & Screening Decision & $\begin{array}{l}\text { FEP } \\
\text { AMR }\end{array}$ \\
\hline 2.1.03.07.0A & $\begin{array}{l}\text { Mechanical } \\
\text { impact on waste } \\
\text { package }\end{array}$ & $\begin{array}{l}\text { Mechanical impact (dynamic loading) on the waste } \\
\text { package may be caused by internal and external forces } \\
\text { such as internal gas pressure, forces caused by } \\
\text { swelling corrosion products, rockfall, and possible waste } \\
\text { package or drip shield movement. Seismic-induced } \\
\text { impacts are addressed in a separate FEP. }\end{array}$ & $\begin{array}{l}\text { Excluded - low } \\
\text { probability (WP) } \\
\text { Excluded - low } \\
\text { consequence (WP) }\end{array}$ & WP \\
\hline 2.1.03.07.0B & $\begin{array}{l}\text { Mechanical } \\
\text { impact on drip } \\
\text { shield }\end{array}$ & $\begin{array}{l}\text { Mechanical impact (dynamic loading) on the drip shield } \\
\text { may be caused by forces such as rockfall and possible } \\
\text { waste package or drip shield movement. Seismic- } \\
\text { induced impacts are addressed in a separate FEP. }\end{array}$ & $\begin{array}{l}\text { Excluded - low } \\
\text { consequence (WP) }\end{array}$ & WP \\
\hline 2.1.03.08.0A & $\begin{array}{l}\text { Early failure of } \\
\text { waste packages }\end{array}$ & $\begin{array}{l}\text { Waste packages may fail prematurely because of } \\
\text { manufacturing defects, improper sealing, or other } \\
\text { factors related to quality control during manufacture and } \\
\text { emplacement. }\end{array}$ & Included (WP) & WP \\
\hline 2.1.03.08.0B & $\begin{array}{l}\text { Early failure of } \\
\text { drip shields }\end{array}$ & $\begin{array}{l}\text { Drip shields may fail prematurely because of } \\
\text { manufacturing defects, improper sealing, or other } \\
\text { factors related to quality control during manufacture and } \\
\text { emplacement. }\end{array}$ & $\begin{array}{l}\text { Excluded - low } \\
\text { consequence (WP) }\end{array}$ & WP \\
\hline 2.1.03.09.0A & $\begin{array}{l}\text { Copper corrosion } \\
\text { in EBS }\end{array}$ & $\begin{array}{l}\text { Chemical reactions involving copper corrosion have } \\
\text { been identified as being of potential interest for } \\
\text { repository programs considering the use of copper } \\
\text { containers. }\end{array}$ & $\begin{array}{l}\text { Excluded - low } \\
\text { consequence (WP) }\end{array}$ & WP \\
\hline 2.1.03.10.0A & $\begin{array}{l}\text { Advection of } \\
\text { liquids and solids } \\
\text { through cracks in } \\
\text { the waste } \\
\text { package }\end{array}$ & $\begin{array}{l}\text { The presence of one or more cracks or other small } \\
\text { openings of sufficient size in a waste package may } \\
\text { provide a pathway for the advective flow of water } \\
\text { (e.g., thin films or droplets) or solid material into the } \\
\text { waste package. The resulting presence of sufficient } \\
\text { water or solid material in the waste package may affect } \\
\text { in-package chemistry and/or criticality. Partial or full } \\
\text { plugging of the waste package cracks by chemical or } \\
\text { physical reactions after their formation (i.e., healing) } \\
\text { could also affect water flow and radionuclide transport } \\
\text { through the waste package. Passivation by corrosion } \\
\text { products is a potential mechanism for waste package } \\
\text { healing. }\end{array}$ & $\begin{array}{l}\text { Excluded - low } \\
\text { consequence (EBS) }\end{array}$ & EBS \\
\hline 2.1.03.10.0B & $\begin{array}{l}\text { Advection of } \\
\text { liquids and solids } \\
\text { through cracks in } \\
\text { the drip shield }\end{array}$ & $\begin{array}{l}\text { The presence of one or more cracks or other small } \\
\text { openings of sufficient size in a drip shield may provide a } \\
\text { pathway for the advective flow of water (e.g., thin films } \\
\text { or droplets) or solid material through the drip shield. } \\
\text { The resulting flux may affect drip shield performance } \\
\text { and/or subsequent dripping onto the waste packages. } \\
\text { Partial or full plugging of the drip shield cracks by } \\
\text { chemical or physical reactions after their formation } \\
\text { (i.e., healing) could also affect water flow through the } \\
\text { drip shield. }\end{array}$ & $\begin{array}{l}\text { Excluded - low } \\
\text { consequence (EBS) }\end{array}$ & EBS \\
\hline
\end{tabular}


Table E-1. TSPA-LA FEP List (Continued)

\begin{tabular}{|c|c|c|c|c|}
\hline FEP Number & FEP Name & FEP Description & Screening Decision & $\begin{array}{l}\text { FEP } \\
\text { AMR }\end{array}$ \\
\hline $2.1 .03 .11 .0 \mathrm{~A}$ & $\begin{array}{l}\text { Physical form of } \\
\text { waste package } \\
\text { and drip shield }\end{array}$ & $\begin{array}{l}\text { The specific forms of the various drip shields, waste } \\
\text { packages, and internal waste containers that are } \\
\text { proposed for the Yucca Mountain repository can affect } \\
\text { long-term performance. Waste package form may } \\
\text { affect container strength through the shape and } \\
\text { dimensions of the waste package and affect heat } \\
\text { dissipation through waste package volume and surface } \\
\text { area. Waste package and drip shield materials may } \\
\text { affect physical and chemical behavior of the disposal } \\
\text { area environment. Waste package and drip shield } \\
\text { integrity will affect the releases of radionuclides from the } \\
\text { disposal system. Waste packages may have both local } \\
\text { effects and repository-scale effects. All types of waste } \\
\text { packages and containers, including CSNF, DSNF, and } \\
\text { DHLW, should be considered. }\end{array}$ & Included (WP) & WP \\
\hline 2.1.04.01.0A & $\begin{array}{l}\text { Flow in the } \\
\text { backfill }\end{array}$ & $\begin{array}{l}\text { Preferential pathways for flow and diffusion may exist } \\
\text { within the backfill and may affect long-term performance } \\
\text { of the waste packages. Backfill may not preclude } \\
\text { hydrological, chemical, and thermal interactions } \\
\text { between waste packages within a drift. }\end{array}$ & $\begin{array}{l}\text { Excluded - low } \\
\text { probability (EBS) }\end{array}$ & EBS \\
\hline 2.1.04.02.0A & $\begin{array}{l}\text { Chemical } \\
\text { properties and } \\
\text { evolution of } \\
\text { backfill }\end{array}$ & $\begin{array}{l}\text { The chemical properties of the backfill may affect } \\
\text { groundwater flow, waste package and drip shield } \\
\text { durability, and radionuclide transport in the waste } \\
\text { disposal region. Properties of the backfill may change } \\
\text { through time, due to processes such as alteration of } \\
\text { minerals. }\end{array}$ & $\begin{array}{l}\text { Excluded - low } \\
\text { probability (EBS) }\end{array}$ & EBS \\
\hline $2.1 .04 .03 .0 \mathrm{~A}$ & $\begin{array}{l}\text { Erosion or } \\
\text { dissolution of } \\
\text { backfill }\end{array}$ & $\begin{array}{l}\text { Solid material in backfill may be carried away by flowing } \\
\text { groundwater, either by erosion of particulate matter or } \\
\text { by dissolution. }\end{array}$ & $\begin{array}{l}\text { Excluded - low } \\
\text { probability (EBS) }\end{array}$ & EBS \\
\hline 2.1.04.04.0A & $\begin{array}{l}\text { Thermal- } \\
\text { mechanical } \\
\text { effects of backfill }\end{array}$ & $\begin{array}{l}\text { Backfill may alter the mechanical evolution of the drift } \\
\text { environment by providing resistance to rockfall and drift } \\
\text { collapse, by changing the thermal properties of the drift, } \\
\text { or by other means. Impacts of the evolution of the } \\
\text { properties of the backfill itself should be considered. }\end{array}$ & $\begin{array}{l}\text { Excluded - low } \\
\text { probability (EBS) }\end{array}$ & EBS \\
\hline $2.1 .04 .05 .0 \mathrm{~A}$ & $\begin{array}{l}\text { Thermal- } \\
\text { mechanical } \\
\text { properties and } \\
\text { evolution of } \\
\text { backfill }\end{array}$ & $\begin{array}{l}\text { The physical properties of the backfill may affect } \\
\text { groundwater flow, waste package and drip shield } \\
\text { durability, and radionuclide transport in the waste } \\
\text { disposal region. Properties of the backfill may change } \\
\text { through time, due to processes such as silica } \\
\text { cementation, thermal effects, and physical compaction. }\end{array}$ & $\begin{array}{l}\text { Excluded - low } \\
\text { probability (EBS) }\end{array}$ & EBS \\
\hline 2.1.04.09.0A & $\begin{array}{l}\text { Radionuclide } \\
\text { transport in } \\
\text { backfill }\end{array}$ & $\begin{array}{l}\text { Radionuclide transport in the drift environment may be } \\
\text { affected by the presence of backfill. Transport } \\
\text { (i.e., advective and diffusive effects and sorption } \\
\text { processes) of both dissolved and colloidal species } \\
\text { should be considered. }\end{array}$ & $\begin{array}{l}\text { Excluded - low } \\
\text { probability (EBS) }\end{array}$ & EBS \\
\hline 2.1.05.01.0A & $\begin{array}{l}\text { Flow through } \\
\text { seals (access } \\
\text { ramps and } \\
\text { ventilation shafts) }\end{array}$ & $\begin{array}{l}\text { Long-term fluid flow through the shaft seal system, and } \\
\text { uncertainty about long-term properties of the shaft seal } \\
\text { system, may influence cumulative radionuclide releases } \\
\text { from the disposal system. }\end{array}$ & $\begin{array}{l}\text { Excluded - low } \\
\text { consequence (UZ) }\end{array}$ & UZ \\
\hline $2.1 .05 .02 .0 \mathrm{~A}$ & $\begin{array}{l}\text { Radionuclide } \\
\text { transport through } \\
\text { seals }\end{array}$ & $\begin{array}{l}\text { Groundwater flow through seals in the access ramps, } \\
\text { ventilation shafts, and exploratory boreholes could affect } \\
\text { long-term performance of the disposal system. } \\
\text { Radionuclide transport through seals should be } \\
\text { considered. }\end{array}$ & $\begin{array}{l}\text { Excluded - low } \\
\text { consequence (UZ) }\end{array}$ & UZ \\
\hline
\end{tabular}


Table E-1. TSPA-LA FEP List (Continued)

\begin{tabular}{|c|c|c|c|c|}
\hline FEP Number & FEP Name & FEP Description & Screening Decision & $\begin{array}{l}\text { FEP } \\
\text { AMR }\end{array}$ \\
\hline 2.1.05.03.0A & $\begin{array}{l}\text { Degradation of } \\
\text { seals }\end{array}$ & $\begin{array}{l}\text { Degradation of seals in the access ramps, ventilation } \\
\text { shafts, and exploratory boreholes could modify flow and } \\
\text { transport properties. Physical properties of the seals } \\
\text { emplaced in the access ramps, ventilation shafts, and } \\
\text { exploratory boreholes may affect the long-term } \\
\text { performance of the disposal system. These properties } \\
\text { include the location of the seals (and the openings they } \\
\text { seal), and the physical and chemical characteristics of } \\
\text { the sealing materials. Possible mechanisms for seal } \\
\text { degradation include: chemical alteration from water } \\
\text { interactions, wetting associated with condensation, and } \\
\text { thermally-induced stress-strain changes. }\end{array}$ & $\begin{array}{l}\text { Excluded - low } \\
\text { consequence (UZ) }\end{array}$ & UZ \\
\hline 2.1.06.01.0A & $\begin{array}{l}\text { Chemical effects } \\
\text { of rock } \\
\text { reinforcement } \\
\text { and cementitious } \\
\text { materials in EBS }\end{array}$ & $\begin{array}{l}\text { Degradation of ground support material (e.g., cement, } \\
\text { rock bolts, wire mesh) used for any purpose in the } \\
\text { disposal region may affect long-term performance } \\
\text { through both chemical and physical processes. } \\
\text { Degradation may occur by physical, chemical, and } \\
\text { microbial processes. }\end{array}$ & $\begin{array}{l}\text { Excluded - low } \\
\text { consequence (EBS) }\end{array}$ & EBS \\
\hline $2.1 .06 .02 .0 \mathrm{~A}$ & $\begin{array}{l}\text { Mechanical } \\
\text { effects of rock } \\
\text { reinforcement } \\
\text { materials in EBS }\end{array}$ & $\begin{array}{l}\text { Degradation of rock bolts, wire mesh, and other } \\
\text { materials used in ground control may affect the long- } \\
\text { term performance of the repository. }\end{array}$ & $\begin{array}{l}\text { Excluded - low } \\
\text { consequence (EBS) }\end{array}$ & EBS \\
\hline $2.1 .06 .04 .0 \mathrm{~A}$ & $\begin{array}{l}\text { Flow through } \\
\text { rock } \\
\text { reinforcement } \\
\text { materials in EBS }\end{array}$ & $\begin{array}{l}\text { Groundwater flow may occur through the ground } \\
\text { support materials (e.g., wire mesh, rock bolts, grout) } \\
\text { and liner (if present). }\end{array}$ & $\begin{array}{l}\text { Excluded - low } \\
\text { consequence (EBS) }\end{array}$ & EBS \\
\hline $2.1 .06 .05 .0 \mathrm{~A}$ & $\begin{array}{l}\text { Mechanical } \\
\text { degradation of } \\
\text { emplacement } \\
\text { pallet }\end{array}$ & $\begin{array}{l}\text { Degradation of the materials used in the pallet } \\
\text { supporting the waste package may occur by physical } \\
\text { processes, and may affect the long-term performance of } \\
\text { the repository. Degradation may be fast (e.g., from } \\
\text { dynamic loading) or slow (e.g., from static loading). }\end{array}$ & $\begin{array}{l}\text { Excluded-low } \\
\text { consequence (EBS) }\end{array}$ & EBS \\
\hline $2.1 .06 .05 .0 \mathrm{~B}$ & $\begin{array}{l}\text { Mechanical } \\
\text { degradation of } \\
\text { invert }\end{array}$ & $\begin{array}{l}\text { Degradation of the materials used in the invert may } \\
\text { occur by physical processes, and may affect the long- } \\
\text { term performance of the repository. Degradation may } \\
\text { be fast (e.g., from dynamic loading) or slow (e.g., from } \\
\text { static loading). }\end{array}$ & $\begin{array}{l}\text { Excluded-low } \\
\text { consequence (EBS) }\end{array}$ & EBS \\
\hline $2.1 .06 .05 .0 \mathrm{C}$ & $\begin{array}{l}\text { Chemical } \\
\text { degradation of } \\
\text { emplacement } \\
\text { pallet }\end{array}$ & $\begin{array}{l}\text { Degradation of the materials used in the pallet } \\
\text { supporting the waste package may occur by chemical or } \\
\text { microbial processes, and may affect the long-term } \\
\text { performance of the repository. }\end{array}$ & $\begin{array}{l}\text { Excluded-low } \\
\text { consequence (EBS) }\end{array}$ & EBS \\
\hline 2.1.06.05.0D & $\begin{array}{l}\text { Chemical } \\
\text { degradation of } \\
\text { invert }\end{array}$ & $\begin{array}{l}\text { Degradation of the materials used in the invert may } \\
\text { occur by chemical or microbial processes, and may } \\
\text { affect the long-term performance of the repository. }\end{array}$ & $\begin{array}{l}\text { Excluded-low } \\
\text { consequence (EBS) }\end{array}$ & EBS \\
\hline 2.1.06.06.0A & $\begin{array}{l}\text { Effects of drip } \\
\text { shield on flow }\end{array}$ & $\begin{array}{l}\text { The drip shield will affect the amount of water reaching } \\
\text { the waste package. Effects of the drip shield on the } \\
\text { disposal region environment (for example, changes in } \\
\text { relative humidity and temperature below the shield) } \\
\text { should be considered for both intact and degraded } \\
\text { conditions. }\end{array}$ & Included (EBS) & EBS \\
\hline 2.1.06.06.0B & $\begin{array}{l}\text { Oxygen } \\
\text { embrittlement of } \\
\text { drip shields }\end{array}$ & $\begin{array}{l}\text { A potential failure mechanism for drip shields is oxygen } \\
\text { embrittlement, resulting from the diffusion of interstitial } \\
\text { oxygen in the titanium at high temperatures. }\end{array}$ & $\begin{array}{l}\text { Excluded-low } \\
\text { probability (WP) }\end{array}$ & WP \\
\hline 2.1.06.07.0A & $\begin{array}{l}\text { Chemical effects } \\
\text { at EBS } \\
\text { component } \\
\text { interfaces }\end{array}$ & $\begin{array}{l}\text { Chemical effects that occur at the interfaces between } \\
\text { materials in the drift may affect the performance of the } \\
\text { system. }\end{array}$ & $\begin{array}{l}\text { Excluded - low } \\
\text { consequence (EBS) }\end{array}$ & EBS \\
\hline
\end{tabular}


Table E-1. TSPA-LA FEP List (Continued)

\begin{tabular}{|c|c|c|c|c|}
\hline FEP Number & FEP Name & FEP Description & Screening Decision & $\begin{array}{l}\text { FEP } \\
\text { AMR }\end{array}$ \\
\hline 2.1.06.07.0B & $\begin{array}{l}\text { Mechanical } \\
\text { effects at EBS } \\
\text { component } \\
\text { interfaces }\end{array}$ & $\begin{array}{l}\text { Physical effects of steady-state contact (static loading) } \\
\text { that occur at the interfaces between materials in the drift } \\
\text { may affect the performance of the system. }\end{array}$ & $\begin{array}{l}\text { Excluded - low } \\
\text { consequence (WP) } \\
\text { Excluded - low } \\
\text { consequence (EBS) }\end{array}$ & $\begin{array}{l}\text { EBS } \\
\text { WP }\end{array}$ \\
\hline 2.1.07.01.0A & Rockfall & $\begin{array}{l}\text { Rockfalls may occur with blocks that are large enough } \\
\text { to mechanically tear or rupture drip shields and/or waste } \\
\text { packages. Seismic-induced rockfall is addressed in a } \\
\text { separate FEP. }\end{array}$ & $\begin{array}{l}\text { Excluded - low } \\
\text { probability (Clad) } \\
\text { Excluded - low } \\
\text { consequence (WP) } \\
\text { Excluded - low } \\
\text { probability (WP) } \\
\text { Excluded - low } \\
\text { consequence (EBS) }\end{array}$ & $\begin{array}{l}\text { EBS } \\
\text { WP } \\
\text { Clad }\end{array}$ \\
\hline 2.1.07.02.0A & Drift collapse & $\begin{array}{l}\text { Partial or complete collapse of the drifts, as opposed to } \\
\text { discrete rockfall, could occur as a result of thermal } \\
\text { effects, stresses related to excavation, or other } \\
\text { mechanisms. Drift collapse could affect the stability of } \\
\text { the engineered barriers and waste packages and/or } \\
\text { result in static loading from rock overburden. Rockfalls } \\
\text { of small blocks may produce rubble throughout part or } \\
\text { all of the drifts. Seismic-induced drift collapse is } \\
\text { addressed in a separate FEP. }\end{array}$ & $\begin{array}{l}\text { Excluded - low } \\
\text { consequence (EBS) }\end{array}$ & EBS \\
\hline 2.1.07.04.0A & $\begin{array}{l}\text { Hydrostatic } \\
\text { pressure on } \\
\text { waste package }\end{array}$ & $\begin{array}{l}\text { Waste packages emplaced in the saturated zone will be } \\
\text { subjected to hydrostatic pressure in addition to stresses } \\
\text { associated with the evolution of the waste and EBS. }\end{array}$ & $\begin{array}{l}\text { Excluded - low } \\
\text { probability (EBS) }\end{array}$ & EBS \\
\hline 2.1.07.04.0B & $\begin{array}{l}\text { Hydrostatic } \\
\text { pressure on drip } \\
\text { shield }\end{array}$ & $\begin{array}{l}\text { Drip shields emplaced in the saturated zone will be } \\
\text { subjected to hydrostatic pressure in addition to stresses } \\
\text { associated with the evolution of the waste and EBS. }\end{array}$ & $\begin{array}{l}\text { Excluded - low } \\
\text { probability (EBS) }\end{array}$ & EBS \\
\hline 2.1.07.05.0A & $\begin{array}{l}\text { Creep of metallic } \\
\text { materials in the } \\
\text { waste package }\end{array}$ & $\begin{array}{l}\text { Metals used in the waste package may deform by creep } \\
\text { processes in response to deviatoric stress or internal } \\
\text { void space. }\end{array}$ & $\begin{array}{l}\text { Excluded - low } \\
\text { probability (WP) }\end{array}$ & WP \\
\hline 2.1.07.05.0B & $\begin{array}{l}\text { Creep of metallic } \\
\text { materials in the } \\
\text { drip shield }\end{array}$ & $\begin{array}{l}\text { Metals used in the drip shield may deform by creep } \\
\text { processes in response to deviatoric stress. }\end{array}$ & $\begin{array}{l}\text { Excluded - low } \\
\text { consequence (WP) }\end{array}$ & WP \\
\hline 2.1.07.06.0A & Floor buckling & $\begin{array}{l}\text { Buckling, or heave, of the drift floor may occur in } \\
\text { response to changing stress. Floor buckling may affect } \\
\text { the performance of EBS components such as the drip } \\
\text { shield, the invert, and the pallet. Effects may include } \\
\text { movement of EBS components and changes in the } \\
\text { topography of the surface of the drift floor and invert that } \\
\text { may affect water flow. }\end{array}$ & $\begin{array}{l}\text { Excluded - low } \\
\text { consequence (EBS) }\end{array}$ & EBS \\
\hline 2.1.08.01.0A & $\begin{array}{l}\text { Water influx at } \\
\text { the repository }\end{array}$ & $\begin{array}{l}\text { An increase in the unsaturated water flux at the } \\
\text { repository may affect thermal, hydrologic, chemical, and } \\
\text { mechanical behavior of the system. Increases in flux } \\
\text { could result from climate change, but the cause of the } \\
\text { increase is not an essential part of the FEP. }\end{array}$ & Included (UZ) & UZ \\
\hline 2.1.08.01.0B & $\begin{array}{l}\text { Effects of rapid } \\
\text { influx into the } \\
\text { repository }\end{array}$ & $\begin{array}{l}\text { Extremely rapid influx could reduce temperatures below } \\
\text { the boiling point during part or all of the thermal period. } \\
\text { Increases in flux could result from climate change, but } \\
\text { the cause of the increase is not an essential part of the } \\
\text { FEP. }\end{array}$ & $\begin{array}{l}\text { Excluded - low } \\
\text { consequence (EBS) }\end{array}$ & EBS \\
\hline $2.1 .08 .02 .0 \mathrm{~A}$ & $\begin{array}{l}\text { Enhanced influx } \\
\text { at the repository }\end{array}$ & $\begin{array}{l}\text { An opening in unsaturated rock may alter the hydraulic } \\
\text { potential, affecting local saturation around the opening } \\
\text { and redirecting flow. Some of the flow may be directed } \\
\text { to the opening where it is available to seep into the } \\
\text { opening. }\end{array}$ & Included (UZ) & UZ \\
\hline
\end{tabular}


Table E-1. TSPA-LA FEP List (Continued)

\begin{tabular}{|c|c|c|c|c|}
\hline FEP Number & FEP Name & FEP Description & Screening Decision & $\begin{array}{l}\text { FEP } \\
\text { AMR }\end{array}$ \\
\hline 2.1.08.03.0A & $\begin{array}{l}\text { Repository dry- } \\
\text { out due to waste } \\
\text { heat }\end{array}$ & $\begin{array}{l}\text { Repository heat evaporates water from the UZ rocks } \\
\text { near the drifts, as the temperature exceeds the } \\
\text { vaporization temperature. This zone of reduced water } \\
\text { content (reduced saturation) could migrate outward } \\
\text { during the heating phase and then migrate back to the } \\
\text { waste package as heat diffuses throughout the } \\
\text { mountain and the radioactive heat sources decay. This } \\
\text { FEP addresses the effects of dry-out within the } \\
\text { repository drifts. }\end{array}$ & Included (EBS) & EBS \\
\hline 2.1.08.04.0A & $\begin{array}{l}\text { Condensation } \\
\text { forms on roofs of } \\
\text { drifts (drift-scale } \\
\text { cold traps) }\end{array}$ & $\begin{array}{l}\text { Emplacement of waste in drifts creates thermal } \\
\text { gradients within the repository. Such thermal gradients } \\
\text { can lead to drift-scale cold traps characterized by latent } \\
\text { heat transfer from warmer to cooler locations. This } \\
\text { mechanism can result in condensation forming on the } \\
\text { roof or other parts of the drifts, leading to enhanced } \\
\text { dripping on the drip shields, waste packages, or } \\
\text { exposed waste material. }\end{array}$ & Included (EBS) & EBS \\
\hline 2.1.08.04.0B & $\begin{array}{l}\text { Condensation } \\
\text { forms at } \\
\text { repository edges } \\
\text { (repository-scale } \\
\text { cold traps) }\end{array}$ & $\begin{array}{l}\text { Emplacement of waste in drifts creates thermal } \\
\text { gradients within the repository. Such thermal gradients } \\
\text { can lead to repository-scale cold traps characterized by } \\
\text { latent heat transfer from warmer to cooler locations. } \\
\text { This mechanism can result in condensation forming at } \\
\text { repository edges or elsewhere in the EBS, leading to } \\
\text { enhanced dripping on the drip shields, waste packages, } \\
\text { or exposed waste material. }\end{array}$ & Included (EBS) & EBS \\
\hline 2.1.08.05.0A & $\begin{array}{l}\text { Flow through } \\
\text { invert }\end{array}$ & $\begin{array}{l}\text { The invert, a porous material consisting of crushed tuff, } \\
\text { separates the waste package from the bottom of the } \\
\text { drift. Flow and transport through and around the invert } \\
\text { can influence radionuclide release to the UZ. }\end{array}$ & Included (EBS) & EBS \\
\hline $2.1 .08 .06 .0 \mathrm{~A}$ & $\begin{array}{l}\text { Capillary effects } \\
\text { (wicking) in EBS }\end{array}$ & $\begin{array}{l}\text { Capillary rise, or wicking, is a potential mechanism for } \\
\text { water to move through the waste and EBS. }\end{array}$ & Included (EBS) & EBS \\
\hline 2.1.08.07.0A & $\begin{array}{l}\text { Unsaturated flow } \\
\text { in the EBS }\end{array}$ & $\begin{array}{l}\text { Unsaturated flow may occur along preferential pathways } \\
\text { in the waste and EBS. Physical and chemical } \\
\text { properties of the EBS and waste form, in both intact and } \\
\text { degraded states, should be considered in evaluating } \\
\text { pathways. }\end{array}$ & Included (EBS) & EBS \\
\hline 2.1.08.09.0A & $\begin{array}{l}\text { Saturated flow in } \\
\text { the EBS }\end{array}$ & $\begin{array}{l}\text { Saturated flow and radionuclide transport may occur } \\
\text { along preferential pathways in the waste and EBS. } \\
\text { Physical and chemical properties of the EBS and waste } \\
\text { form, in both intact and degraded states, should be } \\
\text { considered in evaluating pathways. }\end{array}$ & $\begin{array}{l}\text { Excluded - low } \\
\text { consequence (EBS) }\end{array}$ & EBS \\
\hline 2.1.08.11.0A & $\begin{array}{l}\text { Repository } \\
\text { resaturation due } \\
\text { to waste cooling }\end{array}$ & $\begin{array}{l}\text { Following the peak thermal period, water in the } \\
\text { condensation cap may flow downward, resaturating the } \\
\text { geosphere dry-out zone and flowing into the drifts. This } \\
\text { may lead to an increase in water content and/or } \\
\text { resaturation in the repository. }\end{array}$ & Included (EBS) & EBS \\
\hline $2.1 .08 .12 .0 \mathrm{~A}$ & $\begin{array}{l}\text { Induced } \\
\text { hydrologic } \\
\text { changes in invert }\end{array}$ & $\begin{array}{l}\text { Drainage in the drifts may be altered by plugging of } \\
\text { fractures or floor buckling. Possible effects include } \\
\text { wetting or ponding in the invert until the water level } \\
\text { reaches the fractures in the wall or until there is } \\
\text { sufficient hydraulic head to clear the fractures. Wetting } \\
\text { or ponding could provide a continuing source of water } \\
\text { vapor for interaction with the drip shields, waste } \\
\text { packages, and their supports. }\end{array}$ & $\begin{array}{l}\text { Excluded - low } \\
\text { consequence (EBS) }\end{array}$ & EBS \\
\hline 2.1.08.14.0A & $\begin{array}{l}\text { Condensation on } \\
\text { underside of drip } \\
\text { shield }\end{array}$ & $\begin{array}{l}\text { Condensation of water on the underside of the drip } \\
\text { shield may affect the waste package hydrologic and } \\
\text { chemical environment. }\end{array}$ & $\begin{array}{l}\text { Excluded - low } \\
\text { consequence (EBS) }\end{array}$ & EBS \\
\hline
\end{tabular}


Table E-1. TSPA-LA FEP List (Continued)

\begin{tabular}{|c|c|c|c|c|}
\hline FEP Number & FEP Name & FEP Description & Screening Decision & $\begin{array}{l}\text { FEP } \\
\text { AMR }\end{array}$ \\
\hline $2.1 .08 .15 .0 \mathrm{~A}$ & $\begin{array}{l}\text { Consolidation of } \\
\text { EBS components }\end{array}$ & $\begin{array}{l}\text { Physical and chemical degradation of the drip shield, } \\
\text { invert, waste form, and waste package may cause } \\
\text { collapse and settlement within the repository. This } \\
\text { consolidation may affect the development of the } \\
\text { chemical environment and, therefore, the radionuclide } \\
\text { transport out of the EBS. }\end{array}$ & $\begin{array}{l}\text { Excluded - low } \\
\text { consequence (EBS) }\end{array}$ & EBS \\
\hline 2.1.09.01.0A & $\begin{array}{l}\text { Chemical } \\
\text { characteristics of } \\
\text { water in drifts }\end{array}$ & $\begin{array}{l}\text { When flow in the drifts is re-established following the } \\
\text { peak thermal period, water may have chemical } \\
\text { characteristics influenced by the near-field host rock and } \\
\text { EBS. Specifically, the water chemistry (pH and } \\
\text { dissolved species in the groundwater) may be affected } \\
\text { by interactions with cementitious materials or steel used } \\
\text { in the disposal region. These point source } \\
\text { contaminated waters may coalesce to form a larger } \\
\text { volume of contaminated water. This altered } \\
\text { groundwater is referred to as the carrier plume because } \\
\text { dissolution and transport will occur in this altered } \\
\text { chemical environment as contaminants move through } \\
\text { the EBS, and down into the unsaturated zone. } \\
\text { (Note: there is no defining limit as to what volume of } \\
\text { contaminated water constitutes a plume.) }\end{array}$ & Included (EBS) & EBS \\
\hline 2.1.09.01.0B & $\begin{array}{l}\text { Chemical } \\
\text { characteristics of } \\
\text { water in waste } \\
\text { package }\end{array}$ & $\begin{array}{l}\text { Chemical characteristics of the water in the waste } \\
\text { packages ( } \mathrm{pH} \text { and dissolved species) may be affected } \\
\text { by interactions with steel and other materials used in the } \\
\text { waste packages or waste forms, as well as by the } \\
\text { inflowing water from the drifts and near-field host rock. } \\
\text { The in-package chemistry, in turn may influence } \\
\text { dissolution and transport as contaminants move through } \\
\text { the waste, EBS, and down into the unsaturated zone. }\end{array}$ & Included (WF) & WF \\
\hline 2.1.09.02.0A & $\begin{array}{l}\text { Chemical } \\
\text { interaction with } \\
\text { corrosion } \\
\text { products }\end{array}$ & $\begin{array}{l}\text { Corrosion products produced during degradation of the } \\
\text { waste form, metallic portions of the waste package, and } \\
\text { metals in the drift (i.e., rock bolts, steel in the invert, } \\
\text { gantry rails) may affect the mobilization and transport of } \\
\text { radionuclides. Corrosion products may facilitate } \\
\text { sorption/desorption and co-precipitation/dissolution } \\
\text { processes. Corrosion products may form a "rind" } \\
\text { around the fuel that could (1) restrict the availability of } \\
\text { water for dissolution of radionuclides or (2) inhibit } \\
\text { advective or diffusive transport of water and } \\
\text { radionuclides from the waste form to the EBS. } \\
\text { Corrosion products also have the potential to retard the } \\
\text { transport of radionuclides to the EBS. Finally, corrosion } \\
\text { products may alter the local chemistry, possibly } \\
\text { enhancing dissolution rates for specific waste forms, or } \\
\text { altering radionuclide solubility. }\end{array}$ & $\begin{array}{l}\text { Included (WF) } \\
\text { Included (EBS) }\end{array}$ & $\begin{array}{l}\text { EBS } \\
\text { WF }\end{array}$ \\
\hline 2.1.09.03.0A & $\begin{array}{l}\text { Volume increase } \\
\text { of corrosion } \\
\text { products impacts } \\
\text { cladding }\end{array}$ & $\begin{array}{l}\text { Corrosion products have a higher molar volume than the } \\
\text { intact, uncorroded material. Increases in volume during } \\
\text { waste form and cladding corrosion could change the } \\
\text { stress state in the material being corroded and lead to } \\
\text { cladding unzipping. }\end{array}$ & Included (Clad) & Clad \\
\hline 2.1.09.03.0B & $\begin{array}{l}\text { Volume increase } \\
\text { of corrosion } \\
\text { products impacts } \\
\text { waste package }\end{array}$ & $\begin{array}{l}\text { Corrosion products have a higher molar volume than the } \\
\text { intact, uncorroded material. Increases in volume during } \\
\text { waste form, cladding, and waste package corrosion } \\
\text { could change the stress state in the material being } \\
\text { corroded and lead to waste package damage. }\end{array}$ & $\begin{array}{l}\text { Excluded - low } \\
\text { consequence (WP) }\end{array}$ & WP \\
\hline
\end{tabular}


Table E-1. TSPA-LA FEP List (Continued)

\begin{tabular}{|c|c|c|c|c|}
\hline FEP Number & FEP Name & FEP Description & Screening Decision & $\begin{array}{l}\text { FEP } \\
\text { AMR }\end{array}$ \\
\hline $2.1 .09 .03 .0 \mathrm{C}$ & $\begin{array}{l}\text { Volume increase } \\
\text { of corrosion } \\
\text { products impacts } \\
\text { other EBS } \\
\text { components }\end{array}$ & $\begin{array}{l}\text { Corrosion products have a higher molar volume than the } \\
\text { intact, uncorroded material. This FEP addresses } \\
\text { volume increase in all EBS components other than } \\
\text { waste package, waste form, and cladding. Increases in } \\
\text { volume during corrosion of steel in the invert may } \\
\text { change the stress state or structural integrity of the } \\
\text { invert. }\end{array}$ & $\begin{array}{l}\text { Excluded - low } \\
\text { consequence (EBS) }\end{array}$ & EBS \\
\hline 2.1.09.04.0A & $\begin{array}{l}\text { Radionuclide } \\
\text { solubility, } \\
\text { solubility limits, } \\
\text { and speciation in } \\
\text { the waste form } \\
\text { and EBS } \\
\end{array}$ & $\begin{array}{l}\text { Degradation of the waste form will mobilize } \\
\text { radionuclides in the aqueous phase. Factors to be } \\
\text { considered in this FEP include the initial radionuclide } \\
\text { inventory, justification of the limited inventory included in } \\
\text { evaluations of aqueous concentrations, and the } \\
\text { solubility limits for those radionuclides. }\end{array}$ & Included (WF) & WF \\
\hline 2.1.09.05.0A & $\begin{array}{l}\text { Sorption of } \\
\text { dissolved } \\
\text { radionuclides in } \\
\text { EBS }\end{array}$ & $\begin{array}{l}\text { Sorption of dissolved radionuclides within the waste } \\
\text { package may affect the aqueous concentrations of } \\
\text { radionuclides released to the EBS. }\end{array}$ & Included (EBS) & EBS \\
\hline 2.1.09.06.0A & $\begin{array}{l}\text { Reduction- } \\
\text { oxidation } \\
\text { potential in waste } \\
\text { package }\end{array}$ & $\begin{array}{l}\text { The redox potential in the waste package influences the } \\
\text { oxidation of waste-form materials and the in-package } \\
\text { solubility of radionuclide species. Local variations in the } \\
\text { in-package redox potential can occur. }\end{array}$ & Included (WF) & WF \\
\hline 2.1.09.06.0B & $\begin{array}{l}\text { Reduction- } \\
\text { oxidation } \\
\text { potential in drifts }\end{array}$ & $\begin{array}{l}\text { The redox potential in the EBS influences the oxidation } \\
\text { of the in-drift materials and the in-drift solubility of } \\
\text { radionuclide species. Local variations in the in-drift } \\
\text { redox potential can occur. }\end{array}$ & Included (EBS) & EBS \\
\hline 2.1.09.07.0A & $\begin{array}{l}\text { Reaction kinetics } \\
\text { in waste package }\end{array}$ & $\begin{array}{l}\text { Chemical reactions, such as radionuclide dissolution/ } \\
\text { precipitation reactions and reactions controlling the } \\
\text { reduction-oxidation state, may not be at equilibrium } \\
\text { within the waste package. }\end{array}$ & Included (WF) & WF \\
\hline 2.1.09.07.0B & $\begin{array}{l}\text { Reaction kinetics } \\
\text { in drifts }\end{array}$ & $\begin{array}{l}\text { Chemical reactions, such as radionuclide } \\
\text { dissolution/precipitation reactions and reactions } \\
\text { controlling the reduction-oxidation state, may not be at } \\
\text { equilibrium in the drifts. }\end{array}$ & Included (EBS) & EBS \\
\hline 2.1.09.08.0A & $\begin{array}{l}\text { Diffusion of } \\
\text { dissolved } \\
\text { radionuclides in } \\
\text { EBS }\end{array}$ & $\begin{array}{l}\text { Radionuclide transport of dissolved radionuclides by } \\
\text { diffusion, in response to chemical gradients, may occur } \\
\text { within the EBS. Physical and chemical properties of the } \\
\text { EBS and waste form, in both intact and degraded } \\
\text { states, should be considered in evaluating diffusive } \\
\text { transport. }\end{array}$ & Included (EBS) & EBS \\
\hline 2.1.09.08.0B & $\begin{array}{l}\text { Advection of } \\
\text { dissolved } \\
\text { radionuclides in } \\
\text { EBS }\end{array}$ & $\begin{array}{l}\text { Radionuclide transport of dissolved radionuclides by } \\
\text { advection with the flowing groundwater may occur within } \\
\text { the EBS. Physical and chemical properties of the EBS } \\
\text { and waste form, in both intact and degraded states, } \\
\text { should be considered in evaluating advective transport. }\end{array}$ & Included (EBS) & EBS \\
\hline 2.1.09.09.0A & $\begin{array}{l}\text { Electrochemical } \\
\text { effects in EBS }\end{array}$ & $\begin{array}{l}\text { Electrochemical effects may establish an electric } \\
\text { potential within the drift or between materials in the drift } \\
\text { and more distant metallic materials. Migration of ions } \\
\text { within such an electric field could affect corrosion of } \\
\text { metals in the EBS and waste, and could also have a } \\
\text { direct effect on the transport of radionuclides as charged } \\
\text { ions. }\end{array}$ & $\begin{array}{l}\text { Excluded - low } \\
\text { consequence (Clad) } \\
\text { Excluded - low } \\
\text { consequence (WP) }\end{array}$ & $\begin{array}{l}\text { Clad } \\
\text { WP }\end{array}$ \\
\hline
\end{tabular}


Table E-1. TSPA-LA FEP List (Continued)

\begin{tabular}{|c|c|c|c|c|}
\hline FEP Number & FEP Name & FEP Description & Screening Decision & $\begin{array}{l}\text { FEP } \\
\text { AMR }\end{array}$ \\
\hline 2.1.09.10.0A & $\begin{array}{l}\text { Secondary phase } \\
\text { effects on } \\
\text { dissolved } \\
\text { radionuclide } \\
\text { concentrations }\end{array}$ & $\begin{array}{l}\text { Inclusion of radionuclides in secondary uranium mineral } \\
\text { phases, such as neptunium in schoepite and uranium } \\
\text { silicates, could affect radionuclide concentrations in } \\
\text { water in contact with the waste form. During } \\
\text { radionuclide alteration, the radionuclides could be } \\
\text { chemically bound to immobile compounds and result in } \\
\text { a reduction of available radionuclides for mobilization. }\end{array}$ & $\begin{array}{l}\text { Excluded - low } \\
\text { consequence (WF) }\end{array}$ & WF \\
\hline $2.1 .09 .11 .0 \mathrm{~A}$ & $\begin{array}{l}\text { Chemical effects } \\
\text { of waste-rock } \\
\text { contact }\end{array}$ & $\begin{array}{l}\text { Waste (CSNF, DSNF, and HLW) and rock may be } \\
\text { placed in direct contact by mechanical failure of the drip } \\
\text { shields and/or waste packages. Chemical effects on the } \\
\text { waste (e.g., dissolution) may be enhanced or altered in } \\
\text { a system where waste, rock minerals, and water are all } \\
\text { in physical contact with one another, relative to a } \\
\text { system where only waste and water are in physical } \\
\text { contact. }\end{array}$ & $\begin{array}{l}\text { Excluded - low } \\
\text { consequence (Clad) }\end{array}$ & Clad \\
\hline 2.1.09.12.0A & $\begin{array}{l}\text { Rind (chemically } \\
\text { altered zone) } \\
\text { forms in the near- } \\
\text { field }\end{array}$ & $\begin{array}{l}\text { Thermal-chemical processes involving precipitation, } \\
\text { condensation, and re-dissolution could alter the } \\
\text { properties of the adjacent rock. These alterations may } \\
\text { form a rind, or altered zone, in the rock, with } \\
\text { hydrological, thermal, and mineralogical properties } \\
\text { different from the initial conditions. }\end{array}$ & $\begin{array}{l}\text { Excluded - low } \\
\text { consequence (UZ) }\end{array}$ & $\mathrm{UZ}$ \\
\hline 2.1.09.13.0A & $\begin{array}{l}\text { Complexation in } \\
\text { EBS }\end{array}$ & $\begin{array}{l}\text { The presence of organic complexants in water in the } \\
\text { EBS could augment radionuclide transport by providing } \\
\text { a transport mechanism in addition to simple diffusion } \\
\text { and advection of dissolved material. Organic } \\
\text { complexants may include materials found in natural } \\
\text { groundwater such as humates and fulvates, or materials } \\
\text { introduced with the waste or engineered materials. }\end{array}$ & $\begin{array}{l}\text { Excluded - low } \\
\text { consequence (WF) }\end{array}$ & WF \\
\hline 2.1.09.15.0A & $\begin{array}{l}\text { Formation of true } \\
\text { (intrinsic) colloids } \\
\text { in EBS }\end{array}$ & $\begin{array}{l}\text { True colloids are colloidal-sized assemblages (between } \\
\text { approximately } 1 \text { nanometer and } 1 \text { micrometer in } \\
\text { diameter) consisting of hydrolyzed and polymerized } \\
\text { radionuclides. They may form in the waste package } \\
\text { and EBS during waste-form degradation and } \\
\text { radionuclide transport. True colloids are also called } \\
\text { primary colloids, real colloids, Type I colloids, } \\
\text { Eigenkolloide, and intrinsic colloids (or actinide intrinsic } \\
\text { colloids, for those including actinide elements). }\end{array}$ & $\begin{array}{l}\text { Excluded - low } \\
\text { consequence (WF) }\end{array}$ & WF \\
\hline 2.1.09.16.0A & $\begin{array}{l}\text { Formation of } \\
\text { pseudo-colloids } \\
\text { (natural) in EBS }\end{array}$ & $\begin{array}{l}\text { Pseudo-colloids are colloidal-sized assemblages } \\
\text { (between approximately } 1 \text { nanometer and } 1 \text { micrometer } \\
\text { in diameter) of nonradioactive material that have } \\
\text { radionuclides bound or sorbed to them. Natural } \\
\text { pseudo-colloids include microbial colloids, mineral } \\
\text { fragments (i.e., clay, silica, iron oxyhydroxides), and } \\
\text { humic and fulvic acids. This FEP addresses } \\
\text { radionuclide-bearing pseudo-colloids formed from host- } \\
\text { rock materials and all interactions of the waste and EBS } \\
\text { with the host rock environment except corrosion. }\end{array}$ & Included (WF) & WF \\
\hline 2.1.09.17.0A & $\begin{array}{l}\text { Formation of } \\
\text { pseudo-colloids } \\
\text { (corrosion } \\
\text { product) in EBS }\end{array}$ & $\begin{array}{l}\text { Pseudo-colloids are colloidal-sized assemblages } \\
\text { (between approximately } 1 \text { nanometer and } 1 \text { micrometer } \\
\text { in diameter) of nonradioactive material that have } \\
\text { radionuclides bound or sorbed to them. Corrosion } \\
\text { product pseudo-colloids include iron oxyhydroxides from } \\
\text { corrosion and degradation of the metals in the EBS and } \\
\text { silica from degradation of cementitious materials. }\end{array}$ & Included (WF) & WF \\
\hline $2.1 .09 .18 .0 \mathrm{~A}$ & $\begin{array}{l}\text { Formation of } \\
\text { microbial colloids } \\
\text { in EBS }\end{array}$ & $\begin{array}{l}\text { This FEP addresses the formation and transport of } \\
\text { microbial colloids in the waste and EBS. }\end{array}$ & $\begin{array}{l}\text { Excluded - low } \\
\text { consequence (WF) }\end{array}$ & WF \\
\hline
\end{tabular}


Table E-1. TSPA-LA FEP List (Continued)

\begin{tabular}{|c|c|c|c|c|}
\hline FEP Number & FEP Name & FEP Description & Screening Decision & $\begin{array}{l}\text { FEP } \\
\text { AMR }\end{array}$ \\
\hline 2.1.09.19.0A & $\begin{array}{l}\text { Sorption of } \\
\text { colloids in EBS }\end{array}$ & $\begin{array}{l}\text { Interactions between radionuclide-bearing colloids and } \\
\text { the waste and EBS may result in retardation of the } \\
\text { colloids during transport by sorption mechanisms. }\end{array}$ & $\begin{array}{l}\text { Excluded - low } \\
\text { consequence (EBS) }\end{array}$ & EBS \\
\hline 2.1.09.19.0B & $\begin{array}{l}\text { Advection of } \\
\text { colloids in EBS }\end{array}$ & $\begin{array}{l}\text { Transport of radionuclide-bearing colloids in the waste } \\
\text { and EBS may occur by advection. }\end{array}$ & Included (EBS) & EBS \\
\hline $2.1 .09 .20 .0 \mathrm{~A}$ & $\begin{array}{l}\text { Filtration of } \\
\text { colloids in EBS }\end{array}$ & $\begin{array}{l}\text { Filtration processes may affect transport of radionuclide- } \\
\text { bearing colloids in the waste and EBS. Filtration } \\
\text { includes physical and electrostatic processes in pores } \\
\text { and fractures of natural and anthropogenic materials, } \\
\text { such as concrete and the joints between invert } \\
\text { segments. }\end{array}$ & $\begin{array}{l}\text { Excluded - low } \\
\text { consequence (EBS) }\end{array}$ & EBS \\
\hline $2.1 .09 .21 .0 \mathrm{~A}$ & $\begin{array}{l}\text { Transport of } \\
\text { particles larger } \\
\text { than colloids in } \\
\text { EBS }\end{array}$ & $\begin{array}{l}\text { Groundwater flow through the waste could remove } \\
\text { radionuclide-bearing particles by a rinse mechanism. } \\
\text { Particles of radionuclide-bearing material larger than } \\
\text { colloids could be entrained in suspension and then be } \\
\text { transported in water flowing through the waste and EBS. }\end{array}$ & $\begin{array}{l}\text { Excluded - low } \\
\text { consequence (EBS) }\end{array}$ & EBS \\
\hline 2.1.09.21.0B & $\begin{array}{l}\text { Transport of } \\
\text { particles larger } \\
\text { than colloids in } \\
\text { the SZ }\end{array}$ & $\begin{array}{l}\text { Particles of radionuclide-bearing material larger than } \\
\text { colloids could be entrained in suspension and then be } \\
\text { transported in water flowing through the SZ. }\end{array}$ & $\begin{array}{l}\text { Excluded - low } \\
\text { consequence (SZ) }\end{array}$ & sz \\
\hline $2.1 .09 .21 .0 \mathrm{C}$ & $\begin{array}{l}\text { Transport of } \\
\text { particles larger } \\
\text { than colloids in } \\
\text { the UZ }\end{array}$ & $\begin{array}{l}\text { Particles of radionuclide-bearing material larger than } \\
\text { colloids could be entrained in suspension and then be } \\
\text { transported in water flowing through the UZ. }\end{array}$ & $\begin{array}{l}\text { Excluded - low } \\
\text { consequence (UZ) }\end{array}$ & UZ \\
\hline $2.1 .09 .22 .0 \mathrm{~A}$ & $\begin{array}{l}\text { Sorption of } \\
\text { colloids at air- } \\
\text { water interface }\end{array}$ & $\begin{array}{l}\text { Colloids may be sorbed irreversibly at the gas-water } \\
\text { interface under partially saturated conditions. }\end{array}$ & $\begin{array}{l}\text { Excluded - low } \\
\text { consequence (EBS) }\end{array}$ & EBS \\
\hline $2.1 .09 .23 .0 \mathrm{~A}$ & $\begin{array}{l}\text { Stability of } \\
\text { colloids in EBS }\end{array}$ & $\begin{array}{l}\text { For radionuclide-bearing colloids to affect repository } \\
\text { performance, they must remain suspended in the } \\
\text { groundwater (i.e., be stable) for time scales that are } \\
\text { long relative to the time required for groundwater travel. } \\
\text { Further, they must carry significant concentrations of } \\
\text { radionuclides. The stability of smectite colloids } \\
\text { (applicable for natural groundwater colloids and waste- } \\
\text { form colloids) is determined primarily by ionic strength } \\
\text { but also to an extent by pH. The stability of iron- } \\
\text { (hydr)oxide colloids (applicable to corrosion-product } \\
\text { colloids) is determined by both ionic strength and pH. }\end{array}$ & Included (WF) & WF \\
\hline $2.1 .09 .24 .0 \mathrm{~A}$ & $\begin{array}{l}\text { Diffusion of } \\
\text { colloids in EBS }\end{array}$ & $\begin{array}{l}\text { Colloidal particles, together with any associated } \\
\text { actinides, that are sufficiently small may be transported } \\
\text { through the EBS by diffusion. }\end{array}$ & Included (EBS) & EBS \\
\hline $2.1 .09 .25 .0 \mathrm{~A}$ & $\begin{array}{l}\text { Formation of } \\
\text { colloids (waste- } \\
\text { form) by co- } \\
\text { precipitation in } \\
\text { EBS }\end{array}$ & $\begin{array}{l}\text { Dissolved radionuclides and other ions may co- } \\
\text { precipitate to form colloids. Co-precipitates may consist } \\
\text { of radionuclides bound in the crystal lattice of a } \\
\text { dominating mineral phase or may consist of } \\
\text { radionuclides engulfed by a dominating mineral phase. }\end{array}$ & Included (WF) & WF \\
\hline $2.1 .09 .26 .0 \mathrm{~A}$ & $\begin{array}{l}\text { Gravitational } \\
\text { settling of colloids } \\
\text { in EBS }\end{array}$ & $\begin{array}{l}\text { Over the relatively short transport distances within the } \\
\text { waste package, colloidal particles may experience } \\
\text { gravitational settling, thereby inhibiting transport. }\end{array}$ & $\begin{array}{l}\text { Excluded - low } \\
\text { consequence (EBS) }\end{array}$ & EBS \\
\hline
\end{tabular}


Table E-1. TSPA-LA FEP List (Continued)

\begin{tabular}{|c|c|c|c|c|}
\hline FEP Number & FEP Name & FEP Description & Screening Decision & $\begin{array}{l}\text { FEP } \\
\text { AMR }\end{array}$ \\
\hline 2.1.09.27.0A & $\begin{array}{l}\text { Coupled effects } \\
\text { on radionuclide } \\
\text { transport in EBS }\end{array}$ & $\begin{array}{l}\text { Repository induced changes to the physical and } \\
\text { chemical properties of the EBS and waste form may be } \\
\text { important for evaluating radionuclide transport in the } \\
\text { EBS. The existence of chemical gradients within the } \\
\text { disposal system, resulting from repository material, } \\
\text { waste emplacement, and corrosion products, may } \\
\text { influence the transport of dissolved and colloidal } \\
\text { species. This could include: geochemical reactions that } \\
\text { move (pump) radionuclides; effects on advection, } \\
\text { diffusion, and sorption within and through failed waste } \\
\text { packages; and microbial and electrochemical effects. }\end{array}$ & $\begin{array}{l}\text { Excluded - low } \\
\text { consequence (EBS) }\end{array}$ & EBS \\
\hline 2.1.09.28.0A & $\begin{array}{l}\text { Localized } \\
\text { corrosion on } \\
\text { waste package } \\
\text { outer surface due } \\
\text { to deliquescence }\end{array}$ & $\begin{array}{l}\text { Salt-containing dust, which could accumulate on the } \\
\text { waste package surface during the preclosure ventilation } \\
\text { period, can absorb moisture from the drift atmosphere, } \\
\text { even at low relative humidity, dissolving the salt and } \\
\text { creating concentrated aqueous solutions. This } \\
\text { deliquescence process may result in localized surface } \\
\text { chemistry that could cause penetration of the waste } \\
\text { package outer barrier by localized corrosion. }\end{array}$ & $\begin{array}{l}\text { Excluded - low } \\
\text { consequence (EBS) } \\
\text { Excluded - low } \\
\text { consequence (WP) }\end{array}$ & $\begin{array}{l}\text { EBS } \\
\text { WP }\end{array}$ \\
\hline 2.1.09.28.0B & $\begin{array}{l}\text { Localized } \\
\text { corrosion on drip } \\
\text { shield surfaces } \\
\text { due to } \\
\text { deliquescence }\end{array}$ & $\begin{array}{l}\text { Salt-containing dust, which could accumulate on the drip } \\
\text { shield surface during the preclosure ventilation period, } \\
\text { can absorb moisture from the drift atmosphere, even at } \\
\text { low relative humidity, dissolving the salt and creating } \\
\text { concentrated aqueous solutions. This deliquescence } \\
\text { process may result in localized surface chemistry that } \\
\text { could cause penetration of the drip shield surface by } \\
\text { localized corrosion. }\end{array}$ & $\begin{array}{l}\text { Excluded - low } \\
\text { consequence (EBS) }\end{array}$ & EBS \\
\hline 2.1.10.01.0A & $\begin{array}{l}\text { Microbial activity } \\
\text { in EBS }\end{array}$ & $\begin{array}{l}\text { Biological activity is important to consider because of } \\
\text { the potential impact on aqueous chemical conditions } \\
\text { within the waste and EBS. In deep subsurface } \\
\text { environments, biological activity is limited to } \\
\text { microbiological activity and may include effects of } \\
\text { natural and anthropogenic bacteria (e.g., anaerobic, } \\
\text { methanogenic, sulfate reducers, etc.), protozoans, } \\
\text { yeast, viruses, and algae. This FEP addresses a broad } \\
\text { range of effects of biological impacts, including the } \\
\text { effects of microbes on corrosion of waste packages, } \\
\text { cladding, and waste form; bioreduction of multivalent } \\
\text { contaminants, metals, and sulfate; generation of organic } \\
\text { complexants and gases as metabolic by-products; and } \\
\text { the formation of biofilms and their impact on transport. }\end{array}$ & $\begin{array}{l}\text { Excluded - low } \\
\text { consequence (EBS) }\end{array}$ & EBS \\
\hline 2.1.11.01.0A & $\begin{array}{l}\text { Heat generation } \\
\text { in EBS }\end{array}$ & $\begin{array}{l}\text { Temperature in the waste and EBS will vary through } \\
\text { time. Heat from radioactive decay will be the primary } \\
\text { cause of temperature change, but other factors to be } \\
\text { considered in determining the temperature history } \\
\text { include the in-situ geothermal gradient, thermal } \\
\text { properties of the rock, EBS, and waste materials, } \\
\text { hydrological effects, and the possibility of exothermic } \\
\text { reactions. Considerations of the heat generated by } \\
\text { radioactive decay should take different properties of } \\
\text { different waste types, including DSNF, into account. }\end{array}$ & Included (EBS) & EBS \\
\hline 2.1.11.02.0A & $\begin{array}{l}\text { Non-uniform heat } \\
\text { distribution in } \\
\text { EBS }\end{array}$ & $\begin{array}{l}\text { Uneven heating and cooling at edges of the repository } \\
\text { may lead to non-uniform thermal effects during both the } \\
\text { thermal peak and the cool-down period. }\end{array}$ & Included (EBS) & EBS \\
\hline
\end{tabular}


Table E-1. TSPA-LA FEP List (Continued)

\begin{tabular}{|c|c|c|c|c|}
\hline FEP Number & FEP Name & FEP Description & Screening Decision & $\begin{array}{l}\text { FEP } \\
\text { AMR }\end{array}$ \\
\hline 2.1.11.03.0A & $\begin{array}{l}\text { Exothermic } \\
\text { reactions in the } \\
\text { EBS }\end{array}$ & $\begin{array}{l}\text { Exothermic reactions liberate heat and will alter the } \\
\text { temperature of the disposal system and affect the } \\
\text { properties of the repository and surrounding materials. } \\
\text { Examples of possible exothermic reactions include } \\
\text { oxidation of uranium metal fuels such as represented by } \\
\mathrm{N}-\text { Reactor fuels and hydration of concrete used in the } \\
\text { underground environment. }\end{array}$ & $\begin{array}{l}\text { Excluded - low } \\
\text { consequence (WF) } \\
\text { Excluded - low } \\
\text { consequence (EBS) }\end{array}$ & $\begin{array}{l}\text { EBS } \\
\text { WF }\end{array}$ \\
\hline $2.1 .11 .05 .0 \mathrm{~A}$ & $\begin{array}{l}\text { Thermal } \\
\text { expansion/stress } \\
\text { of in-package } \\
\text { EBS components }\end{array}$ & $\begin{array}{l}\text { Thermally induced stresses could alter the performance } \\
\text { of the waste or EBS. For example, thermal stresses } \\
\text { could cause the waste form to develop cracks and } \\
\text { create pathways for preferential fluid flow and, thereby, } \\
\text { accelerate degradation of the waste. }\end{array}$ & $\begin{array}{l}\text { Excluded - low } \\
\text { consequence (Clad) }\end{array}$ & Clad \\
\hline $2.1 .11 .06 .0 \mathrm{~A}$ & $\begin{array}{l}\text { Thermal } \\
\text { sensitization of } \\
\text { waste packages }\end{array}$ & $\begin{array}{l}\text { Phase changes in waste package materials can result } \\
\text { from long-term storage at moderately hot temperatures } \\
\text { in the repository. Stress corrosion cracking (SCC), } \\
\text { intergranular corrosion, or mechanical degradation may } \\
\text { ensue. }\end{array}$ & $\begin{array}{l}\text { Excluded - low } \\
\text { consequence (WP) }\end{array}$ & WP \\
\hline 2.1.11.06.0B & $\begin{array}{l}\text { Thermal } \\
\text { sensitization of } \\
\text { drip shields }\end{array}$ & $\begin{array}{l}\text { Phase changes in drip shield materials can result from } \\
\text { long-term storage at moderately hot temperatures in the } \\
\text { repository. Stress corrosion cracking (SCC), } \\
\text { intergranular corrosion, or mechanical degradation may } \\
\text { ensue. }\end{array}$ & $\begin{array}{l}\text { Excluded - low } \\
\text { probability (WP) }\end{array}$ & WP \\
\hline 2.1.11.07.0A & $\begin{array}{l}\text { Thermal } \\
\text { expansion/stress } \\
\text { of in-drift EBS } \\
\text { components }\end{array}$ & $\begin{array}{l}\text { Repository heat at Yucca Mountain could result in } \\
\text { thermally induced stress changes that would affect the } \\
\text { mechanical and chemical evolution of the repository. } \\
\text { These stress changes could affect the EBS } \\
\text { components, thus causing the formation of pathways for } \\
\text { groundwater flow through the EBS or altering and/or } \\
\text { enhancing existing pathways. Relevant processes } \\
\text { include changes in physical properties of the drip } \\
\text { shields, waste packages, pallet, and invert. }\end{array}$ & $\begin{array}{l}\text { Excluded - low } \\
\text { consequence (WP) } \\
\text { Excluded - low } \\
\text { consequence (EBS) }\end{array}$ & $\begin{array}{l}\text { EBS } \\
\text { WP }\end{array}$ \\
\hline $2.1 .11 .08 .0 \mathrm{~A}$ & $\begin{array}{l}\text { Thermal effects } \\
\text { on chemistry and } \\
\text { microbial activity } \\
\text { in the EBS }\end{array}$ & $\begin{array}{l}\text { Temperature changes may affect chemical and } \\
\text { microbial processes in the waste and EBS. }\end{array}$ & $\begin{array}{l}\text { Included (WF) } \\
\text { Included (EBS) }\end{array}$ & $\begin{array}{l}\text { EBS } \\
\text { WF }\end{array}$ \\
\hline $2.1 .11 .09 .0 \mathrm{~A}$ & $\begin{array}{l}\text { Thermal effects } \\
\text { on flow in the } \\
\text { EBS }\end{array}$ & $\begin{array}{l}\text { High temperatures in the EBS may influence seepage } \\
\text { into, and flow within, the waste and EBS. Thermally- } \\
\text { induced changes to fluid saturation and/or relative } \\
\text { humidity could influence in-package chemistry. Thermal } \\
\text { gradients in the repository could lead to localized } \\
\text { accumulation of moisture. Wet zones could form below } \\
\text { the areas of moisture accumulation. }\end{array}$ & Included (EBS) & EBS \\
\hline $2.1 .11 .09 .0 \mathrm{~B}$ & $\begin{array}{l}\text { Thermally-driven } \\
\text { flow (convection) } \\
\text { in waste } \\
\text { packages }\end{array}$ & $\begin{array}{l}\text { Temperature differentials may result in convective flow } \\
\text { in the EBS. Convective flow within the waste packages } \\
\text { could influence in-package chemistry. }\end{array}$ & $\begin{array}{l}\text { Excluded - low } \\
\text { consequence (WF) }\end{array}$ & WF \\
\hline $2.1 .11 .09 .0 \mathrm{C}$ & $\begin{array}{l}\text { Thermally driven } \\
\text { flow (convection) } \\
\text { in drifts }\end{array}$ & $\begin{array}{l}\text { Temperature differentials may result in convective flow } \\
\text { in the EBS. Convective flow within the drifts could } \\
\text { influence in-drift chemistry. }\end{array}$ & Included (EBS) & EBS \\
\hline
\end{tabular}


Table E-1. TSPA-LA FEP List (Continued)

\begin{tabular}{|c|c|c|c|c|}
\hline FEP Number & FEP Name & FEP Description & Screening Decision & $\begin{array}{l}\text { FEP } \\
\text { AMR }\end{array}$ \\
\hline 2.1.11.10.0A & $\begin{array}{l}\text { Thermal effects } \\
\text { on transport in } \\
\text { EBS }\end{array}$ & $\begin{array}{l}\text { Temperature changes in the repository may influence } \\
\text { advection, diffusion, and sorption in the EBS. The Soret } \\
\text { effect is a diffusion process caused by a thermal } \\
\text { gradient. In liquids having both light and heavy } \\
\text { molecules (or ions) and a temperature or thermal } \\
\text { gradient, the heavier solute molecules tend to } \\
\text { concentrate in the colder region. Temperature } \\
\text { differences in the waste and EBS may result in a } \\
\text { component of diffusive solute flux that is proportional to } \\
\text { the temperature gradient. }\end{array}$ & $\begin{array}{l}\text { Excluded - low } \\
\text { consequence (EBS) }\end{array}$ & EBS \\
\hline 2.1.12.01.0A & $\begin{array}{l}\text { Gas generation } \\
\text { (repository } \\
\text { pressurization) }\end{array}$ & $\begin{array}{l}\text { Gas generation in the repository might lead to } \\
\text { pressurization of the repository, produce multiphase } \\
\text { flow, and affect radionuclide transport. This FEP } \\
\text { addresses repository pressurization. }\end{array}$ & $\begin{array}{l}\text { Excluded - low } \\
\text { consequence (EBS) }\end{array}$ & EBS \\
\hline 2.1.12.02.0A & $\begin{array}{l}\text { Gas generation } \\
\text { (He) from waste } \\
\text { form decay }\end{array}$ & $\begin{array}{l}\text { Helium }(\mathrm{He}) \text { gas production may occur by alpha decay } \\
\text { in the waste. Helium production might cause local } \\
\text { pressure buildup in cracks in the fuel and in the void } \\
\text { between fuel and cladding, leading to cladding and } \\
\text { waste package failure. }\end{array}$ & $\begin{array}{l}\text { Excluded - low } \\
\text { consequence (Clad) } \\
\text { Excluded - low } \\
\text { consequence (EBS) }\end{array}$ & $\begin{array}{l}\text { EBS } \\
\text { Clad }\end{array}$ \\
\hline 2.1.12.03.0A & $\begin{array}{l}\text { Gas generation } \\
(\mathrm{H} 2) \text { from waste } \\
\text { package } \\
\text { corrosion }\end{array}$ & $\begin{array}{l}\text { Gas generation can affect the mechanical behavior of } \\
\text { the host rock and engineered barriers, chemical } \\
\text { conditions, and fluid flow, and, as a result, the transport } \\
\text { of radionuclides. Gas generation due to oxic corrosion } \\
\text { of waste packages, cladding, and/or structural materials } \\
\text { will occur at early times following closure of the } \\
\text { repository. Anoxic corrosion may follow the oxic phase } \\
\text { if all oxygen is depleted. The formation of a gas phase } \\
\text { around the waste package may exclude oxygen from } \\
\text { the iron, thus inhibiting further corrosion. }\end{array}$ & $\begin{array}{l}\text { Excluded - low } \\
\text { consequence (Clad) } \\
\text { Excluded - low } \\
\text { consequence (WP) } \\
\text { Excluded - low } \\
\text { consequence (EBS) }\end{array}$ & $\begin{array}{l}\text { EBS } \\
\text { WP } \\
\text { Clad }\end{array}$ \\
\hline $2.1 .12 .04 .0 \mathrm{~A}$ & $\begin{array}{l}\text { Gas generation } \\
\text { (CO2, } \mathrm{CH} 4, \mathrm{H} 2 \mathrm{~S}) \\
\text { from microbial } \\
\text { degradation }\end{array}$ & $\begin{array}{l}\text { Microbes are known to produce inorganic acids, } \\
\text { methane, organic byproducts, carbon dioxide, and other } \\
\text { chemical species that could change the longevity of } \\
\text { materials in the repository and the transport of } \\
\text { radionuclides from the near-field. The rate of microbial } \\
\text { gas production will depend on the nature of the } \\
\text { microbial populations established, the prevailing } \\
\text { conditions (temperature, pressure, geochemical } \\
\text { conditions), and the organic or inorganic substrates } \\
\text { present. Initial analysis indicates the most important } \\
\text { source of nutrient in the YMP repository will be metals. } \\
\text { Other possible nutrients include cellulosic material, } \\
\text { plastics, and synthetic materials. Minimal amounts of } \\
\text { organics are mandated by regulation. }\end{array}$ & $\begin{array}{l}\text { Excluded - low } \\
\text { consequence (WF) } \\
\text { Excluded - low } \\
\text { consequence (EBS) }\end{array}$ & $\begin{array}{l}\text { EBS } \\
\text { WF }\end{array}$ \\
\hline $2.1 .12 .06 .0 \mathrm{~A}$ & $\begin{array}{l}\text { Gas transport in } \\
\text { EBS }\end{array}$ & $\begin{array}{l}\text { Gas in the waste and EBS could affect the long-term } \\
\text { performance of the disposal system. Radionuclides } \\
\text { may be transported as gases or in gases. Gas bubbles } \\
\text { may affect flowpaths, and two-phase flow conditions } \\
\text { may be important. }\end{array}$ & $\begin{array}{l}\text { Excluded - low } \\
\text { consequence (EBS) }\end{array}$ & EBS \\
\hline $2.1 .12 .07 .0 \mathrm{~A}$ & $\begin{array}{l}\text { Effects of } \\
\text { radioactive gases } \\
\text { in EBS }\end{array}$ & $\begin{array}{l}\text { Radioactive gases may exist or be produced in the } \\
\text { repository. These gases may subsequently escape } \\
\text { from the repository. Typical radioactive gases include } \\
14 \mathrm{C} \text { (in } 14 \mathrm{CO} 2 \text { and } 14 \mathrm{CH} 4 \text { produced during microbial } \\
\text { degradation), tritium, fission gases ( } \mathrm{Ar}, \mathrm{Xe}, \mathrm{Kr} \text { ), and } \\
\text { radon. }\end{array}$ & $\begin{array}{l}\text { Excluded - low } \\
\text { consequence (WF) } \\
\text { Excluded - low } \\
\text { consequence (EBS) }\end{array}$ & $\begin{array}{l}\text { EBS } \\
\text { WF }\end{array}$ \\
\hline
\end{tabular}


Table E-1. TSPA-LA FEP List (Continued)

\begin{tabular}{|c|c|c|c|c|}
\hline FEP Number & FEP Name & FEP Description & Screening Decision & $\begin{array}{l}\text { FEP } \\
\text { AMR }\end{array}$ \\
\hline $2.1 .12 .08 .0 \mathrm{~A}$ & $\begin{array}{l}\text { Gas explosions in } \\
\text { EBS }\end{array}$ & $\begin{array}{l}\text { Explosive gas mixtures could collect in the sealed } \\
\text { repository. An explosion in the repository could have } \\
\text { radiological consequences if the structure of the } \\
\text { repository were damaged or near-field processes } \\
\text { enhanced or inhibited. }\end{array}$ & $\begin{array}{l}\text { Excluded - low } \\
\text { probability (EBS) }\end{array}$ & EBS \\
\hline $2.1 .13 .01 .0 \mathrm{~A}$ & Radiolysis & $\begin{array}{l}\text { Alpha, beta, gamma, and neutron irradiation of water } \\
\text { can cause disassociation of molecules, leading to gas } \\
\text { production and changes in chemical conditions } \\
\text { (potential, pH, and concentration of reactive radicals). }\end{array}$ & $\begin{array}{l}\text { Excluded - low } \\
\text { consequence (WF) } \\
\text { Excluded - low } \\
\text { consequence (WP) } \\
\text { Excluded - low } \\
\text { consequence (EBS) } \\
\end{array}$ & $\begin{array}{l}\text { EBS } \\
\text { WF } \\
\text { WP }\end{array}$ \\
\hline $2.1 .13 .02 .0 \mathrm{~A}$ & $\begin{array}{l}\text { Radiation } \\
\text { damage in EBS }\end{array}$ & $\begin{array}{l}\text { Radiolysis due to the alpha, beta, gamma-ray, and } \\
\text { neutron irradiation of water could result in enhancement } \\
\text { of the radionuclide migration from the surface of a } \\
\text { degraded waste form into groundwater. When } \\
\text { radionuclides decay, the emitted high-energy particle } \\
\text { could result in the production of radicals in the water or } \\
\text { air surrounding the spent nuclear fuel. If these radicals } \\
\text { migrate (diffuse) to the surface of the fuel, they may } \\
\text { then enhance the degradation/corrosion rate of the fuel } \\
\text { (UO2). This effect would increase the dissolution rate } \\
\text { for radionuclides from the fuel material (fuel matrix) into } \\
\text { the groundwater. Strong radiation fields could lead to } \\
\text { radiation damage to the waste forms (CSNF, DSNF, } \\
\text { DHLW), waste packages, drip shield, seals, and } \\
\text { surrounding rock. }\end{array}$ & $\begin{array}{l}\text { Excluded - low } \\
\text { consequence (WF) } \\
\text { Excluded - low } \\
\text { consequence (WP) } \\
\text { Excluded - low } \\
\text { consequence (EBS) }\end{array}$ & $\begin{array}{l}\text { EBS } \\
\text { WF } \\
\text { WP }\end{array}$ \\
\hline $2.1 .13 .03 .0 \mathrm{~A}$ & $\begin{array}{l}\text { Radiological } \\
\text { mutation of } \\
\text { microbes }\end{array}$ & $\begin{array}{l}\text { Radiation fields could cause mutation of } \\
\text { microorganisms, leading to unexpected chemical } \\
\text { reactions and impacts. }\end{array}$ & $\begin{array}{l}\text { Excluded - low } \\
\text { consequence (EBS) }\end{array}$ & EBS \\
\hline $2.1 .14 .15 .0 \mathrm{~A}$ & $\begin{array}{l}\text { In-package } \\
\text { criticality (intact } \\
\text { configuration) }\end{array}$ & $\begin{array}{l}\text { The waste package internal structures and the waste } \\
\text { form remain intact. If there is a breach (or are } \\
\text { breaches) in the waste package which allows water to } \\
\text { either accumulate or flow through the waste package } \\
\text { then criticality could occur in-situ. In-package criticality } \\
\text { resulting from disruptive events is addressed in } \\
\text { separate FEPs. }\end{array}$ & $\begin{array}{l}\text { Excluded - low } \\
\text { probability (Crit) }\end{array}$ & Crit \\
\hline $2.1 .14 .16 .0 \mathrm{~A}$ & $\begin{array}{l}\text { In-package } \\
\text { criticality } \\
\text { (degraded } \\
\text { configurations) }\end{array}$ & $\begin{array}{l}\text { The waste package internal structures and the waste } \\
\text { form may degrade. If a critical configuration (sufficient } \\
\text { fissile material and neutron moderator, lack of neutron } \\
\text { absorbers) develops, criticality could occur in-situ. } \\
\text { Potential in-situ critical configurations are defined in } \\
\text { Figures 3.2a and 3.2b of Disposal Criticality Analysis } \\
\text { Methodology Topical Report (YMP } 2003 \\
\text { [DIRS 165505]). In-package criticality resulting from } \\
\text { disruptive events is addressed in separate FEPs. }\end{array}$ & $\begin{array}{l}\text { Excluded - low } \\
\text { probability (Crit) }\end{array}$ & Crit \\
\hline $2.1 .14 .17 .0 \mathrm{~A}$ & $\begin{array}{l}\text { Near-field } \\
\text { criticality }\end{array}$ & $\begin{array}{l}\text { Near-field criticality could occur if fissile material-bearing } \\
\text { solution from the waste package is transported into the } \\
\text { drift and the fissile material is precipitated into a critical } \\
\text { configuration. Potential near-field critical configurations } \\
\text { are defined in Figure 3.3a of Disposal Criticality Analysis } \\
\text { Methodology Topical Report (YMP } 2003 \\
\text { [DIRS 165505]). In-package criticality resulting from } \\
\text { disruptive events is addressed in separate FEPs. }\end{array}$ & $\begin{array}{l}\text { Excluded - low } \\
\text { probability (Crit) }\end{array}$ & Crit \\
\hline
\end{tabular}


Table E-1. TSPA-LA FEP List (Continued)

\begin{tabular}{|c|c|c|c|c|}
\hline FEP Number & FEP Name & FEP Description & Screening Decision & $\begin{array}{l}\text { FEP } \\
\text { AMR }\end{array}$ \\
\hline 2.1.14.18.0A & $\begin{array}{l}\text { In-package } \\
\text { criticality resulting } \\
\text { from a seismic } \\
\text { event (intact } \\
\text { configuration) }\end{array}$ & $\begin{array}{l}\text { The waste package internal structures and the waste } \\
\text { form remain intact either during or after a seismic } \\
\text { disruptive event. If there is a breach (or are breaches) } \\
\text { in the waste package which allows water to either } \\
\text { accumulate or flow through the waste package then } \\
\text { criticality could occur in-situ. }\end{array}$ & $\begin{array}{l}\text { Excluded - low } \\
\text { probability (Crit) }\end{array}$ & Crit \\
\hline 2.1.14.19.0A & $\begin{array}{l}\text { In-package } \\
\text { criticality resulting } \\
\text { from a seismic } \\
\text { event (degraded } \\
\text { configurations) }\end{array}$ & $\begin{array}{l}\text { Either during or as a result of a seismic disruptive event, } \\
\text { the waste package internal structures and the waste } \\
\text { form may degrade. If a critical configuration develops, } \\
\text { criticality could occur in-situ. Potential in-situ critical } \\
\text { configurations are defined in Figures } 3.2 a \text { and } 3.2 \mathrm{~b} \text { of } \\
\text { Disposal Criticality Analysis Methodology Topical Report } \\
\text { (YMP } 2003 \text { [DIRS 165505]). }\end{array}$ & $\begin{array}{l}\text { Excluded - low } \\
\text { probability (Crit) }\end{array}$ & Crit \\
\hline 2.1.14.20.0A & $\begin{array}{l}\text { Near-field } \\
\text { criticality resulting } \\
\text { from a seismic } \\
\text { event }\end{array}$ & $\begin{array}{l}\text { Either during or as a result of a seismic disruptive event, } \\
\text { near-field criticality could occur if fissile material-bearing } \\
\text { solution from the waste package is transported into the } \\
\text { drift and the fissile material is precipitated into a critical } \\
\text { configuration. Potential near-field critical configurations } \\
\text { are defined in Figure 3.3a of Disposal Criticality Analysis } \\
\text { Methodology Topical Report (YMP } 2003 \\
\text { [DIRS 165505]). }\end{array}$ & $\begin{array}{l}\text { Excluded - low } \\
\text { probability (Crit) }\end{array}$ & Crit \\
\hline 2.1.14.21.0A & $\begin{array}{l}\text { In-package } \\
\text { criticality resulting } \\
\text { from rockfall } \\
\text { (intact } \\
\text { configuration) }\end{array}$ & $\begin{array}{l}\text { The waste package internal structures and the waste } \\
\text { form remain intact either during or after a rockfall event. } \\
\text { If there is a breach (or are breaches) in the waste } \\
\text { package which allows water to either accumulate or flow } \\
\text { through the waste package then criticality could occur } \\
\text { in-situ. }\end{array}$ & $\begin{array}{l}\text { Excluded - low } \\
\text { probability (Crit) }\end{array}$ & Crit \\
\hline $2.1 .14 .22 .0 \mathrm{~A}$ & $\begin{array}{l}\text { In-package } \\
\text { criticality resulting } \\
\text { from rockfall } \\
\text { (degraded } \\
\text { configurations) }\end{array}$ & $\begin{array}{l}\text { Either during or as a result of a rockfall event, the waste } \\
\text { package internal structures and the waste form may } \\
\text { degrade. If a critical configuration develops, criticality } \\
\text { could occur in-situ. Potential in-situ critical } \\
\text { configurations are defined in Figures 3.2a and 3.2b of } \\
\text { Disposal Criticality Analysis Methodology Topical Report } \\
\text { (YMP } 2003 \text { [DIRS 165505]). }\end{array}$ & $\begin{array}{l}\text { Excluded - low } \\
\text { probability (Crit) }\end{array}$ & Crit \\
\hline 2.1.14.23.0A & $\begin{array}{l}\text { Near-field } \\
\text { criticality resulting } \\
\text { from rockfall }\end{array}$ & $\begin{array}{l}\text { Either during or as a result of a rockfall event, near-field } \\
\text { criticality could occur if fissile material-bearing solution } \\
\text { from the waste package is transported into the drift and } \\
\text { the fissile material is precipitated into a critical } \\
\text { configuration. Potential near-field critical configurations } \\
\text { are defined in Figure } 3.3 \text { a of Disposal Criticality Analysis } \\
\text { Methodology Topical Report (YMP } 2003 \\
\text { [DIRS 165505]). }\end{array}$ & $\begin{array}{l}\text { Excluded - low } \\
\text { probability (Crit) }\end{array}$ & Crit \\
\hline 2.1.14.24.0A & $\begin{array}{l}\text { In-package } \\
\text { criticality resulting } \\
\text { from an igneous } \\
\text { event (intact } \\
\text { configuration) }\end{array}$ & $\begin{array}{l}\text { The waste package internal structures and the waste } \\
\text { form remain intact either during of after an igneous } \\
\text { disruptive event. If there is a breach (or are breaches) } \\
\text { in the waste package which allows water to either } \\
\text { accumulate or flow through the waste package then } \\
\text { criticality could occur in-situ. }\end{array}$ & $\begin{array}{l}\text { Excluded - low } \\
\text { probability (Crit) }\end{array}$ & Crit \\
\hline 2.1.14.25.0A & $\begin{array}{l}\text { In-package } \\
\text { criticality resulting } \\
\text { from an igneous } \\
\text { event (degraded } \\
\text { configurations) }\end{array}$ & $\begin{array}{l}\text { Either during or as a result of an igneous disruptive } \\
\text { event, the waste package internal structures and the } \\
\text { waste form may degrade. If a critical configuration } \\
\text { develops, criticality could occur in-situ. Potential in-situ } \\
\text { critical configurations are defined in Figures } 3.2 a \\
\text { and 3.2b of Disposal Criticality Analysis Methodology } \\
\text { Topical Report (YMP 2003 [DIRS 165505]). }\end{array}$ & $\begin{array}{l}\text { Excluded - low } \\
\text { probability (Crit) }\end{array}$ & Crit \\
\hline
\end{tabular}


Table E-1. TSPA-LA FEP List (Continued)

\begin{tabular}{|c|c|c|c|c|}
\hline FEP Number & FEP Name & FEP Description & Screening Decision & $\begin{array}{l}\text { FEP } \\
\text { AMR }\end{array}$ \\
\hline 2.1.14.26.0A & $\begin{array}{l}\text { Near-field } \\
\text { criticality resulting } \\
\text { from an igneous } \\
\text { event }\end{array}$ & $\begin{array}{l}\text { Either during or as a result of an igneous disruptive } \\
\text { event, near-field criticality could occur if fissile material- } \\
\text { bearing solution from the waste package is transported } \\
\text { into the drift and the fissile material is precipitated into a } \\
\text { critical configuration. Potential near-field critical } \\
\text { configurations are defined in Figure 3.3a of Disposal } \\
\text { Criticality Analysis Methodology Topical Report (YMP } \\
2003 \text { [DIRS 165505]). }\end{array}$ & $\begin{array}{l}\text { Excluded - low } \\
\text { probability (Crit) }\end{array}$ & Crit \\
\hline $2.2 .01 .01 .0 \mathrm{~A}$ & $\begin{array}{l}\text { Mechanical } \\
\text { effects of } \\
\text { excavation and } \\
\text { construction in } \\
\text { the near-field }\end{array}$ & $\begin{array}{l}\text { Excavation will produce some disturbance of the rocks } \\
\text { surrounding the drifts due to stress relief. Stresses } \\
\text { associated directly with excavation (e.g., boring and } \\
\text { blasting operations) may also cause some changes in } \\
\text { rock properties. Properties that may be affected include } \\
\text { rock strength, fracture spacing and block size, and } \\
\text { hydrologic properties such as permeability. }\end{array}$ & Included (UZ) & UZ \\
\hline 2.2.01.01.0B & $\begin{array}{l}\text { Chemical effects } \\
\text { of excavation and } \\
\text { construction in } \\
\text { the near-field }\end{array}$ & $\begin{array}{l}\text { Excavation may result in chemical changes to the } \\
\text { incoming groundwater and to the rock in the excavation } \\
\text { disturbed zone. }\end{array}$ & $\begin{array}{l}\text { Excluded - low } \\
\text { consequence (UZ) }\end{array}$ & UZ \\
\hline 2.2.01.02.0A & $\begin{array}{l}\text { Thermally- } \\
\text { induced stress } \\
\text { changes in the } \\
\text { near-field }\end{array}$ & $\begin{array}{l}\text { Changes in host rock properties may result from thermal } \\
\text { effects or other factors related to emplacement of the } \\
\text { waste. Properties that may be affected include rock } \\
\text { strength, fracture spacing and block size, and hydrologic } \\
\text { properties such as permeability and sorption. }\end{array}$ & $\begin{array}{l}\text { Excluded - low } \\
\text { consequence (EBS) } \\
\text { Excluded - low } \\
\text { consequence (UZ) }\end{array}$ & $\begin{array}{l}\text { EBS } \\
\text { UZ }\end{array}$ \\
\hline 2.2.01.02.0B & $\begin{array}{l}\text { Chemical } \\
\text { changes in the } \\
\text { near-field from } \\
\text { backfill }\end{array}$ & $\begin{array}{l}\text { Changes in host rock properties may result from } \\
\text { chemical effects of backfill. Properties that may be } \\
\text { affected include permeability and sorption. }\end{array}$ & $\begin{array}{l}\text { Excluded - low } \\
\text { probability (EBS) }\end{array}$ & EBS \\
\hline 2.2.01.03.0A & $\begin{array}{l}\text { Changes in fluid } \\
\text { saturations in the } \\
\text { excavation } \\
\text { disturbed zone }\end{array}$ & $\begin{array}{l}\text { Fluid flow in the region near the repository may be } \\
\text { affected by the presence of the excavation, waste, and } \\
\text { EBS. Some dry-out will occur during excavation and } \\
\text { operations. }\end{array}$ & $\begin{array}{l}\text { Excluded - low } \\
\text { consequence (UZ) }\end{array}$ & UZ \\
\hline 2.2.01.04.0A & $\begin{array}{l}\text { Radionuclide } \\
\text { solubility in the } \\
\text { excavation } \\
\text { disturbed zone }\end{array}$ & $\begin{array}{l}\text { Radionuclide solubility limits in the excavation-disturbed } \\
\text { zone may differ from those in the EBS. }\end{array}$ & $\begin{array}{l}\text { Excluded - low } \\
\text { consequence (UZ) }\end{array}$ & UZ \\
\hline 2.2.01.05.0A & $\begin{array}{l}\text { Radionuclide } \\
\text { transport in the } \\
\text { excavation } \\
\text { disturbed zone }\end{array}$ & $\begin{array}{l}\text { Radionuclide transport through the excavation disturbed } \\
\text { zone may differ from transport in the EBS and the } \\
\text { undisturbed host rock. Transport processes such as } \\
\text { dissolution and precipitation, sorption, and colloid } \\
\text { filtration should be considered. }\end{array}$ & $\begin{array}{l}\text { Excluded - low } \\
\text { consequence (UZ) }\end{array}$ & UZ \\
\hline 2.2.03.01.0A & Stratigraphy & $\begin{array}{l}\text { Stratigraphic information is necessary information for } \\
\text { the performance assessment. This information should } \\
\text { include identification of the relevant rock units, soils and } \\
\text { alluvium, and their thickness, lateral extents, and } \\
\text { relationships to each other. Major discontinuities should } \\
\text { be identified. }\end{array}$ & $\begin{array}{l}\text { Included (UZ) } \\
\text { Included (SZ) }\end{array}$ & $\begin{array}{l}\text { UZ } \\
\text { SZ }\end{array}$ \\
\hline $2.2 .03 .02 .0 \mathrm{~A}$ & $\begin{array}{l}\text { Rock properties } \\
\text { of host rock and } \\
\text { other units }\end{array}$ & $\begin{array}{l}\text { Physical properties such as porosity and permeability of } \\
\text { the relevant rock units, soils, and alluvium are } \\
\text { necessary for the performance assessment. Possible } \\
\text { heterogeneities in these properties should be } \\
\text { considered. Questions concerning events and } \\
\text { processes that may cause these physical properties to } \\
\text { change over time are considered in other FEPs. }\end{array}$ & $\begin{array}{l}\text { Included (UZ) } \\
\text { Included (SZ) }\end{array}$ & $\begin{array}{l}\mathrm{UZ} \\
\mathrm{SZ}\end{array}$ \\
\hline
\end{tabular}


Table E-1. TSPA-LA FEP List (Continued)

\begin{tabular}{|c|c|c|c|c|}
\hline FEP Number & FEP Name & FEP Description & Screening Decision & $\begin{array}{l}\text { FEP } \\
\text { AMR }\end{array}$ \\
\hline $2.2 .06 .01 .0 \mathrm{~A}$ & $\begin{array}{l}\text { Seismic activity } \\
\text { changes porosity } \\
\text { and permeability } \\
\text { of rock }\end{array}$ & $\begin{array}{l}\text { Seismic activity (fault displacement or vibratory ground } \\
\text { motion) has a potential to change rock stresses and } \\
\text { result in strains that affect flow properties in rock outside } \\
\text { the excavation-disturbed zone. It could result in strains } \\
\text { that alter the permeability in the rock matrix. These } \\
\text { effects may decrease the transport times for potentially } \\
\text { released radionuclides. }\end{array}$ & $\begin{array}{l}\text { Excluded - low } \\
\text { consequence (DE) } \\
\text { Excluded - low } \\
\text { consequence (UZ) } \\
\text { Excluded - low } \\
\text { consequence (SZ) }\end{array}$ & $\begin{array}{l}\text { DE } \\
\text { UZ } \\
\text { SZ }\end{array}$ \\
\hline 2.2.06.02.0A & $\begin{array}{l}\text { Seismic activity } \\
\text { changes porosity } \\
\text { and permeability } \\
\text { of faults }\end{array}$ & $\begin{array}{l}\text { Seismic activity (fault displacement or vibratory ground } \\
\text { motion) has a potential to produce jointed-rock motion } \\
\text { and change stress and strains that alter the permeability } \\
\text { along faults. This could result in reactivation of pre- } \\
\text { existing faults or generation of new faults, which could } \\
\text { significantly change the flow and transport paths, alter } \\
\text { or short-circuit the flow paths and flow distributions } \\
\text { close to the repository, and/or create new pathways } \\
\text { through the repository. These effects may decrease the } \\
\text { transport times for potentially released radionuclides. }\end{array}$ & $\begin{array}{l}\text { Excluded - low } \\
\text { consequence (DE) } \\
\text { Excluded - low } \\
\text { consequence (UZ) } \\
\text { Excluded - low } \\
\text { consequence (SZ) }\end{array}$ & $\begin{array}{l}\mathrm{DE} \\
\mathrm{UZ} \\
\mathrm{SZ}\end{array}$ \\
\hline $2.2 .06 .02 .0 \mathrm{~B}$ & $\begin{array}{l}\text { Seismic activity } \\
\text { changes porosity } \\
\text { and permeability } \\
\text { of fractures }\end{array}$ & $\begin{array}{l}\text { Seismic activity (fault displacement or vibratory ground } \\
\text { motion) has a potential to change stress and strains that } \\
\text { alter the permeability along fractures. This could result } \\
\text { in reactivation of pre-existing fractures or generation of } \\
\text { new fractures, which could significantly change the flow } \\
\text { and transport paths, alter or short-circuit the flow paths } \\
\text { and flow distributions close to the repository, and/or } \\
\text { create new pathways through the repository. These } \\
\text { effects may decrease the transport times for potentially } \\
\text { released radionuclides. }\end{array}$ & $\begin{array}{l}\text { Excluded - low } \\
\text { consequence (DE) } \\
\text { Excluded - low } \\
\text { consequence (UZ) } \\
\text { Excluded - low } \\
\text { consequence (SZ) }\end{array}$ & $\begin{array}{l}\text { DE } \\
\text { UZ } \\
\text { SZ }\end{array}$ \\
\hline 2.2.06.03.0A & $\begin{array}{l}\text { Seismic activity } \\
\text { alters perched } \\
\text { water zones }\end{array}$ & $\begin{array}{l}\text { Strain caused by stress changes from tectonic or } \\
\text { seismic events could alter the rock permeabilities that } \\
\text { allow formation and persistence of perched-water } \\
\text { zones. }\end{array}$ & $\begin{array}{l}\text { Excluded - low } \\
\text { consequence (DE) } \\
\text { Excluded - low } \\
\text { consequence (UZ) }\end{array}$ & $\begin{array}{l}\text { DE } \\
\text { UZ }\end{array}$ \\
\hline $2.2 .06 .04 .0 \mathrm{~A}$ & $\begin{array}{l}\text { Effects of } \\
\text { subsidence }\end{array}$ & $\begin{array}{l}\text { Subsidence above the mined underground facility or } \\
\text { other openings may affect the properties of the overlying } \\
\text { rocks and surface topography. Changes in rock } \\
\text { properties, such as enhanced permeability, may alter } \\
\text { flow paths from the surface to the repository. Changes } \\
\text { in surface topography may alter run-off and infiltration, } \\
\text { and may perhaps create impoundments. }\end{array}$ & $\begin{array}{l}\text { Excluded - low } \\
\text { consequence (UZ) }\end{array}$ & UZ \\
\hline $2.2 .06 .05 .0 \mathrm{~A}$ & Salt creep & $\begin{array}{l}\text { Salt creep may lead to changes in the stress field, } \\
\text { compaction of the waste packages, and consolidation of } \\
\text { the long-term components of the sealing system. }\end{array}$ & $\begin{array}{l}\text { Excluded - by } \\
\text { regulation (SYS) }\end{array}$ & SYS \\
\hline $2 \cdot 2.07 .01 .0 \mathrm{~A}$ & $\begin{array}{l}\text { Locally saturated } \\
\text { flow at } \\
\text { bedrock/alluvium } \\
\text { contact }\end{array}$ & $\begin{array}{l}\text { In washes in arid areas, infiltration can descend to the } \\
\text { alluvium/bedrock interface and then proceed down the } \\
\text { wash at that interface as a saturated flow system } \\
\text { distinct from the surface and distinct from the local water } \\
\text { table. }\end{array}$ & Included (UZ) & UZ \\
\hline 2.2.07.02.0A & $\begin{array}{l}\text { Unsaturated } \\
\text { groundwater flow } \\
\text { in the geosphere }\end{array}$ & $\begin{array}{l}\text { Groundwater flow occurs in unsaturated rocks in most } \\
\text { locations above the water table at Yucca Mountain, } \\
\text { including at the location of the repository. See related } \\
\text { FEPs for discussions of specific issues related to } \\
\text { unsaturated flow. }\end{array}$ & Included (UZ) & UZ \\
\hline 2.2.07.03.0A & $\begin{array}{l}\text { Capillary rise in } \\
\text { the UZ }\end{array}$ & $\begin{array}{l}\text { Capillary rise involves the drawing up of water, above } \\
\text { the water table or above locally saturated zones, in } \\
\text { continuous pores of the unsaturated zone until the } \\
\text { suction gradient is balanced by the gravitational pull } \\
\text { downward. }\end{array}$ & Included (UZ) & UZ \\
\hline
\end{tabular}


Table E-1. TSPA-LA FEP List (Continued)

\begin{tabular}{|c|c|c|c|c|}
\hline FEP Number & FEP Name & FEP Description & Screening Decision & $\begin{array}{l}\text { FEP } \\
\text { AMR }\end{array}$ \\
\hline $2.2 .07 .04 .0 \mathrm{~A}$ & $\begin{array}{l}\text { Focusing of } \\
\text { unsaturated flow } \\
\text { (fingers, weeps) }\end{array}$ & $\begin{array}{l}\text { Unsaturated flow can differentiate into zones of greater } \\
\text { and lower saturation (fingers) that may persist as } \\
\text { preferential flow paths. Heterogeneities in rock } \\
\text { properties, including fractures and faults, may contribute } \\
\text { to focusing. Focused flow may become locally } \\
\text { saturated. }\end{array}$ & Included (UZ) & UZ \\
\hline $2.2 .07 .05 .0 \mathrm{~A}$ & $\begin{array}{l}\text { Flow in the UZ } \\
\text { from episodic } \\
\text { infiltration }\end{array}$ & $\begin{array}{l}\text { Episodic flow could occur in the UZ as a result of } \\
\text { episodic infiltration. Episodic flow may affect } \\
\text { radionuclide transport. }\end{array}$ & $\begin{array}{l}\text { Excluded - low } \\
\text { consequence (UZ) }\end{array}$ & UZ \\
\hline 2.2.07.06.0A & $\begin{array}{l}\text { Episodic or pulse } \\
\text { release from } \\
\text { repository }\end{array}$ & $\begin{array}{l}\text { Episodic or pulse release of radionuclides from the } \\
\text { repository and radionuclide transport in the UZ may } \\
\text { occur both because of episodic flow into the repository, } \\
\text { and because of pulse releases from failed waste } \\
\text { packages. }\end{array}$ & $\begin{array}{l}\text { Excluded - low } \\
\text { consequence (EBS) } \\
\text { Excluded - low } \\
\text { consequence (UZ) }\end{array}$ & $\begin{array}{l}\text { EBS } \\
\text { UZ }\end{array}$ \\
\hline 2.2.07.06.0B & $\begin{array}{l}\text { Long-term } \\
\text { release of } \\
\text { radionuclides } \\
\text { from the } \\
\text { repository }\end{array}$ & $\begin{array}{l}\text { The release of radionuclides from the repository may } \\
\text { occur over a long period of time, as a result of the timing } \\
\text { and magnitude of the waste packages and drip shield } \\
\text { failures, waste form degradation, and radionuclide } \\
\text { transport through the invert. }\end{array}$ & $\begin{array}{l}\text { Included (EBS) } \\
\text { Included (UZ) }\end{array}$ & $\begin{array}{l}\text { EBS } \\
\text { UZ }\end{array}$ \\
\hline $2 \cdot 2.07 .07 .0 \mathrm{~A}$ & $\begin{array}{l}\text { Perched water } \\
\text { develops }\end{array}$ & $\begin{array}{l}\text { Zones of perched water may develop above the water } \\
\text { table. If these zones occur above the repository, they } \\
\text { may affect UZ flow between the surface and the waste } \\
\text { packages. If they develop below the repository, for } \\
\text { example at the base of the Topopah Spring welded unit, } \\
\text { they may affect flow pathways and radionuclide } \\
\text { transport between the waste packages and the } \\
\text { saturated zone. }\end{array}$ & Included (UZ) & UZ \\
\hline 2.2.07.08.0A & $\begin{array}{l}\text { Fracture flow in } \\
\text { the UZ }\end{array}$ & $\begin{array}{l}\text { Fractures or other analogous channels may act as } \\
\text { conduits for fluids to move into the subsurface to } \\
\text { interact with the repository and as conduits for fluids to } \\
\text { leave the vicinity of the repository and be conducted to } \\
\text { the SZ. Water may flow through only a portion of the } \\
\text { fracture network, including flow through a restricted } \\
\text { portion of a given fracture plane. }\end{array}$ & Included (UZ) & UZ \\
\hline $2 \cdot 2.07 .09 .0 \mathrm{~A}$ & $\begin{array}{l}\text { Matrix imbibition } \\
\text { in the UZ }\end{array}$ & $\begin{array}{l}\text { Water flowing in fractures or other channels in the } \\
\text { unsaturated zone may be imbibed into the surrounding } \\
\text { rock matrix. This may occur during steady flow, } \\
\text { episodic flow, or into matrix pores that have been dried } \\
\text { out during the thermal period. }\end{array}$ & Included (UZ) & UZ \\
\hline $2.2 .07 .10 .0 \mathrm{~A}$ & $\begin{array}{l}\text { Condensation } \\
\text { zone forms } \\
\text { around drifts }\end{array}$ & $\begin{array}{l}\text { Condensation of the two-phase flow generated by } \\
\text { repository heat may form in the rock where the } \\
\text { temperature drops below the local vaporization } \\
\text { temperature. Waste package emplacement geometry } \\
\text { and thermal loading may affect the scale at which } \\
\text { condensation caps form (over waste packages, over } \\
\text { panels, or over the entire repository), and the extent to } \\
\text { which "shedding" will occur as water flows from the } \\
\text { region above one drift to the region above another drift } \\
\text { or into the rock between drifts. }\end{array}$ & Included (UZ) & UZ \\
\hline $2.2 .07 .11 .0 \mathrm{~A}$ & $\begin{array}{l}\text { Resaturation of } \\
\text { geosphere dry- } \\
\text { out zone }\end{array}$ & $\begin{array}{l}\text { Following the peak thermal period, water in the } \\
\text { condensation cap may flow downward into the drifts. } \\
\text { Influx of cooler water from above, such as might occur } \\
\text { from episodic flow, may accelerate return flow from the } \\
\text { condensation cap by lowering temperatures below the } \\
\text { condensation point. Percolating groundwater will also } \\
\text { contribute to resaturation of the dry-out zone. Vapor } \\
\text { flow, as distinct from liquid flow by capillary processes, } \\
\text { may also contribute. }\end{array}$ & Included (UZ) & UZ \\
\hline
\end{tabular}


Table E-1. TSPA-LA FEP List (Continued)

\begin{tabular}{|c|c|c|c|c|}
\hline FEP Number & FEP Name & FEP Description & Screening Decision & $\begin{array}{l}\text { FEP } \\
\text { AMR }\end{array}$ \\
\hline 2.2.07.12.0A & $\begin{array}{l}\text { Saturated } \\
\text { groundwater flow } \\
\text { in the geosphere }\end{array}$ & $\begin{array}{l}\text { Groundwater flow in the saturated zone below the water } \\
\text { table may affect long-term performance of the } \\
\text { repository. The location, magnitude, and direction of } \\
\text { flow under present and future conditions and the } \\
\text { hydraulic properties of the rock are all relevant. }\end{array}$ & Included (SZ) & SZ \\
\hline $2.2 .07 .13 .0 \mathrm{~A}$ & $\begin{array}{l}\text { Water-conducting } \\
\text { features in the SZ }\end{array}$ & $\begin{array}{l}\text { Geologic features in the saturated zone may affect } \\
\text { groundwater flow by providing preferred pathways for } \\
\text { flow. }\end{array}$ & Included (SZ) & SZ \\
\hline $2 \cdot 2 \cdot 07.14 .0 \mathrm{~A}$ & $\begin{array}{l}\text { Chemically- } \\
\text { induced density } \\
\text { effects on } \\
\text { groundwater flow }\end{array}$ & $\begin{array}{l}\text { Chemically-induced spatial variation in groundwater } \\
\text { density may affect groundwater flow. }\end{array}$ & $\begin{array}{l}\text { Excluded - low } \\
\text { consequence (SZ) }\end{array}$ & SZ \\
\hline 2.2.07.15.0A & $\begin{array}{l}\text { Advection and } \\
\text { dispersion in the } \\
\text { SZ }\end{array}$ & $\begin{array}{l}\text { Advection and dispersion processes may affect } \\
\text { radionuclide transport in the saturated zone. }\end{array}$ & Included (SZ) & $S z$ \\
\hline 2.2.07.15.0B & $\begin{array}{l}\text { Advection and } \\
\text { dispersion in the } \\
\text { UZ }\end{array}$ & $\begin{array}{l}\text { Advection and dispersion processes may affect } \\
\text { radionuclide transport in the UZ. }\end{array}$ & Included (UZ) & UZ \\
\hline 2.2.07.16.0A & $\begin{array}{l}\text { Dilution of } \\
\text { radionuclides in } \\
\text { groundwater }\end{array}$ & $\begin{array}{l}\text { Dilution due to mixing of contaminated and } \\
\text { uncontaminated water may affect radionuclide } \\
\text { concentrations in groundwater during transport in the } \\
\text { saturated zone and during pumping at a withdrawal well. }\end{array}$ & Included (SZ) & $\mathrm{SZ}$ \\
\hline 2.2.07.17.0A & $\begin{array}{l}\text { Diffusion in the } \\
\text { SZ }\end{array}$ & $\begin{array}{l}\text { Molecular diffusion processes may affect radionuclide } \\
\text { transport in the SZ. }\end{array}$ & Included (SZ) & $S z$ \\
\hline 2.2.07.18.0A & $\begin{array}{l}\text { Film flow into the } \\
\text { repository }\end{array}$ & $\begin{array}{l}\text { Water may enter waste emplacement drifts by a film } \\
\text { flow process. This differs from the traditional view of } \\
\text { flow in a capillary network where the wetting phase } \\
\text { exclusively occupies capillaries with apertures smaller } \\
\text { than some level defined by the capillary pressure. A } \\
\text { film flow process could allow water to enter a waste } \\
\text { emplacement drift at non-zero capillary pressure. } \\
\text { Dripping into the drifts could also occur through } \\
\text { collection of the film flow on the local minima of surface } \\
\text { roughness features along the crown of the drift. }\end{array}$ & Included (UZ) & UZ \\
\hline $2.2 .07 .19 .0 \mathrm{~A}$ & $\begin{array}{l}\text { Lateral flow from } \\
\text { Solitario Canyon } \\
\text { Fault enters drifts }\end{array}$ & $\begin{array}{l}\text { Water movement down Solitario Canyon Fault could } \\
\text { enter waste emplacement drifts through lateral flow } \\
\text { mechanisms in the Topopah Spring welded } \\
\text { hydrogeologic unit. This percolation pathway is more } \\
\text { likely to transmit episodic transient flow to waste } \\
\text { emplacement locations due to the major fault pathway } \\
\text { through the overlying units. }\end{array}$ & Included (UZ) & UZ \\
\hline 2.2.07.20.0A & $\begin{array}{l}\text { Flow diversion } \\
\text { around repository } \\
\text { drifts }\end{array}$ & $\begin{array}{l}\text { Flow in unsaturated rock tends to be diverted by } \\
\text { openings such as waste emplacement drifts due to the } \\
\text { effects of capillary forces. The resulting diversion of } \\
\text { flow could have an effect on seepage into the } \\
\text { repository. Flow diversion around the drift openings } \\
\text { could also lead to the development of a zone of lower } \\
\text { flow rates and low saturation beneath the drift, known as } \\
\text { the drift shadow. }\end{array}$ & Included (UZ) & UZ \\
\hline
\end{tabular}


Table E-1. TSPA-LA FEP List (Continued)

\begin{tabular}{|c|c|c|c|c|}
\hline FEP Number & FEP Name & FEP Description & Screening Decision & $\begin{array}{l}\text { FEP } \\
\text { AMR }\end{array}$ \\
\hline 2.2.07.21.0A & $\begin{array}{l}\text { Drift shadow } \\
\text { forms below } \\
\text { repository }\end{array}$ & $\begin{array}{l}\text { Flow in unsaturated rock tends to be diverted by } \\
\text { openings such as waste emplacement drifts due to the } \\
\text { effects of capillary forces. Flow diversion around the } \\
\text { drift openings could lead to the development of a zone } \\
\text { of lower flow rates and low saturation beneath the drift, } \\
\text { known as the drift shadow. Radionuclide transport rates } \\
\text { through the unsaturated rock may be dependent on } \\
\text { whether or not radionuclide releases occur from drifts } \\
\text { that are underlain by a drift shadow. }\end{array}$ & $\begin{array}{l}\text { Excluded - low } \\
\text { consequence (EBS) }\end{array}$ & EBS \\
\hline $2.2 .08 .01 .0 \mathrm{~A}$ & $\begin{array}{l}\text { Chemical } \\
\text { characteristics of } \\
\text { groundwater in } \\
\text { the SZ }\end{array}$ & $\begin{array}{l}\text { Chemistry and other characteristics of groundwater in } \\
\text { the saturated zone may affect groundwater flow and } \\
\text { radionuclide transport of dissolved and colloidal species. } \\
\text { Groundwater chemistry and other characteristics, } \\
\text { including temperature, pH, Eh, ionic strength, and major } \\
\text { ionic concentrations, may vary spatially throughout the } \\
\text { system as a result of different rock mineralogy. }\end{array}$ & $\begin{array}{l}\text { Included (SZ) } \\
\text { Included (Bio) }\end{array}$ & $\begin{array}{l}\text { SZ } \\
\text { Bio }\end{array}$ \\
\hline $2.2 .08 .01 .0 \mathrm{~B}$ & $\begin{array}{l}\text { Chemical } \\
\text { characteristics of } \\
\text { groundwater in } \\
\text { the UZ }\end{array}$ & $\begin{array}{l}\text { Chemistry and other characteristics of groundwater in } \\
\text { the unsaturated zone may affect groundwater flow and } \\
\text { radionuclide transport of dissolved and colloidal species. } \\
\text { Groundwater chemistry and other characteristics, } \\
\text { including temperature, pH, Eh, ionic strength, and major } \\
\text { ionic concentrations, may vary spatially throughout the } \\
\text { system as a result of different rock mineralogy. }\end{array}$ & Included (UZ) & UZ \\
\hline $2.2 .08 .03 .0 \mathrm{~A}$ & $\begin{array}{l}\text { Geochemical } \\
\text { interactions and } \\
\text { evolution in the } \\
\text { SZ }\end{array}$ & $\begin{array}{l}\text { Groundwater chemistry and other characteristics, } \\
\text { including temperature, pH, Eh, ionic strength, and major } \\
\text { ionic concentrations, may change through time, as a } \\
\text { result of the evolution of the disposal system or from } \\
\text { mixing with other waters. Geochemical interactions may } \\
\text { lead to dissolution and precipitation of minerals along } \\
\text { the groundwater flow path, affecting groundwater flow, } \\
\text { rock properties, and sorption of radionuclides. Effects } \\
\text { on hydrologic flow properties of the rock, radionuclide } \\
\text { solubilities, sorption processes, and colloidal transport } \\
\text { are relevant. Kinetics of chemical reactions should be } \\
\text { considered in the context of the time scale of concern. }\end{array}$ & $\begin{array}{l}\text { Excluded - low } \\
\text { consequence (SZ) }\end{array}$ & $S Z$ \\
\hline 2.2.08.03.0B & $\begin{array}{l}\text { Geochemical } \\
\text { interactions and } \\
\text { evolution in the } \\
\text { UZ }\end{array}$ & $\begin{array}{l}\text { Groundwater chemistry and other characteristics, } \\
\text { including temperature, pH, Eh, ionic strength, and major } \\
\text { ionic concentrations, may change through time, as a } \\
\text { result of the evolution of the disposal system or from } \\
\text { mixing with other waters. Geochemical interactions may } \\
\text { lead to dissolution and precipitation of minerals along } \\
\text { the groundwater flow path, affecting groundwater flow, } \\
\text { rock properties, and sorption of radionuclides. Effects } \\
\text { on hydrologic flow properties of the rock, radionuclide } \\
\text { solubilities, sorption processes, and colloidal transport } \\
\text { are relevant. Kinetics of chemical reactions should be } \\
\text { considered in the context of the time scale of concern. }\end{array}$ & $\begin{array}{l}\text { Excluded - low } \\
\text { consequence (UZ) }\end{array}$ & UZ \\
\hline $2.2 .08 .04 .0 \mathrm{~A}$ & $\begin{array}{l}\text { Re-dissolution of } \\
\text { precipitates } \\
\text { directs more } \\
\text { corrosive fluids to } \\
\text { waste packages }\end{array}$ & $\begin{array}{l}\text { Re-dissolution of precipitates that have plugged pores } \\
\text { as a result of evaporation of groundwater in the dry-out } \\
\text { zone, may produce a pulse of fluid reaching the waste } \\
\text { packages when gravity-driven flow resumes, which is } \\
\text { more corrosive than the original fluid in the rock. }\end{array}$ & $\begin{array}{l}\text { Included (EBS) } \\
\text { Included (UZ) }\end{array}$ & $\begin{array}{l}\text { EBS } \\
\text { UZ }\end{array}$ \\
\hline $2.2 .08 .05 .0 \mathrm{~A}$ & $\begin{array}{l}\text { Diffusion in the } \\
\text { UZ }\end{array}$ & $\begin{array}{l}\text { Molecular diffusion processes may affect radionuclide } \\
\text { transport in the UZ. This includes osmotic processes in } \\
\text { response to chemical gradients. }\end{array}$ & $\begin{array}{l}\text { Excluded - low } \\
\text { consequence (UZ) }\end{array}$ & UZ \\
\hline 2.2.08.06.0A & $\begin{array}{l}\text { Complexation in } \\
\text { the SZ }\end{array}$ & $\begin{array}{l}\text { Complexing agents such as humic and fulvic acids } \\
\text { present in natural groundwaters could affect } \\
\text { radionuclide transport in the } \mathrm{SZ} \text {. }\end{array}$ & Included (SZ) & $S z$ \\
\hline
\end{tabular}


Table E-1. TSPA-LA FEP List (Continued)

\begin{tabular}{|c|c|c|c|c|}
\hline FEP Number & FEP Name & FEP Description & Screening Decision & $\begin{array}{l}\text { FEP } \\
\text { AMR }\end{array}$ \\
\hline 2.2.08.06.0B & $\begin{array}{l}\text { Complexation in } \\
\text { the UZ }\end{array}$ & $\begin{array}{l}\text { Complexing agents such as humic and fulvic acids } \\
\text { present in natural groundwaters could affect } \\
\text { radionuclide transport in the UZ. }\end{array}$ & Included (UZ) & $\mathrm{UZ}$ \\
\hline 2.2.08.07.0A & $\begin{array}{l}\text { Radionuclide } \\
\text { solubility limits in } \\
\text { the SZ }\end{array}$ & $\begin{array}{l}\text { Solubility limits for radionuclides may be different in } \\
\text { saturated zone groundwater than in the water in the } \\
\text { unsaturated zone or in the waste and EBS. }\end{array}$ & $\begin{array}{l}\text { Excluded - low } \\
\text { consequence (SZ) }\end{array}$ & SZ \\
\hline 2.2.08.07.0B & $\begin{array}{l}\text { Radionuclide } \\
\text { solubility limits in } \\
\text { the UZ }\end{array}$ & $\begin{array}{l}\text { Solubility limits for radionuclides may be different in } \\
\text { unsaturated zone groundwater than in the water in the } \\
\text { waste and EBS. }\end{array}$ & $\begin{array}{l}\text { Excluded - low } \\
\text { consequence (UZ) }\end{array}$ & UZ \\
\hline 2.2.08.07.0C & $\begin{array}{l}\text { Radionuclide } \\
\text { solubility limits in } \\
\text { the biosphere }\end{array}$ & $\begin{array}{l}\text { Solubility limits for radionuclides may be different in the } \\
\text { biosphere pathways than in the water in the saturated } \\
\text { zone. }\end{array}$ & $\begin{array}{l}\text { Excluded - low } \\
\text { consequence (Bio) }\end{array}$ & Bio \\
\hline 2.2.08.08.0A & $\begin{array}{l}\text { Matrix diffusion in } \\
\text { the SZ }\end{array}$ & $\begin{array}{l}\text { Matrix diffusion is the process by which radionuclides } \\
\text { and other species transported in the } \mathrm{SZ} \text { by advective } \\
\text { flow in fractures or other pathways move into the matrix } \\
\text { of the porous rock by diffusion. Matrix diffusion can be } \\
\text { a very efficient retarding mechanism, especially for } \\
\text { strongly sorbed radionuclides, due to the increase in } \\
\text { rock surface accessible to sorption. }\end{array}$ & Included (SZ) & SZ \\
\hline 2.2.08.08.0B & $\begin{array}{l}\text { Matrix diffusion in } \\
\text { the UZ }\end{array}$ & $\begin{array}{l}\text { Matrix diffusion is the process by which radionuclides } \\
\text { and other species transported in the UZ by advective } \\
\text { flow in fractures or other pathways move into the matrix } \\
\text { of the porous rock by diffusion. This includes osmotic } \\
\text { processes in response to chemical gradients. Matrix } \\
\text { diffusion can be a very efficient retarding mechanism, } \\
\text { especially for strongly sorbed radionuclides, due to the } \\
\text { increase in rock surface accessible to sorption. }\end{array}$ & Included (UZ) & $\mathrm{UZ}$ \\
\hline $2.2 .08 .09 .0 \mathrm{~A}$ & $\begin{array}{l}\text { Sorption in the } \\
\text { SZ }\end{array}$ & $\begin{array}{l}\text { Sorption of dissolved and colloidal radionuclides in the } \\
\text { SZ can occur on the surfaces of both fractures and } \\
\text { matrix in rock or soil along the transport path. Sorption } \\
\text { may be reversible or irreversible, and it may occur as a } \\
\text { linear or nonlinear process. Sorption kinetics and the } \\
\text { availability of sites for sorption should be considered. } \\
\text { Sorption is a function of the radioelement type, mineral } \\
\text { type, and groundwater composition. }\end{array}$ & Included (SZ) & SZ \\
\hline 2.2.08.09.0B & $\begin{array}{l}\text { Sorption in the } \\
\text { UZ }\end{array}$ & $\begin{array}{l}\text { Sorption of dissolved and colloidal radionuclides in the } \\
\text { UZ can occur on the surfaces of both fractures and } \\
\text { matrix in rock or soil along the transport path. Sorption } \\
\text { may be reversible or irreversible, and it may occur as a } \\
\text { linear or nonlinear process. Sorption kinetics and the } \\
\text { availability of sites for sorption should be considered. } \\
\text { Sorption is a function of the radioelement type, mineral } \\
\text { type, and groundwater composition. }\end{array}$ & Included (UZ) & UZ \\
\hline $2.2 .08 .10 .0 \mathrm{~A}$ & $\begin{array}{l}\text { Colloidal } \\
\text { transport in the } \\
\text { SZ }\end{array}$ & $\begin{array}{l}\text { Radionuclides may be transported in groundwater in the } \\
\mathrm{SZ} \text { as colloidal species. Types of colloids include true } \\
\text { colloids, pseudo colloids, and microbial colloids. }\end{array}$ & Included (SZ) & $S Z$ \\
\hline 2.2.08.10.0B & $\begin{array}{l}\text { Colloidal } \\
\text { transport in the } \\
\text { UZ }\end{array}$ & $\begin{array}{l}\text { Radionuclides may be transported in groundwater in the } \\
\text { UZ as colloidal species. Types of colloids include true } \\
\text { colloids, pseudo colloids, and microbial colloids. }\end{array}$ & Included (UZ) & UZ \\
\hline 2.2.08.11.0A & $\begin{array}{l}\text { Groundwater } \\
\text { discharge to } \\
\text { surface within the } \\
\text { reference } \\
\text { biosphere }\end{array}$ & $\begin{array}{l}\text { Radionuclides transported in groundwater as solutes or } \\
\text { solid materials (colloids) from the far-field may } \\
\text { discharge at specific "entry" points that are within the } \\
\text { reference biosphere. Natural surface discharge points, } \\
\text { including those resulting from water table or capillary } \\
\text { rise, may be surface water bodies (rivers, lakes), } \\
\text { springs, wetlands, holding ponds, or unsaturated soils. }\end{array}$ & $\begin{array}{l}\text { Excluded - low } \\
\text { consequence (SZ) } \\
\text { Excluded - low } \\
\text { consequence (Bio) }\end{array}$ & $\begin{array}{l}\text { SZ } \\
\text { Bio }\end{array}$ \\
\hline
\end{tabular}


Table E-1. TSPA-LA FEP List (Continued)

\begin{tabular}{|c|c|c|c|c|}
\hline FEP Number & FEP Name & FEP Description & Screening Decision & $\begin{array}{l}\text { FEP } \\
\text { AMR }\end{array}$ \\
\hline 2.2.08.12.0A & $\begin{array}{l}\text { Chemistry of } \\
\text { water flowing into } \\
\text { the drift }\end{array}$ & $\begin{array}{l}\text { Inflowing water chemistry may be used in analysis or } \\
\text { modeling that requires initial water chemistry in the drift. } \\
\text { Chemistry of water flowing into the drift is affected by } \\
\text { initial water chemistry in the rock, mineral and gas } \\
\text { composition in the rock, and thermal-hydrological- } \\
\text { chemical processes in the rock. }\end{array}$ & Included (UZ) & UZ \\
\hline 2.2.08.12.0B & $\begin{array}{l}\text { Chemistry of } \\
\text { water flowing into } \\
\text { the waste } \\
\text { package }\end{array}$ & $\begin{array}{l}\text { Inflowing water chemistry may be used in analysis or } \\
\text { modeling that requires initial water chemistry in the } \\
\text { waste package. }\end{array}$ & Included (WF) & WF \\
\hline 2.2.09.01.0A & $\begin{array}{l}\text { Microbial activity } \\
\text { in the SZ }\end{array}$ & $\begin{array}{l}\text { Microbial activity in the SZ may affect radionuclide } \\
\text { mobility in rock and soil through colloidal processes, by } \\
\text { influencing the availability of complexing agents, or by } \\
\text { influencing groundwater chemistry. }\end{array}$ & $\begin{array}{l}\text { Excluded - low } \\
\text { consequence (SZ) }\end{array}$ & $S Z$ ** \\
\hline 2.2.09.01.0B & $\begin{array}{l}\text { Microbial activity } \\
\text { in the UZ }\end{array}$ & $\begin{array}{l}\text { Microbial activity in the UZ may affect radionuclide } \\
\text { mobility in rock and soil through colloidal processes, by } \\
\text { influencing the availability of complexing agents, or by } \\
\text { influencing groundwater chemistry. Changes in } \\
\text { microbial activity could be caused by the response of } \\
\text { the soil zone to changes in climate. }\end{array}$ & Included (UZ) & UZ \\
\hline $2.2 .10 .01 .0 \mathrm{~A}$ & $\begin{array}{l}\text { Repository- } \\
\text { induced thermal } \\
\text { effects on flow in } \\
\text { the UZ }\end{array}$ & $\begin{array}{l}\text { Thermal effects in the geosphere could affect the long- } \\
\text { term performance of the disposal system, including } \\
\text { effects on groundwater flow (e.g., density-driven flow), } \\
\text { mechanical properties, and chemical effects in the UZ. }\end{array}$ & $\begin{array}{l}\text { Excluded - low } \\
\text { consequence (UZ) }\end{array}$ & UZ \\
\hline 2.2.10.02.0A & $\begin{array}{l}\text { Thermal } \\
\text { convection cell } \\
\text { develops in SZ }\end{array}$ & $\begin{array}{l}\text { Thermal effects due to waste emplacement result in } \\
\text { convective flow in the saturated zone beneath the } \\
\text { repository. }\end{array}$ & $\begin{array}{l}\text { Excluded - low } \\
\text { consequence (SZ) }\end{array}$ & SZ \\
\hline 2.2.10.03.0A & $\begin{array}{l}\text { Natural } \\
\text { geothermal } \\
\text { effects on flow in } \\
\text { the SZ }\end{array}$ & $\begin{array}{l}\text { The existing geothermal gradient, and spatial or } \\
\text { temporal variability in that gradient, may affect } \\
\text { groundwater flow in the saturated zones. }\end{array}$ & Included (SZ) & SZ \\
\hline 2.2.10.03.0B & $\begin{array}{l}\text { Natural } \\
\text { geothermal } \\
\text { effects on flow in } \\
\text { the UZ }\end{array}$ & $\begin{array}{l}\text { The existing geothermal gradient, and spatial or } \\
\text { temporal variability in that gradient, may affect } \\
\text { groundwater flow in the UZ. }\end{array}$ & Included (UZ) & UZ \\
\hline 2.2.10.04.0A & $\begin{array}{l}\text { Thermo- } \\
\text { mechanical } \\
\text { stresses alter } \\
\text { characteristics of } \\
\text { fractures near } \\
\text { repository }\end{array}$ & $\begin{array}{l}\text { Heat from the waste causes thermal expansion of the } \\
\text { surrounding rock, generating changes in the stress field } \\
\text { that may change the properties (both hydrologic and } \\
\text { mechanical) of fractures in the rock. Cooling following } \\
\text { the peak thermal period will also change the stress field, } \\
\text { further affecting fracture properties near the repository. }\end{array}$ & $\begin{array}{l}\text { Excluded - low } \\
\text { consequence (UZ) } \\
\text { Excluded - low } \\
\text { consequence (SZ) }\end{array}$ & $\begin{array}{l}\text { UZ } \\
\text { SZ }\end{array}$ \\
\hline 2.2.10.04.0B & $\begin{array}{l}\text { Thermo- } \\
\text { mechanical } \\
\text { stresses alter } \\
\text { characteristics of } \\
\text { faults near } \\
\text { repository }\end{array}$ & $\begin{array}{l}\text { Heat from the waste causes thermal expansion of the } \\
\text { surrounding rock, generating changes to the stress field } \\
\text { that may change the properties (both hydrologic and } \\
\text { mechanical) in and along faults. Cooling following the } \\
\text { peak thermal period will also change the stress field, } \\
\text { further affecting fault properties near the repository. }\end{array}$ & $\begin{array}{l}\text { Excluded - low } \\
\text { consequence (UZ) } \\
\text { Excluded - low } \\
\text { consequence (SZ) }\end{array}$ & $\begin{array}{l}\mathrm{UZ} \\
\mathrm{SZ}\end{array}$ \\
\hline 2.2.10.05.0A & $\begin{array}{l}\text { Thermo- } \\
\text { mechanical } \\
\text { stresses alter } \\
\text { characteristics of } \\
\text { rocks above and } \\
\text { below the } \\
\text { repository }\end{array}$ & $\begin{array}{l}\text { Thermal-mechanical compression at the repository may } \\
\text { produce tension fracturing in the Paintbrush non-welded } \\
\text { tuff and other units above the repository. These } \\
\text { fractures may alter unsaturated zone flow between the } \\
\text { surface and the repository. Extreme fracturing may } \\
\text { propagate to the surface, affecting infiltration. Thermal } \\
\text { fracturing in rocks below the repository may affect flow } \\
\text { and radionuclide transport to the saturated zone. }\end{array}$ & $\begin{array}{l}\text { Excluded - low } \\
\text { consequence (UZ) } \\
\text { Excluded - low } \\
\text { consequence (SZ) }\end{array}$ & $\begin{array}{l}\text { UZ } \\
\text { SZ }\end{array}$ \\
\hline
\end{tabular}


Table E-1. TSPA-LA FEP List (Continued)

\begin{tabular}{|c|c|c|c|c|}
\hline FEP Number & FEP Name & FEP Description & Screening Decision & $\begin{array}{l}\text { FEP } \\
\text { AMR }\end{array}$ \\
\hline 2.2.10.06.0A & $\begin{array}{l}\text { Thermo-chemical } \\
\text { alteration in the } \\
\text { UZ (solubility, } \\
\text { speciation, phase } \\
\text { changes, } \\
\text { precipitation/diss } \\
\text { olution) }\end{array}$ & $\begin{array}{l}\text { Thermal effects may affect radionuclide transport } \\
\text { directly, by causing changes in radionuclide speciation } \\
\text { and solubility in the UZ, or indirectly, by causing } \\
\text { changes in the host rock mineralogy that affect the flow } \\
\text { path. Relevant processes include volume effects } \\
\text { associated with silica phase changes, precipitation and } \\
\text { dissolution of fracture-filling minerals (including silica } \\
\text { and calcite), and alteration of zeolites and other } \\
\text { minerals to clays. }\end{array}$ & $\begin{array}{l}\text { Excluded - low } \\
\text { consequence (UZ) }\end{array}$ & UZ \\
\hline 2.2.10.07.0A & $\begin{array}{l}\text { Thermo-chemical } \\
\text { alteration of the } \\
\text { Calico Hills unit }\end{array}$ & $\begin{array}{l}\text { Fracture pathways in the Calico Hills may be altered by } \\
\text { the thermal and chemical properties of the water flowing } \\
\text { out of the repository. }\end{array}$ & $\begin{array}{l}\text { Excluded - low } \\
\text { consequence (UZ) }\end{array}$ & UZ \\
\hline 2.2.10.08.0A & $\begin{array}{l}\text { Thermo-chemical } \\
\text { alteration in the } \\
\text { SZ (solubility, } \\
\text { speciation, phase } \\
\text { changes, } \\
\text { precipitation/diss } \\
\text { olution) }\end{array}$ & $\begin{array}{l}\text { Thermal effects may affect radionuclide transport } \\
\text { directly by causing changes in radionuclide speciation } \\
\text { and solubility in the SZ, or, indirectly, by causing } \\
\text { changes to host rock mineralogy that affect the flow } \\
\text { path. Relevant processes include volume effects } \\
\text { associated with silica phase changes, precipitation and } \\
\text { dissolution of fracture filling minerals (including silica } \\
\text { and calcite), and alteration of zeolites and other } \\
\text { minerals to clays. }\end{array}$ & $\begin{array}{l}\text { Excluded - low } \\
\text { consequence (SZ) }\end{array}$ & SZ \\
\hline $2.2 .10 .09 .0 \mathrm{~A}$ & $\begin{array}{l}\text { Thermo-chemical } \\
\text { alteration of the } \\
\text { Topopah Spring } \\
\text { basal vitrophyre }\end{array}$ & $\begin{array}{l}\text { Heating the Topopah Spring basal vitrophyre with } \\
\text { available water may cause alteration of the glasses to } \\
\text { clays and zeolites. Possible effects include volume } \\
\text { increases that plug fractures, changes in flow paths, } \\
\text { creation of perched water zones, and an increase in the } \\
\text { sorptive properties of the unit. }\end{array}$ & $\begin{array}{l}\text { Excluded - low } \\
\text { consequence (UZ) }\end{array}$ & UZ \\
\hline $2.2 .10 .10 .0 \mathrm{~A}$ & $\begin{array}{l}\text { Two-phase } \\
\text { buoyant flow/heat } \\
\text { pipes }\end{array}$ & $\begin{array}{l}\text { Heat from waste can generate two-phase buoyant flow. } \\
\text { The vapor phase (water vapor) could escape from the } \\
\text { mountain. A heat pipe consists of a system for } \\
\text { transferring energy between a hot and a cold region } \\
\text { (source and sink respectively) using the heat of } \\
\text { vaporization and movement of the vapor as the transfer } \\
\text { mechanism. Two-phase circulation continues until the } \\
\text { heat source is too weak to provide the thermal gradients } \\
\text { required to drive it. Alteration of the rock adjacent to the } \\
\text { drift may include dissolution that maintains the } \\
\text { permeability necessary to support the circulation (as } \\
\text { inferred for some geothermal systems). }\end{array}$ & Included (UZ) & UZ \\
\hline 2.2.10.11.0A & $\begin{array}{l}\text { Natural air flow in } \\
\text { the UZ }\end{array}$ & $\begin{array}{l}\text { Natural convective air circulation has been observed at } \\
\text { a borehole at the top of the mountain. Repository heat } \\
\text { may increase this flow. }\end{array}$ & $\begin{array}{l}\text { Excluded - low } \\
\text { consequence (UZ) }\end{array}$ & UZ \\
\hline $2.2 .10 .12 .0 \mathrm{~A}$ & $\begin{array}{l}\text { Geosphere dry- } \\
\text { out due to waste } \\
\text { heat }\end{array}$ & $\begin{array}{l}\text { Repository heat evaporates water from the UZ rocks } \\
\text { near the drifts as the temperature exceeds the } \\
\text { vaporization temperature. This zone of reduced water } \\
\text { content (reduced saturation) migrates outward during } \\
\text { the heating phase (about the first } 1000 \text { years) and then } \\
\text { migrates back to the waste packages as heat diffuses } \\
\text { throughout the mountain and the radioactive sources } \\
\text { decay. This FEP addresses the effects of dry-out within } \\
\text { the rocks. }\end{array}$ & Included (UZ) & UZ \\
\hline 2.2.10.13.0A & $\begin{array}{l}\text { Repository- } \\
\text { induced thermal } \\
\text { effects on flow in } \\
\text { the SZ }\end{array}$ & $\begin{array}{l}\text { Thermal effects in the geosphere could affect the long- } \\
\text { term performance of the disposal system, including } \\
\text { effects on groundwater flow (e.g., density-driven flow), } \\
\text { mechanical properties, and chemical effects in the SZ. }\end{array}$ & $\begin{array}{l}\text { Excluded - low } \\
\text { consequence (SZ) }\end{array}$ & SZ \\
\hline
\end{tabular}


Table E-1. TSPA-LA FEP List (Continued)

\begin{tabular}{|c|c|c|c|c|}
\hline FEP Number & FEP Name & FEP Description & Screening Decision & $\begin{array}{l}\text { FEP } \\
\text { AMR }\end{array}$ \\
\hline $2.2 .10 .14 .0 \mathrm{~A}$ & $\begin{array}{l}\text { Mineralogic } \\
\text { dehydration } \\
\text { reactions }\end{array}$ & $\begin{array}{l}\text { Mineralogic dehydration reactions release water } \\
\text { affecting hydrologic conditions. Dehydration of zeolites } \\
\text { below the repository may lead to large-scale volume } \\
\text { changes affecting flow and/or drift stability. }\end{array}$ & $\begin{array}{l}\text { Excluded - low } \\
\text { consequence (UZ) }\end{array}$ & $\mathrm{UZ}$ \\
\hline $2.2 .11 .01 .0 \mathrm{~A}$ & $\begin{array}{l}\text { Gas effects in the } \\
\mathrm{SZ}\end{array}$ & $\begin{array}{l}\text { Pressure variations due to gas generation may affect } \\
\text { flow patterns and contaminant transport in the SZ. } \\
\text { Degassing could affect flow and transport of gaseous } \\
\text { contaminants. Potential gas sources include } \\
\text { degradation of repository components and naturally } \\
\text { occurring gases from clathrates, microbial degradation } \\
\text { of organic material, or deep gases in general. }\end{array}$ & $\begin{array}{l}\text { Excluded - low } \\
\text { consequence (SZ) }\end{array}$ & $S Z$ \\
\hline 2.2.11.02.0A & $\begin{array}{l}\text { Gas effects in the } \\
\text { UZ }\end{array}$ & $\begin{array}{l}\text { Pressure variations due to gas generation may affect } \\
\text { flow patterns and contaminant transport in the UZ or } \\
\text { may intrude into the repository. Degassing could affect } \\
\text { flow and transport of gaseous contaminants. Gases } \\
\text { could also affect other contaminants if water flow is } \\
\text { driven by large gas bubbles forming in the repository. } \\
\text { Potential gas sources include degradation of repository } \\
\text { components and naturally occurring gases from } \\
\text { clathrates, microbial degradation of organic material, or } \\
\text { deep gases in general. }\end{array}$ & $\begin{array}{l}\text { Excluded - low } \\
\text { consequence (UZ) }\end{array}$ & UZ \\
\hline 2.2.11.03.0A & $\begin{array}{l}\text { Gas transport in } \\
\text { geosphere }\end{array}$ & $\begin{array}{l}\text { Gas released from the drifts and gas generated in the } \\
\text { near-field rock will flow through fracture systems in the } \\
\text { near-field rock and in the geosphere. Certain gaseous } \\
\text { or volatile radionuclides may be able to migrate through } \\
\text { the far-field faster than the groundwater advection rate. }\end{array}$ & $\begin{array}{l}\text { Excluded - low } \\
\text { consequence (UZ) }\end{array}$ & UZ \\
\hline $2.2 .12 .00 .0 \mathrm{~A}$ & $\begin{array}{l}\text { Undetected } \\
\text { features in the } \\
\text { UZ }\end{array}$ & $\begin{array}{l}\text { Undetected features in the UZ portion of the geosphere } \\
\text { can affect long-term performance of the disposal } \\
\text { system. Undetected but important features may be } \\
\text { present, and may have significant impacts. These } \\
\text { features include unknown active fracture zones, } \\
\text { inhomogeneities, faults and features connecting } \\
\text { different zones of rock, different geometries for fracture } \\
\text { zones, and induced fractures due to the construction or } \\
\text { presence of the repository. }\end{array}$ & $\begin{array}{l}\text { Excluded - low } \\
\text { consequence (UZ) }\end{array}$ & UZ \\
\hline 2.2.12.00.0B & $\begin{array}{l}\text { Undetected } \\
\text { features in the SZ }\end{array}$ & $\begin{array}{l}\text { Undetected features in the SZ portion of the geosphere } \\
\text { can affect long-term performance of the disposal } \\
\text { system. Undetected but important features may be } \\
\text { present, and may have significant impacts. These } \\
\text { features include unknown active fracture zones, } \\
\text { inhomogeneities, faults and features connecting } \\
\text { different zones of rock, and different geometries for } \\
\text { fracture zones. }\end{array}$ & Included (SZ) & $S Z$ \\
\hline $2.2 .14 .09 .0 \mathrm{~A}$ & Far-field criticality & $\begin{array}{l}\text { Far-field criticality could occur if fissile material-bearing } \\
\text { solution from the waste package is transported beyond } \\
\text { the drift and the fissile material is precipitated into a } \\
\text { critical configuration. Potential far-field critical } \\
\text { configurations are defined in Figure } 3.3 \mathrm{~b} \text { of Disposal } \\
\text { Criticality Analysis Methodology Topical Report (YMP } \\
2003 \text { [DIRS } 165505] \text { ). In-package criticality resulting } \\
\text { from disruptive events is addressed in separate FEPs. }\end{array}$ & $\begin{array}{l}\text { Excluded - low } \\
\text { probability (Crit) }\end{array}$ & Crit \\
\hline
\end{tabular}


Table E-1. TSPA-LA FEP List (Continued)

\begin{tabular}{|c|c|c|c|c|}
\hline FEP Number & FEP Name & FEP Description & Screening Decision & $\begin{array}{l}\text { FEP } \\
\text { AMR }\end{array}$ \\
\hline $2.2 .14 .10 .0 \mathrm{~A}$ & $\begin{array}{l}\text { Far-field criticality } \\
\text { resulting from a } \\
\text { seismic event }\end{array}$ & $\begin{array}{l}\text { Either during or as a result of a seismic disruptive event, } \\
\text { far-field criticality could occur if fissile material-bearing } \\
\text { solution from the waste package is transported beyond } \\
\text { the drift and the fissile material is precipitated into a } \\
\text { critical configuration. Potential far-field critical } \\
\text { configurations are defined in Figure } 3.3 \mathrm{~b} \text { of Disposal } \\
\text { Criticality Analysis Methodology Topical Report (YMP } \\
2003 \text { [DIRS 165505]). }\end{array}$ & $\begin{array}{l}\text { Excluded - low } \\
\text { probability (Crit) }\end{array}$ & Crit \\
\hline $2.2 .14 .11 .0 \mathrm{~A}$ & $\begin{array}{l}\text { Far-field criticality } \\
\text { resulting from } \\
\text { rockfall }\end{array}$ & $\begin{array}{l}\text { Either during or as a result of a rockfall event, far-field } \\
\text { criticality could occur if fissile material-bearing solution } \\
\text { from the waste package is transported beyond the drift } \\
\text { and the fissile material is precipitated into a critical } \\
\text { configuration. Potential far-field critical configurations } \\
\text { are defined in Figure } 3.3 \mathrm{~b} \text { of Disposal Criticality Analysis } \\
\text { Methodology Topical Report (YMP } 2003 \\
\text { [DIRS 165505]). }\end{array}$ & $\begin{array}{l}\text { Excluded - low } \\
\text { probability (Crit) }\end{array}$ & Crit \\
\hline 2.2.14.12.0A & $\begin{array}{l}\text { Far-field criticality } \\
\text { resulting from an } \\
\text { igneous event }\end{array}$ & $\begin{array}{l}\text { Either during or as a result of an igneous disruptive } \\
\text { event, far-field criticality could occur if fissile material- } \\
\text { bearing solution from the waste package is transported } \\
\text { beyond the drift and the fissile material is precipitated } \\
\text { into a critical configuration. Potential far-field critical } \\
\text { configurations are defined in Figure } 3.3 \mathrm{~b} \text { of Disposal } \\
\text { Criticality Analysis Methodology Topical Report } \\
\text { (YMP } 2003 \text { [DIRS 165505]). }\end{array}$ & $\begin{array}{l}\text { Excluded - low } \\
\text { probability (Crit) }\end{array}$ & Crit \\
\hline $2.3 .01 .00 .0 \mathrm{~A}$ & $\begin{array}{l}\text { Topography and } \\
\text { morphology }\end{array}$ & $\begin{array}{l}\text { This FEP is related to the topography and surface } \\
\text { morphology of the disposal region. Topographical } \\
\text { features include outcrops and hills, water-filled } \\
\text { depressions, wetlands, recharge areas and discharge } \\
\text { areas. Topography, precipitation, and surficial } \\
\text { permeability distribution in the system will determine the } \\
\text { flow boundary conditions (i.e., location and amount of } \\
\text { recharge and discharge in the system). }\end{array}$ & Included (UZ) & UZ \\
\hline $2.3 .02 .01 .0 \mathrm{~A}$ & Soil type & $\begin{array}{l}\text { Soil type is determined by many different factors } \\
\text { (e.g., formative process, geology, climate, vegetation, } \\
\text { land use). The physical and chemical attributes of the } \\
\text { surficial soils (such as organic matter content and pH) } \\
\text { may influence the mobility of radionuclides. }\end{array}$ & Included (Bio) & Bio \\
\hline 2.3.02.02.0A & $\begin{array}{l}\text { Radionuclide } \\
\text { accumulation in } \\
\text { soils }\end{array}$ & $\begin{array}{l}\text { Radionuclide accumulation in soils may occur as a } \\
\text { result of upwelling of contaminated groundwater } \\
\text { (leaching, evaporation at discharge location), deposition } \\
\text { of contaminated water or particulates (irrigation water, } \\
\text { runoff), and/or atmospheric deposition. }\end{array}$ & Included (Bio) & Bio \\
\hline $2.3 .02 .03 .0 \mathrm{~A}$ & $\begin{array}{l}\text { Soil and } \\
\text { sediment } \\
\text { transport in the } \\
\text { biosphere }\end{array}$ & $\begin{array}{l}\text { Contaminated sediments can be transported to and } \\
\text { through the biosphere by surface runoff and fluvial } \\
\text { processes, and, to a lesser extent, by aeolian processes } \\
\text { and bioturbation. Sediment transport and redistribution } \\
\text { may cause concentration or dilution of radionuclides in } \\
\text { the biosphere. }\end{array}$ & Included (Bio) & Bio \\
\hline 2.3.04.01.0A & $\begin{array}{l}\text { Surface water } \\
\text { transport and } \\
\text { mixing }\end{array}$ & $\begin{array}{l}\text { Radionuclides released from an underground repository } \\
\text { might enter the biosphere through discharge of deep } \\
\text { groundwater into a lake or river. Transport and mixing } \\
\text { within the surface water bodies affects the subsequent } \\
\text { behavior and transport of radionuclides in the biosphere. } \\
\text { Transport and mixing includes dilution, sedimentation, } \\
\text { aeration, streamflow, and river meander. }\end{array}$ & Included (Bio) & Bio \\
\hline 2.3.06.00.0A & Marine features & $\begin{array}{l}\text { This FEP addresses marine and coastal features and } \\
\text { processes. Processes include erosion, sedimentation, } \\
\text { deposition, sea-level change, and storms. }\end{array}$ & $\begin{array}{l}\text { Excluded - low } \\
\text { probability (Bio) }\end{array}$ & Bio \\
\hline
\end{tabular}


Table E-1. TSPA-LA FEP List (Continued)

\begin{tabular}{|c|c|c|c|c|}
\hline FEP Number & FEP Name & FEP Description & Screening Decision & $\begin{array}{l}\text { FEP } \\
\text { AMR }\end{array}$ \\
\hline 2.3.09.01.0A & $\begin{array}{l}\text { Animal burrowing } \\
\text { / intrusion }\end{array}$ & $\begin{array}{l}\text { Burrowing animals may intrude into the repository, } \\
\text { promoting release and spread of contamination. } \\
\text { Burrowing animals may also contact or ingest } \\
\text { contaminated soil. }\end{array}$ & $\begin{array}{l}\text { Excluded - low } \\
\text { probability (Bio) }\end{array}$ & Bio \\
\hline 2.3.11.01.0A & Precipitation & $\begin{array}{l}\text { Precipitation is an important control on the amount of } \\
\text { recharge. It transports solutes with it as it flows } \\
\text { downward through the subsurface or escapes as runoff. } \\
\text { Precipitation influences agricultural practices of the } \\
\text { receptor. The amount of precipitation depends on } \\
\text { climate. }\end{array}$ & $\begin{array}{l}\text { Included (UZ) } \\
\text { Included (Bio) }\end{array}$ & $\begin{array}{l}\text { UZ } \\
\text { Bio }\end{array}$ \\
\hline 2.3.11.02.0A & $\begin{array}{l}\text { Surface runoff } \\
\text { and flooding }\end{array}$ & $\begin{array}{l}\text { Surface runoff and evapotranspiration are components } \\
\text { in the water balance, together with precipitation and } \\
\text { infiltration. Surface runoff produces erosion, and can } \\
\text { feed washes, arroyos, and impoundments, where } \\
\text { flooding may lead to increased recharge. }\end{array}$ & Included (UZ) & UZ \\
\hline $2.3 .11 .03 .0 \mathrm{~A}$ & $\begin{array}{l}\text { Infiltration and } \\
\text { recharge }\end{array}$ & $\begin{array}{l}\text { Infiltration into the subsurface provides a boundary } \\
\text { condition for groundwater flow. The amount and } \\
\text { location of the infiltration influences the hydraulic } \\
\text { gradient and the height of the water table. Different } \\
\text { sources of recharge water could change the } \\
\text { composition of groundwater passing through the } \\
\text { repository. Mixing of these waters with other } \\
\text { groundwaters could result in precipitation, dissolution, } \\
\text { and altered chemical gradients. }\end{array}$ & Included (UZ) & UZ \\
\hline 2.3.11.04.0A & $\begin{array}{l}\text { Groundwater } \\
\text { discharge to } \\
\text { surface outside } \\
\text { the reference } \\
\text { biosphere }\end{array}$ & $\begin{array}{l}\text { Radionuclides transported in groundwater as solutes or } \\
\text { solid materials (colloids) from the far-field may } \\
\text { discharge at specific "entry" points that are outside the } \\
\text { reference biosphere. Natural surface discharge points, } \\
\text { including those resulting from water table or capillary } \\
\text { rise, may be surface water bodies (rivers, lakes), } \\
\text { springs, wetlands, holding ponds, or unsaturated soils. }\end{array}$ & $\begin{array}{l}\text { Excluded - by } \\
\text { regulation (SZ) } \\
\text { Excluded - by } \\
\text { regulation (Bio) }\end{array}$ & $\begin{array}{l}\text { SZ } \\
\text { Bio }\end{array}$ \\
\hline $2.3 .13 .01 .0 \mathrm{~A}$ & $\begin{array}{l}\text { Biosphere } \\
\text { characteristics }\end{array}$ & $\begin{array}{l}\text { The principal components, conditions, or characteristics } \\
\text { of the biosphere system can influence radionuclide } \\
\text { transport and affect the long-term performance of the } \\
\text { disposal system. These include the characteristics of } \\
\text { the reference biosphere such as climate, soils and } \\
\text { microbes, flora and fauna, and their influences on } \\
\text { human activities. }\end{array}$ & Included (Bio) & Bio \\
\hline 2.3.13.02.0A & $\begin{array}{l}\text { Radionuclide } \\
\text { alteration during } \\
\text { biosphere } \\
\text { transport }\end{array}$ & $\begin{array}{l}\text { Once in the biosphere, radionuclides may be } \\
\text { transported and transferred through and between } \\
\text { different compartments of the biosphere. Temporally- } \\
\text { and spatially-dependent physical and chemical } \\
\text { environments in the biosphere may lead to alteration of } \\
\text { both the physical and chemical properties of the } \\
\text { radionuclides as they move through or between the } \\
\text { different compartments of the biosphere. These } \\
\text { alterations could consequently control exposure to the } \\
\text { human population. }\end{array}$ & Included (Bio) & Bio \\
\hline 2.3.13.03.0A & $\begin{array}{l}\text { Effects of } \\
\text { repository heat } \\
\text { on the biosphere }\end{array}$ & $\begin{array}{l}\text { Heat released from radioactive decay of the waste may } \\
\text { increase the temperatures at the surface above the } \\
\text { repository. This could result in local or extensive } \\
\text { changes in the ecological characteristics. }\end{array}$ & $\begin{array}{l}\text { Excluded - low } \\
\text { consequence (SYS) } \\
\text { Excluded - by } \\
\text { regulation (SYS) }\end{array}$ & SYS \\
\hline
\end{tabular}


Table E-1. TSPA-LA FEP List (Continued)

\begin{tabular}{|c|c|c|c|c|}
\hline FEP Number & FEP Name & FEP Description & Screening Decision & $\begin{array}{l}\text { FEP } \\
\text { AMR }\end{array}$ \\
\hline $2.3 .13 .04 .0 \mathrm{~A}$ & $\begin{array}{l}\text { Radionuclide } \\
\text { release outside } \\
\text { the reference } \\
\text { biosphere }\end{array}$ & $\begin{array}{l}\text { Radionuclide releases outside the reference biosphere } \\
\text { can occur. This could include areas surrounding distant } \\
\text { springs and surface water bodies (such as at Ash } \\
\text { Meadows), remote natural outfalls, discharge areas } \\
\text { such as playas (e.g., Franklin Playa), or forests, } \\
\text { grasslands, or wetlands that occur in isolated areas in } \\
\text { the region. This might also include withdrawal from } \\
\text { wells in remote areas. Radionuclide accumulation could } \\
\text { occur in these areas. Sediment transport and } \\
\text { redistribution may cause concentration or dilution of } \\
\text { radionuclides. Flora and fauna in these areas may be } \\
\text { exposed and radionuclides be bioaccumulated and } \\
\text { enter the food chain. Intermittent use of these areas by } \\
\text { humans may also lead to exposure. }\end{array}$ & $\begin{array}{l}\text { Excluded - by } \\
\text { regulation (Bio) }\end{array}$ & Bio \\
\hline $2.4 .01 .00 .0 \mathrm{~A}$ & $\begin{array}{l}\text { Human } \\
\text { characteristics } \\
\text { (physiology, } \\
\text { metabolism) }\end{array}$ & $\begin{array}{l}\text { This FEP addresses human characteristics. These } \\
\text { include physiology, metabolism, and variability among } \\
\text { individual humans. }\end{array}$ & Included (Bio) & Bio \\
\hline $2.4 .04 .01 .0 \mathrm{~A}$ & Human lifestyle & $\begin{array}{l}\text { Human lifestyle, including everyday household activities } \\
\text { and leisure activities, will influence the critical exposure } \\
\text { pathways to humans. }\end{array}$ & Included (Bio) & Bio \\
\hline 2.4.07.00.0A & Dwellings & $\begin{array}{l}\text { This FEP addresses human dwellings, and the ways in } \\
\text { which dwellings might affect human exposures. } \\
\text { Exposure pathways might be influenced by building } \\
\text { materials and location. }\end{array}$ & Included (Bio) & Bio \\
\hline $2.4 .08 .00 .0 \mathrm{~A}$ & $\begin{array}{l}\text { Wild and natural } \\
\text { land and water } \\
\text { use }\end{array}$ & $\begin{array}{l}\text { Human uses of wild and natural lands (forests, bush, } \\
\text { coastlines) and water (lakes, rivers, oceans) may affect } \\
\text { the long-term performance of the repository. Wild and } \\
\text { natural land use will be primarily controlled by natural } \\
\text { factors (topography, climate, etc.). }\end{array}$ & Included (Bio) & Bio \\
\hline $2.4 .09 .01 .0 \mathrm{~A}$ & $\begin{array}{l}\text { Implementation } \\
\text { of new } \\
\text { agricultural } \\
\text { practices or land } \\
\text { use }\end{array}$ & $\begin{array}{l}\text { Agricultural land use depends on many interrelated } \\
\text { factors including climate, geology, topography, human } \\
\text { lifestyle, and economics. Land use may include } \\
\text { practices such as traditional crop farming, greenhouses, } \\
\text { and hydroponics. Agricultural practices have the } \\
\text { potential for radionuclide transfer through the food chain } \\
\text { and may influence alternate pathways. Changes in } \\
\text { current agricultural practices could change the } \\
\text { significance of various exposure pathways. }\end{array}$ & $\begin{array}{l}\text { Excluded - by } \\
\text { regulation (Bio) }\end{array}$ & Bio \\
\hline 2.4.09.01.0B & $\begin{array}{l}\text { Agricultural land } \\
\text { use and irrigation }\end{array}$ & $\begin{array}{l}\text { Agricultural areas exist near Yucca Mountain, } \\
\text { particularly in the direction of groundwater flow. Current } \\
\text { practices include irrigation, plowing, fertilization, crop } \\
\text { storage, and soil modification and amendment. Existing } \\
\text { practices may play a significant role in determining } \\
\text { exposure pathways and dose. }\end{array}$ & Included (Bio) & Bio \\
\hline 2.4.09.02.0A & $\begin{array}{l}\text { Animal farms and } \\
\text { fisheries }\end{array}$ & $\begin{array}{l}\text { Domestic livestock or fish could become contaminated } \\
\text { through the intake of contaminated feed, water, or soil. } \\
\text { Such contamination could then enter the food chain. }\end{array}$ & Included (Bio) & Bio \\
\hline $2.4 .10 .00 .0 \mathrm{~A}$ & $\begin{array}{l}\text { Urban and } \\
\text { industrial land } \\
\text { and water use }\end{array}$ & $\begin{array}{l}\text { Urban and industrial uses of land and water (industry, } \\
\text { urban development, earthworks, energy production, } \\
\text { etc.) may affect the long-term performance of the } \\
\text { repository. Urban and industrial land use will be } \\
\text { controlled by both natural factors (topography, climate, } \\
\text { etc.) and human factors (economics, population density, } \\
\text { etc.). }\end{array}$ & Included (Bio) & Bio \\
\hline
\end{tabular}


Table E-1. TSPA-LA FEP List (Continued)

\begin{tabular}{|c|c|c|c|c|}
\hline FEP Number & FEP Name & FEP Description & Screening Decision & $\begin{array}{l}\text { FEP } \\
\text { AMR }\end{array}$ \\
\hline 3.1.01.01.0A & $\begin{array}{l}\text { Radioactive } \\
\text { decay and } \\
\text { ingrowth }\end{array}$ & $\begin{array}{l}\text { Radioactivity is the spontaneous disintegration of an } \\
\text { unstable atomic nucleus that results in the emission of } \\
\text { subatomic particles. Radioactive species (isotopes) of a } \\
\text { given element are known as radionuclides. Radioactive } \\
\text { decay of the fuel in the repository changes the } \\
\text { radionuclide content in the fuel with time and generates } \\
\text { heat. Radionuclide quantities in the system at any time } \\
\text { are the result of the radioactive decay and the ingrowth } \\
\text { of decay products as a consequence of that decay. } \\
\text { Over a } 10,000-y e a r \text { performance period, these } \\
\text { processes will produce decay products that need to be } \\
\text { considered in order to adequately evaluate the release } \\
\text { and transport of radionuclides to the accessible } \\
\text { environment. }\end{array}$ & $\begin{array}{l}\text { Included (WF) } \\
\text { Included (UZ) } \\
\text { Included (SZ) } \\
\text { Included (Bio) }\end{array}$ & $\begin{array}{l}\text { Bio } \\
\text { SZ } \\
\text { UZ } \\
\text { WF }\end{array}$ \\
\hline 3.2.07.01.0A & Isotopic dilution & $\begin{array}{l}\text { Mixing or dilution of the radioactive species from the } \\
\text { waste with species of the same element from other } \\
\text { sources (i.e., stable and/or naturally occurring isotopes } \\
\text { of the same element) could lead to a reduction of the } \\
\text { radiological consequences. }\end{array}$ & $\begin{array}{l}\text { Excluded - low } \\
\text { consequence (SZ) }\end{array}$ & SZ \\
\hline $3.2 .10 .00 .0 \mathrm{~A}$ & $\begin{array}{l}\text { Atmospheric } \\
\text { transport of } \\
\text { contaminants }\end{array}$ & $\begin{array}{l}\text { Atmospheric transport includes radiotoxic and } \\
\text { chemotoxic species in the air as gas, vapor, } \\
\text { particulates, or aerosol. Transport processes include } \\
\text { wind, plowing and irrigation, degassing, saltation, and } \\
\text { precipitation. }\end{array}$ & Included (Bio) & Bio \\
\hline 3.3.01.00.0A & $\begin{array}{l}\text { Contaminated } \\
\text { drinking water, } \\
\text { foodstuffs and } \\
\text { drugs }\end{array}$ & $\begin{array}{l}\text { This FEP addresses human diet and fluid intake. } \\
\text { Consumption of food, water, soil, drugs, etc., will affect } \\
\text { human exposure to radionuclides. Other influences } \\
\text { include filtration of water, dilution of diet with } \\
\text { uncontaminated food, and food preparation techniques. }\end{array}$ & Included (Bio) & Bio \\
\hline 3.3.02.01.0A & Plant uptake & $\begin{array}{l}\text { Uptake and accumulation of contaminants by plants } \\
\text { could affect potential exposure pathways. Plant uptake } \\
\text { from contaminated soils and irrigation water is possible. } \\
\text { Particulate deposition onto plant surfaces is also } \\
\text { possible. These plants may be used as feed for } \\
\text { livestock and/or consumed directly by humans. }\end{array}$ & Included (Bio) & Bio \\
\hline 3.3.02.02.0A & Animal uptake & $\begin{array}{l}\text { Livestock may accumulate radionuclides as a result of } \\
\text { ingestion (water, feed and soil/sediment) and inhalation } \\
\text { (aerosols and particulates). Depending on the livestock, } \\
\text { they may be used for human consumption directly, or } \\
\text { their produce (milk, eggs, etc.) may be consumed. }\end{array}$ & Included (Bio) & Bio \\
\hline 3.3.02.03.0A & Fish uptake & $\begin{array}{l}\text { Uptake and bioaccumulation of contaminants in aquatic } \\
\text { organisms could affect potential exposure pathways. }\end{array}$ & Included (Bio) & Bio \\
\hline 3.3.03.01.0A & $\begin{array}{l}\text { Contaminated } \\
\text { non-food } \\
\text { products and } \\
\text { exposure }\end{array}$ & $\begin{array}{l}\text { Contaminants may be concentrated in various } \\
\text { products: clothing (e.g., hides, leather, linen, wool); } \\
\text { furniture (e.g., wood, metal); building materials } \\
\text { (e.g., stone, clay for bricks, wood, dung); fuel } \\
\text { (e.g., peat), tobacco, pets. }\end{array}$ & Included (Bio) & Bio \\
\hline 3.3.04.01.0A & Ingestion & $\begin{array}{l}\text { Ingestion is human exposure to repository-derived } \\
\text { radionuclides through eating contaminated foodstuffs or } \\
\text { drinking contaminated water. }\end{array}$ & Included (Bio) & Bio \\
\hline 3.3.04.02.0A & Inhalation & $\begin{array}{l}\text { Inhalation pathways for repository-derived radionuclides } \\
\text { should be considered. Two possible pathways } \\
\text { are: inhalation of gases and vapors emanating directly } \\
\text { from the ground after transport through the far-field; and } \\
\text { inhalation of suspended, contaminated particulate } \\
\text { matter (e.g., decay products of radon, dust, smoke, } \\
\text { pollen, and soil particles). }\end{array}$ & Included (Bio) & Bio \\
\hline
\end{tabular}


Table E-1. TSPA-LA FEP List (Continued)

\begin{tabular}{|c|c|c|c|c|}
\hline FEP Number & FEP Name & FEP Description & Screening Decision & $\begin{array}{l}\text { FEP } \\
\text { AMR }\end{array}$ \\
\hline 3.3.04.03.0A & $\begin{array}{l}\text { External } \\
\text { exposure }\end{array}$ & $\begin{array}{l}\text { External exposure is human exposure to repository- } \\
\text { derived radionuclides by contact, use, or exposure to } \\
\text { contaminated materials. }\end{array}$ & Included (Bio) & Bio \\
\hline 3.3.05.01.0A & Radiation doses & $\begin{array}{l}\text { The radiation dose is calculated from exposure rates } \\
\text { (external, inhalation, and ingestion) and dose } \\
\text { coefficients. The latter are based upon radiation type, } \\
\text { human metabolism, metabolism of the element of } \\
\text { concern in the human body, and duration of exposure. }\end{array}$ & Included (Bio) & Bio \\
\hline 3.3.06.00.0A & $\begin{array}{l}\text { Radiological } \\
\text { toxicity and } \\
\text { effects }\end{array}$ & $\begin{array}{l}\text { This FEP addresses the estimation of human health } \\
\text { effects resulting from radiation doses. }\end{array}$ & $\begin{array}{l}\text { Excluded - by } \\
\text { regulation (Bio) }\end{array}$ & Bio \\
\hline 3.3.06.01.0A & $\begin{array}{l}\text { Repository } \\
\text { excavation }\end{array}$ & $\begin{array}{l}\text { Excavation of the repository and/or its contents may } \\
\text { result in the production of tailings, which may } \\
\text { subsequently release toxic contaminants. }\end{array}$ & $\begin{array}{l}\text { Excluded - by } \\
\text { regulation (SYS) } \\
\text { Excluded - low } \\
\text { consequence (SYS) }\end{array}$ & SYS \\
\hline 3.3.06.02.0A & $\begin{array}{l}\text { Sensitization to } \\
\text { radiation }\end{array}$ & $\begin{array}{l}\text { Human and other organisms may become sensitized to } \\
\text { radiation exposure so that its effects are more severe. }\end{array}$ & $\begin{array}{l}\text { Excluded - by } \\
\text { regulation (Bio) }\end{array}$ & Bio \\
\hline 3.3.07.00.0A & $\begin{array}{l}\text { Non-radiological } \\
\text { toxicity and } \\
\text { effects }\end{array}$ & $\begin{array}{l}\text { This FEP addresses the estimation of human health } \\
\text { effects resulting from the non-radiological toxicity of the } \\
\text { waste. }\end{array}$ & $\begin{array}{l}\text { Excluded - by } \\
\text { regulation (Bio) }\end{array}$ & Bio \\
\hline 3.3.08.00.0A & $\begin{array}{l}\text { Radon and radon } \\
\text { decay product } \\
\text { exposure }\end{array}$ & $\begin{array}{l}\text { This FEP addresses human exposure to radon and } \\
\text { radon decay products. } 226 \mathrm{Ra} \text { occurs in nuclear fuel } \\
\text { waste and it gives rise to } 222 \mathrm{Rn} \text { gas, the radioactive } \\
\text { decay products of which can result in radiation doses to } \\
\text { humans upon inhalation. }\end{array}$ & Included (Bio) & Bio \\
\hline
\end{tabular}

* FEP 1.2.03.02.0A is an Included FEP in the DE FEP AMR. While the TSPA Disposition contains some discussion of the exclusion of drip shield separation, which suggests a mixed include/exclude screening decision, drip shield separation is excluded as part of FEP 1.2.03.02.0C.

** FEP 2.2.09.01.0A is OA is an Excluded FEP in the SZ FEP AMR. While the Screening Argument contains some discussion of the inclusion of microbial activity in the UZ, which suggests a mixed include/exclude screening decision, microbial activity in the UZ is included as part of FEP 2.2.09.01.0B. 


\section{INTENTIONALLY LEFT BLANK}


APPENDIX F

FEPS MAPPED BY SCENARIO CLASS 


\section{FEPS MAPPED BY SCENARIO CLASS}

This Appendix lists the included FEPs (based on DTN: MO0508SEPFEPLA.002 [DIRS 175064]) and identifies the scenario class that contains each included FEP. Note that only one scenario class is listed for each included FEP. However, most of the nominal scenario class FEPs are also included in the seismic and igneous scenario classes.

Table F-1. Scenario Classes for Included FEPs

\begin{tabular}{|c|c|c|c|}
\hline FEP Number & FEP Name & $\begin{array}{l}\text { FEP } \\
\text { AMR }\end{array}$ & $\begin{array}{c}\text { Scenario } \\
\text { Class }^{*}\end{array}$ \\
\hline $0.1 .02 .00 .0 \mathrm{~A}$ & Timescales of concern & SYS & ** \\
\hline $0.1 .03 .00 .0 \mathrm{~A}$ & Spatial domain of concern & SYS & ** \\
\hline $0.1 .09 .00 .0 \mathrm{~A}$ & Regulatory requirements and exclusions & SYS & ** \\
\hline $0.1 .10 .00 .0 \mathrm{~A}$ & Model and data issues & SYS & ** \\
\hline 1.1.02.02.0A & Preclosure ventilation & $\begin{array}{l}\text { EBS } \\
\text { UZ }\end{array}$ & Nominal \\
\hline 1.1.07.00.0A & Repository design & SYS & ** \\
\hline 1.1.13.00.0A & Retrievability & SYS & ** \\
\hline 1.2.02.01.0A & Fractures & $\begin{array}{l}\mathrm{UZ} \\
\mathrm{SZ}\end{array}$ & Nominal \\
\hline 1.2.02.02.0A & Faults & $\begin{array}{l}\mathrm{UZ} \\
\mathrm{SZ}\end{array}$ & Nominal \\
\hline 1.2.02.03.0A & Fault displacement damages EBS components & $\begin{array}{l}\text { DE } \\
\text { EBS }\end{array}$ & Seismic \\
\hline 1.2.03.02.0A & Seismic ground motion damages EBS components & $\begin{array}{l}\text { DE } \\
\text { EBS }\end{array}$ & Seismic \\
\hline 1.2.03.02.0D & $\begin{array}{l}\text { Seismic-induced drift collapse alters in-drift } \\
\text { thermohydrology }\end{array}$ & $\begin{array}{l}\text { DE } \\
\text { EBS }\end{array}$ & Seismic \\
\hline 1.2.03.03.0A & Seismicity associated with igneous activity & $\mathrm{DE}$ & Seismic \\
\hline 1.2.04.03.0A & Igneous intrusion into repository & $\mathrm{DE}$ & Igneous \\
\hline 1.2.04.04.0A & Igneous intrusion interacts with EBS components & $\mathrm{DE}$ & Igneous \\
\hline 1.2.04.04.0B & Chemical effects of magma and magmatic volatiles & $\mathrm{DE}$ & Igneous \\
\hline 1.2.04.06.0A & Eruptive conduit to surface intersects repository & $\mathrm{DE}$ & Igneous \\
\hline 1.2.04.07.0A & Ashfall & $\begin{array}{l}\mathrm{DE} \\
\text { Bio }\end{array}$ & Igneous \\
\hline 1.2.04.07.0C & Ash redistribution via soil and sediment transport & $\mathrm{DE}$ & Igneous \\
\hline 1.3.01.00.0A & Climate change & $\begin{array}{l}\text { UZ } \\
\text { Bio }\end{array}$ & Nominal \\
\hline 1.3.07.02.0A & Water table rise affects $S Z$ & $\begin{array}{l}\text { SZ } \\
\text { Bio }\end{array}$ & Nominal \\
\hline 1.3.07.02.0B & Water table rise affects UZ & UZ & Nominal \\
\hline 1.4.01.01.0A & Climate modification increases recharge & $U Z$ & Nominal \\
\hline 1.4.07.01.0A & Water management activities & $\begin{array}{l}\text { SZ } \\
\text { Bio }\end{array}$ & Nominal \\
\hline
\end{tabular}


Table F-1. Scenario Classes for Included FEPs (Continued)

\begin{tabular}{|c|c|c|c|}
\hline FEP Number & FEP Name & $\begin{array}{l}\text { FEP } \\
\text { AMR } \\
\end{array}$ & $\begin{array}{c}\text { Scenario } \\
\text { Class }^{*}\end{array}$ \\
\hline 1.4.07.02.0A & Wells & $\begin{array}{l}\text { SZ } \\
\text { Bio }\end{array}$ & Nominal \\
\hline 2.1.01.01.0A & Waste inventory & WF & Nominal \\
\hline 2.1.01.02.0B & Interactions between co-disposed waste & WF & Nominal \\
\hline 2.1.01.03.0A & Heterogeneity of waste inventory & WF & Nominal \\
\hline 2.1.01.04.0A & $\begin{array}{l}\text { Repository-scale spatial heterogeneity of emplaced } \\
\text { waste }\end{array}$ & SYS & ** \\
\hline 2.1.02.01.0A & $\begin{array}{l}\text { DSNF degradation (alteration, dissolution, and } \\
\text { radionuclide release) }\end{array}$ & WF & Nominal \\
\hline 2.1.02.02.0A & $\begin{array}{l}\text { CSNF degradation (alteration, dissolution, and } \\
\text { radionuclide release) }\end{array}$ & WF & Nominal \\
\hline $2.1 .02 .03 .0 \mathrm{~A}$ & $\begin{array}{l}\text { HLW glass degradation (alteration, dissolution, and } \\
\text { radionuclide release) }\end{array}$ & WF & Nominal \\
\hline $2.1 .02 .05 .0 \mathrm{~A}$ & HLW glass cracking & WF & Nominal \\
\hline $2.1 .02 .07 .0 \mathrm{~A}$ & $\begin{array}{l}\text { Radionuclide release from gap and grain } \\
\text { boundaries }\end{array}$ & WF & Nominal \\
\hline $2.1 .02 .09 .0 \mathrm{~A}$ & Chemical effects of void space in waste package & WF & Nominal \\
\hline 2.1.02.12.0A & Degradation of cladding prior to disposal & Clad & Nominal \\
\hline 2.1.02.23.0A & Cladding unzipping & Clad & Nominal \\
\hline 2.1.02.25.0B & Naval SNF Cladding & Clad & Nominal \\
\hline 2.1.02.28.0A & Grouping of DSNF waste types into categories & WF & Nominal \\
\hline 2.1.03.01.0A & General corrosion of waste packages & WP & Nominal \\
\hline 2.1.03.01.0B & General corrosion of drip shields & WP & Nominal \\
\hline 2.1.03.02.0A & Stress corrosion cracking (SCC) of waste packages & WP & Nominal \\
\hline 2.1.03.03.0A & Localized corrosion of waste packages & WP & Nominal \\
\hline $2.1 .03 .05 .0 \mathrm{~A}$ & $\begin{array}{l}\text { Microbially influenced corrosion (MIC) of waste } \\
\text { packages }\end{array}$ & WP & Nominal \\
\hline 2.1.03.08.0A & Early failure of waste packages & WP & Nominal \\
\hline 2.1.03.11.0A & Physical form of waste package and drip shield & WP & Nominal \\
\hline 2.1.06.06.0A & Effects of drip shield on flow & EBS & Nominal \\
\hline 2.1.08.01.0A & Water influx at the repository & UZ & Nominal \\
\hline 2.1.08.02.0A & Enhanced influx at the repository & $\mathrm{UZ}$ & Nominal \\
\hline $2.1 .08 .03 .0 \mathrm{~A}$ & Repository dry-out due to waste heat & EBS & Nominal \\
\hline 2.1.08.04.0A & $\begin{array}{l}\text { Condensation forms on roofs of drifts (drift-scale } \\
\text { cold traps) }\end{array}$ & EBS & Nominal \\
\hline 2.1.08.04.0B & $\begin{array}{l}\text { Condensation forms at repository edges (repository- } \\
\text { scale cold traps) }\end{array}$ & EBS & Nominal \\
\hline 2.1.08.05.0A & Flow through invert & EBS & Nominal \\
\hline $2.1 .08 .06 .0 \mathrm{~A}$ & Capillary effects (wicking) in EBS & EBS & Nominal \\
\hline 2.1.08.07.0A & Unsaturated flow in the EBS & EBS & Nominal \\
\hline 2.1.08.11.0A & Repository resaturation due to waste cooling & EBS & Nominal \\
\hline 2.1.09.01.0A & Chemical characteristics of water in drifts & EBS & Nominal \\
\hline 2.1.09.01.0B & Chemical characteristics of water in waste package & WF & Nominal \\
\hline $2.1 .09 .02 .0 \mathrm{~A}$ & Chemical interaction with corrosion products & $\begin{array}{l}\text { EBS } \\
\text { WF }\end{array}$ & Nominal \\
\hline 2.1.09.03.0A & $\begin{array}{l}\text { Volume increase of corrosion products impacts } \\
\text { cladding }\end{array}$ & Clad & Nominal \\
\hline
\end{tabular}


Table F-1. Scenario Classes for Included FEPs (Continued)

\begin{tabular}{|c|c|c|c|}
\hline FEP Number & FEP Name & $\begin{array}{l}\text { FEP } \\
\text { AMR }\end{array}$ & $\begin{array}{c}\text { Scenario } \\
\text { Class* }^{*}\end{array}$ \\
\hline 2.1.09.04.0A & $\begin{array}{l}\text { Radionuclide solubility, solubility limits, and } \\
\text { speciation in the waste form and EBS }\end{array}$ & WF & Nominal \\
\hline 2.1.09.05.0A & Sorption of dissolved radionuclides in EBS & EBS & Nominal \\
\hline 2.1.09.06.0A & Reduction-oxidation potential in waste package & WF & Nominal \\
\hline 2.1.09.06.0B & Reduction-oxidation potential in drifts & EBS & Nominal \\
\hline 2.1.09.07.0A & Reaction kinetics in waste package & WF & Nominal \\
\hline 2.1.09.07.0B & Reaction kinetics in drifts & EBS & Nominal \\
\hline 2.1.09.08.0A & Diffusion of dissolved radionuclides in EBS & EBS & Nominal \\
\hline 2.1.09.08.0B & Advection of dissolved radionuclides in EBS & EBS & Nominal \\
\hline 2.1.09.16.0A & Formation of pseudo-colloids (natural) in EBS & WF & Nominal \\
\hline 2.1.09.17.0A & $\begin{array}{l}\text { Formation of pseudo-colloids (corrosion product) in } \\
\text { EBS }\end{array}$ & WF & Nominal \\
\hline 2.1.09.19.0B & Advection of colloids in EBS & EBS & Nominal \\
\hline 2.1.09.23.0A & Stability of colloids in EBS & WF & Nominal \\
\hline 2.1.09.24.0A & Diffusion of colloids in EBS & EBS & Nominal \\
\hline 2.1.09.25.0A & $\begin{array}{l}\text { Formation of colloids (waste-form) by co- } \\
\text { precipitation in EBS }\end{array}$ & WF & Nominal \\
\hline 2.1.11.01.0A & Heat generation in EBS & EBS & Nominal \\
\hline 2.1.11.02.0A & Non-uniform heat distribution in EBS & EBS & Nominal \\
\hline 2.1.11.08.0A & $\begin{array}{l}\text { Thermal effects on chemistry and microbial activity } \\
\text { in the EBS }\end{array}$ & $\begin{array}{l}\text { EBS } \\
\text { WF }\end{array}$ & Nominal \\
\hline 2.1.11.09.0A & Thermal effects on flow in the EBS & EBS & Nominal \\
\hline 2.1.11.09.0C & Thermally driven flow (convection) in drifts & EBS & Nominal \\
\hline 2.2.01.01.0A & $\begin{array}{l}\text { Mechanical effects of excavation and construction } \\
\text { in the near-field }\end{array}$ & UZ & Nominal \\
\hline 2.2.03.01.0A & Stratigraphy & $\begin{array}{l}\text { UZ } \\
\text { SZ }\end{array}$ & Nominal \\
\hline 2.2.03.02.0A & Rock properties of host rock and other units & $\begin{array}{l}\text { UZ } \\
\text { SZ }\end{array}$ & Nominal \\
\hline 2.2.07.01.0A & Locally saturated flow at bedrock/alluvium contact & $U Z$ & Nominal \\
\hline 2.2.07.02.0A & Unsaturated groundwater flow in the geosphere & $U Z$ & Nominal \\
\hline 2.2.07.03.0A & Capillary rise in the UZ & $U Z$ & Nominal \\
\hline 2.2.07.04.0A & Focusing of unsaturated flow (fingers, weeps) & UZ & Nominal \\
\hline 2.2.07.06.0B & $\begin{array}{l}\text { Long-term release of radionuclides from the } \\
\text { repository }\end{array}$ & $\begin{array}{l}\text { EBS } \\
\text { UZ }\end{array}$ & Nominal \\
\hline 2.2.07.07.0A & Perched water develops & UZ & Nominal \\
\hline 2.2.07.08.0A & Fracture flow in the UZ & UZ & Nominal \\
\hline 2.2.07.09.0A & Matrix imbibition in the UZ & UZ & Nominal \\
\hline 2.2.07.10.0A & Condensation zone forms around drifts & $U Z$ & Nominal \\
\hline 2.2.07.11.0A & Resaturation of geosphere dry-out zone & UZ & Nominal \\
\hline 2.2.07.12.0A & Saturated groundwater flow in the geosphere & $S Z$ & Nominal \\
\hline 2.2.07.13.0A & Water-conducting features in the SZ & $S Z$ & Nominal \\
\hline 2.2.07.15.0A & Advection and dispersion in the SZ & $S Z$ & Nominal \\
\hline 2.2.07.15.0B & Advection and dispersion in the UZ & $U Z$ & Nominal \\
\hline 2.2.07.16.0A & Dilution of radionuclides in groundwater & $S Z$ & Nominal \\
\hline 2.2.07.17.0A & Diffusion in the SZ & SZ & Nominal \\
\hline
\end{tabular}


Table F-1. Scenario Classes for Included FEPs (Continued)

\begin{tabular}{|c|c|c|c|}
\hline FEP Number & FEP Name & $\begin{array}{l}\text { FEP } \\
\text { AMR }\end{array}$ & $\begin{array}{c}\text { Scenario } \\
\text { Class }^{*}\end{array}$ \\
\hline 2.2.07.18.0A & Film flow into the repository & UZ & Nominal \\
\hline 2.2.07.19.0A & Lateral flow from Solitario Canyon Fault enters drifts & UZ & Nominal \\
\hline 2.2.07.20.0A & Flow diversion around repository drifts & $U Z$ & Nominal \\
\hline 2.2.08.01.0A & Chemical characteristics of groundwater in the SZ & $\begin{array}{l}\text { SZ } \\
\text { Bio }\end{array}$ & Nominal \\
\hline 2.2.08.01.0B & Chemical characteristics of groundwater in the UZ & UZ & Nominal \\
\hline 2.2.08.04.0A & $\begin{array}{l}\text { Re-dissolution of precipitates directs more corrosive } \\
\text { fluids to waste packages }\end{array}$ & $\begin{array}{l}\text { EBS } \\
\text { UZ }\end{array}$ & Nominal \\
\hline 2.2.08.06.0A & Complexation in the SZ & SZ & Nominal \\
\hline 2.2.08.06.0B & Complexation in the UZ & UZ & Nominal \\
\hline 2.2.08.08.0A & Matrix diffusion in the SZ & SZ & Nominal \\
\hline 2.2.08.08.0B & Matrix diffusion in the UZ & $\mathrm{UZ}$ & Nominal \\
\hline 2.2.08.09.0A & Sorption in the SZ & $\mathrm{SZ}$ & Nominal \\
\hline 2.2.08.09.0B & Sorption in the UZ & UZ & Nominal \\
\hline 2.2.08.10.0A & Colloidal transport in the SZ & SZ & Nominal \\
\hline 2.2.08.10.0B & Colloidal transport in the UZ & $\mathrm{UZ}$ & Nominal \\
\hline 2.2.08.12.0A & Chemistry of water flowing into the drift & UZ & Nominal \\
\hline 2.2.08.12.0B & Chemistry of water flowing into the waste package & WF & Nominal \\
\hline 2.2.09.01.0B & Microbial activity in the UZ & $U Z$ & Nominal \\
\hline 2.2.10.03.0A & Natural geothermal effects on flow in the SZ & SZ & Nominal \\
\hline 2.2.10.03.0B & Natural geothermal effects on flow in the UZ & UZ & Nominal \\
\hline 2.2.10.10.0A & Two-phase buoyant flow/heat pipes & UZ & Nominal \\
\hline 2.2.10.12.0A & Geosphere dry-out due to waste heat & UZ & Nominal \\
\hline 2.2.12.00.0B & Undetected features in the SZ & SZ & Nominal \\
\hline 2.3.01.00.0A & Topography and morphology & UZ & Nominal \\
\hline 2.3.02.01.0A & Soil type & Bio & Nominal \\
\hline 2.3.02.02.0A & Radionuclide accumulation in soils & Bio & Nominal \\
\hline 2.3.02.03.0A & Soil and sediment transport in the biosphere & Bio & Nominal \\
\hline 2.3.04.01.0A & Surface water transport and mixing & Bio & Nominal \\
\hline 2.3.11.01.0A & Precipitation & $\begin{array}{l}\text { UZ } \\
\text { Bio }\end{array}$ & Nominal \\
\hline 2.3.11.02.0A & Surface runoff and flooding & UZ & Nominal \\
\hline 2.3.11.03.0A & Infiltration and recharge & $\mathrm{UZ}$ & Nominal \\
\hline 2.3.13.01.0A & Biosphere characteristics & Bio & Nominal \\
\hline 2.3.13.02.0A & Radionuclide alteration during biosphere transport & Bio & Nominal \\
\hline 2.4.01.00.0A & Human characteristics (physiology, metabolism) & Bio & Nominal \\
\hline 2.4.04.01.0A & Human lifestyle & Bio & Nominal \\
\hline 2.4.07.00.0A & Dwellings & Bio & Nominal \\
\hline 2.4.08.00.0A & Wild and natural land and water use & Bio & Nominal \\
\hline 2.4.09.01.0B & Agricultural land use and irrigation & Bio & Nominal \\
\hline 2.4.09.02.0A & Animal farms and fisheries & Bio & Nominal \\
\hline 2.4.10.00.0A & Urban and industrial land and water use & Bio & Nominal \\
\hline 3.1.01.01.0A & Radioactive decay and ingrowth & $\begin{array}{l}\text { Bio } \\
\text { SZ } \\
\text { UZ } \\
\text { WF }\end{array}$ & Nominal \\
\hline
\end{tabular}


Table F-1. Scenario Classes for Included FEPs (Continued)

\begin{tabular}{|l|l|l|l|}
\hline FEP Number & \multicolumn{1}{|c|}{ FEP Name } & \multicolumn{1}{|c|}{$\begin{array}{c}\text { FEP } \\
\text { AMR }\end{array}$} & \multicolumn{1}{|c|}{$\begin{array}{c}\text { Scenario } \\
\text { Class* }\end{array}$} \\
\hline 3.2.10.00.0A & Atmospheric transport of contaminants & Bio & Nominal \\
\hline 3.3.01.00.0A & Contaminated drinking water, foodstuffs and drugs & Bio & Nominal \\
\hline $3.3 .02 .01 .0 \mathrm{~A}$ & Plant uptake & Bio & Nominal \\
\hline $3.3 .02 .02 .0 \mathrm{~A}$ & Animal uptake & Bio & Nominal \\
\hline 3.3.02.03.0A & Fish uptake & Bio & Nominal \\
\hline 3.3.03.01.0A & Contaminated non-food products and exposure & Bio & Nominal \\
\hline $3.3 .04 .01 .0 \mathrm{~A}$ & Ingestion & Bio & Nominal \\
\hline $3.3 .04 .02 .0 \mathrm{~A}$ & Inhalation & Bio & Nominal \\
\hline 3.3.04.03.0A & External exposure & Bio & Nominal \\
\hline 3.3.05.01.0A & Radiation doses & Bio & Nominal \\
\hline 3.3.08.00.0A & Radon and radon decay product exposure & Bio & Nominal \\
\hline
\end{tabular}

* Only one scenario class is listed for each included FEP. However, FEPs included in the Nominal Scenario Class are also typically included in the Igneous and Seismic scenario classes.

** These Included system-level FEPs are not explicitly implemented in the scenario classes. Rather, their inclusion in implicit in all of the scenario classes. 


\section{INTENTIONALLY LEFT BLANK}


APPENDIX G

TSPA-LA DATABASE TABLES AND FIELDS 


\section{TSPA-LA DATABASE TABLES AND FIELDS}

The 21 tables that comprise the FEPs database and the fields contained therein are described below. Fields containing input or confirmation from the FEP AMRs are noted with a double underline.

AMRtoAMRTitle: This table contains the title of the supporting technical AMRs and FEP AMRs that provide the FEP screening decisions and technical bases.

- AMR: The AMR number in DI number format (XXX-XXX-XX-\#\#\#\#\#\#).

- AMRTitle: Title of the AMR.

- AMRRev: Revision number of the AMR.

- AMRICN: ICN of the AMR.

- DIRS: DIRS number of the AMR.

Buttons: This table contains a list of the FEP AMR buttons on the FEP detail form and the technical subject area (i.e., category) of FEP they apply to. It is used for enabling and disabling the buttons on the FEP detail form.

- Order: Primary key to keep the list of buttons in the desired order.

- FEPCat: FEP technical subject area abbreviation (e.g., Bio, Crit, Clad).

- Button: Name of the button control associated with the technical subject area (e.g., btnAMRBio).

Columns: This table contains the name of the columns for the FEPs matrix form.

- Counter: Primary key to keep the columns in the desired order.

- Column Number: Column number as specified in the Matrix_Column field of the FEPS Table. They are not necessarily ordered or sequential.

- Column: Name of the column to be displayed on the FEPs matrix.

- Columnabbr: Abbreviation of the column name for the printed report.

Deleted FEP Info: This table contains a list of those TSPA-SR FEPs that were deleted for TSPA-LA. No scope was actually eliminated; however, combining and splitting of FEPs caused some FEPs to be "deleted".

- YMP FEP Database Number: The number of the deleted FEP.

- Notes: Information about why the FEP was deleted

FEP History File: This table contains the changes made to the FEPs database from the preliminary TSPA-LA FEP list (DTN: MO0301SEPFEPS1.000 [DIRS 161496]) through the final qualified TSPA-LA FEP data set (DTN: MO0508SEPFEPLA.002 [DIRS 175064]). Whenever a change is made to any field in the FEPS Table, the pre-change information in all of the fields of the FEPS table (even unchanged fields) is automatically copied verbatim to the corresponding fields of the FEP History File (listed below). Descriptive information about each change must be entered manually in the Notes field. The FEP History File can, therefore, be used to examine all changes made to the FEP information in the FEPS table. For example, if the 
Notes field indicates "Description edited", then the existing YMP Description in the FEPS table can be compared to the previous YMP Description in the FEP History File to see the differences.

- YMP FEP Database Number: The FEP number prior to the modification.

- FEP Name: The FEP name prior to the modification.

- Source Identifier: The source identifier of the FEP prior to the modification.

- YMP Description: The FEP description prior to the modification.

- Screening Decision: The screening decision of the FEP prior to the modification.

- Screening Argument: The screening argument of the FEP prior to the modification.

- TSPA Disposition: The TSPA disposition of the FEP prior to the modification.

- Supplemental Discussion: The supplemental discussion related to the FEP prior to the modification.

- AMR: The input FEP AMR prior to the modification.

- Modified by: The last person to modify the FEP prior to this modification.

- Mod Date: The date the FEP was last modified prior to this modification.

- Mod Time: The time the FEP was last modified prior to this modification.

- Notes: Descriptive information about this modification. This information is also prepended to the Notes (Historical_Notes) field of the FEPS Table.

- Matrix Row: The matrix row of the FEP prior to the modification.

- Matrix Column: The matrix column of the FEP prior to the modification.

- Matrix SubColumn: The subcolumn (if applicable) of the FEP prior to the modification.

- Entry Date: The date this modification was accomplished.

- Keyword History: The former descriptor phrases associated with the FEP. Descriptor phrases were developed during interim screening to capture finer conceptual or modeling details, generally associated with source FEPs, that were not explicitly identified in the FEP name or description. Descriptor phrases were eliminated in May of 2004 but the field was maintained because of the descriptor phrases in the FEP table prior to that date. Descriptor phrases were a predecessor to the TSPA-LA keywords.

FEPMappingNEAtoLA: This table contains the source FEP (NEA and YMP-specific) identifiers and the corresponding TSPA-LA FEP numbers that address the source FEPs. There are one or more TSPA-LA FEP numbers for every source FEP. Source FEPs are listed in the SourceFEPs table and source FEP identifiers are listed in Table G-1.

- Unique No: Source FEP number/identifier.

- LA FEP Number: TSPA-LA FEP number.

FEPMappingSRtoLA: This table contains the TSPA-SR FEP numbers and the related TSPA-LA FEP numbers.

- SR FEP Number: TSPA-SR FEP number.

- LA FEP Number: TSPA-LA FEP number. 
FEPS: This is the main TSPA-LA FEP table and contains most of the data describing a specific FEP. Fields containing input or confirmation from the FEP AMRs are noted with a double underline.

- YMP FEP Database Number: Primary key used for identifying the FEP within the database. The number was derived from the TSPA-SR FEP number as described in Section 4.2.2. In general, the last numeric character of the TSPA-SR number was replaced with an alpha character for TSPA-LA.

- FEP Name: Short, descriptive title of the FEP.

- Source Identifier: This field once contained the link to the source FEP number/identifier. However, this field is not used for TSPA-LA and is maintained merely to preserve the historical traceability of the FEP.

- YMP Description: Description of each FEP and its potential relevance to YMP.

- Screening Decision: A statement of whether the FEP is included in the quantitative TSPA-LA models or excluded from TSPA-LA on specific criteria (e.g., Low Probability, Low Consequence, or By Regulation).

- Screening Argument: A summary discussion of the technical basis for exclusion, with citations to appropriate TSPA-LA AMRs and other documents (for excluded FEPs, this is the key text).

- TSPA Disposition: A summary discussion of the implementation of the FEP in TSPA-LA, with citations to appropriate supporting technical AMRs (for included FEPs, this is the key text).

- AMR: Identifies the input FEP AMR where the screening discussion is documented. Text of the Screening Decision, Screening Argument, and TSPA Disposition were taken from the input FEP AMR, verbatim wherever possible (some "cosmetic" editing of the text was required because Microsoft Access cannot transfer some fonts, equations, tables, etc. verbatim). The input FEP AMR identifier also indicates the technical subject area in which the FEP is grouped. For shared FEPs, all of the input FEP AMRs are listed. The input FEP AMRs can be accessed directly from the database using the hyperlink buttons.

- Modified By: Name of the last person to modify the FEP record.

- Mod Date: Date the FEP record was last modified.

- Mod Time: Time the FEP record was last modified.

- Historical Notes: The entire history of miscellaneous notes and comments related to this FEP. All changes made subsequent to the preliminary TSPA-LA FEP list (DTN: MO0301SEPFEPS1.000 [DIRS 161496]) are automatically captured in the FEP History File Table and the associated Notes are prepended to this field, separated from previous notes by a line of asterisks. Prior to the development of data set DTN: MO0501SEPFEPLA.001 [DIRS 172601], the name of this field was "Notes".

- Matrix Row: Row number of the FEP's home row.

- Matrix Column: Column number of the FEP's home column.

- Matrix SubColumn: Allows a finer division of the FEP's home column to provide additional categorization if necessary.

- Included: A placeholder for the included/excluded status of the FEP. It is completed each time the FEPs database software program is initiated. If the Screening Decision is "Included", the word "Included" is written in this field. If the screening decision 
contains the word "Excluded", regardless of reason, the word "Excluded" is written in this field. A FEP cannot be both included and excluded. This column with the single word in it makes the coding to do the transform query for building the matrix easier.

- Notes: This field was added during the development of data set DTN: MO0501SEPFEPLA.001 [DIRS 172601], and is different from the "Historical_Notes" field. It provides additional information, as appropriate, regarding | the traceability of FEPs to supporting technical AMRs.

FEPS REV00 ICN02: This is the TSPA-SR FEPs table (BSC 2002 [DIRS 159684]) in its entirety. The table is retained for historical purposes. While many of these entries were extracted from the TSPA-SR versions of the FEP AMRs, the double underline is not used as those FEP AMRs have all been superseded. A mapping of these TSPA-SR FEPs to the appropriate TSPA-LA FEPs is provided in the FEPMAppingSRtoLA Table.

- YMP FEP Database Number: Numeric identifier that places the FEP in the proper location within the database structure. The numbering scheme follows a hierarchical structure classifying FEPs into layers (x...), categories (x.x...), headings (x.x.xx...), primary FEPs (X.X.Xx.Xx...), and secondary FEPs (X.X.XX.XX.Xx).

- FEP Name: Short, descriptive title of the FEP.

- FEP Class: Identification of primary, secondary, and classification (layer, category, heading) entries. Primary FEPs are those FEPs for which the YMP has developed and documented screening discussions. Secondary FEPs are mapped to primary FEPs either because they are redundant with the associated primary FEP or because they represent a subcase of the primary FEP that is more effectively addressed at a higher level. Secondary FEPs are retained in the database for completeness, but users of the database are referred to the related Primary FEPs for the screening discussions.

- NEA Category: Alphanumeric identifier used for the preliminary mapping of the FEPs relative to the NEA database headings. This field is based on preliminary mapping and has been superseded by the YMP FEP Database Number field. It is retained only for traceability to earlier versions of the database. Note that for new FEPs that were identified during and subsequent to the December 1998 to April 1999 workshops, the Source Identifier is repeated in this field.

- Related Primary FEP(s): Identification of entries containing related information. For primary FEPs, other related primary FEPs (if any) are listed. For secondary FEPs and classification entries, this field is blank. Related secondary and classification FEPs can instead be determined through the hierarchical numbering scheme.

- Source Identifier: Alphanumeric identifier that provides traceability to the originator (e.g., NEA contributing program, YMP-specific workshop, AMR, etc.). Note that the Source Identifier is not related to the NEA Category or YMP FEP Database Number.

- YMP Primary Description: Description of each FEP and its potential relevance to YMP, typically edited from the Originator FEP Description. Where secondary FEPs are associated with a primary FEP, the description also includes all of the features, events, and processes described by the secondary FEPs. For shared FEPs, descriptions from each input FEP AMR are listed but are not integrated.

- Originator Description: Verbatim text of the FEP description from originator documentation. The originator is noted in parentheses where possible. 
- Screening Decision: A statement of whether the FEP is included in the quantitative TSPA models or excluded from the TSPA-SR on specific criteria provided by the regulations.

- Screening Argument: A summary discussion of the technical basis for the Screening Decision, with citations to appropriate AMRs (for excluded FEPs, this is the key text).

- TSPA Disposition: A summary discussion of the treatment of the FEP in the TSPA-SR, with citations and cross-references to the appropriate AMRs (for included FEPs this is the key text).

- Supplemental Discussion: Provides additional information supporting the Screening Decision beyond what is summarized in the Screening Argument and TSPA Disposition fields.

- AMR: Identifies the TSPA-SR FEP AMR where the screening discussion is documented. Verbatim text for several fields including the Screening Decision, Screening Argument, TSPA Disposition, Supplemental Discussion, and Treatment of Secondary FEPs was taken from the input FEP AMR. The input FEP AMR identifier also indicates the technical subject area in which the FEP is grouped. For shared FEPs, all of the input AMRs are listed. The input AMRs can be accessed directly from the database using hyperlink buttons.

- IRSR: Identifies NRC IRSR subissues related to the FEP.

- Modified by: Name of last person to modify the FEP record.

- Mod Date: Date of last modification to the FEP record.

- Mod Time: Time of last modification to the FEP record.

- F Keyword: Placeholder for an identifier feature keyword from a specified list that is used for keyword searches. This field was never implemented for TSPA-SR and is blank.

- E Keyword: Placeholder for an identifier event keyword from a specified list that is used for keyword searches. This field was never implemented for TSPA-SR and is blank.

- P Keyword: Placeholder for an identifier process keyword from a specified list that is used for keyword searches. This field was never implemented for TSPA-SR and is blank.

- Notes: Miscellaneous notes and comments related to the FEP.

- Treatment of Secondary FEP(s): For primary FEPs, a list of the underlying secondary FEPs is provided with a short description of the relationship of each secondary FEP to the primary FEP and a summary of how the secondary FEP is addressed in the Screening Argument or TSPA Disposition.

FEPtoAMR: This table relates the TSPA-LA FEP number to the appropriate supporting technical AMRs. Supporting technical AMRs are provided only for included FEPs. For excluded FEPs, the AMR is "N/A."

- FEP Number: The TSPA-LA FEP number.

- AMR: The AMR number (in DI number format) of the supporting technical AMR for included FEPs, and N/A for excluded FEPs.

- DIRS: DIRS number of the supporting technical AMR. 
Hlinks: This table provides the hyperlinks for the FEPs into the FEP AMRs. The link is the FEP number (with no periods) preceded by a "b".

- FEP Number: The TSPA-LA FEP number.

- Bio Link: Hyperlinks into the Biosphere FEP AMR.

- DE Link: Hyperlinks into the Disruptive Events FEP AMR.

- EBS Link: Hyperlinks into the Engineered Barrier System FEP AMR.

- SZ Link: Hyperlinks into the Saturated Zone FEP AMR.

- UZ Link: Hyperlinks into the Unsaturated Zone FEP AMR.

- WF Link: Hyperlinks into the Waste Form FEP AMR.

- WP Link: Hyperlinks into the Waste Package and Drip Shield FEP AMR.

- SYS Link: Hyperlinks into the System Level FEP AMR.

- Crit Link: Hyperlinks into the Criticality FEP AMR.

- Clad Link: Hyperlinks into the Cladding FEP AMR.

- Coll Link: Hyperlinks into the Colloids FEP AMR. This FEP AMR is not used for TSPA-LA, therefore this field is not used.

KeywordsSource: This table contains a list of TSPA-LA keywords and the associated TSPA-LA FEP. Keywords capture the key aspects of the FEP name, FEP description, and relevant source FEPs. The set of keywords for a single FEP represents the basic scope of the FEP (as defined in the FEP name and FEP description) as well as any finer conceptual or modeling details identified only in relevant source FEPs. TSPA-LA keywords derived from descriptor phrases (see the "FEP History File" Table). They were created by parsing the individual descriptor phrases into a set of unique keywords.

- Keyword: Keywords used for the keyword search function.

- FEP No: Associated TSPA-LA FEP.

MatrixSecondaries: This table contains the matrix rows and columns that a FEP relates to in addition to the home matrix rows and columns identified in the FEPS Table. It is appended to the FEP table to build the FEP matrix. There is no limit to the number of additional matrix boxes that a FEP can relate to.

- YMP FEP Database Number: The TSPA-LA FEP number.

- FEP Name: The name of the FEP.

- Matrix Row: A secondary matrix row that this FEP "resides" in. (Note: a FEP can reside in multiple secondary matrix rows as appropriate.)

- Matrix Column: A secondary matrix column that this FEP "resides" in. (Note: a FEP can reside in multiple secondary matrix columns as appropriate.)

- Included: This field is a placeholder that is updated each time the FEP Database is opened. It contains either the word "Included" or "Excluded" Its only purpose is to facilitate the query that fills the grid squares. 
Potential FEP Log: This table contains information about the tracking and resolution of all potential FEPs identified between the preliminary TSPA-LA FEP list (DTN: MO0301SEPFEPS1.000 [DIRS 161496]) and the final TSPA-LA FEP data set.

- IndexNumber: A key to track the order of FEP configuration management entries.

- Date Submitted: The date the potential FEP was entered into FEP configuration management.

- Submitted By: The name of the person (or organization) who entered the potential FEP into FEP configuration management.

- Issue Title: A short title/description of the potential FEP.

- $\underline{\text { Source: }}$ The name of the person (or organization) that identified the potential FEP issue. Where appropriate a source document or e-mail may be identified.

- Discussion of Issue: A discussion of the potential FEP and the reason it might be considered in TSPA-LA.

- Resolution: How the potential FEP was dispositioned (i.e., new FEP, change to existing FEP, or no change).

- Date of Resolution: The date the final disposition of the potential FEP was accomplished.

ReportTable: This one table is actually in the software (Section 6.1.2.1.2) rather than the data file. It is a temporary table used to store the FEPs selected for a detail report.

- FEP Number: The selected TSPA-LA FEP numbers.

Rev Data: This table stores the revision identifier (e.g., DTN) of the data file. The revision information is displayed throughout the FEPs database to allow users to ensure that they are using the version of the data that is desired. (Note: there is no software requirement to use the most up-to-date data)

- RevNumber: This field contains the revision identifier of this revision of the data file. Normally the DTN is included in this field.

- RevDate: The date of the revision.

Rows: This table contains the name of the rows for the FEPs matrix form.

- Counter: Primary key to keep the rows in the desired order.

- Row Number: Row number as specified in the Matrix_Row field of the FEPS Table. They are not necessarily ordered or sequential.

- Row: Name of the row to be displayed on the FEPs matrix.

- RowAbbr: Abbreviation of the row name for the printed report.

Source FEP Categories: This table contains the identifiers for the specific categories of source (NEA and YMP-specific) FEPs. These specific categories are listed in Table G-1.

- SourceCode: Abbreviation used in the source identifier category.

- SourceCategory: The name of the source identifier category. 
Table G-1. Source FEP Information

\begin{tabular}{|c|c|c|}
\hline Source FEP Category & $\begin{array}{c}\text { Number of } \\
\text { Source } \\
\text { FEPs }\end{array}$ & $\begin{array}{c}\text { Source Identifier } \\
\text { and Format }\end{array}$ \\
\hline \multicolumn{3}{|l|}{ From OECD (2000 [DIRS 152952], Appendix D) } \\
\hline Sweden - Joint SKI/SKB Scenario Development Project, 1989 & $158^{*}$ & JX.X.XX \\
\hline International - NEA Systematic Approaches to Scenario Development, 1992 & $146^{*}$ & Nx.X.xx \\
\hline Canada - AECL Scenario Analysis for Canadian Disposal Concept, 1994 & 281 & Ax.xxx \\
\hline U.K. - HMIP Assessment of Nirex Proposals-System Concept Group, 1993 & 79 & Hx.x.x \\
\hline Sweden - SKI SITE-94 Deep Repository Performance Assessment Project, 1995 & $106^{*}$ & Sxxx \\
\hline Switzerland - NAGRA Scenario Development for Kristallin-I, 1994 & $258^{*}$ & Kx.xx \\
\hline USA - DOE Waste Isolation Pilot Plant, CCA, 1996 & $246^{*}$ & Wx.xxx \\
\hline Canada - AECL Intrusion Resistant Underground Structure (IRUS) Study, 1997 & 144 & $\operatorname{lxxx}$ \\
\hline \multicolumn{3}{|l|}{ From Freeze et al. (2001 [DIRS 154365], Tables 3 through 6) } \\
\hline YMP Site Characterization Plan & 91 & YSCPXx \\
\hline Other YMP Documents & 201 & YMxx \\
\hline DSNF Workshop, 1999 & 40 & CA-x, MLD-X \\
\hline WF Workshop, 1999 & 12 & WF/xxxx \\
\hline DE Workshop, 1999 & 24 & $\begin{array}{l}\text { DE/xxxx, ISC-x, } \\
\text { NFC-x, FFC-x }\end{array}$ \\
\hline SZ Workshop, 1999 & 1 & $\mathrm{SZ} / \mathrm{xxxx}$ \\
\hline TH Workshop, 1999 & 1 & $\mathrm{TH} / \mathrm{xxxx}$ \\
\hline IDGE Workshop, 1999 & 2 & $\mathrm{ID} / \mathrm{xxxx}$ \\
\hline WP Workshop, 1999 & 2 & WP/xxxx \\
\hline WF Cladding AMR for TSPA-SR & 2 & WFClad AMR-x \\
\hline WF Colloid AMR for TSPA-SR & 4 & WFCol AMR-x \\
\hline WF Miscellaneous FEP AMR for TSPA-SR & 4 & WFMisc AMR-X \\
\hline EBS FEP AMR for TSPA-SR & 3 & EBS- $x$ \\
\hline Igneous Activity (NRC) Meeting, 2000 & 3 & NRC IA-X \\
\hline NRC NFE Audit, 1999 & 2 & NRC NFE-x \\
\hline NRC Structural Deformation and Seismicity IRSR, 1999 & 1 & NRC SDS- $x$ \\
\hline Unsaturated and Saturated Flow under Isothermal Conditions KTI Meeting, 2000 & 2 & NRC USFIC-x \\
\hline Total & 1813 & \\
\hline
\end{tabular}

* Slight differences between number of source FEPs from OECD (2000 [DIRS 152952], Appendix D) and number of FEPs indicated in Tables 2-2 and 2-4 is due to alternate interpretations of the same information (e.g., classification headings may or may not be counted as FEPs). 
SourceFEPs: This table contains a list of source FEPs and their descriptions. Source FEPs are NEA and YMP-specific FEPs that provide the basis for the TSPA-LA FEP list. NEA source FEPs and descriptions are taken directly from Version 1.1 of the NEA International FEP database (OECD 2000 [DIRS 152952], Appendix D). Each source FEP is explicitly mapped to one or more TSPA-LA FEPs (see Table "FEPMappingNEAtoLA") that, in the opinion of the FEP Team, capture (sometimes explicitly and sometimes implicitly) the subject of the source FEP. In some cases the source FEPs identify finer conceptual or modeling details that are not otherwise identified explicitly (although they are captured implicitly) in the FEP name and/or FEP description. A list of source FEP categories can be found in Table G-1.

- FEP name: The name of the source FEP.

- FEP description: The description of the source FEP, verbatim from the source.

- Unique No: The source FEP number/identifier assigned to the source FEP

- Class Code: Numeric identifier for the source identifier category used to group source FEPs in database pull-down menus (corresponds to different source identifiers in Table G-1).

SRFEPTree: This table defines the hierarchical structure of the TSPA-SR FEPs. This table is used to build the TSPA-SR FEPs Tree.

- YMP FEP Database Number: The TSPA-SR FEP number.

- FEP Name: The name of the TSPA-SR FEP.

- ParentFEP: The FEP one level above this FEP.

- Description: The FEP description.

SUBColumns: This table contains the name of the columns for the FEPs matrix form.

- SubColumn Number: Subcolumn number as specified number as specified in the Matrix_SubColumn field of the FEPS Table. They are not necessarily ordered or sequential.

- SubColumnname: Name of the subcolumn to be displayed on the FEPs matrix.

- SubColumnAbbr: Abbreviation of the subcolumn name for the printed report. 


\section{INTENTIONALLY LEFT BLANK}

